SIIELF NO.

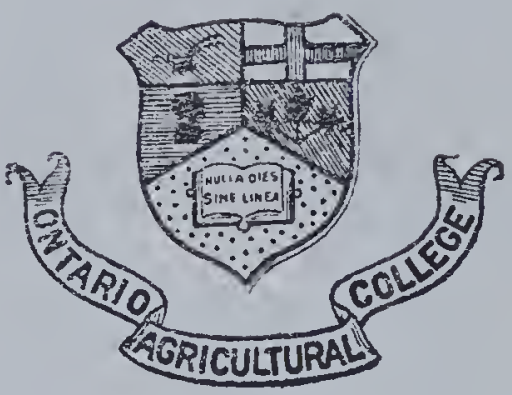

ONTARIO AGRICULTURAL COLLEGL LIBRARY. 
promecody

B.fw. Coble a

Charkottetorn

Deer.9.5

Pes

Alàil Onié 1". 

SOILS AND PLANT LIFE AS RELATED TO AGRICULTURE 


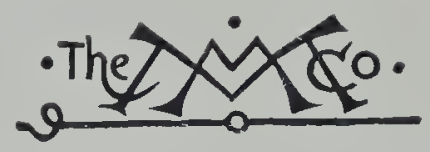

THE MACMILLAN COMPANY

NEW YORK - BOSTON - CHICAGO - DALLAS ATLANTA - SAN FRANCISCO
MACMILLAN \& CO., Limited
LONDON - BOMBAY - CALCUTTA MELBOURNE

THE MACMILLAN CO. OF CANADA, LTD. TORONTO 
Digitized by the Internet Archive in 2020 with funding from University of Alberta Libraries 


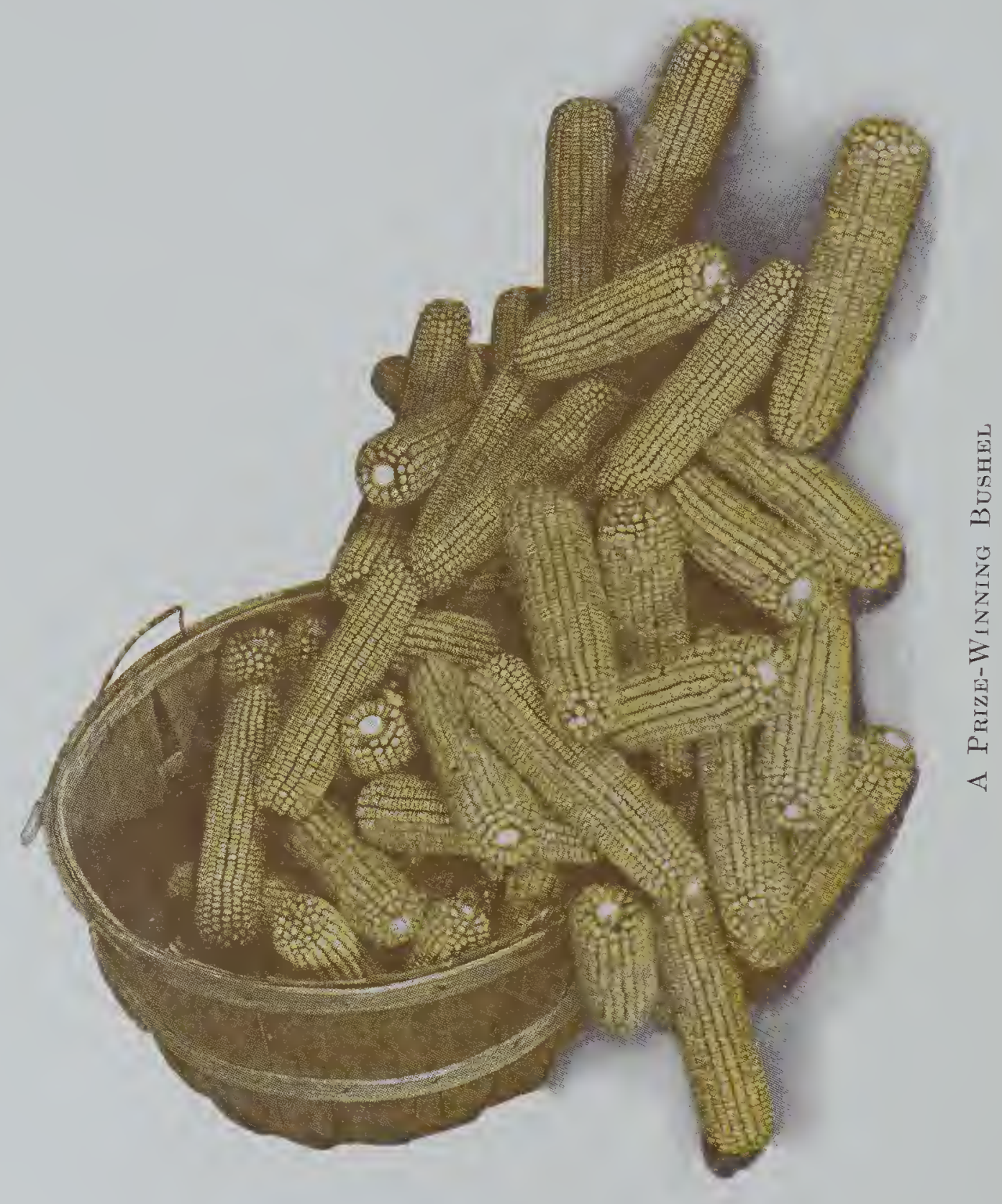




\section{SOILS AND PLAN'T LIFE}

AS

\section{RELATED TO AGRICULTURE}

BY

J. C. CUNNINGHAM

PROFESSOR OF IORTICULTURE AND BOTANY IN TWO-YEAR COURSE IN AGRICULTURE AND TEACHER OF AgRICULTURE TO RURAL AND GRADE TEACHERS

IOWA STATE COLLEGE, AMES, IOWA

AND

W. H. LANCELOT

INSTRUCTOR IN CHEMISTRY, TWO-YEAR COURSE IN AGRICULTURE IOWA STATE' COLLEGE

New 想ark

\section{THE MACMILLAN COMPANY}

1915

All rights reserved 
Coptright, 1915,

BY THE MACMILIAN COMPANY.

Set up and electrotyped. Published August, 1915.

Nortorad 掫ess

J. S. Cushing Co. - Berwick \& Smith Co.

Norwood, Mass., U.S.A.

\section{UNIVERSITY LIBRARY}




\section{PREFACE}

This publication represents a desire on the part of the senior author to present a first study in agriculture for rural, grade, and high schools, based upon sound educational principles.

An enumeration of a few of these principles will serve as a key to the plan of the book:

1. Pupils must be led by easy steps from the known to the unknown.

2. One thing at a time must be taught and this one thing must be thoroughly understood.

3. Real progress in education depends upon a pupil's ability to discern agreements and differences.

4. A teacher should stimulate and direct, but all education comes from the pupil's voluntary effort.

Our purpose in the pages that follow is to stimulate and direct the pupils in such a manner that they will proceed by "easy steps from the known to the unknown" and that their mental powers will be developed by their own voluntary efforts.

If this book is to be merely one from which a certain number of pages are assigned to-day to be recited in a parrot-like manner to-morrow, it must prove a complete failure.

If the exercises are performed as the authors have intended, a few — and only a few — set rules will be observed:

First. - The pupil must understand clearly before beginning just what he is setting out to do.

Second. - He should follow the directions carefully.

Third. - In his conclusion, he should be expected not 
only to show a clear discernment of "agreements and differences" but to state them clearly in his notebook.

The exercises which are here presented can not be performed in all schools by each pupil. The work can easily be completed, however, by assigning one exercise to a certain pupil or group of pupils, the next to another individual or group, and so on. The exercises may be worked out either in the schoolroom or at home, according to the judgment of the teacher. There is no better training for a pupil than that of presenting before a class the facts he has found out for himself.

In the back of the book will be found a list of materials which should be gathered together and stored in some sort of box before school opens. Better still, a cabinet may be made, or secured, in which the materials can be compactly stored. This will save space, which is always at a premium in the schoolroom. All pieces of apparatus should be washed clean, wiped dry, and put back in their places as soon as the work is completed. This will save the teacher much trouble, while it will at the same time tend to teach the pupils neatness and order.

Each pupil should have a durably bound notebook of specified size, a drawing pencil, and a small hand lens.

In addition to a box for the storage of equipment, another should be provided in which a few plants or other perishable articles may be protected from freezing. Ordinarily, it simplifies the work to have some person in the community grow the potted plants which require care and attention in order that they may develop properly.

The material in this book is presented as a first study in agriculture. It deals alone with soils and plants, for we think that agricultural subjects can best be divided into plant studies and animal studies. The latter should be presented as a second, or advanced year's work.

It must not be understood that the chapters in this book 
are necessarily to be followed in the order given. On the other hand, any combination of chapters which is best fitted to the season may be adopted. For instance, when school opens in the fall, flowers and seeds can be easily obtained. Chapter XII will make an excellent starting point at this time. Then may follow Chapters XIII and VII, after which one may turn back to the beginning of the book and proceed in regular order, reviewing or omitting the chapters already studied. Exercise 36, however, should be started in the late fall, regardless of the order that is followed in the book.

Teaching agriculture is a delightful task, provided we do not attempt to tell "how to farm." All we should attempt to do is to stimulate and direct the pupil in his desire to find out the fundamental principles of good farming.

It is our privilege to unify or to "make one" the school work and the common experiences and practices of the farm to the end that life in the open country may be richer and fuller for all of us who dwell there.

In the preparation of this work, the senior author has been ably assisted by W. H. Lancelot, a man of wide experience both in educational and in editorial work.

Recognition is also due to Mr. Willard Zeller, a highly successful corn grower and breeder of Cooper, Iowa, who reviewed the chapter on cor'n.

H. L. Eichling, Associate Professor of Agronomy, and teacher of agriculture for rural and grade teachers in the summer school of Iowa State College, has carefully reviewed the chapters on soils and farm crops and has offered very many helpful suggestions.

I desire to express my appreciation of this valuable assistance.

Anes, Iowa,

J. C. CUNNINGHAM.

June 1, 1915. 



\section{A LETTER TO THE STUDENT}

Nearly sixty years ago a lad ten or twelve years of age gathered together in his father's cellar a collection of bottles, jars, chemicals, and other equipment. He had gone to school but three months in his life. Yet with the help of his mother, he read the best books she could secure. He obtained a copy of Parker's School Philosophy and worked out in his "den" in the cellar almost every experiment in the book. Moreover, he tested to his satisfaction many of the statements he encountered in his reading.

People would have smiled if, fifty years ago, any one had said of this lad of Port Huron, Michigan: "He will make the streets of your cities at night as light as day. He will reproduce music and the human voice on cylinders of wax. He will make it possible for every village to have a moving picture show. He will use electricity instead of horses to propel your street cars." Yet Thomas Alva Edison has brought these very things and more to pass. He laid the foundation for these great inventions by working out for himself the statements he found in his books.

The boy on the following page holds in his hands a rock and a bit of soil. He has been told that soil comes from rocks; that plants draw their nourishment from the soil and the air; that when they die, they also become a part of the soil. On the pages that follow are found brief directions for learning some of the truths about the soil and plants. Let us together perform the experiments. Very few, or 
perhaps none of us, will become great inventors like Mr. Edison; yet we can open a storehouse, filled with

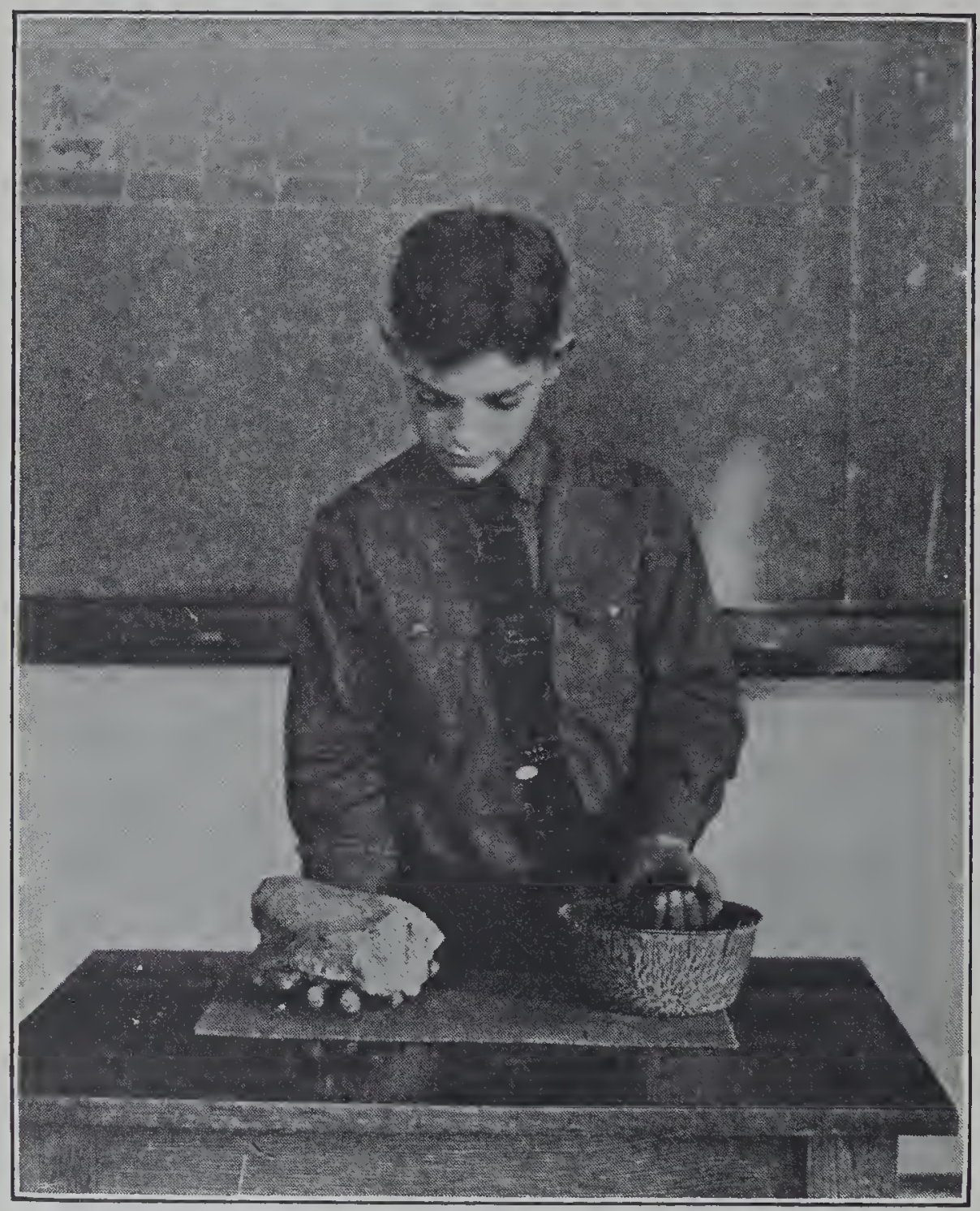

Boy with a rock and a bit of soil.

wonderful treasures of knowledge about the plants, the animals, and the soil that we see every day.

Great buildings are constructed by laying stone upon stone. Real knowledge is, gained by proving one truth after another.

The first question to ask is, "What is my object, or what do I wish to find out?" 
The second step is procedure: "How shall I go about it to find out?"

The third is the conclusion: "What have I found out, or" proved?"

We should keep a notebook, in which to make a neat, careful record of the experiments we perform. Here is an illustration from a student's notebook, which shows about how the exercises which follow should be recorded:

\section{EXERCISE 9}

Object. - To learn what effect plowing under a heavy crop of straw has upon the rise of water in the soil.

Procedure. - I stretched a piece of cheesecloth across the bottom of a lamp chimney and tied it firmly in place. Then I filled the chimney two thirds full of fine soil, added one half inch of finely chopped straw, and added fine soil again until the chimney was full. I put the lower end of the chimney into a pan of water, and watched the moisture rise through the soil.

I filled another chimney exactly as I had filled the first, except that I left out the layer of straw. I put the lower end of this chimney into the water and watched the moisture rise through the soil.

Conclusion. - The water was drawn up through the soil just as a lamp wick draws up the oil. In the first chimney, the water rose as far as the straw, and there it stopped. In the second chimney, it rose to the surface of the soil. This must mean, then, that when any thing like a layer of straw or weeds or perhaps even clods is plowed under, the "wicks" or tubes in the soil are broken. In this case, the moisture could not rise to the roots of the young plants, and they would be injured and perhaps die unless there was plenty of rain.

Exercises, such as this, will very often lead to a desire on your part to perform the same work on a larger scale in the 


\section{xii}

field. The general procedure, however, should be the same. Know your object, or what you wish to find out; proceed by securing a plot of ground and following carefully the plan, which is to test your theories; and finally, think over your results very carefully, turning them over and over in your mind, as we say, so that you may not finally reach a conclusion that is untrue, or one that is only partly true.

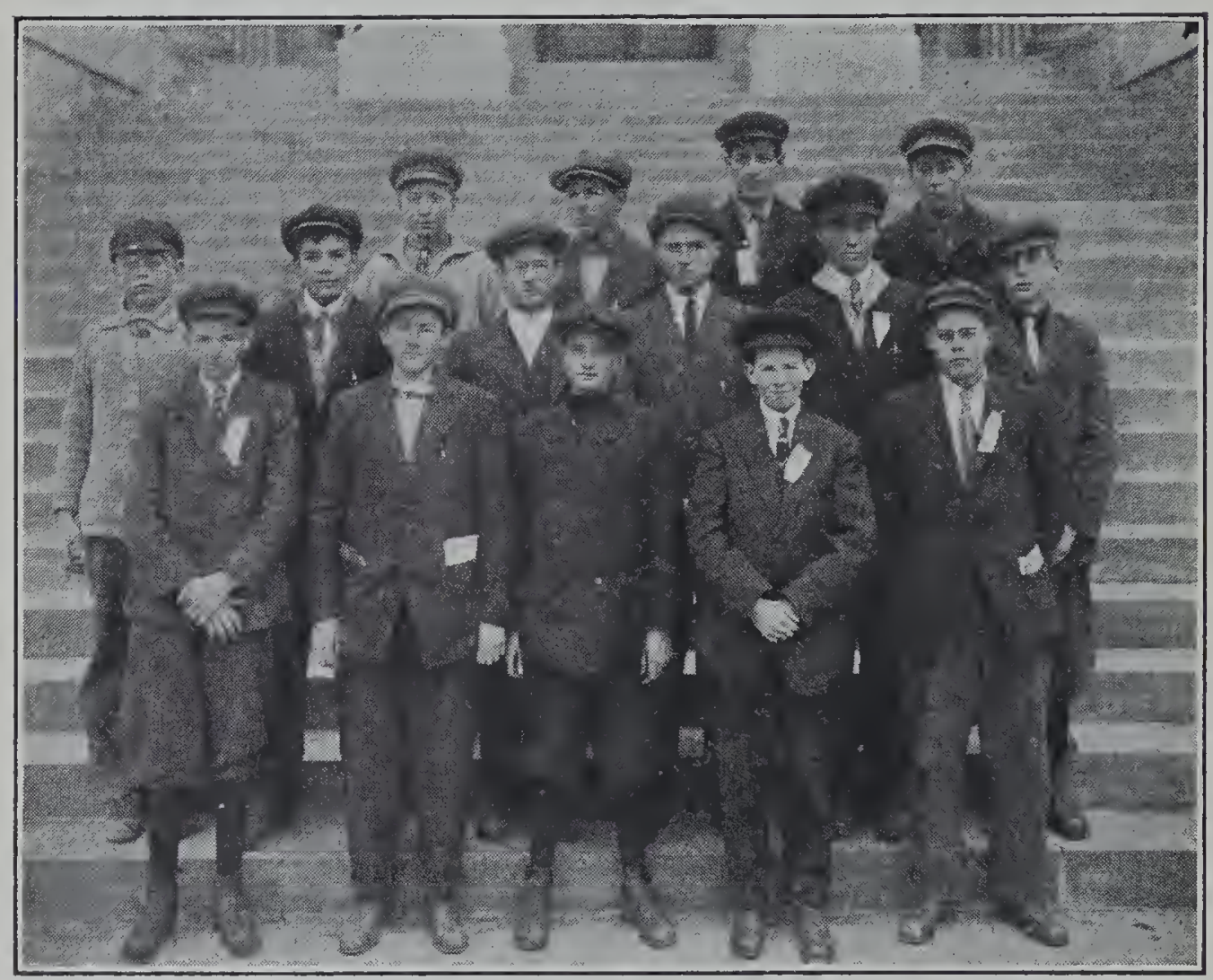

Winners of a corn growing contest.

A great many people will be interested in your conclusions, especially if they prove to be accurate and true, for the principal way of securing the much needed increase in our crop yields is not to farm more land, since the best of it is now under the plow, but to increase the yield per acre of that which we are now farming.

W. H. LANCELOT. 


\section{CONTENTS}

PAGES

Preface

A Letiter to The Student. . . . . . . . ix-xii

\section{SOILS}

\section{CHAPTER I}

How Solls are Made and Mixed . . . . 1-12

What the Soil is, 1 - Grinding up the Rocks, 1 - Soil Names, or Types, 4 - Two Sources of Soil Material, 5The Part Plant Life plays in making Soils, 7 - The Part Animal Life plays in making and mixing Soils, 8 - Elements in the Soil and Air which Plants must have in Order to make a Healthy Growth, 10.

\section{CHAPTER II}

The Water in the Soll . . . . . . . .

How the Soil loses Water, 13-The Water which runs off the Surface, 13 - The Water which filters down through the Soil and drains away, 16-How Water enters Drain Tile, 18 - Three Kinds of Water in the Soil, 19- How Film Moisture works its Way upward in the Soil, 21 - How the Farmer prevents the Escape of Film Moisture, 23.

\section{CHAPTER III}

The Air in the Soll. . . . . . . . .

Why Air is necessary in the Soil, 25- Why we seek to control the Air Space in the Soil, 25-How we may get More $\Lambda$ ir into the Soil, 28. 


\section{CHAPTER IV}

The Temperature of the Soll.

Proper Temperature Necessary for Germination, $30-$ How Temperature of the Soil is governed, $30-$ How the Air Space in a Soil affects its Temperature, $31-$ How the Moisture in a Soil affects its Temperature, $33-\mathrm{How}$ the Color of a Soil affects its Temperature, 34-The Advantages of a Warm Soil, 34.

\section{CHAPTER V}

The Tillage of Soils $36-\mathbf{4 3}$

Why we till the Soil, 36 - Improving the Texture and Structure of the Soil, 36-One Cause of Cloddy Fields, 39-Covering, or Working into the Soil, Organic Matter, 40 - Putting Seed into the Seed Bed, 40-Destroying Weeds, 41- Forming a Dust Mulch, 42-Making it Possible for Air and Water to enter the Soil, 42.

\section{PLANT LIFE}

\section{CHAPTER VI}

The Round of Plant Life

The Life Cycle of Plants, 44 - How the Parts of a Plant work together, 44.

\section{CHAPTER VII}

The Seed : Its Selection and Distribution.

The Functions of the Seed, $46-$ How the Embryo is protected, $46-$ How Seeds are scattered by Nature, 46 - How Seeds are scattered by Man, 49-Making a Seed Collection, 50-How Nature selects Seeds, 52How Man selects Seeds, 52-Selecting Specimens for Corn Judging, 56 - Nature stores No Seeds but provides for Loss, 57 - Man's Storage of Seeds, 58. 


\section{CHAPTER VIII}

\section{Seed Germination}

What a Seed is, 62 - Two Great Classes of Plants, 62 - The Conditions required for Seed Germination, 64 Moisture and Germination, 65-Temperature and Germination, 67-Changes which take place within the Germinating Seed, 68 - Heat generated during Germination, 71 - How Size of Seed affects Growth of Young Plant, 73-Direction of Growth, 74-The Embryo becomes a Seedling, 75 .

\section{CHAPTER IX}

The Work of Roots

$77-88$

What Roots do, 77 - Gathering Food and Moisture, 77 - Roots are able to select the Minerals which they need, 79 -The Origin of Roots, $80-$ How Roots work their Way through the Soil, 81 - The Extent and Depth of Roots, 82 - How Roots help dissolve Mineral Matter, 84- How Roots hold Plants Erect, 85-The Root a Storehouse of Food, 87 - Benefits of Roots, 88.

\section{CHAPTER X}

The Work of Leaves

Functions and Uses of Leaves, 89 - The Manufacture of Starch, 89-The Green Leaf likened to a Mill, 90How Other Foods are made, 91 - Amount of. Water, Food Material, and Ash in Plants, 92-The Water given off by Leaves, 93 - Storage of Food in the Leaves, 96.

\section{CHAPTER XI}

The Work of Stems

The Functions of Stems, 98-The Forms of Stems, 98-Prostrate Stems, 98 - Climbing Stems, 99 - Erect Stems, 99 - Study of the Forms of Stems, $100-$ How Water travels from Roots to Leaves, $101-$ How to tell the Age of a Tree, 102 - How Food travels from Leaves 
to Roots, 103 - The Flow of Sap, 104-The Cambium

Layer, 104 - Rope, Twine and Linen Material, 105.

\section{CHAPTER XII}

ThE WORK OF Flowers

The Work in which All Parts join, 107 - What the Flower does, 107 - Parts of the Flower on Separate Plants or on Different Parts of the Same Plant, $110-$ How the Pollen gets from one Plant to another, $110-$ The Flowers which depend upon Insects to carry Pollen, 11.1 - The Flowers which depend upon Wind to carry Pollen, 111 - What happens after the Pollen reaches the Stigma, 112 - Cross-fertilization the Rule, 113Cross-fertilization by Hand, 113.

\section{CHAPTER XIII}

The Formation and Development of Seed

How the Food is stored in the Seed, 117 - How Man may thwart Nature's Plan, 118 - The Forms and Uses of the Various Food Materials in the Seed, 120.

\section{CHAPTER XIV}

The Propagation of Plants . . . . . .

How Plants are Propagated, 122-Propagation by Spores, 124-How Spores are Spread, 127 - How to prevent the Spread and Growth of the Spores of Disease, 128 - Conditions which favor the Entrance and Growth of Spores, 133 - Propagation by Seed, 133-Propagation by some Part of the Plant other than Seed or Spore, 134 - Plants formed while still attached to the Parent Plant, 134 - Plants formed by Portions which become detached from Parent Plant, 136 - Plants formed by the Union of Two Plants, 138.

\section{CHAPTER XV}

Why Man Cultivates Plants . . . . . . 145-148

Classes of Plants according to the Parts for which they are cultivated, 145 . 


\section{CHAP'TER XVI}

Uses of Coln, 149 - Distribution of Corn, 150 - How the Corn Plant has changed as it has moved Northward, 151 - Clinatic Requirements of the Corn Plant, 152 Soil Requirements of the Corn Plant, 154-The Production of Corn, 154-Selection of the Seed, 154-The Selection of the Seed Supply, 169-How Selection of Seed may influence the Yield, 172-Drying out the Seed, 172 - Storing the Seed, 173-Testing the Seed, 174-Grading the Seed, 179-The Ideal Seed Bed for Corn, 181 - Preparing a Seed Bed in Sod Ground, 182 - Preparing a Seed Bed in Cornstalk Ground, 184Preparing a Seed Bed in Stubble Ground, 185- Planting the Seed, 185 - The Time of Planting, 187-The Depth of Planting, 188 - Distance between the Rows, 189 - The Number of Kernels in Each Hill, 189-The Replanting of the Missing Hills, 190 -Cultivation begins with the Harrow, 191 - Later Cultivation of the Crop, 191 - Depth of Cultivation, 193 - Frequency of Cultivation, 194 - Cultivation of Listed Corn, $195-$ Harvesting the Crop, 196 - Crops used as Substitutes for Corn, 198 - Planting and cultivating Kafir Corn and Similar Drouth-resistant Crops, 200.

\section{CHAP'TER XVII}

The Siall Grains

Why Wheat is so extensively grown, 203-Climatic Conditions Favorable for the Growth of Wheat, 205 Winter and Spring Wheat, 205 - Systems of Rotation, 205 - The Seed Bed and how to prepare it, 206 - Selection of the Seed, 207-Planting the Seed, 210-Harvesting the Wheat, 211 - The Uses of Wheat, 212 Oats a Cool Climate Crop, 213 - Varieties of Oats, 214 - Preparation of the Seed Bed, 215 - The Selection of Oats for Seed, 216-Harvesting the Crop, 218 - Shocking and Stacking Oats, 218 - The Uses of Oats, 219Oatmeal, 219 - Methods of Cultivation and Uses of Barley, 221 - Soil Requirements and Uses of Rye, 221 - 
The Soil Requirements of Rice, 222 - Preparation of the Seed Bed, 222 - Planting the Seed, 223-Caring for the Growing Crop, 223 - How the Grain is prepared for Use, 223 - Uses of Rice, 224.

\section{CHAPTER XVIII}

Grasses for Pastures, Meadows and Lawns .

Characteristics of all the Grasses, 225 - A Peculiar Habit of Growth, 226 - Wild Grasses, 227 - Cultivated Grasses, 227 - Where and how Timothy is grown, $227-$ Advantages and Disadvantages of Timothy, 228 - When to cut Timothy, 229 - The Character and Value of Blue Grass, 230 - The Seeding of Blue Grass, 231-Advantages and Disadvantages of Blue Grass, 232 - The Range and Character of Redtop, 2:32 - Its Advantages and Disadvantages, 233 - The Range and Character of Bermuda Grass, 234 - Advantages and Disadvantages of Bermuda Grass, 234-Where each Grass thrives, 236-Why Clovers should be grown with Grasses, 236 .

\section{CHAPTER XIX}

\section{Clovers and Other legumes}

Characteristics of the Legumes, 238 - How Legumes benefit the Farmer, 239 - How Legumes add Nitrogen to the Soil, 240 - How Roots of Legumes open the Soil, 241 - How Legumes add Humus to the Soil, 241 - How Legumes make other Plant Food Available, 241 - How Legumes balance the Food Ration, 242 - How Legumes assist in the Control of Insects and Fungous Pests, $242-$ Where the Different Legumes grow, 242 - Why Clovers frequently fail, 250 - How Acid Soil affects Clovers, 252 - How a Lack of Phosphorus affects Clovers, 254How a Lack of Humus affects Clovers, 255 - How Absence of Friendly Bacteria affects the Clovers, 255How the Nurse Crop may affect Clovers, 256 - How the Method of Seeding may affect Clovers, 256 - How Drouth may affect Young Clovers, 257-How to succeed with Clovers, 258-How to correct an Acid Soil, 258- How 
to add Humus and Phosphorus to the Soil, 259-How Bacteria are added to the Soil, 259 - The most Suitable Nurse Crops for Clovers, 260 - How the Seed should be planted, 261 - Seed Selection and Analysis, 201 - Table of Weed Seed Weights, 265-Methods of Culture of the Legumes, 266 - Securing the Maximum Benefits from Legumes, 272.

\section{CHAPTER XX}

The Fiber Crops

Three Crops yielding Valuable Fibers, 274 - Valuable Products Other than Fiber, 274-The Importance of Cotton, 275-Where Cotton is grown in the United States, 275 - The Cotton Plant, 276 - Growing the Cotton Crop, 277 - Harvesting the Crop, 280 - Gimning the Cotton, 280 - Proportion and Value of Seed and Lint, 281 - How and where Flax is Grown, 282 - Methods of Handling and Value of the Fiber and Seed, 283.

\section{CHAPTER XXI}

Fruit Growing

Horticulture and Agriculture, 287 - Where Our Fruits originated, 287 - Developing the Young Tree, 288 - The Location of the Orchard, 289 - The Distances between the Trees, 289-Cutting back and Planting the Young Trees or Vines, 290 - Cultivation of the Young Plants, 291 - The Training of the Young Plants, 292 - When and how Fruit Buds form, 292 - Conditions which favor the Formation of Fruit Buds, 293-Age of Wood upon which Fruit Buds appear, 294 - The Reasons for Pruning, 298-Methods of Pruning, 299-Precautions to be taken in Pruning, 304 - Protecting Fruit-bearing Plants from their Enemies, 305-Gathering and Storing the Fruit, 309.

\section{CHAPTER XXII}

Vegetable Growing

Cool Season Crops, 311 - Warm Season Crops, $312-$ Getting ahead of the Season, 312-In the Garden 
Proper, 315 - The First Planting, 317 - When the DanPAGES ger of Frost is Past, 323.

\section{CHAPTER XXIII}

Permanent Agriculture

The Result of selling Crops from the Land, 331 - How the Three Important Elements of Fertility may be restored to the Soil, 332 - The Care and Importance of Barnyard Manure, 336.

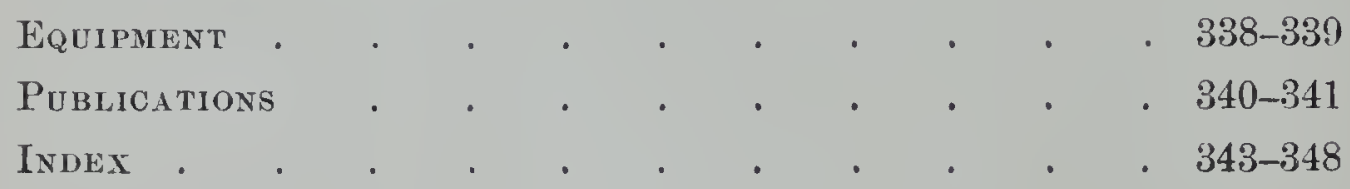




\section{SOILS AND PLANT LIFE AS RELATED TO AGRICULTURE}





\section{SOILS AND PLANT LIFE}

\section{CHAPTER I \\ HOW SOILS ARE MADE AND MIXED}

1. What the Soil Is. - The soil, as we now see it, is composed of broken-down rock, mixed with decaying plant and animal matter. For millions upon millions of years, no doubt, the work of soil making has been going on.

2. Grinding up the Rocks. - The earth was once made up of rock. Men who have studied the subject long and carefully tell us that the heat and the cold, the wind and the water, the gases of the air, the plants, and the animals have all had a part in breaking down the rocks into rock powder and mixing it through and through that more plants and animals might exist. We are told that vast fields of ice, called glaciers, moved slowly over many parts of the country ages ago, carrying with them rock masses and grinding to powder whatever came beneath their mountain-like weight. We read about these great glaciers and see pictures of them as well in our geographies.

We are told also that rocks expand with heat and contract with cold, becoming broken up in this way. We know that hot water will break a cold tumbler. We have seen stones cracked or broken about the fire where we cooked our picnic or camp supper. We have seen where the water has washed out great hollow places in the rock. Moreover, we must know that when the cracks and crev- 
ices in rocks become filled with water and freeze, the rocks are broken apart, just as a jug is broken if the water in it is allowed to freeze. The particles of rock are not only broken and washed into finer and finer pieces but are

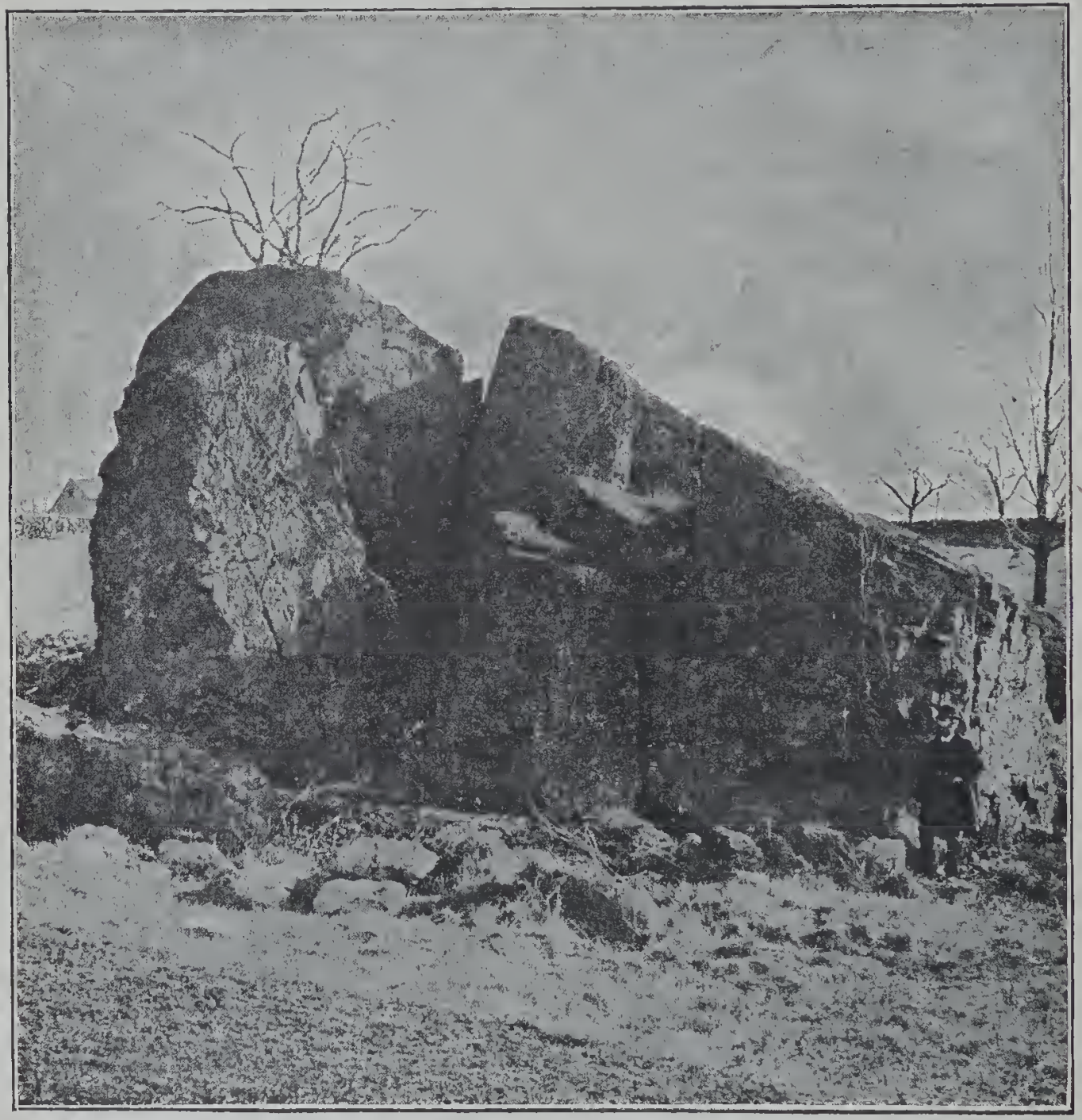

Fig. 1. - Rock split by freezing.

mixed thoroughly with other kinds of rocks and with decaying plants and animals to make the rich, fertile soil as we know it.

Let us study first, then, how the water mixes and lays down the soil. 


\section{EXERCISE 1}

Object. - To see how layers of soil are made by the action of water.

Procedure. - Bring half a cupful of soil from any field at home or from any place near the school. Put half of it in a pint jar or in a wide-mouthed bottle and the remainder in another. Then fill each a little over half full of water. Shake well and allow them to stand until the close of school to-day. Then shake again and set them aside until class period to-morrow. This is done in order to break apart all the small lumps. Number the jars one and two.

Does the soil seem to have settled in distinct layers? Which sized particles settled first? Have you not seen the soil along the bank of a stream in layers like this?

Now shake jar number two vigorously again and allow the contents to settle one minute. Pour off the water into a third empty jar, leaving in the bottom of the second the soil that has settled. Allow the third jar to stand one hour, and pour off the water into a fourth jar, leaving the soil that settled in the third jar. Allow the fourth jar to stand until class time to-morrow.

The soil that settled in one minute is the sand; that, in one hour is called silt; that, in twenty-four hours, the clay.

Do you find that the layers of soil in jar number one look like the soils in jars two, three and four?

Dip a little of the soil out of jars two, three and four with a small wooden paddle and examine each carefully with a hand lens and by rubbing between the thumb and fingers. Which one is pasty? Which is made up of coarse particles? Would you like to have a field of pure clay? Why not? Would you like to have one of pure 
sand? Is it not best to have the sand, silt and clay all mixed?

Conclusion. - You have seen the largest stones, or pebbles, in the swiftest part of the creek or river, and the soil in layers near the stream; and you have seen the finest mud on the top of the soil where the water had dried up along the roadside. Explain why these things are so.

3. Soil Names, or Types. - We have seen how a soil may be made up of sand, silt and clay. If it contains a large amount of sand, we call it a sandy soil ; if of clay, a clay soil. A soil made up of about one half sand, and the other half silt and clay is called a loam soil. If the percentage of silt is large, it is called a silt loam; of clay, a clay loam; of gravel, a gravelly loam; of stone, a stony loam.

\section{EXERCISE 2}

Object. - To find the percentage of sand, clay and silt in the soil of fields at home or near the school building.

Procedure. - Secure two or more samples of soil, about one half cupful each, from different fields. Place each in a jar, which has first been weighed, and weigh again after the sample has been put into it. From these weights, find the weight of each sample. Now separate the sand, silt and clay just as you did in Exercise 1. Find the weight of each of these constituents in each sample, taking care that all appear about equally moist when weighed. These weights can be determined more easily if all jars used are first weighed and the weights recorded. After you have found the weight of the sand, the silt and the clay in each sample, find what per cent each of these is of the original sample.

Conclusion. - Do you find any difference in the percentage of sand or clay which the different fields contain? 
Ask the owner or your father which field can be plowed sooner after a rain. Can you tell him why? If a stream flows through a soil containing considerable sand, the soil near the water is sandier than that farther away. Why is this true?

4. Two Sources of Soil Material. - The soils which we have been studying are made up of a great deal more than just pulverized rock. Some of the soils, especially if they came from a field which last year was a pasture or meadow, or from a fence row, or from the woods, were dark in color, crumbled easily in our hands, and had that good, rich " earth" smell. Along the fence row, the weeds and grass have grown up, ripened, died down and decayed year after year. The soil here must contain a great deal of partly decayed plants, which is called humus. This makes soil fertile.

\section{EXERCISE 3}

Object. - To find out how much of the soil comes from the rocks and how much from the plants.

Procedure.- Secure a small can full of soil from under an old fence or from a field which was in pasture or meadow last year; also another can from a hillside field that has been plowed for a number of years, or from the middle of a well traveled road. Examine each carefully, and tell all you can about the color and the way each crumbles in your hand. Make a mud ball the size of a large marble out of each soil and let them dry for ten days. Then try to break each one with your fingers or a stick.

Now place five ounces of one of the soils as it came from the field or fence row in an iron pan or old shovel, and heat it red hot for at least an hour. Do you see any change in color? As soon as the soil is cool, examine it to see if it crumbles as easily as it did before. Heat 


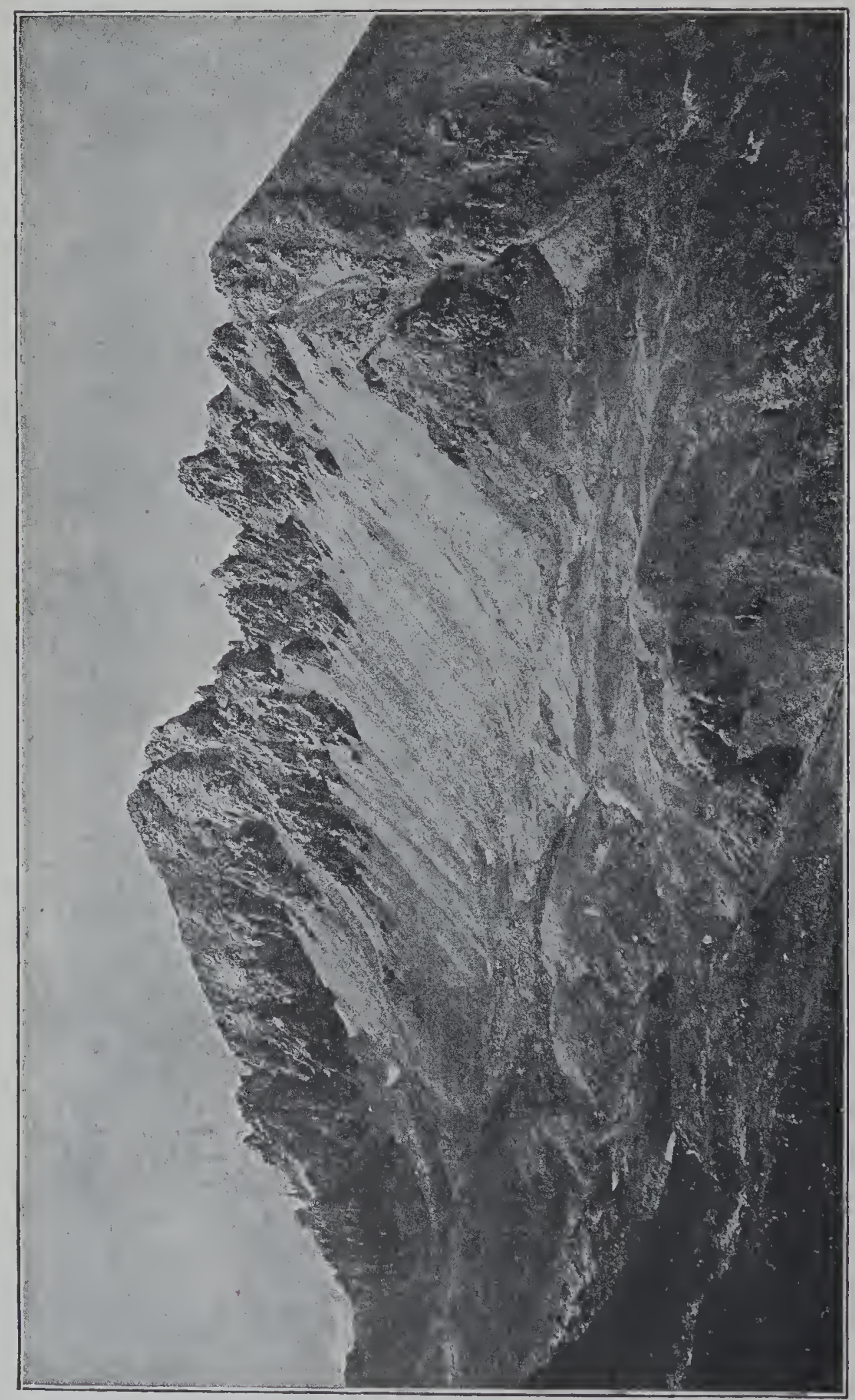

ن 
five ounces of the second soil in the same way for at least an hour. Be sure to tell about any change in color that may take place during heating. Did any smoke come off from either soil? Will rocks burn? Will hay, or grass, or weeds burn? When each soil is cool, carefully weigh again. Which one has lost the greater weight? What reason can you give for this loss?

Conclusion. - Tell which it is, rocks or plants, that gives a rich. soil the dark color and good earth smell. Tell why it is that a new field can be worked sooner after a rain than an old one. By scraping the roads we get all the organic matter, or humus, worked out of them; and they then bake hard and firm. If a farmer should burn his cornstalks or straw instead of working them into the soil again, how would it affect the supply of humus in his land? Frequent cultivation aërates the soil and hastens decay. Why will several crops of corn in succession exhaust the humus in the soil? Land that has been in pasture is found to be rich in humus. Likewise the addition of manure increases the amount of humus in the soil. State two ways in which humus may be added to a soil which lacks it.

5. The Part Plant Life plays in making Soils. - An armful of fodder, left lying in the field, or at the bottom of a haystack, soon begins to decay. The dead plants become covered with blue-black molds, which are themselves living plants, and which are visible to the naked eye. These molds, or fungi, as they are called, absorb a part of the fodder. The part which remains is acted upon by tiny plants, called bacteria, which are too small to be seen with the naked eye. These work upon the plant remains until the whole is broken down into simple substances which the roots of living plants may take up again. 
When wheat is received at the mills, it is run between great steel rollers, and it then passes through a long series of processes until it is separated into flour, bran, middlings and various other products.

We may compare the changes which take place in a decaying plant with those which take place in the wheat as it passes through the mill, but we find a difference.

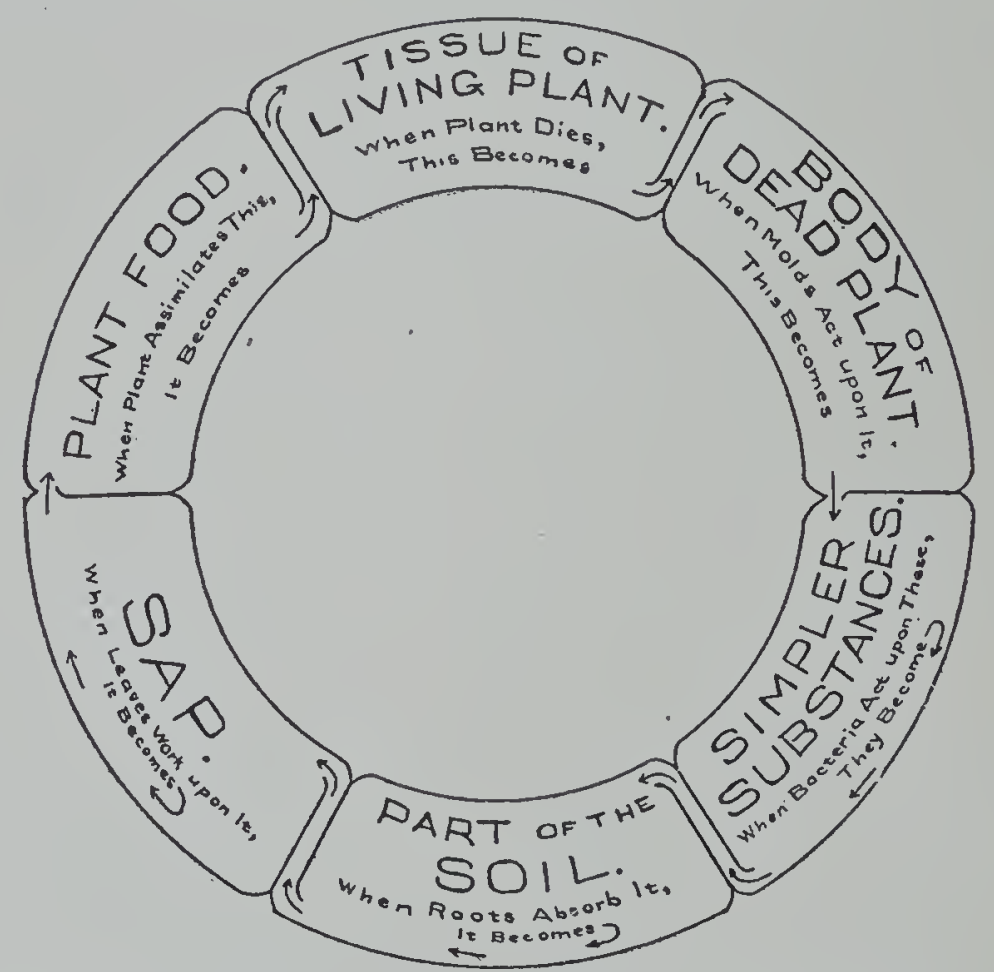

FIg. 3. - The cycle from plant to plant again.

The products of the wheat can not be gathered together again to make the kernels from which they came, whereas in Nature the plants are broken down and separated by the molds and bacteria into simple compounds, which are taken up by roots and finally made again into living plants. The drawing above will fix in our minds better than words how this comes about.

6. The Part Animal Life plays in making and mixing Soils. - A plant may be eaten by an animal. A part 
goes to build up the animal's body. The rest is thrown off and becomes a part of the soil. Sooner or later the animal dies, and its body, too, goes back to the earth again. Thus we see that soil becomes the meeting place of the mineral kingdom and the kingdom of life.

Animals not only help to make soils, but they also play a very important part in mixing them through and through. Gophers spoil our alfalfa, clover and timothy fields, and we try to keep them out. The same is true of ground hogs, squirrels and other digging animals; and yet these rodents have for ages performed an important part in soil making. Each ant-hill is a real soil-mixing mill.

Perhaps the most important visible member of animal life in soil making and mixing is the common earthworm, angleworm, or fishworm, as we may choose to call it. "These insignificant creatures burrow in moist, rich soil and derive their nourishment from the organic matter it may contain. In order, however, to obtain this comparatively small amount of nutritive matter, they devour the earth without any selective power and pass it through their alimentary tracts, rejecting the non-nutritious portions, which nearly equal in bulk that first taken in. The numerous holes made, while in part perhaps to afford passage to the surface, are mainly excavated in this process of soil eating, and actually represent the amount of material which the worms have passed through their digestive systems.

"Darwin states that in certain parts of England these worms bring to the surface every year, in the form of excreta, more than ten tons per acre of fine, dry mold, 'so that the whole superficial bed of vegetable mold passes through their bodies in the course of every few years.' By collecting and weighing the excretions deposited on a small area during a given time, he found that the rate of 
accumulation was an inch in every five years. The importance of the worms, both as mellowers of the soil and as levelers of inequalities is therefore very great."

7. Elements in the Soil and Air which Plants must have in Order to make a Healthy Growth. - In this brief lesson, we have learned that soil is made up of powdered rock and decaying vegetable and animal matter. We have learned how they are mixed by various agents. The soil contains a large number of distinct substances called elements. Only ten of them, however, are essential to plant growth. Their names together with their chemical symbols are given below:

Carbon (C)

Nitrogen $(\mathrm{N})$

Potassium (K)

Hydrogen $(\mathrm{H})$

Sulfur (S)

Oxygen $(\mathrm{O})$

Phosphorus (P)

Iron $(\mathrm{Fe})$

Calcium (Ca)

Magnesium (Mg)

We shall learn in chemistry of the various ways in which these elements combine in the soil to form plant food. It is enough here for us to know that without any one of them a plant can not make healthy growth.

Carbon, as usually seen, is a black solid. Coal and charcoal owe their black color to the fact that they are nearly pure carbon. This element comprises about a half of the dry matter of all plants, that which is present in coal and charcoal coming from plants that have lived in the past. All of our foods likewise contain carbon, which accounts for their turning black, or charring, when burned. Under certain conditions, carbon will unite with oxygen, forming carbon dioxide, a gas which is found in the atmosphere. The leaves of plants take this gas from the air, and in this way, plants get all their 
carbon. It is the only element which they do not take from the soil.

Hydrogen and oxygen are odorless, invisible gases. They are not at all alike, but will unite with each other,

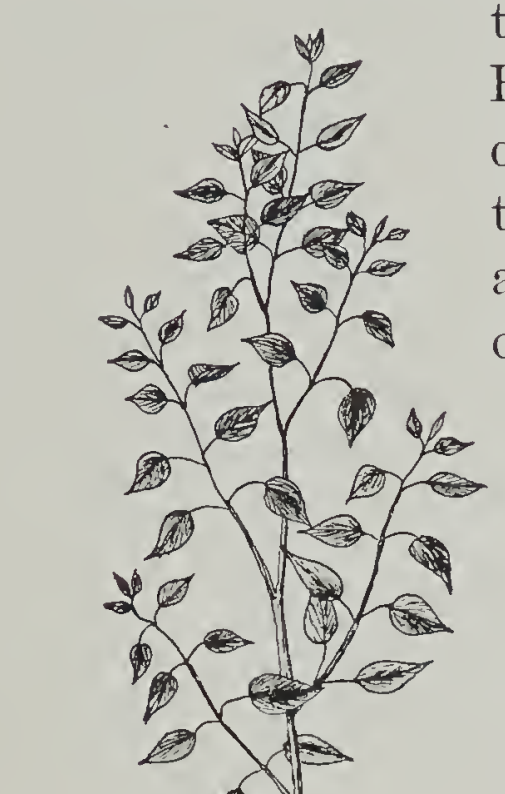
the compound formed being water, $\mathrm{H}_{2} \mathrm{O}$. Plants of course draw a great deal of water from the soil, and from this water they take the hydrogen and oxygen which they must have in order to live.

Nitrogen, too, is an invisible gas, but it differs greatly from both hydrogen and oxygen. It comprises nearly four fifths of the atmosphere; yet plants, whose leaves are held aloft in it, can take none whatever from the air. Instead,

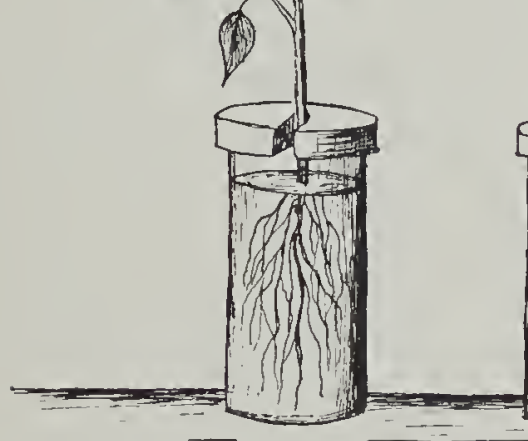

A

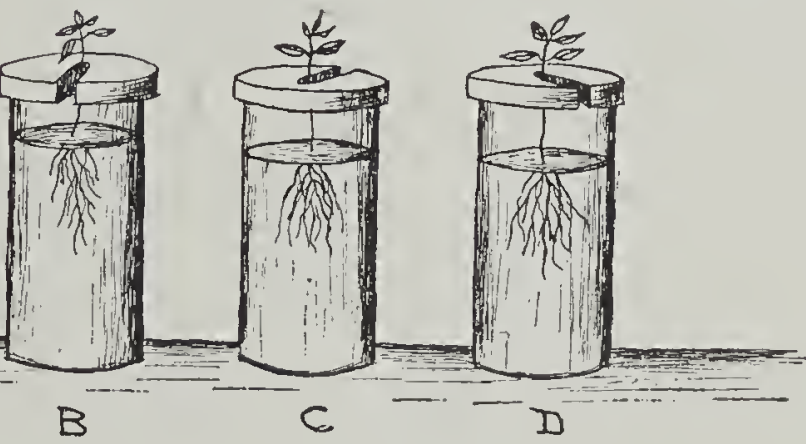

B

c

Fig. 4. - Plants growing in water cultures.

$A$, plant receives all the essential elements; $B$, plant receives all essential elements except nitrogen; $C$, plant receives all essential elements except phosphorus; $D$, plant receives all essential elements cxcept potassium.

it combines with other elements; and the compounds so formed, which are found in the soil, are dissolved and carried upward into the plant by the soil water:

Sulfur is commonly seen as a yellow powder, which produces suffocating fumes when burned. Phosphorus is 
less familiar to us. Because it is so easily ignited, it is much used in making matches. Iron, potassium, calcium and magnesium are metals. These six elements combine in many different ways in the soil, forming compounds which, like those of nitrogen, are dissolved by the soil water and carried along by it when it passes upward into the plant.

There are very few soils which are deficient in any of the essential elements save nitrogen, phosphorus and potassium. The great problem of maintaining a sufficient supply of these three elements in the land so that agriculture may be carried on perpetually remains one for the consideration of all people who till the soil or expect to continue to get from it an adequate food supply. The strength of nations has always been drawn from the soil. A system of permanent agriculture is therefore indispensable to the prosperity and happiness of our people. As a fitting close to our first study of agriculture, we shall make our last lesson one on maintaining the fertility of the soil.

\section{QUESTIONS}

1. Define the term soil. come?

2. From what three kingdoms do the materials for soils

3. Name three agents which have helped to break down rock. Tell how each works.

4. How can you separate soil into clay, sand and silt?

5. Name three agents which have helped to mix soil. Tell how each works.

6. Define humus. How does a soil feel, when handled, and how does it smell when it contains plenty of humus?

7. Compare the weight of a cupful of soil containing plenty of humus with one lacking humus.

8. Name the ten elements essential to plant growth and tell how the plant gets each one.

9. What part of the dry matter of plants is carbon? 


\section{CHAPTER II}

\section{THE WATER IN THE SOIL}

A sorl may be ever so rich in both mineral and organic matter and yet lack water. There can be no crops unless water is added to the soil in the form of rain or by means of irrigation.

8. How the Soil loses Water. - We may liken the soil to a great sponge, standing ready to receive whatever moisture comes to it. Soils, like sponges, vary in their ability to receive and hold water. Rain or irrigation water received by the soil is lost or escapes in four ways:

- First: it runs off the surface.

Second: it filters down through the soil and drains away.

Third : it evaporates from the surface as standing water, or as water which was first taken in by the soil and later worked its way to the surface.

Fourth: it is taken in by the roots of plants and escapes as water vapor from their leaves.

9. The Water which runs off the Surface. - The amount of water which runs off from any soil depends of course upon the amount of rain, the rate at which it falls and the amount of moisture already in the soil. There is another factor, however, greater than any of these; the rate at which the soil can take up water and the capacity of the soil to hold water. Let us prove that this is true. 


\section{EXERCISE 4}

Object. - To see how soil types vary in the rate at which they take up water.

Procedure. - Tie pieces of cheesecloth firmly over the small ends of three lamp chimneys or glass cylinders.

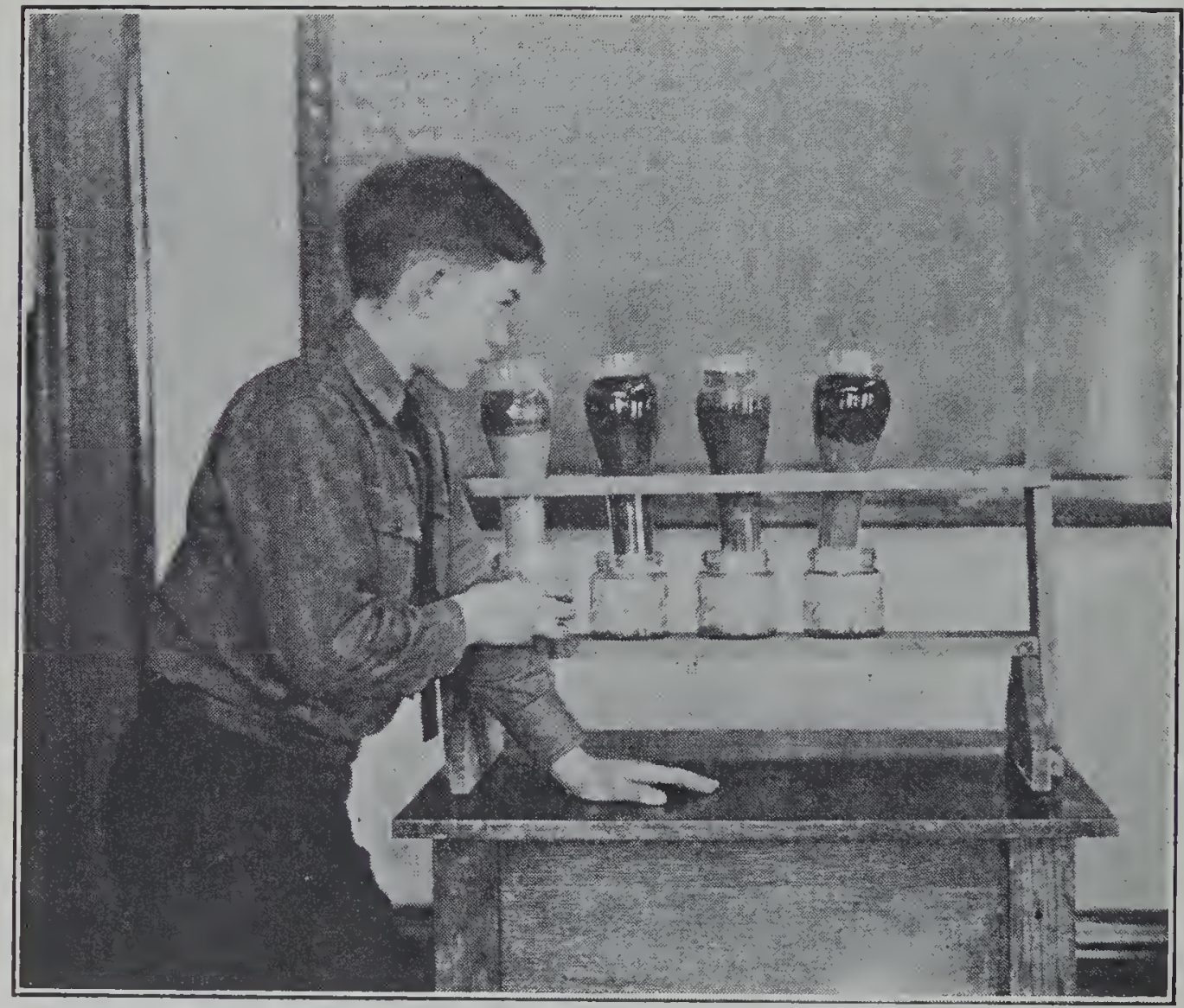

Frg. 5. - Adding water to the soil.

Fill the first one with clay, the second with silt, the third with sand. These soils should be air dried, and then worked through a piece of fine screen wire. Tap the chimneys or cylinders firmly on the table to settle the soil. Place the tubes in a rack, and proceed as shown in the following illustration.

Three tumblers or cups of equal capacity should be 
used, so that each cylinder may receive the same amount of water. Record the time when you begin, and see how long it takes each soil to take up the water, how long it takes the water to reach the bottom of each chimney, or cylinder, after being added at the top, and how much water passes through each soil in a given time. The amount of water that passes through each soil may be collected in glasses below the chimneys and measured. A table like this will help you to keep an accurate record in your notebook:

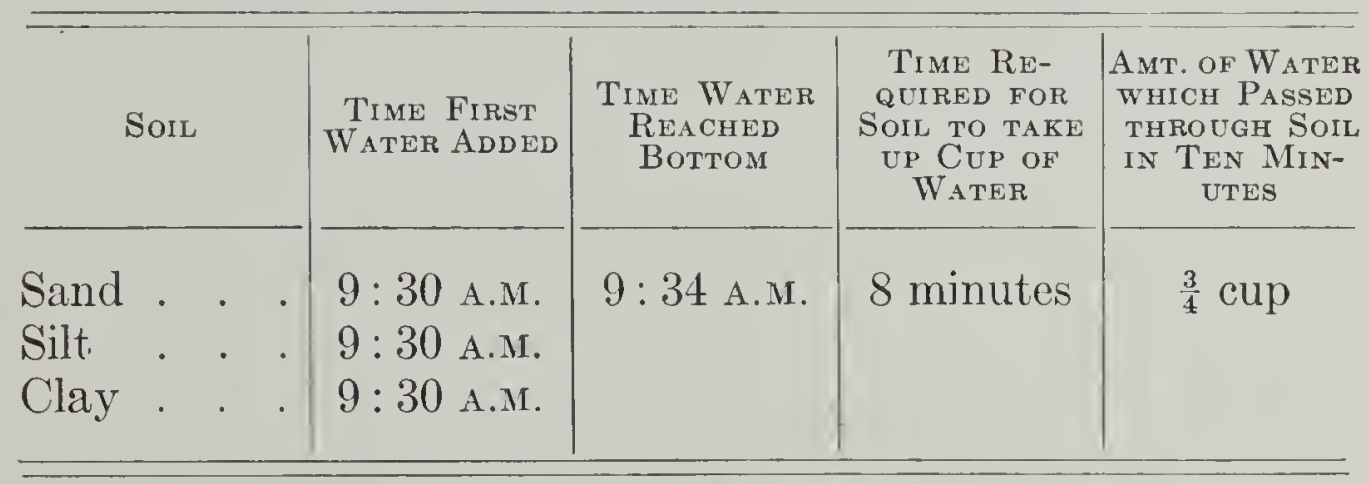

Conclusion. - There are millions of acres of sandy hills in the United States and there are scarcely any gullies washed in them. Clay hills are always full of washouts. How long did it take the clay to take up the cup of water? Why do the clay hills wash so much worse than those made up largely of sand?

\section{EXERCISE 5}

Object. - To determine the relation of the amount of humus in the soil to the amount of water it will take up and hold.

Procedure. - Fill a can with soil from the middle of a well traveled road; another with soil from an old fence row near by, so that the two soils will be as nearly alike as possible except for the amount of organic matter which 
each contains. Dry them in air and sift each one. Secure other samples if possible, being careful to get two of each type of soil, one of which is worn out while the other is rich in humus.

Cut holes about one inch in diameter in the bottom of tomato cans, if you do not have on hand those prepared for this exercise. Place a piece of screen wire over each hole, then a piece of cheesecloth over the wire. Fill as many of these cans level full as you have samples of soil. Label each one, for instance, "Sandy Loam from the Center of the Road," "Sandy Soil from Old Fence Row," etc. Remember always to work them in pairs, the worn out and the rich soil of the same type. Carefully record the weight of each can both before it is filled with soil and afterwards so that you can tell exactly how much soil is in each one.

Place the cans in a pan or bucket and pour water around but not on them. It should stand within one half inch of the top of the cans. At the class period the following day, remove them and set them in a cool place to drain. After two days weigh each can again.

Conclusion. - Tell how much water each soil has taken up. Figure the percentage of moisture taken up and held by the soil in each can. A soil containing plenty of humus does not dry out as readily as one poor in humus. Why? Ask your father or any good farmer in the neighborhood which field dries out first, one which was in pasture or meadow a year or two ago, or one which has been cultivated for a number of years. Ask him if a clay soil, rich in organic matter, dries out as soon as a sandy one. Summarize, all this information in your conclusion.

10. The Water which filters down through the Soil and drains away. - The sky may be clear overhead. 
Perhaps we have had no rain for two or three weeks; yet here may be a bubbling spring, or there a clay tile running full of water.

First, let us consider the source of the water of the spring. Water, as it falls from the clouds, is taken up more or less readily by the soil. It filters down through

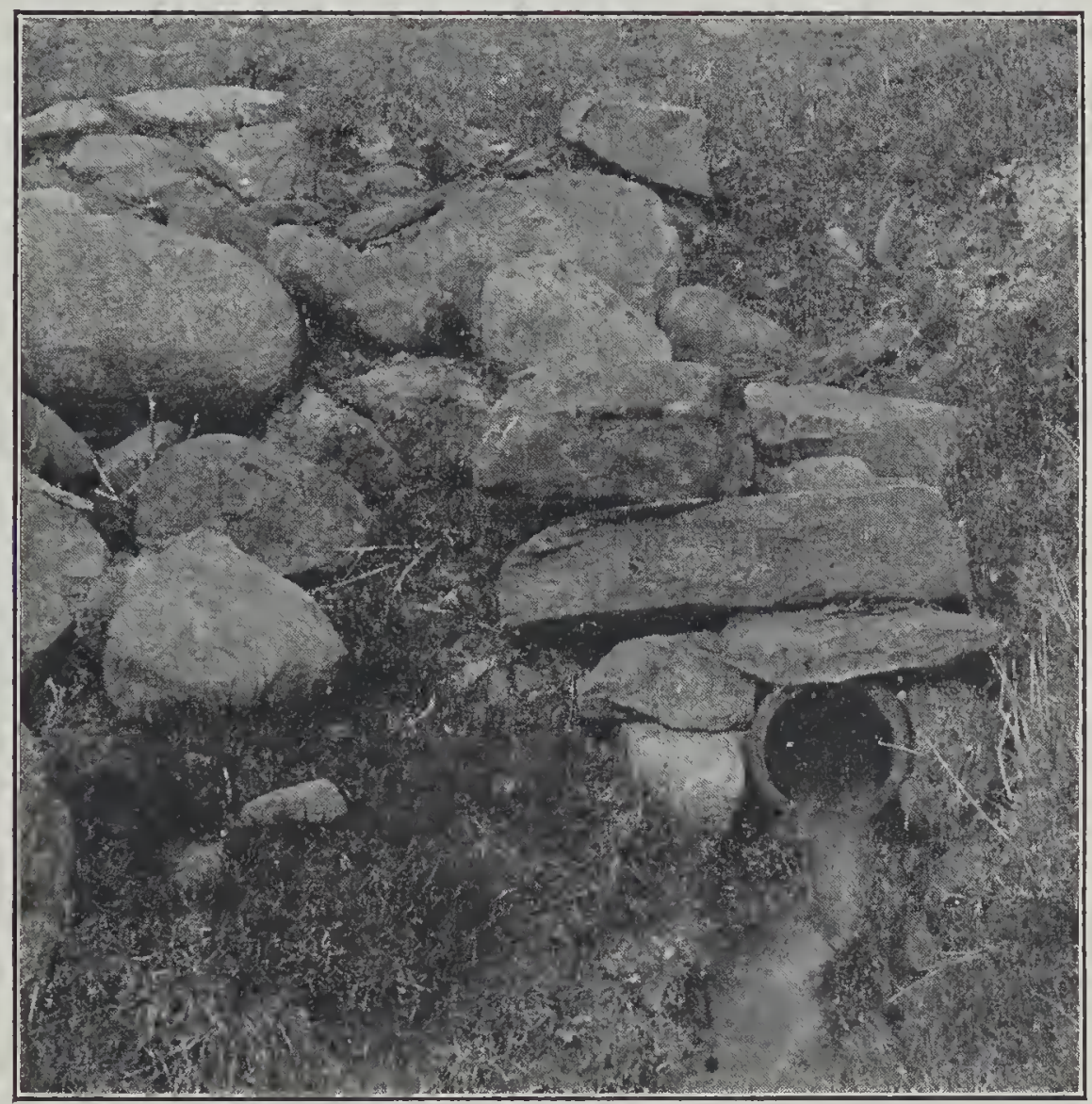

Fig. 6. - Running tile.

silt, sand, gravel or whatever it may be until it reaches some layer which will allow it to flow downward no further. It then flows along this layer until on some. lower ground it comes to the surface. Whenever water issues from a natural opening, we call it a spring.

There are millions of acres of land throughout the United States from which water can not drain naturally. 
As we shall soon learn, this water must be removed before plants can make a healthy growth.

Some artificial means, then, must be adopted to remove this free moisture. This is accomplished by the use of the tile drain. If all the tile drain which is now laid in the states of Iowa and Illinois alone were placed end to end, it would makè a continuous line tens of thousands of miles in length.

11. How Water enters Drain Tile. - Since the water escapes through these drains, the question at once arises, How does it get into the tile? Does it enter at the joints or through the walls of the tile?

Fit a cork firmly into a hole in the bottom of a flower pot. Fill the pot with water. Has any water escaped through the walls of the pot at the end of an hour? Of a day? If little or no water can escape through the walls of pots, little or none can enter. Flower pots and drain tile are made of the same material. This means, then, does it not, that water enters at the joints of the tile.

Lines of tile are laid not closer than a rod apart as a rule, and often they are two rods apart. How is all the water from this area of soil to escape through one small tile? Does it enter at the top, the sides, or the bottom when it finds its way through the joints into the drain?

\section{EXERCISE 6}

Object. - To see how and where water enters the tile drain.

Procedure. - Fill a quart can with fine sand or sandy loam. Punch three holes in the can with a nail: one about three fourths of an inch from the bottom; the second the same distance above the first and a little to the 
right of it; the third about three quarters of an inch above the second and a little to the right of it. Make a cup-shaped hole in the top of the soil and add water until it begins to flow from each of the holes in the side of the can.

Conclusion. - From which hole did the water first begin to flow? Let the lowest hole represent the bottom, the middle one the side, and the highest one the top of the tile. Does this not mean that the water must fill the soil from the bottom upward, then work its way laterally through the soil until it reaches the tile, entering the joints at the bottom? From here it flows out to the drainage ditch or natural outlet. Trace a given amount of water from a rain cloud through a tile-drained soil to the creek or river.

12. Three Kinds of Water in the Soil. - We have just been studying how a certain amount of water escapes from the soil. This water, which moves through the soil and drains away, is known as free, or gravity, water. It is of no benefit to plants whatever. On the other hand, it is an absolute detriment to them. When this gravity water has drained away, there remains a tiny film about each soil particle, known as film, or capillary, water. This is the moisture, of which the plant makes use. There is, however, still another kind of moisture, known as hygroscopic moisture. It is the water which may be driven off by heating the soil to a high temperature after it is thoroughly air dried. It plays no part whatever in plant growth.

\section{EXERCISE 7}

Object. - To determine the percentage of each kind of water in a soil.

Procedure. - Secure a tomato can or a tin can with a 
cover and remove the bottom with a can opener. Press lid into place and invert the can. Place first a piece of screen wire and then a piece of cheesecloth on the inside of the can next to the lid. Fill the can level full with any soil you may select from your air-dried and screened samples. Carefully weigh the can and soil. Add water until the whole soil mass is saturated and the water stands on the surface. Carefully weigh again. Remove the lid from the bottom of the can and allow the water to drain out for at least two days. Carefully weigh a third time. Spread the soil on a cloth or in a large shallow pan and allow it to dry in the open or near a stove for two or three days. Weigh a fourth time.

By heating over a slow fire without burning, the amount of hygroscopic moisture present could be determined; but since this is rather difficult, it is not required here.

The moisture first lost was the gravity, or free water; that in the sunlight or near the stove, the film water; that, which would be lost in the oven or in a pan over a slow fire, the hygroscopic.

The following table will assist you in keeping your notes:

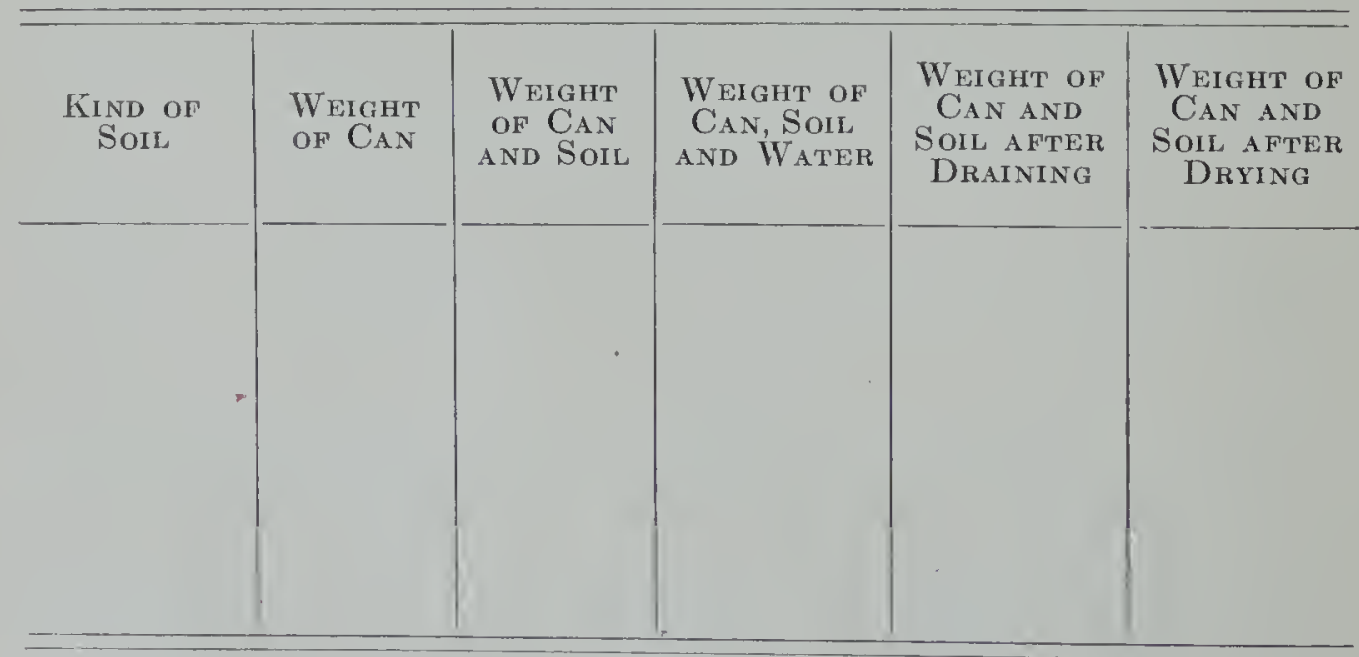


Conclusion. - Figure the percentage of gravity and film moisture in the soil. If others have worked with different kinds of soil, compare your results with theirs.

13. How Film Moisture works its Way upward in the Soil. - The film moisture held in the soil tends to work its way upward toward the surface. This is called capillary action. We may know that water will rise a short distance in a very small glass tube when we thrust it into a pail of water. We know a lamp wick pulls up oil by the same process. The soil is full of these tiny tubes, which are not straight, to be sure, since they consist of irregular openings between the soil particles; and through them the moisture rises from the subsoil. Do these tubes vary in size in different soils?

\section{EXERCISE 8}

Object. - To record the rate at which film moisture rises in different soils.

Procedure. - Repeat Exercise 4, but set the lower end of the chimneys in pans of water instead of adding water at the top. Raise the lower end of the chimneys slightly from the bottom of the pan by thrusting a toothpick or splinter under one side. Otherwise the water may not enter freely.

Conclusion. - Record the length of time it took the moisture to reach the surface of the soil in each cylinder or chimney. Tell why it rose quickly in some and slowly in others.

Since the moisture in the soil rises through these capillary tubes, as we have just shown, is it not important to keep them unbroken?

\section{EXERCISE 9}

Object. - To study the effect of breaking the capillary tubes in the soil by plowing under clods or heavy straw. 
To study the effect on the rise of water in the soil of discing stubble or trashy ground before plowing.

Procedure. - Fasten cheesecloth firmly over the lower end of chimneys or glass cylinders as you did in Exercises 4 and 8. Fill the first chimney full of fine, sifted soil. Fill the second one two thirds full of the same soil, then add a small handful of fine clods, then soil again until the chimney is full. Fill the third chimney exactly as you

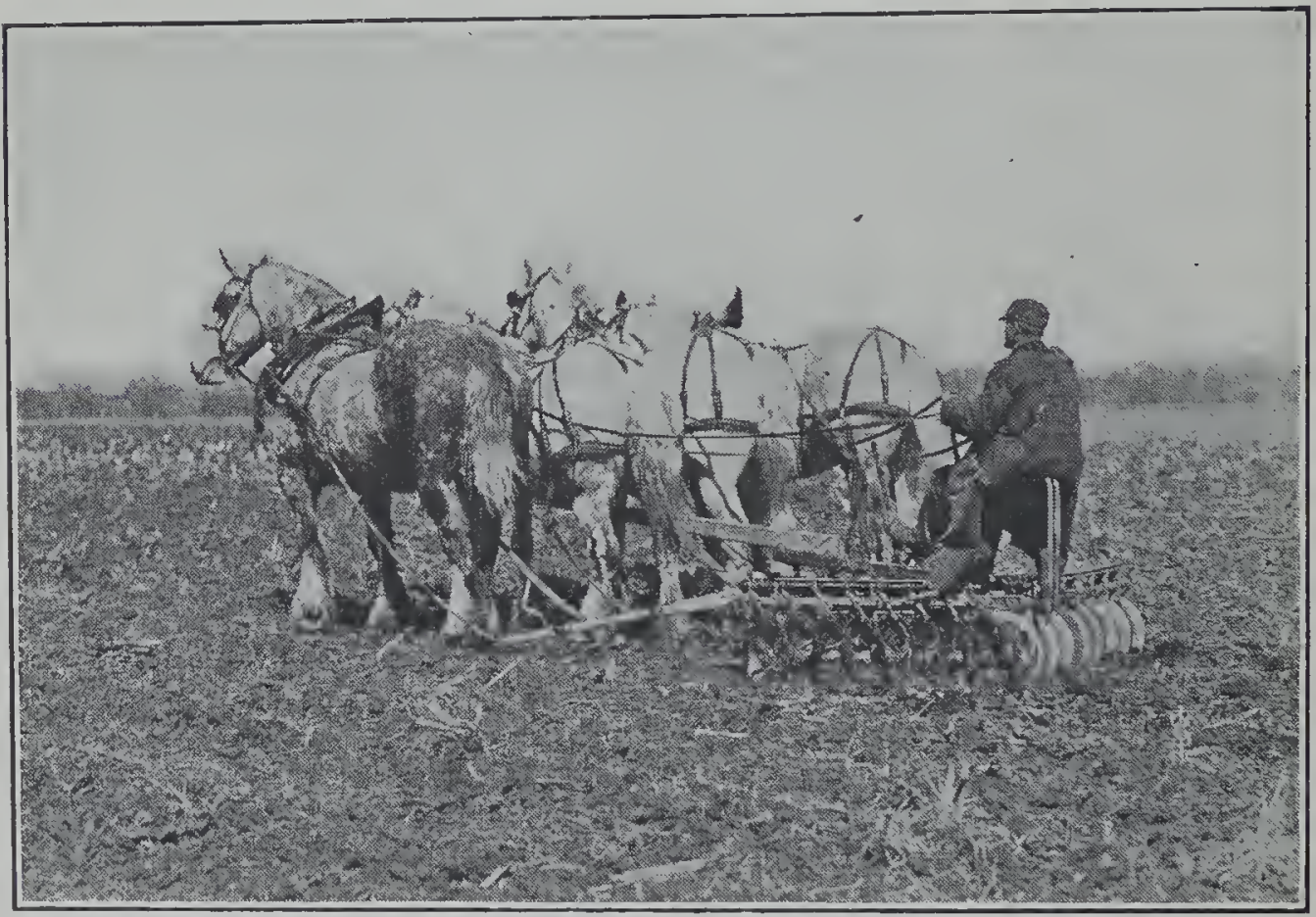

Frg. 7. - Farmer discing.

Courtesy Iowa State College.

filled the second, only substitute a half inch of fine straw for the clods. Fill a fourth chimney as you did the third, but instead of putting the straw in a layer, cut and mix it throroughly with the soil in the upper part of the chimney. Note that while the straw in the third chimney is in a layer, just as it would be if we plowed stubble without discing, that in the fourth chimney is mixed with the soil just as it is when stubble is disced before plowing. 
Place the lower ends of the chimneys or cylinders in pans of water, and watch the moisture rise in the soil.

Conclusion. - Will it pay to disc stubble or trashy fields before plowing? Why? What is an ideal condition of the soil for the freest rise of moisture through it?

\section{How the Farmer prevents the Escape of Film} Moisture. - The roots of plants often feed very near the surface of the soil. These roots need the moisture that comes up by capillary action. The farmer wants therefore to bring this water up to the roots, and yet not to let it escape into the air. He can do this by mulching with straw, but this may keep out the air, which we shall later learn is very important. Moreover, it would be out of the question for him to mulch all his fields in this way. A mulch, then, of soil, or a dust mulch, as it is called, is used. The following simple demonstration will show how a dust, or powder, will prevent the moisture from reaching the air :

Place two lumps of sugar in a saucer containing a small amount of water colored with red ink. On the top of one of the lumps, place half a spoonful of powdered sugar, soda or starch. Notice how the colored water comes to the surface of the first lump and stops at the powdered material in the second.

\section{QUESTIONS}

1. Name four ways by which water escapes from the soil.

2. Which takes up water more rapidly, a sandy soil or a clay soil?

3. Which takes up water more rapidly, a soil rich in humus or one lacking in humus?

4. Define the term spring.

5. Explain what causes the water to issue from a spring.

6. Explain fully how water enters a tile drain. 
7. What three kinds of water do we find in the soil?

8. How can you determine the amount of each kind of water in a sample of soil?

9. What is the effect upon the rise of water in the soil of plowing under trash or clods?

10. How may moisture be prevented from escaping from the surface of the soil? 


\section{CHAPTER III}

\section{THE AIR IN THE SOIL}

Tillabibe land is made up of soil particles, each of which is inclosed in a film of moisture while the spaces between them are filled with air. A square rod of ordinary soil may contain from sixty to seventy-five cubic feet of air in the upper fourteen inches.

15. Why Air is Necessary in the Soil. - Air, which consists chiefly of oxygen and nitrogen, plays a very important part both in soil-making and in plant growth. We have already learned that plants, decayed through the action of fungi and bacteria, help to form soil. These organisms, you will remember, break down the dead plants into simple compounds which the living roots can absorb again. (See Section 5.)

The fungi and bacteria which cause decay can not live without oxygen, nor can the roots of plants live without it. Moreover, a germinating seed takes in oxygen and throws off carbon dioxide. In fact, as we shall later learn, it is impossible for any seed to germinate without oxygen.

In addition to oxygen and nitrogen, air also contains carbon dioxide. This gas, which is given off by germinating seeds and decaying vegetable matter, helps to dissolve the plant food in the soil.

16. Why we seek to control the Air Space in the Soil. - Since the air in the soil is so essential to plant growth 
and soil-making, it follows that any method we may employ to get more air into the soil will ordinarily increase its fertility. In regions, however, where the rainfall is not sufficient to settle the soil well or to allow the decomposition of the organic matter, the amount of air in the soil may be too great. In this case, the upward movement of water, such as was shown in Exercise 8, will be interfered with, and not enough moisture will reach the roots or germinating seeds. The aim of the farmer in these dry regions is to increase the moisture-holding capacity of the soils without making them so light that the movement of the air will dry them out.

The amount of air a soil contains depends (1) upon the character of the soil, (2) upon the amount of organic matter it contains and (3) upon the amount of moisture present.

\section{EXERCISE 10}

Object. - To determine the amount of air space in the soil.

Procedure. - Secure as many ordinary tin cans as you have samples of fertile and infertile, air-dried and sifted soils. Fill each can with a soil and tap lightly on the table to settle it. The space between the soil particles is now occupied by air. Add water slowly to each can, keeping a careful record of the amount.

When the water has displaced all the air and stands at the surface of the soil, you will be able to determine the amount of air in the sample by the amount of water that has been required to displace it.

Conclusion. - State which soils contain the greatest amount of air space. Does the amount of organic matter, or humus, make any difference in the amount of air the soil contains? Why is it that a soil needs air? 


\section{EXERCISE 11}

Object. - To determine the influence of compacting the soil upon the amount of air space in it.

Procedure. - Follow the instructions given in Exercise 10 , only before adding the water thoroughly pack the

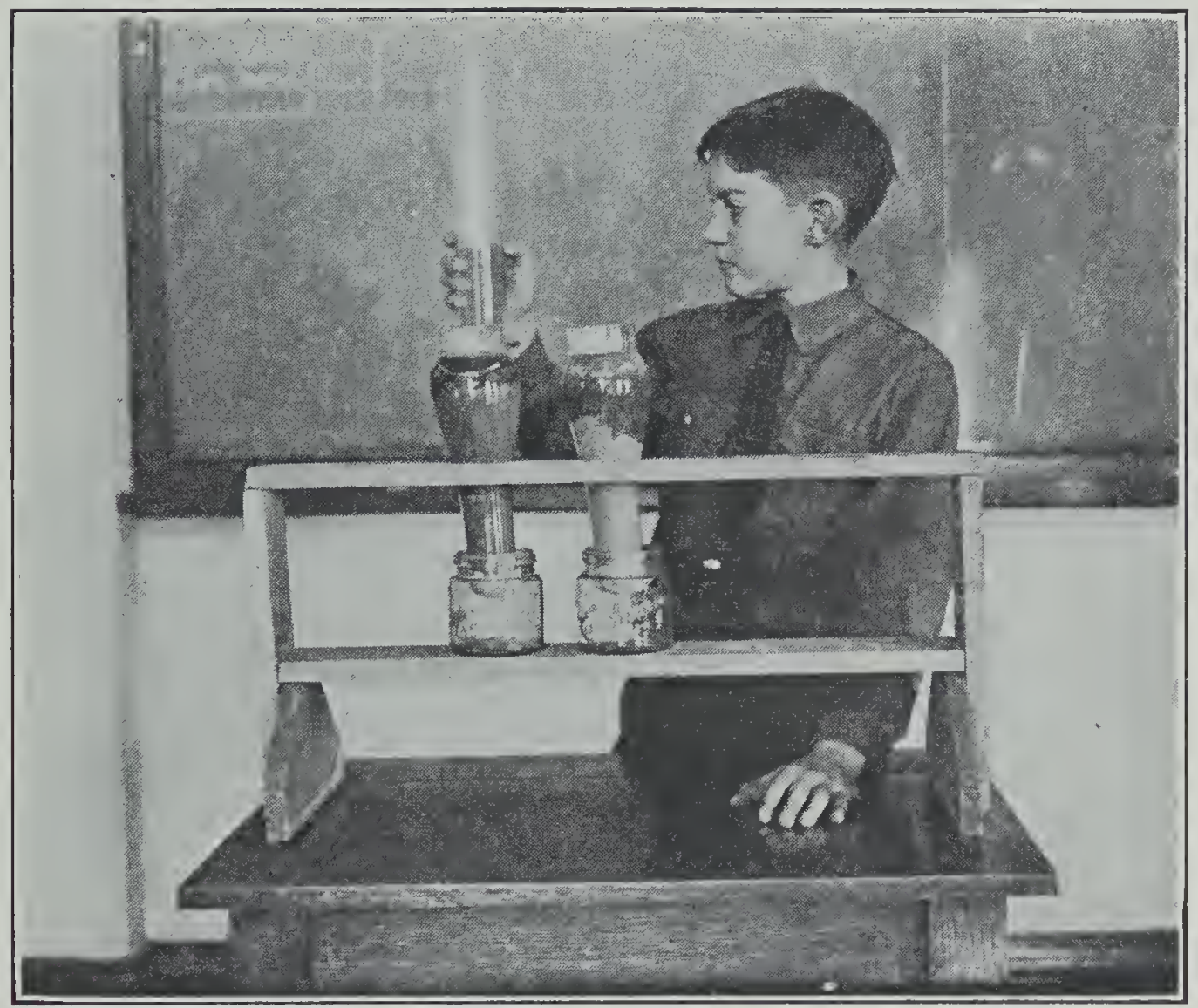

Fig. 8. - Measuring the water before adding it to the soil.

soils in the cans with a short piece of broomstick or the head of a small mallet.

Conclusion. - Compare the amount of air space in the soil before packing, as determined in Exercise 10, with that after packing, as found in this exercise. In dry farming regions, where the soil is liable to be too loose and light, would it be advisable to roll or pack it? 
17. How we may get More Air into the Soil. - From the western limit of the Corn Belt to the Atlantic Ocean and in all the land subject to irrigation, there is need of plenty of air in the soil. This does not mean that large air spaces, such as are caused by clods or small piles of weeds or straw, are necessary; it means rather that much

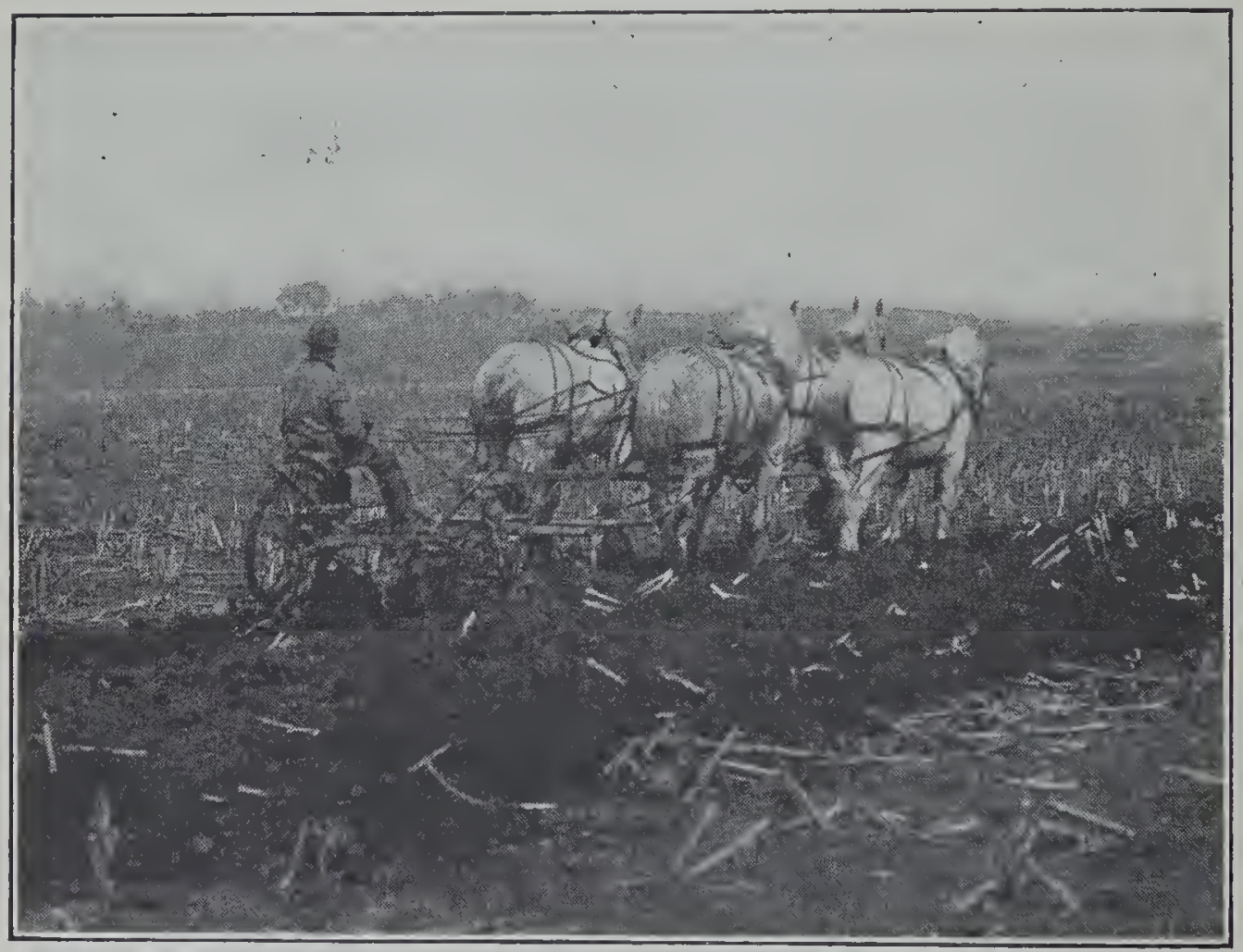

Fig. 9. - Farmer plowing.

of the air which finds its way into the small spaces in mellow, well-tilled land is needed.

The amount of air in the soil is influenced first by cultivation or tillage; second, by manuring; third, by drainäge; fourth, by rotation of crops.

The plow turns up particles of soil which may have been shut off from a supply of air. Then, too, the bottom of the furrow is in direct contact with the air until it is covered on the next round. 
Harrowing, discing and cultivating all help to increase the amount of air in the soil. Rolling and subsurface packing, on the other hand, diminish the amount of air in the soil. These latter operations are performed largely in the dry farming regions.

How much more water did the soil containing humus take up than the same soil lacking humus in Exercise 10? Remember that it was there shown that the air space in a soil increases with the amount of humus, or organic matter, which it contains. By adding manure to the soil, we increase the amount of air in it.

In Exercise 10, we expelled the air from the soil by adding water. When we remove water from the soil by tile drains, we allow air to take the place of the water. Moreover, a generous supply of air enters these tiles and moves upward through the soil.

Many plants, such as alfalfa and sweet clover, send their roots deep into the soil. When these crops are plowed up, the roots decay, allowing the air to fill the space which they had occupied. This is one of the benefits of crop rotation.

\section{QUESTIONS}

1. What are the uses of air in the soil?

2. How many cubic feet of air may the upper fourteen inches of a square rod of soil contain?

3. What influence has plowing and discing upon the volume of air in the soil?

4. Why is it that farmers in the dry farming regions work to reduce the volume of air in their soils?

5. What influence do clods have upon the soil air?

6. Name two ways in which tile drains help to get air into the soil.

7. What influence has manuring upon the amount of air in the soil?

8. How does the rotation of crops influence soil air? 


\section{CHAPTER IV}

\section{THE TEMPERATURE OF THE SOLL}

\section{Proper Temperature Necessary for Germination.}

- Throughout the winter months, the seeds and roots of plants in the earth lie dormant. Plant food, moisture and air are present in the soil; but the proper temperature is lacking. Seeds can not germinate, nor plants grow unless the soil absorbs enough of the heat of the sun to raise the temperature of the fields somewhat above freezing. Very few of the seeds or plants awaken from their winter's rest at a temperature near thirty-two degrees Fahrenheit, the melting point of ice. Wheat will germinate and make some growth at forty-one degrees but it thrives best at eighty-three. Oats may germinate at thirty-eight; their most vigorous growth, however, is made at seventy-seven degrees. The soil in a cornfield should register a temperature of at least forty-nine degrees, while ninety-two degrees is the best, or optimum temperature for the germination of this seed. Cucumbers, muskmelons and squashes should not be planted until the oaks are fully in leaf, when the soil temperature is around eighty degrees.

19. How Temperature of the Soil is governed.Since a warm soil is so important a factor in the germination of seeds and the development of roots, let us consider the laws that govern the temperature of the soil. These laws, or principles, may be summarized in three sentences:

The temperature of the soil depends first upon the amount of air space in it. 
The temperature of a soil depends secondly upon the amount of moisture in it.

The temperature of a soil depends thirdly upon its color.

20. How the Air Space in a Soil affects its Temperature. - The greater the amount of air space, the warmer the soil. Air is warmer than the earth in the spring. Therefore when either air or rain water, which is warmed in passing through the air, enters the soil in the spring, the temperature of the land is raised.

We have already in Exercises 10 and 11 determined the amount of air space in certain soils. Let us now see what influence this has upon the temperature. Wé remember from Exercise 1 that while sand is made up of coarse particles, clay consists of particles so small and fine that it becomes pasty when wet.

\section{EXERCISE 12}

Object. - To determine how the size of particles, and consequently of the air space in a soil, influences its temperature.

Procedure. - Fill two cans, one with clay, the other with sand. Plunge the bulb of a thermometer into each soil, about one inch below the surface. Moisten each soil and place the cans in the sunlight. Copy the following table into your notebook and complete it by recording the temperatures every hour.

\begin{tabular}{l|l|l|l|l|l|l|l}
\hline \hline Soll & 9 A.M. & 10 А.M. & 11 А.м. & 12 A.M. & 1 Р.м. & 2 Р.M. & 3 Р.м. \\
\hline $\begin{array}{l}\text { Sand } \\
\text { Clay }\end{array}$ & & & & & & & \\
\hline
\end{tabular}


Conclusions. - Market gardeners always try to select a dark, sandy soil for their early vegetables. Give one reason why this kind of soil warms up earlier in the spring. Lime, added to a clay soil, tends to gather the fine particles into small grains. Would you expect the temperature of a clay soil to be somewhat higher after a dressing,

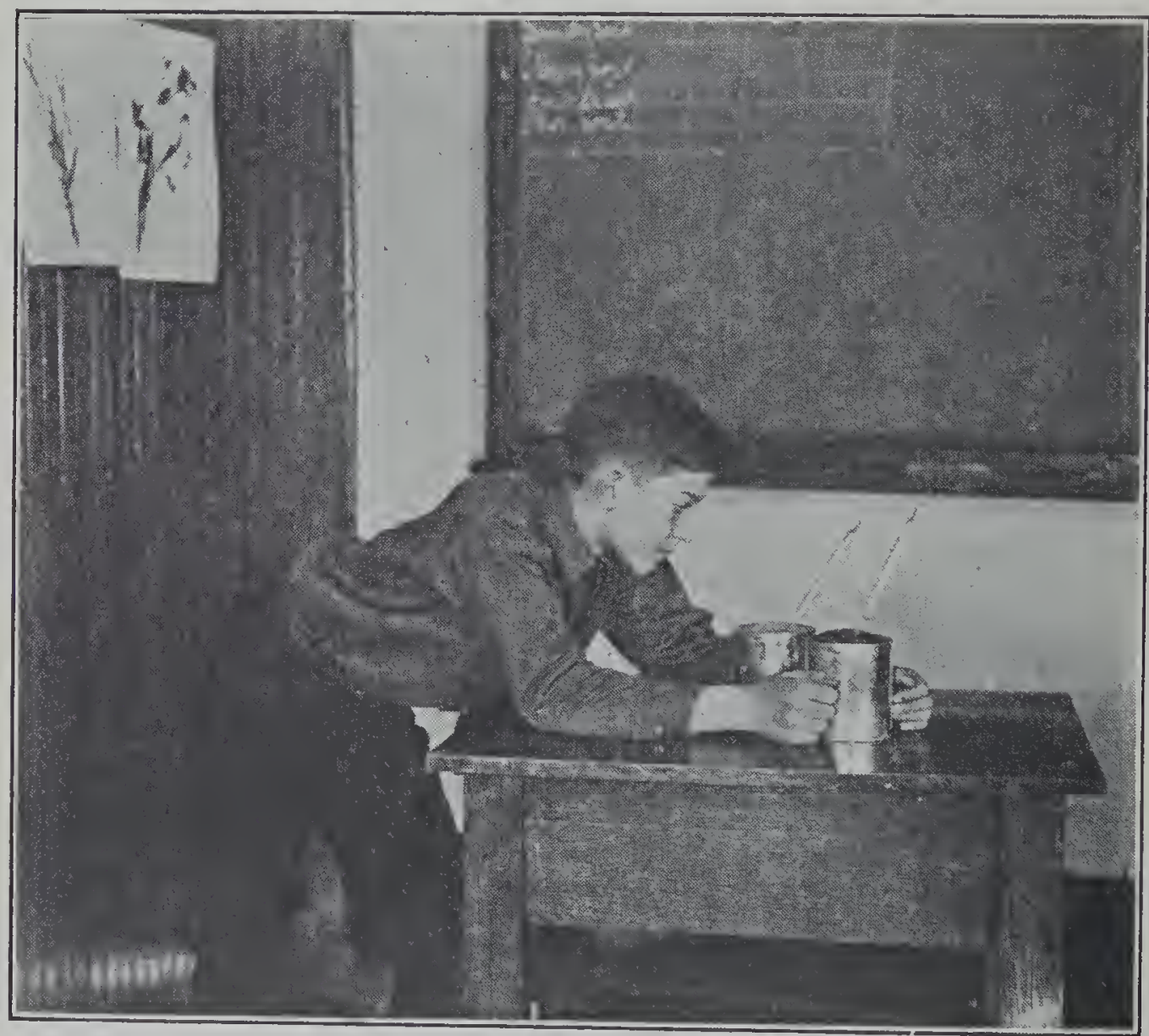

FIG. 10. - Thermometers in the soil.

or application of lime was added? In Exercise 10, the amount of air space was found to be greater in the soil containing humus from the old fence row than in that from the center of the road. Would you expect the temperature of the soil in the sun along the fence row to be higher than that in the center of the road? Why? If you 
have time, test with the thermometer to see if your answer is correct. Summarize your answers into a short story about the influence of air space upon the temperature of soils.

21. How the Moisture in a Soil affects its Temperature. - We all know that a wet, soggy soil, which is filled with free or gravity water, is much colder in the spring than is a well-drained soil, which contains only film moisture. Let us investigate this with our thermometers.

\section{EXERCISE 13}

Object. - To show the influence of the amount of moisture in a soil upon its temperature.

Procedure. - Fill two cans from the same sample of soil ; that is, with soil from a fence row, from a cultivated field, or from a garden as you may choose. Add water to the first can until it stands at the surface of the soil. Add none to the second can. Plunge the bulb of a thermometer about an inch below the surface of each soil. Prepare a table as you did in the preceding exercise, but substituting the words "saturated soil" and "dry soil" for "sand " and "clay." Place the cans where both the sun and the wind will strike them.

Conclusions. - Men often wrap a piece of a sack about a jug in the summer time to keep the water cool. The sack is usually kept moist so that water is evaporating from it all the time. Evaporation is a cooling process. In which soil did the thermometer read lower, that which was saturated, or the other one? Why? What is one of the great benefits of tile draining? Which soils will allow ready passage of water through them, those containing plenty, or little, of humus? Why? Sandy soils, or clay soils? Why? 
22. How the Color of a Soil affects its Temperature. It is a peculiar fact that dark colored things absorb more of the sun's heat than do those which are light colored. That this is true of soils is shown by the following experiment :

\section{EXERCISE 14}

Object. - To determine the influence of the color of a soil upon its temperature.

Procedure. - Fill two cans to within an inch of the top with any soil you may choose. Fill the remainder of one can with some white powder, as slaked lime or chalk dust, the other with coal dust or soot. Thrust the bulb of a thermometer into each can to a depth of about an inch. Record the temperatures one hour after the two cans have been placed in the sunlight.

Conclusions. - White reflects light, black absorbs it; and when light is absorbed, it is converted into heat. Is not a dark suit or dress warmer in the summer than a white one? Why? Should a light colored horse stand more heat in the summer time, other things being equal, than a black one? Why? If time permits, compare the temperatures of light and dark colored soils in the fields. Are the fields to which green or barnyard manure was added a year or two ago darker in color than those to which none was added? Are the fields which were in clover or pasture last year darker than those which have been continuously cultivated?

Name four ways by which a farmer may make the soil of his fields warmer.

23. The Advantages of a Warm Soil. - Seeds awaken, or germinate, much more readily in a warm soil than in a cold one. The growing plant also thrives better where the soil temperature is favorable. The bacteria and 
other organisms in the soil, which break down the dead plants, work much more rapidly at the higher temperatures. The soil is a storehouse of plant food. A certain amount of this must be unlocked each year to supply the plants. Plant food becomes available in a shorter time if the soil is warm.

\section{QUESTIONS}

1. Why are plants dormant in the winter?

2. At what temperature will corn germinate best?

3. At what temperature will wheat germinate best?

4. Upon what three things does the temperature of the soil depend?

5. Compare the temperatures of a sandy and a clay soil and give reasons for the difference.

6. Why will adding lime to a clay soil raise the temperature?

7. Compare the temperature of an undrained field which is wet with that of a drained field and give reasons for the difference.

8. Why is a dark colored soil warmer than a light colored one?

9. How may a person change the color of his soil?

10. What benefits are derived from a warm soil? 


\section{CHAPTER V}

\section{THE TILLAGE OF SOILS}

24. Why we till the Soil. - The question of tillage of soils is so interwoven with that of air in the soil, water in the soil, and the temperature of the soil that it is difficult for us to set it aside as a separate lesson. There are, however, some deep and fundamental objects of tillage which we should fix in mind. We till the soil:

First: to improve its texture and structure.

Second: to cover, or to work into the soil trash, straw, manure or plants by plowing or discing.

Third: to put seed into the prepared seed bed.

Fourth: to destroy weeds.

Fifth : to prevent the escape of moisture from the soil by making a dust mulch.

Sixth : to enable air and water to enter the soil.

25. Improving the Texture and Structure of the Soil. If we are to study how tilling the soil will change its texture and structure, we must know the meaning of these terms as applied to farm lands. The size of the individual particles in the soil determines its texture. The manner in which these particles fit together determines the structure.

The question at once arises. How does tillage change the size of particles? It can not, in itself, change the texture of the soil, for the particles are broken up by mightier forces than the plow, or harrow, or disc. These operations do, however, expose the soil particles so that the sun and the water, the heat and the cold, can break them into finer particles. 
There are two ways in which the particles of soil may fit together, and hence two soil structures are commonly recognized:

First: that in which the particles are stuck together in tiny masses, forming what is known as the crumb structure.

Second: that in which the particles are run together in large masses, forming lumps, or clods. This is known as the puddled structure.

The formation of lumps and clods; i.e., the puddled structure, may be brought about in four ways: (1) by plowing the ground when it is too wet; (2) by allowing animals to trample the fields when the soil is full of moisture; (3) by leaving the fields too long in one crop; and (4) by neglecting to add organic matter.

\section{EXERCISE 15}

Object. - To show the effect of freezing upon the structure of soils.

Procedure. - Make four mud pies out of clay such as was obtained in Exercise 1. These pies should be about an inch and a half in diameter, one half inch thick, and contain enough water to prevent cracking when molded. Set one pie on a window sill or on a shelf to dry. It should not be allowed to freeze. Place the other three outside the schoolroom where they will freeze thoroughly. Bring them into the schoolroom after they have been frozen solid for a day or two, and thaw them out carefully. As soon as the frost is out of them, but while they are still wet, place one upon the window sill or shelf inside the schoolroom, and the other two outside to freeze thoroughly again. Bring the two frozen pies in again later; and when they have thawed out a second time, set a third one on the shelf, and put the last one out to freeze once 
more. Remember that this pie should not have been allowed at any time to lose its moisture. Bring it again into the schoolroom, thaw it out gradually, and put it on the shelf with the others.

Conclusions. - Break and crumble each of the pies in your hand. Remember that one of them has not been frozen at all, another has been frozen once, the third, twice, and the fourth, three times. Record in your notebook which one crumbled most, easily, which one next, etc. What did the freezing do to the particles of soil which had been stuck together by pressure of the fingers while wet? Have you not noticed how much more mellow a soil is in the spring than in the fall? What are some of the advantages of fall plowing?

\section{EXERCISE 16}

Object. - To determine the effect upon structure of working organic matter into the soil.

Procedure. - Make a mud pie out of clay as you did in the preceding exercise, only just moisten it instead of making it wet. Make a second one in the same way, but make it of one part sawdust, peat or powdered leaf mold, and two parts clay. Mix the ingredients dry before adding water. Make a third and fourth pie as you did the first two, but using sand instead of clay, then a fifth and sixth one, using silt in the same way. Put the pies in an oven, on the radiator or on the back of the stove to dry them out thoroughly.

Conclusions. - Crumble each pie carefully in your hands. Which crumbles more readily, the clay alone, or the clay and organic matter? Did the addition of the organic matter have as much effect upon the silt as upon the clay? Did it not have least effect upon the sand? In which soil are the particles smallest? Would you say 
then that clay soils need green and barnyard manures more than sandy ones as far as structure is concerned? Which of all these soils could be plowed first after a rain?

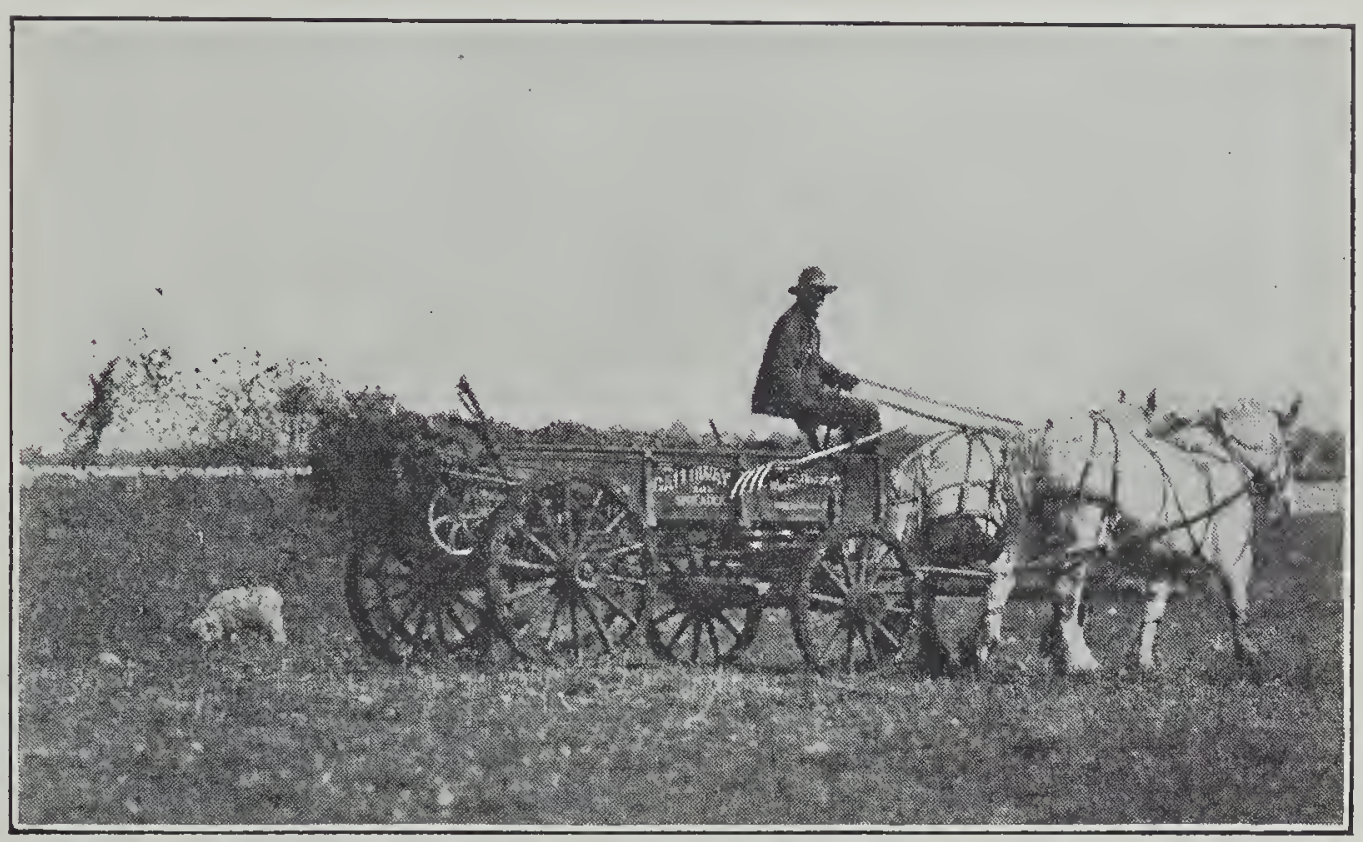

FIG. 11. - Adding organic matter to the soil.

26. One Cause of Cloddy Fields. - The next experiment will bring out one of the common causes of the cloddy fields which often prove troublesome to farmers.

\section{EXERCISE 17}

Object. - To study the effect of stirring or tramping soils when wet.

Procedure. - Make three groups of mud pies out of clay, silt and sand; or use types of soils from the fields in which these materials predominate. Each group is to consist of one pie of clay, one of silt and one of sand. If the soil is brought from the field, it will probably be moist enough for the pies of the first group. If the soil is dry, add just enough water to moisten and put it in the condition of well tilled land. To each pie of the second 
group, add enough water to make the soil sticky. To the third group, add water until the whole is a saturated mass. In this case, the clay, the silt, and the sand, of which the different pies are made should be thoroughly worked in your hands. Set the pies in the oven or on the back of the stove to bake.

Conclusion. - After baking, crumble each pie carefully in your hands, making note of how hard each one is to crush. Would you say that plowing or trampling a sandy soil would puddle it as much as it would a clay soil? Would it puddle a silt soil as readily as a clay soil? What effect would the addition of organic matter have on each of these soils?

27. Covering, or Working into the Soil, Organic Matter. - As already stated, the second object of tillage is to cover or work into the soil any organic matter which may be on the surface. This may be accomplished by using the plow or disc.

With the plow, a narrow strip of land is turned up, twisted over and laid bottom side up. Where there is any great amount of trash or straw on the ground, a rolling cutter, or coulter, as it is called, is used. This rolling knife cuts through the trash so that it can not gather, and lift or clog the plow.

If tall weeds, green manuring crops, or any other plants are plowed under, some means must be employed to draw them down to the bottom of the furrow, allowing the dirt to cover them completely. A chain or a bent rod is commonly used to draw the heavy plant growth under the overturning furrow slice.

28. Putting Seed into the Seed Bed. - The operation of seeding will be studied again in connection with certain 
crops. The work of seeding generally stirs or tills the soil to a considerable extent. A small furrow is usually opened by the drill shoe, or the planter blade; and the dirt is filled in again over the seed by some shovel or wheel attachment behind.

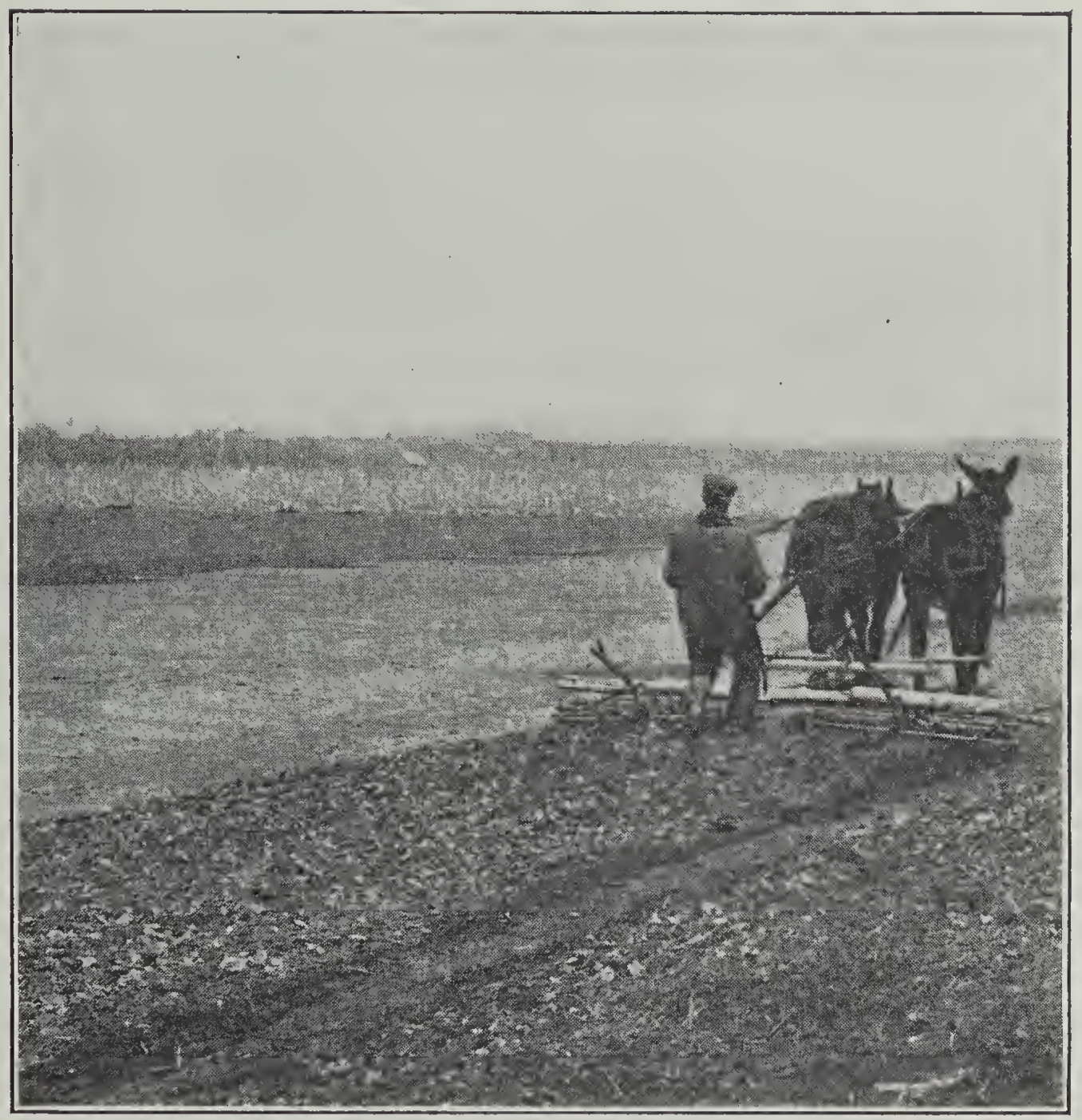

FIG. 12. - Farmer harrowing.

29. Destroying Weeds. - One of the primary objects of tillage is to destroy weeds. The tool which is used depends upon how deeply or thoroughly we wish to cultivate the soil, in addition to killing the weeds; and it 
depends also upon the size of the weeds and the nature of their root system. Any plant is most easily destroyed when it is just breaking through the ground. The common harrow is one of the best tools we have for destroying young weeds.

As the weeds become a little older, the disc or cultivator is used to destroy them. The disc is not used, however, on such plants as the quack grass. This weed is spread by long, underground stems, which run about beneath the surface at a depth of two or three inches. A disc only serves to cut these stems into pieces and scatter them through the fields, where each piece becomes a new plant. Such weeds are plowed up, exposing the roots to the sun without breaking them any more than necessary.

30. Forming a Dust Mulch. - In Section 14, we observed how the moisture rises through the soil until it escapes into the air unless prevented by a dust mulch. Such a mulch may be formed and maintained with the harrow, the fine-toothed cultivator, or with the subsurface packer, which is extensively used in the dry farming regions.

\section{Making it Possible for Air and Water to enter the} Soil. - Plants can not exist without air and water. The roots and germinating seeds, as well as the leaves and stems, must have air. Plants absorb no moisture through their leaves or stems; the roots alone gather the water. We have already seen in Section 16 why the soil needs air. It must be put in condition to receive and hold this air and water.

The plow stirs the soil, making it light and friable; the harrow breaks the lumps, making the earth even more mellow; and the cultivator loosens the surface so that the rain will not run off and that the air may enter. 


\section{QUESTIONS}

1. Give six reasons for tilling the soil.

2. Define the terms texture and structure as applied to soils.

3. What effect does freezing have upon the structure of soils?

4. Name two soil structures.

5. Name two ways of bringing about the crumb structure.

6. Name four causes of a puddled condition of the soil.

7. How can you draw tall weeds or other plants under when you plow?

8. What is the best implement to use to destroy weeds that are just sprouting? To destroy weeds an inch or two high? To destroy tall weeds?

9. What is the use of a dust mulch, and how is it maintained?

10. How does cultivation help air and water to enter the soil? 


\section{CHAPTER VI}

\section{THE ROUND OF PLANT LIFE}

Thus far our lessons have been about soil, for from the soil plants draw their moisture and all of their food except carbon. Plants can not exist without soil ; neither can soil exist without plants. The two are inseparable, and our lessons should lead naturally from one to the other.

32. The Life Cycle of Plants. - The year is made up of seasons, one following the other. As spring passes imperceptibly into summer with nothing but an arbitrary division between, so one period in the life cycle of a plant passes imperceptibly into another. For convenience in our study, we have divided the life of a plant into seven periods, devoting to each period one chapter, or lesson. These are as follows:

(1) The Seed: Its Selection and Distribution.

(2) Seed Germination.

(3) The Work of Roots.

(4) The Work of Leaves.

(5) The Work of Stems.

(6) The Work of Flowers.

(7) The Formation and Development of Seed.

33. How the Parts of a Plant work together. - A seed is selected and stored away by man, or it is carried by the wind or in the fur of some passing animal. Thus it is planted in a well prepared seed bed or becomes covered in 
Nature's own way. As the warm days of spring come on :

The seed absorbs moisture and takes in oxygen. The tiny plant within the seed begins to grow. It breaks the seed coat and pushes its way further downward into the soil and upward into the light.

"The roots search for food and moisture in the soil as though they had eyes."

The leaves are held up to the sunlight; and by its help they manufacture the food that nourishes not only the plant itself, but man and beast as well.

The stems develop for the sole purpose of

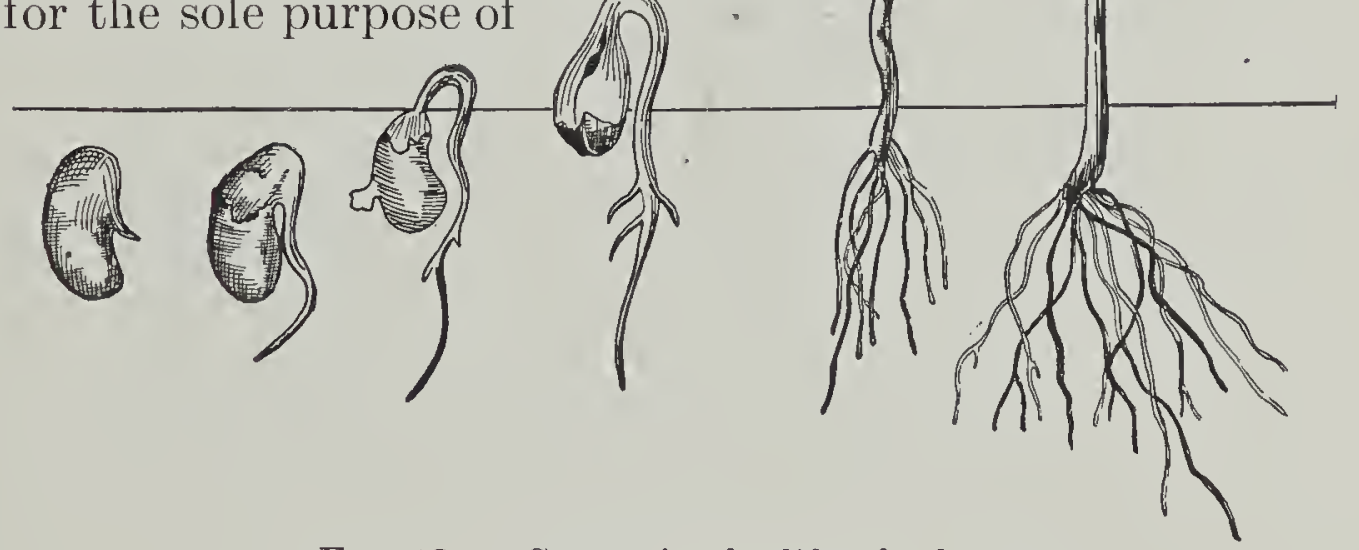

Fig. 13. - Stages in the life of a bean.

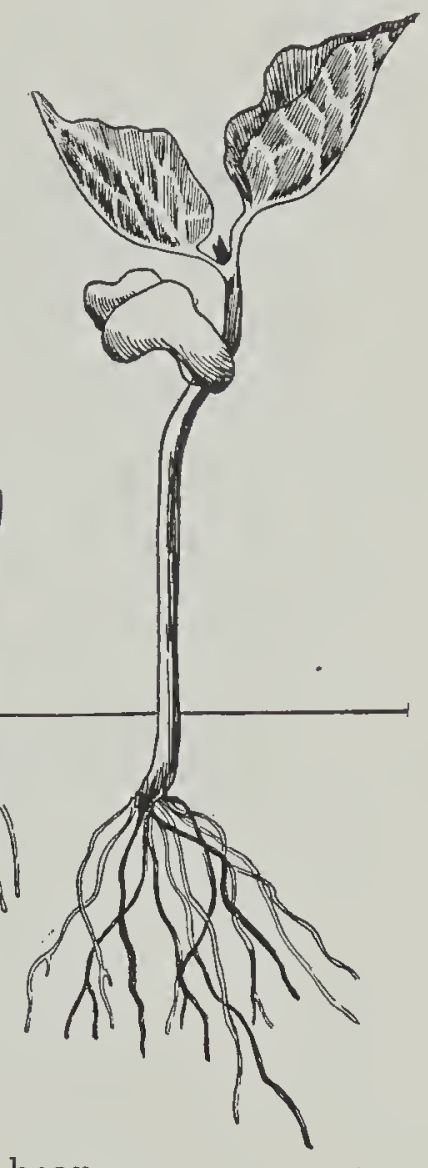

holding these leaves up to the light and conducting to them minerals and water from the soil.

Lastly the flowers appear, not for beauty, not for fragrance, although we enjoy both. Flowers form seed.

Not all the seeds produced by a single flower or by a single plant can develop on the same spot of ground. They must be scattered by Nature or by man, and in their new locations, they must begin just as the seed which produced them began. 


\section{CHAPTER VII}

\section{THE SEED: ITS SELECTION AND DISTRIBUTION}

34. The Functions of the Seed.-- Every part of a plant has one or more duties to perform. The seed has three:

First: to protect the tiny plant, embryo or germ within it.

Second: to assist in the work of distribution; that is, to help to bring about its own removal from the parent plant that it may find a favorable place in which to germinate.

Third: to nourish the young plant within it until the latter is able to gather and manufacture its own food.

35. How the Embryo is protected. - Each seed has its characteristic seedcoat, or covering. Sometimes it is thick, shell-like and woody as in the case of the nuts; sometimes it is thin, paper-like and almost waterproof as in the bean and corn; again, the seedcoat may become covered with layers of fiber, or lint as in the cotton. No matter what the form and structure of a seedcoat may be, it protects the embryo plant within against the enemies outside. Among these enemies are moisture, heat, drouth, insects, molds, and animals. The chief of these is moisture.

36. How Seeds are scattered by Nature. - Seedcoats not only protect the embryos within, but often assist the seeds in becoming scattered. It is of the greatest importance to a plant family to have the seeds of each member 


\section{THE SEED: ITS SELECTION AND DISTRIBUTION 47}

scattered away from the parent. Nature has provided for this in many ways. The most important of these ways are: (1) wind; (2) water ; (3) animals; (4) explosive or creeping habit of the seed pod.

Those seeds which are scattered by the wind have either a feathery growth attached, like the dandelion, which enables them to fly through the air, or they have a keel-

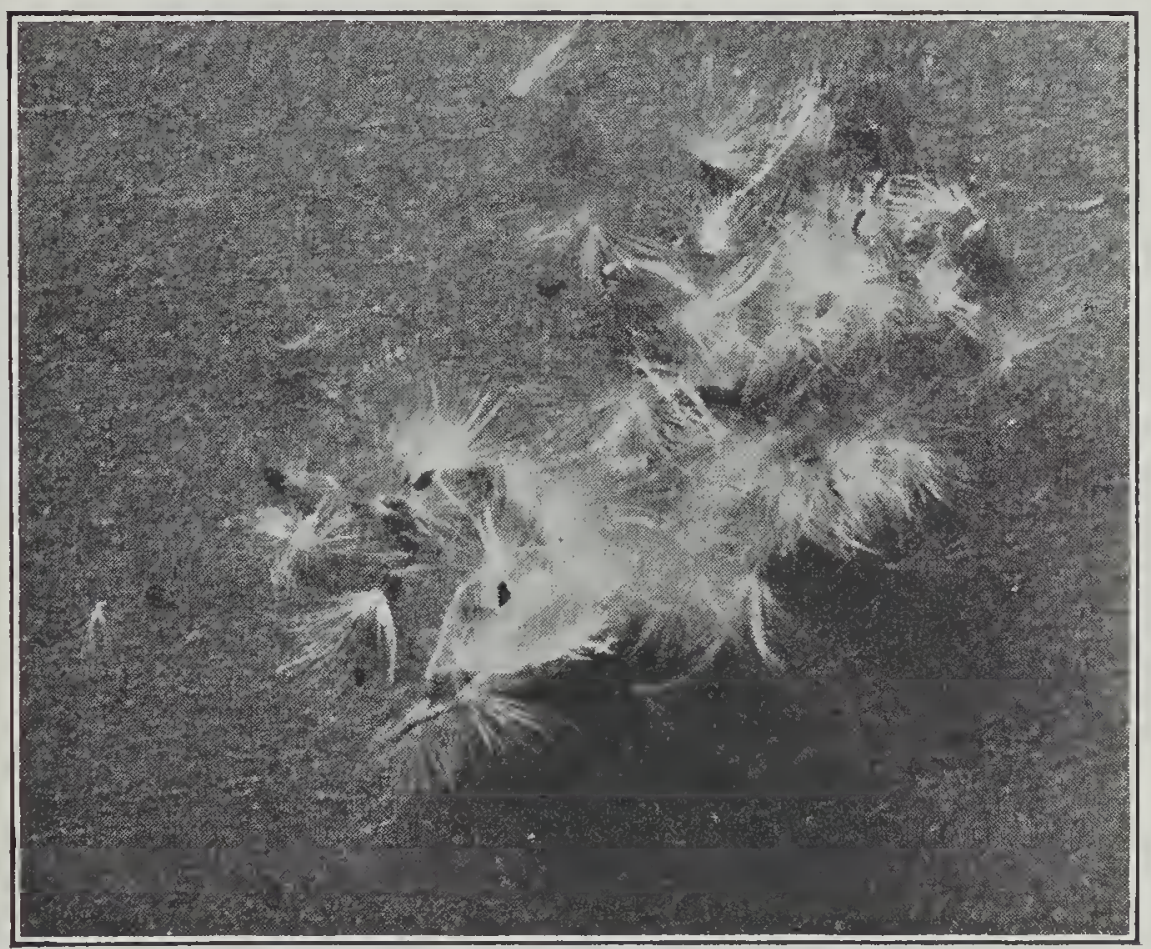

Fig. 14. - Sceds scattered by the wind.

shaped attachment, which, acting like a ship's rudder, turns the seed about in the air. The seeds in this last group often whirl through the air as they fall from the parent plant. The soft maple and the basswood are excellent examples. Plants like the tumbling pigweed and the Russian thistle, when mature, break off easily from their roots and go bumping and tumbling along the ground before the wind, scattering their seeds as they go.

Those seeds which are scattered by the water are usually 
light enough to float. It is not easy for water to enter seeds of this class, but many of them will grow even after being water-soaked:

Those seeds that are scattered by animals may be divided into three groups: (1) those which cling by means of hooks or spines to the fur, hair or bodies of animals; (2) those which have food stored within or around them,

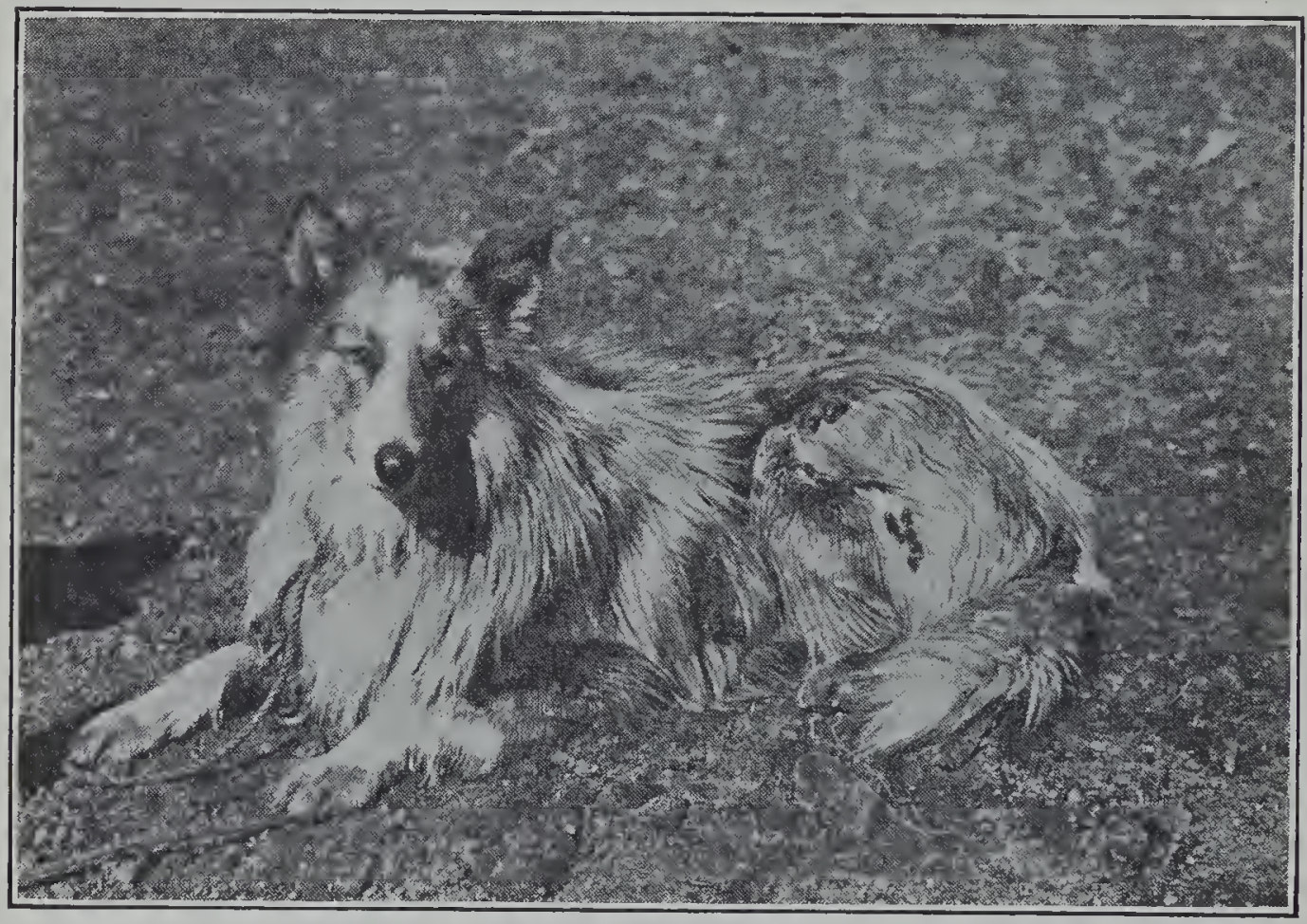

Fig. 15. - Seeds scattered by animals. Note the Cockleburs in the fur of the collie.

and which the birds and other animals carry some distance and drop; and (3) those which the animals eat and which pass uninjured through the digestive tract.

Some seeds, as those of the squirting cucumber, are thrown some distance from the parent plant by the pod, itself, much as we snap a fresh cherry pit between our thumb and finger. When the pods of some other plants such as the yellow oxalis, become dry, they snap the seed 
away, as we would a bean with a bent stick. Still other seeds, such as those of the wild oat, actually work their way along the ground in a sort of creeping motion.

37. How Seeds are scattered by Man. - Man has played an important part in scattering seeds from state to state and from one part of the world to another. Very few of our noxious weeds are natives of America, most of them having been introduced by man from foreign lands. The quack grass, the docks, the Canada thistle, Russian thistle, pigweed, foxtail and many others were not found in this country when the white man first began to settle here. Man scatters seeds of weeds (1) in commercial seeds, (2) from railway and trolley cars, (3) in wool and hay, (4) in manure, and (5) in the packing about goods and nursery stock.

Many of the grains, grasses, trees and shrubs which grow

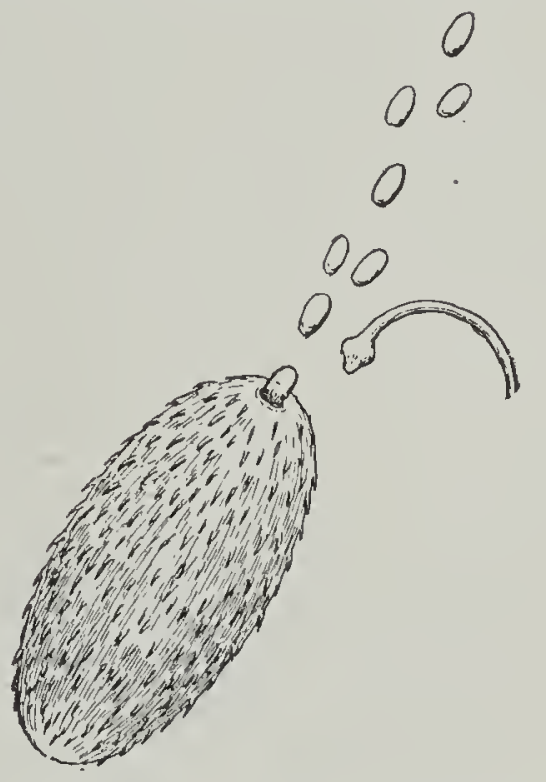

Fig. 16. - Explosive seeds: the squirting cucumber. in our fields and about our homes were first brought to us from foreign countries. Of the following plants, - corn, wheat, oats, red clover, alfalfa, timothy, blue grass, cotton, apples, peaches, pears and oranges, - corn alone originated on this continent. New varieties of seeds, as well as those which have long grown here, are being introduced each year from foreign countries. The annual shipment of seed from state to state is enormous. The shipper may fail to clean his seed properly. Commercial seeds, therefore, become the carriers of weed seeds.

Almost every year, some new variety of plant springs 
up along our railroads. The seeds have dropped out of leaky grain cars, or have been pushed out with the bedding from stock cars.

Certain seeds, particularly those with hooks and spines, become imbedded in the wool of sheep. When the wool is shipped, the seeds go along and often germinate in the waste piles at the mills. Hay, also, may act as a carrier of seeds, either good or bad.

Stock is shipped from all parts of the country to our large markets. More and more, the litter and manure from the stockyards are being shipped to the country to be scattered on the fields. Weed and other seeds often become scattered in this way.

The roots of trees and shrubs must be packed in some moist substance when they are shipped from place to place. Chaff, straw, hay and moss are used. China, glassware and crockery are usually packed in the same materials to prevent breakage. In this packing are often found small quantities of seed.

More weed seeds and seeds of foreign plants find their way to our farms in commercial seeds than in any other way. It is therefore of the greatest importance that we examine any seed intended for planting lest such seeds be mixed with seeds of weeds and other plants that we do not want.

38. Making a Seed Collection. - We are at once confronted with the difficulty of knowing the different weed seeds.

Prepare a collection of the seeds of our common weeds, which mature in the late summer and fall.

A small bottle, or vial, may be used to hold each sample, and a case of heavy pasteboard or wood made to hold the entire collection. Each bottle should be numbered; and 
THE SEED: ITS SELECTION AND DISTRIBUTION 51

on the inside of the cover of the case, a sheet of paper should be pasted on which should be written the number and name of each seed. The nature of the ground where each plant was found should also be written on this paper, the heading being as follows:

\begin{tabular}{c|c|c}
\hline Siem No. & Name & Where Found \\
\hline 1 & Cocklebur & Cultivated Field \\
\hline
\end{tabular}

If neither you nor your teacher knows the name of any given plant, - and none of us knows the names of all of them - send both seed and plant to your agricultural college or university, asking what the plant is. Very shortly you will receive a letter giving its name.

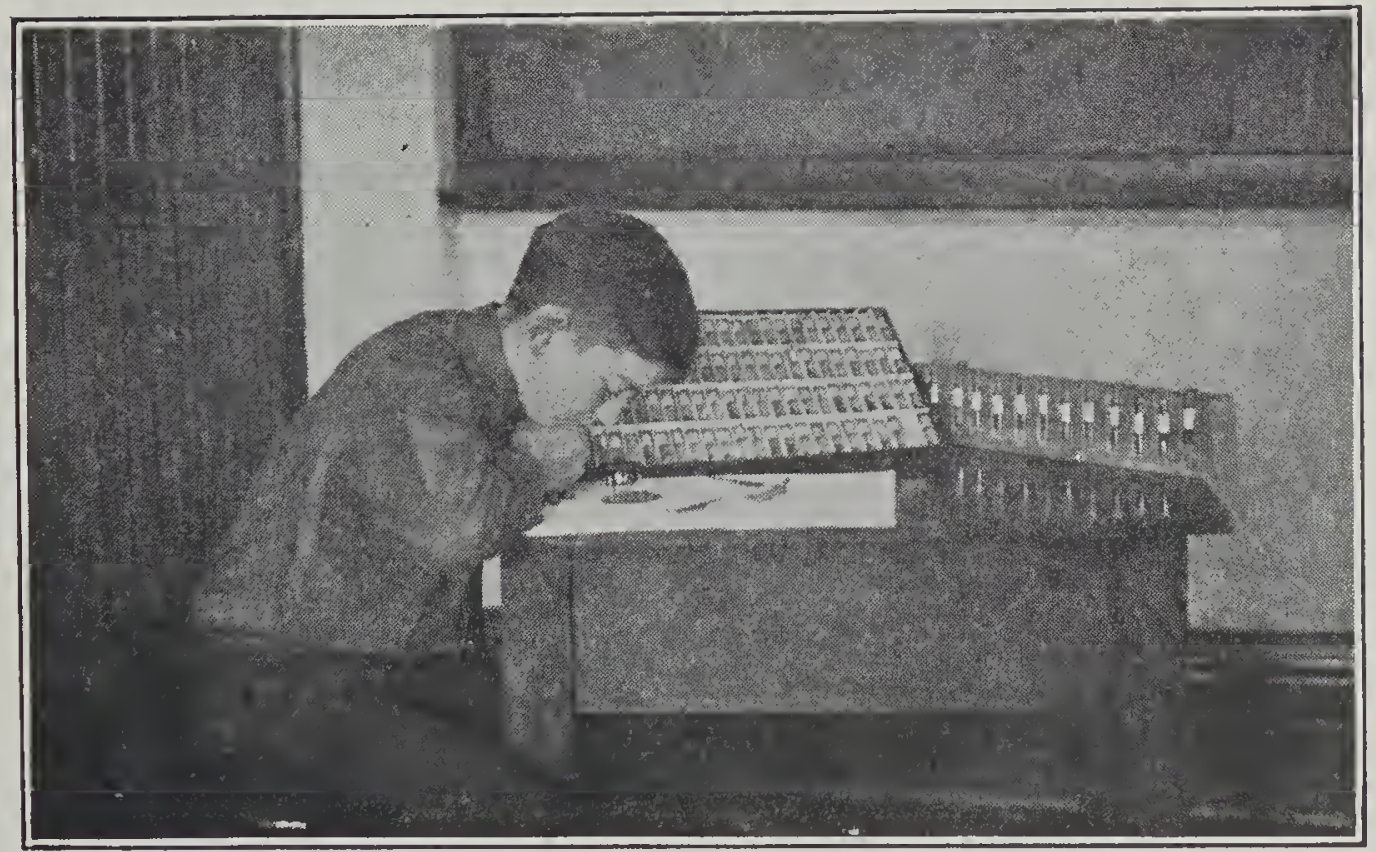

Fig. 17. - A collection of seeds.

The method by which we determine the purity of a seed sample will be made a part of our study of clovers. 
39. How Nature selects Seeds. - Nature carries on a rigid seed selection. The strong seed produces a strong plant which soon overshadows and crowds out its weaker competitors. The seeds which produce plants that are able to survive the heat and the cold, the drought or the flood, the insect or the disease, are the ones which come to make up the plant life of any locality.

The farmer destroys the weeds and other enemies which retard the growth of the planted seed. The problem of careful selection and storage of the seed, however, remains.

40. How Man selects Seeds. - As in the selection of an animal, the selection of any seed should begin with the parent. We want to know that the parent plant is vigorous; that it is of a desirable type; that it is more productive than the average of its kind, bearing fruit or seed of high quality; that it is able to withstand the ravages of insects, the attacks of diseases, and perhaps the extremes of a variable climate; that its root system is strong enough to hold it erect in times of high winds; and so we might name many other things that man considers in connection with the parent plant whose seeds he wishes to sow in his fields.

In connection with any given species or variety of plant, there are usually particular characteristics to consider in addition to the general ones named above. Moreover, it should be understood that just as any given characteristic may be regarded as highly desirable, so its opposite, which may be found growing in the same field or even beside it in the same hill or row, is just as highly undesirable.

In the following exercise, you will select from the field stalks of corn which show desirable characteristics and at 
the same time others which show the opposite, or undesirable characteristics.

\section{EXERCISE 18}

Object. - To study types of corn stalks, from which seed ears may be chosen, and also types which are to be avoided.

Procedure. - Select and bring to the school building from any field you may choose fourteen or more stalks of corn as directed below. Each of these stalks will show either a desirable or an undesirable characteristic. Those which are desirable appear first and in italics. Note carefully the reasons given as to why the one is considered desirable and the other undesirable.

(1) A strong, sturdy stalk of medium height and tapering gradually to the top.

(1) A slender, spindling stalk with or without an ear.

It has been found that the best ears are commonly borne on stalks of the first description. A really good ear is rarely found on a slender, spindling stalk, no matter how tall it may be.

(2) A stalk with an ear at medium height from the ground.

(2) A stalk with an ear borne either very low or very high.

As a rule, the largest, best formed ears are not found near the ground, nor high up on the stalk. Moreover, both are hard to husk. Hence, seed ears are chosen from those plants whose ears are borne at a medium height.

(3) A shank long enough to allow the ear to hang with the tip downward.

(3) A shank so short that the ear is held with the tip pointing upward.

If tip extends upward, rain may enter, water gather at the base of the ear, and molds or decay result. This is 
undesirable in the parent plant, and would likewise be undesirable in the offspring.

(4) A shank of medium size and strength.

(4) A shank too large and strong; or one that is small and weak; or two stalks, each showing one of these faults.

If the shank is too large, the cob is also large, and the proportion of corn to cob, i.e., the shelling percentage, is small. Also the ear will be held with tip upward, and it will be hard to break off when husking. On the other hand, if the shank is too small, the ear is liable to be broken off by the fall winds.

(5) A stalk bearing an ear, whose husks are of medium thickness and do not fit too closely.

(5) A stalk bearing an ear whose husks are too thick and fit too closely; or one bearing an ear whose husks are too thin and loose; or better yet, secure a specimen of each description.

If the husks are thick and close, the ear will dry out slowly, maturing late; also it will be hard to husk. If they are too thin and loose, the corn may be damaged by the elements or otherwise.

(6) A stalk whose ear is well matured at the time when the first killing frosts of autumn are about due.

(6) A stalk whose ear is wet, heavy and immature at this time.

In most parts of the Corn Belt, early maturity is considered highly desirable as it lessens the danger of having the crop injured when the fall frosts come. To this end, seed is often selected in the field before the first frosts have come in the fall. If well matured ears are chosen at that time for seed, the crop raised from this seed should likewise mature early. In this way, the time required to mature the crop has been gradually reduced by northern growers with the result that corn is now raised successfully 
far north of where it could have been grown even twentyfive years ago.

(7) A stalk, bearing an ear whose tip is unexposed to the weather.

(7) A stalk, the tip of whose ear is exposed to the weather.

If the tip protrudes from among the husks, some kernels are invariably damaged by the elements, smut, insects, birds or otherwise. If such ears are used for seed, similarly damaged corn may be expected in the resulting crop.

(8) A barren stalk; i.e., one bearing no ear.

Barren stalks are found in every field. They occupy space and receive care and attention without yielding any return. Since they bear no ears, many people suppose that they can not reproduce themselves. This is only half true. The pollen from their tassels, which are really the male flowers, falls upon the silks of near-by stalks, fertilizing the kernels, which are a part of the female flowers. Thus ears are formed containing the "blood " of the barren plant; and if kernels from these ears are later used for seed, they will have a tendency to produce barren plants. Therefore in selecting seed ears in the field, the careful grower rejects those found near a barren stalk.

(9) A stalk from whose base a sucker has grown.

A sucker is a stem, which branches from the main stem of the plant near or below the surface of the ground. It usually draws its nourishment from the plant which bears it. As a rule, it bears no ear, or a mere nubbin, while by draining the plant of nourishment, it weakens the latter, reducing its productive power. Hence stalks bearing suckers are considered undesirable. Many of the best growers will not select a seed ear from such a plant; nor will they choose an ear from any plant standing near it, upon which its pollen might have fallen. 
Conclusion. - It is clearly evident from our study of parent plants that no two plants are exactly alike. The fact that they do vary slightly or radically enables a person to select specimens which approach the ideal.

By the selection of seed, the sugar content of sugar beets has been raised from twelve to more than eighteen per cent.

By the selection of seed in America, the length of the lint on Egyptian cotton has been almost doubled within three years.

By selection of seed, the average number of rows on an ear of corn has been raised from about thirteen to twenty.

Moreover, by seed selection, the Corn Belt has been pushed northward almost to the Canadian line, notwithstanding the original home of the corn plant was in southern Mexico.

Plants are improved and new varieties originated by crossing one blossom with another. This is a delicate and uncertain piece of work and requires the knowledge of a specialist. Seed selection, on the other hand, is something that each one of us can do.

In the foregoing exercise have been given twelve characteristics of the corn plant, which are undesirable and which we should seek to avoid. Go over them carefully and state which ones could be avoided with certainty by the farmer who selected his seed from the wagon or crib in November.

41. Selecting Specimens for Corn Judging. - The comparison and judging of ears of corn will be left for our lesson on that crop. Of course it is not enough that an ear be borne on the right kind of stalk. It is necessary that the ear, itself, and the kernels as well, possess certain 
characteristics which are held to be desirable. If you think you are able to recognize good corn when you see it, you may select now and store away for your judging later in the year at least twenty good ears.

Bear in mind that a good ear of corn, -

(1) Should be perfectly sound and mature so that seed from it is practically certain to grow.

(2) Is nearly cylindrical in shape, or very slightly tapering, but rather "full " in the middle.

(3) Has a butt well rounded, with kernels not too square or blocky, and fitting closely around the shank.

(4) Has a tip well covered with kernels.

(5) Has straight rows free from depressions.

(6) Has kernels of uniform size and of keystone shape.

42. Nature stores no Seeds but provides for Loss. Nature has no granaries in which to store her supply of seeds for another season's crop. As we have seen, the seeds are scattered far and wide. Those which escape being devoured by the birds and other animals must pass the winter in whatever place they chance to fall. Thus exposed, many of them can not survive the extreme cold of winter or the sudden changes of spring. The loss is enormous, but Nature has provided for it by producing an enormous quantity of seed. A single pigweed may produce as many as fifty thousand seeds, while one Russian thistle has been known to produce two hundred and fifty thousand. One bushel of corn will plant about seven acres, which in a good year should produce four hundred bushels. This four hundred bushels in turn, you see, would plant two thousand eight hundred acres. Thus Nature's habit of producing more seed than would be needed for planting if properly stored, enables man and 
beast to live. The granaries and elevators overflowing with oats and barley, the train loads of corn and wheat, are Nature's surplus.

43. Man's Storage of Seed. - If the tiller of the soil is to feed his animals, his own family and the great mass of people who do not produce their own food, he must carefully store that seed which he is to use for planting.

Just how the seed should be made ready and stored that its vitality may be preserved most effectually has doubtless troubled the minds of men since they first began to cultivate the wild plants of the forest and prairie. The principles of seed storage are by no means well understood even yet, though in recent years we have gained much knowledge along this line.

In February of 1900, Mr. J. W. T. Duvel determined to find out what influence the climate and duration of storage under different conditions had upon the vitality of seed. He selected apparently strong seed of the 1899 harvest, tested samples for vitality, placed clean, fresh seed in manila paper seed envelopes, and sent two or more packages of each kind to the following places:

Mobile, Alabama.

San Juan, Porto Rico.

Baton Rouge, Louisiana.

Wagoner, Oklahoma.
Lake City, Florida.

Durham, New Hampshire. Auburn, Alabama.

Ann Arbor, Michigan.

The seeds arrived at each place about the middle of February and were stored in an ordinary store room or attic, which had little or no heat. Each sample contained from one hundred to two hundred seeds. The following kinds were sent: sweet corn, onion, cabbage, radish, 
calrot, pea, bean, pansy, phlox, tomato, watermelon and lettuce.

At the end of a little more than one hundred days, one sample of each kind of seed was returned and tested for vitality. Out of one hundred strong seeds of sweet corn stored at Ann Arbor, Michigan, all germinated, while only eighty out of one hundred stored at Mobile, Alabama, germinated. A sample of weaker sweet corn showed only 48 per cent germination when stored at Mobile, and 92 per cent at Ann Arbor. The average germination of all seeds at the end of this period ranged from 53.59 per cent at Mobile to 86.23 per cent at Ann Arbor.

At the end of about two hundred and fifty days, a second sample of each kind of seed was returned from each place and tested. The sample of one hundred strong sweet corn seed from Ann Arbor all germinated except two seeds while only twenty seeds of the sample stored at Mobile did so. The weaker sample of sweet corn showed a germination of twelve per cent at Mobile and of 80 per cent at Ann Arbor. By comparing this with the first test, we see that strong seeds are less injured by an unfavorable climate than are weak ones.

The onion seed had lost all of its vitality at Mobile at the close of the second test, while at Ann Arbor, ninetyseven out of every hundred seeds were capable of germination. The average germination of all seeds at the second test ranged from 24.31 per cent for those stored at Mobile to 84.58 per cent for those stored at Ann Arbor. The average annual rainfall at Mobile is 91.18 inches, while at Ann Arbor it is 28.58 inches. Do you see the connection between moisture and the vitality of stored seed?

The table (p. 60), which is taken from a bulletin of the United States Department of Agriculture, gives other results of this interesting test. 


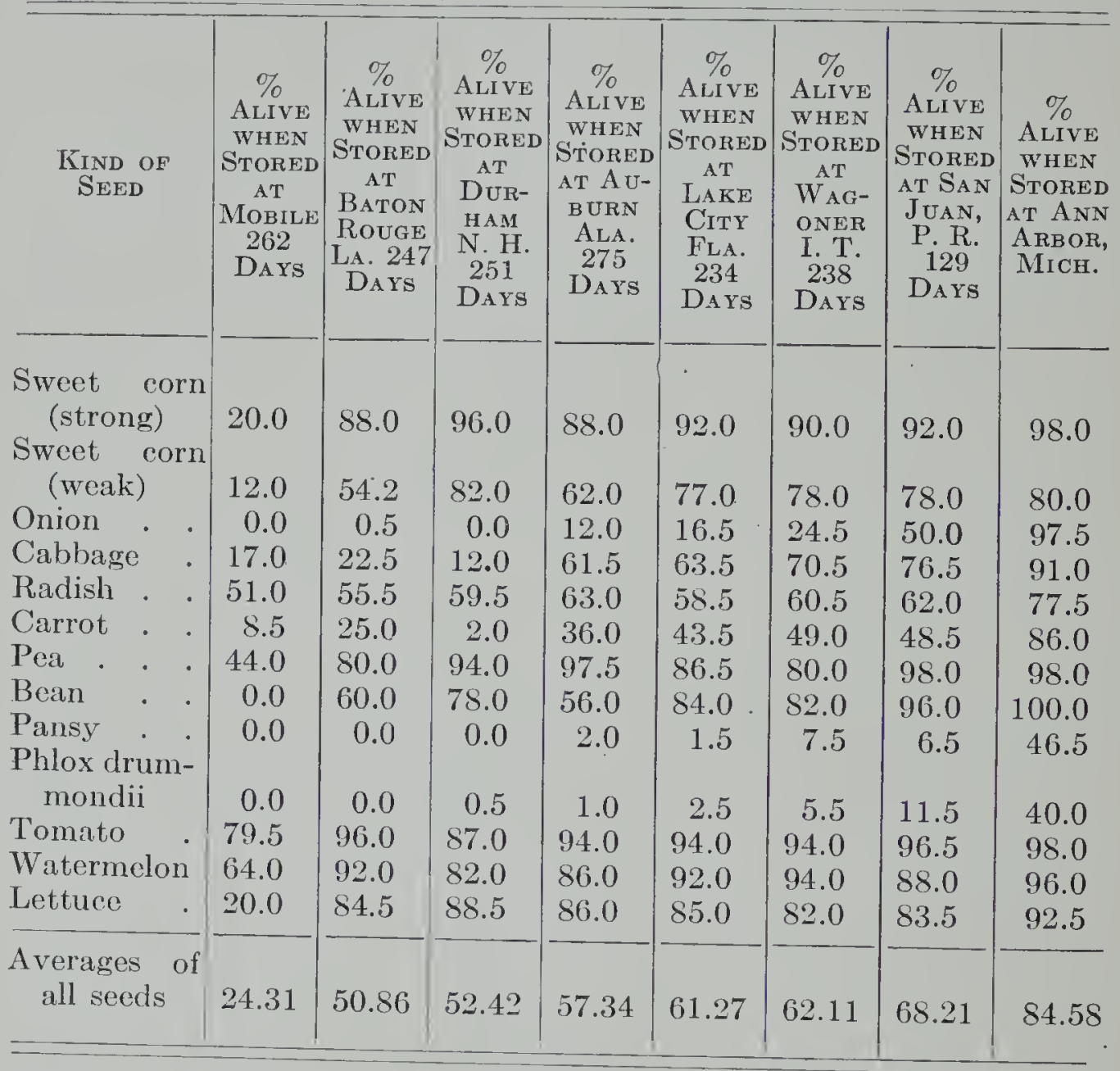

Mr. Duvel summarized his careful work in twentyseven statements. Six of these are as follows, important words being here put in italics:

"A seed is a living organism, and must be dealt with as such if good results are expected when put under favorable conditions for germination."

"The first factors determining the vitality of a seed are maturity, weather conditions at the time of harvesting, and methods of harvesting and curing."

"Seed harvested in damp, rainy weather is much weaker in vitality than seed harvested under more favorable conditions. Likewise, seed once injured will never regain its full vigor." 
"Experiments have shown that moisture is the chief factor in determining the longevity of seeds as they are commercially handled. Seeds stored in dry climates retain their vitality much better than those stored in places having a humid atmosphere."

"Seeds that are to be sent to countries having moist climates should be put up in air-tight packages. Experiments have shown that by the judicious use of bottles and paraffined packages, seeds can be preserved practically as well in one climate as in another."

"The life of a seed is undoubtedly dependent on many factors, but the one important factor governing the longevity of good seed is dryness."

The application of these principles of seed storage will be considered under our lessons on the different crops.

\section{QUESTIONS}

1. What are the functions of seeds?

2. Name four ways by which Nature scatters seeds. How can you tell by looking at any given seeds how they will be scattered? seeds.

3. Name four ways by which man thoughtlessly scatters

4. Name four common weeds of the cultivated fields; four of the meadows; four of the lawns.

5. How does Nature carry on seed selections?

6. Why should seeds of cultivated plants be selected as far as possible in the fields?

7. How does Nature store her seeds? How does she provide for loss?

8. How do seeds stored in a moist place or climate compare in germination with those stored where it is dry?

9. What is the greatest enemy of stored seeds?

10. Name the three factors which at first - that is, at harvest time - determine the vitality of the seed. 


\section{CHAPTER VIII \\ SEED GERMINATION}

44. What a Seed is. - A seed is a very small, or embryo plant, the germ, having food stored in or around it, by which it is nourished until it is able to maintain an independent growth. Both the germ and the stored food are covered and protected by a seedcoat, into which they are very tightly packed.

45. Two Great Classes of Plants. - The little plant within the seed, called the embryo, or germ, consists of three parts; viz., the leaf or leaves, which are called the seed leaves, or cotyledons; the hypocotyl, or the part of the tiny plant below the cotyledons, the lower end of which is called the radicle; and the plumule, or the part above the cotyledons.

Those plants which bear inclosed seeds, - and this includes practically all common plants except evergreen trees - are divided into two great classes. This classification is based upon the number of seed leaves, or cotyledons, in the embryo. If only one cotyledon is present, the plant is known as a monocotyledon; if two are present, it is a dicotyledon. These two great classes of plants differ not only in their embryos, but still more widely in their stems and leaves, so that we are easily able to distinguish them at any stage of their existence. These differences will be shown in later chapters.

.The monocotyledons include the plants of the grass 
family, and hence all of our cereal crops, as corn, wheat, rice, oats, barley and rye, for they are all grasses.

The dicotyledons include the clovers, beans, peas, cotton, the common vegetables, and broad-leaved plants generally.

When we examine the seed of either of these two classes of plants, we are usually easily able to distinguish the parts. We find the embryo, or germ, in the monocotyledons at the base of the seed, as in the case of corn, and having but one cotyledon, while the stored food occupies a large space outside the embryo and is called the endo-
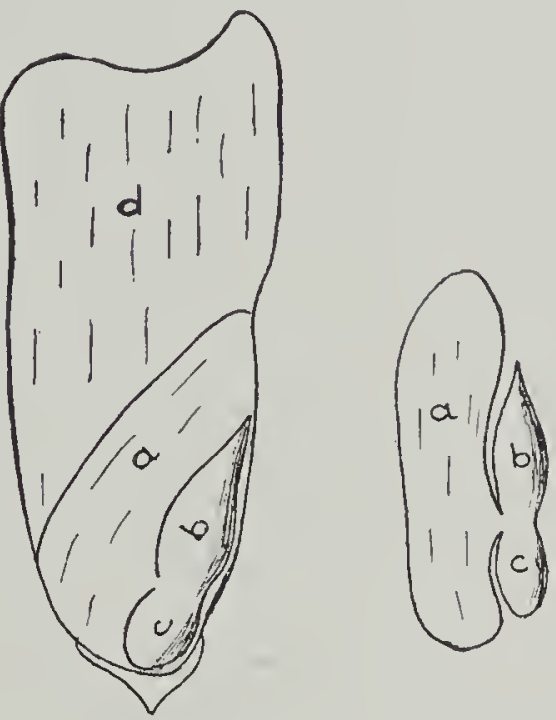
sperm. In the seeds of the dicotyledons, there

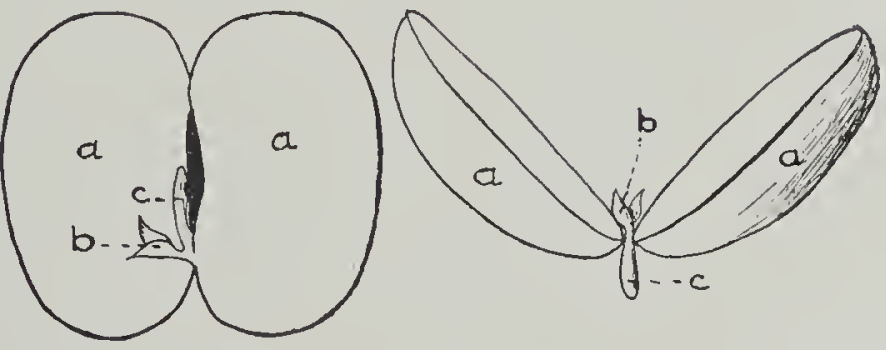

FIG. 18. - Corn and bean showing parts; the embryo of cach removed.

$a$, cotyledons ; $b$, plumules ; $c$, hypocotyl, the lower cnd of which is called the radicle; $d$, cndosperm.

is no endosperm, or food, stored on the outside of the embryo. The food is contained in the cotyledons instead, which accounts for their large size. They occupy the entire space within the seedcoat, or hull, except that taken up by the little plumule and hypocotyl. Study carefully Figure 18, noting particularly the plumule 
and hypocotyl in each seed and where the food is stored in each one.

\section{EXERCISE 19}

Object. - To study the parts of the seeds of the two great classes of plants.

Procedure. - Soak a few beans and grains of corn for an hour or more. Shave away the entire face of one of the grains of corn on the germ side with a sharp knife. When the plumule and hypocotyl are plainly visible, set the kernel up where you can see it easily and make a careful drawing.

Open the halves of a bean, being careful not to break the plumule and hypocotyl, which lie near the spot where the bean was attached to the pod. Make a drawing of one half of the bean, showing the parts in place.

Label all parts in both drawings.

Conclusions. - State fully in what respects the two embryos are alike and in what respects they differ. Do not fail to explain clearly where the food that is provided. for the little plant after germination is stored in each seed.

46. The Conditions required for Seed Germination. When the right conditions surround a living, mature seed, the embryo awakens, sprouts or, as we say, it germinates. We are at once interested to know what these right conditions are and how far it is within the power of the farmer to provide them. Let us state and then prove that before a living seed will germinate, it must have (1) oxygen, (2) a proper amount of moisture, and (3) a proper temperature.

\section{EXERCISE 20}

Object. - To prove that a seed must have oxygen in order to germinate.

Procedure. - Fill a jelly glass or a pint fruit jar half 
full of fresh water. Fill another with water which has been boiled for several minutes to drive out the oxygen. As soon as the boiled water has reached about the same temperature as the other, drop a few seeds of rough rice - i.e., rice as it comes from the fields, having the hulls still on it - into each jar. Pour a few drops of machine or other oil on the surface of the boiled water, to prevent any oxygen from entering the water in this jar. Set the two jars aside in a warm place for a week or more; then observe which seeds have made the better growth.

Conclusions.Write briefly in your own words what has taken place in each jar. Why do you think the seeds in one jar have made a better growth than those in the other?

When we speak of
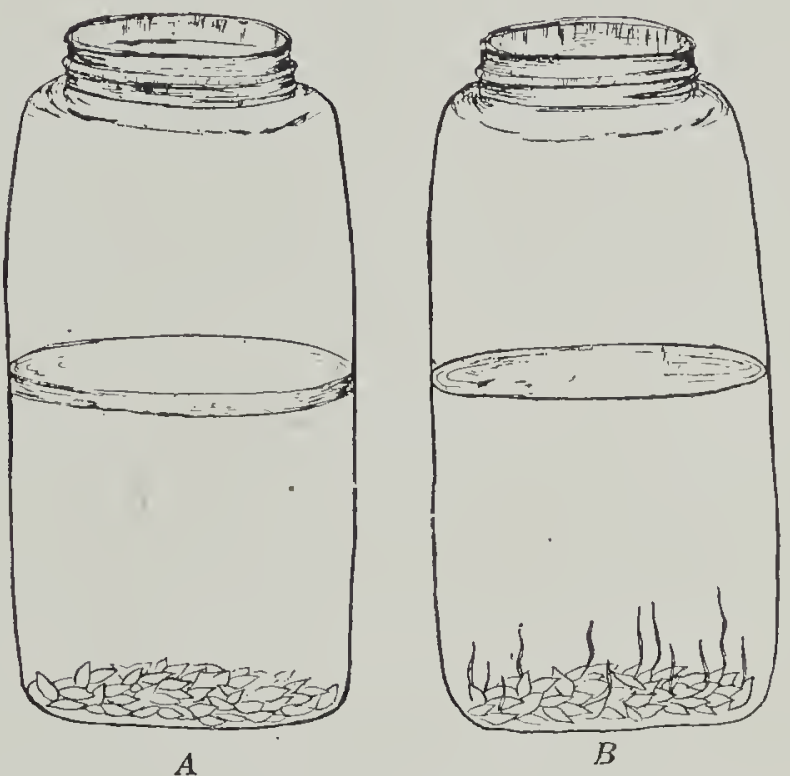

FIG. 19. - Rice in boiled and unboiled water. oxygen, we must think of the air, for oxygen is a part of the air. (See Section 15.) Review Exercises 10 and 11. Tell four ways by which a farmer may make it possible for a generous supply of oxygen to reach the planted seed. (See Section 17.)

47. Moisture and Germination. - There are a few kinds of seed, which, like that of the rice, will germinate under water; a few will germinate in the desert countries with very little water; the majority of seeds, however, germinate and make their best growth with a moderate 
amount of moisture. All seeds require some moisture before they will germinate.

\section{EXERCISE 21}

Object. - To show that seeds require moisture for germination.

Procedure. - Fill a narrow bread pan two thirds full of water. Secure a piece of window glass at least a third longer than the pan, but so narrow that one end of it will drop into the pan while the other extends out beyond. Cut a piece of blotting paper the same size and lay it upon the glass.

Moisten the following seeds slightly to make them stick to the blotter; then lay them in rows lengthwise upon it :

A row of rough rice.

A row of alfalfa seeds.

A row of Teparie beans. ${ }^{1}$

A row of wheat.

1 These little Teparie beans have a unique and interesting history. They now form an important article of diet for many of the Indians of Arizona and adjacent states where the rainfall is only about nine inches per year. "Throughout a one thousand mile circle of semi-arid and subtropical country are found the scattered relics of prehistoric agricultural tribes. The ruins of their houses and their ditches, their pottery, their implements of stone, and sometimes their bones remain to us. But of greater value and interest than any of these are the descendants of these tribes, and some of the ancient crop plants which yet endure." Teparie beans have come down to us from these ancient tribes. The seed will germinate in a surprisingly short time; and the plants will endure severe drouth and set seed in the hottest and driest weather. They may lose every leaf ; but with a passing shower, they put forth leaves again and continue growth. They are sure to occupy an important place in the agricultural development of the semi-arid Southwest. 
Put one end of the glass with the blotter and rows of seeds in place into one end of the pan and let it sink beneath the water, while the other end extends out beyond the other end of the pan. If any of the seeds float off when you place the end of the glass in water, put them back into place with your fingers. One end of each row will now be under water while the other end will be out in the air. Keep the water at the same height in the pan each day. A few drops of formalin in the water will help to keep molds from destroying your seeds.

Conclusions. - Copy the following table into your notebook, and fill it out by taking notes the first, the second, and the third days, and after this every third day for two or more weeks, or until you are able to fill in the second column with certainty for all the seeds :

\begin{tabular}{|c|c|c|c|}
\hline Kind of $\mathrm{S}_{\text {eed }}$ & $\begin{array}{c}\text { Date EMbryo } \\
\text { BRoke THE SEED- } \\
\text { COAT }\end{array}$ & $\begin{array}{l}\text { DistaNCE FROM } \\
\text { WATER WHERE } \\
\text { PLANT MADE } \\
\text { STRONGEST } \\
\text { GROWTH }\end{array}$ & $\begin{array}{c}\text { Kind of Climate } \\
\text { WHERE Plant } \\
\text { Is GRown }\end{array}$ \\
\hline $\begin{array}{l}\text { Rice } \\
\text { Alfalfa } \\
\text { Teparie beans } \\
\text { Wheat . }\end{array}$ & & & \\
\hline
\end{tabular}

Review Exercises 4, 5, 6, 8 and 9, and tell again clearly how drainage, manuring, surface cultivation and rotation of crops will help to get the proper amount of moisture to the planted seed.

48. Temperature and Germination. - It has been rather easy for us to show that a seed must have oxygen and moisture before it will germinate. It is not so easy to prove at just what temperature a seed germinates best 
and makes its best growth. We can not control the temperature during our experiments as we did the other two factors, oxygen and moisture. The figures which were given in Section 18 were secured by using germinating boxes, in which the temperature was controlled as we control it in an incubator.

We all know in a general way about what time of year it is best to plant the different seeds. Secure the help of any experienced person in your neighborhood and arrange in your notebook a table similar to the following, using as many different kinds of seed as you like:

\begin{tabular}{|c|c|c|c|}
\hline Kind of SEed & $\begin{array}{c}\text { Date of EaRLiest } \\
\text { Planting With } \\
\text { ESTimate OF } \\
\text { AVERAGE TEMPERA- } \\
\text { TURE }\end{array}$ & $\begin{array}{c}\text { Date of Latest } \\
\text { Planting WITH } \\
\text { ESTIMATE OF } \\
\text { AvERAGE TEMPERA- } \\
\text { TURE }\end{array}$ & $\begin{array}{c}\text { DATE of Plant- } \\
\text { ING FOR BEST } \\
\text { RESULTS WITH } \\
\text { ESTIMATE OF } \\
\text { AVERAGE } \\
\text { TEMPERATURE }\end{array}$ \\
\hline $\begin{array}{l}\text { Sweet peas . } \\
\text { Corn · } \\
\text { Muskmelon. }\end{array}$ & $\begin{array}{ll}\text { Mar. } 10 & 40 \mathrm{~F} . \\
\text { Apr. } 15 & 55 \mathrm{~F} \\
\text { May } 10 & 65 \mathrm{~F}\end{array}$ & $\begin{array}{ll}\text { May } 1 & 63 \mathrm{~F} . \\
\text { June } 1 & 75 \mathrm{~F} . \\
\text { June } 20 & 80 \mathrm{~F} .\end{array}$ & $\begin{array}{ll}\text { April } 1 & 50 \mathrm{~F} . \\
\text { May } 10 & 65 \mathrm{~F} . \\
\text { June } 1 & 75 \mathrm{~F} .\end{array}$ \\
\hline
\end{tabular}

Review Chapter IV, and state clearly all the plans, or methods, you know, by which a farmer might cause the temperature of his fields to be higher in the spring than that of adjoining farms.

49. Changes which take place within the Germinating Seed. - We have already learned that "a seed is a living organism." (Section 43.) This being the case, we should expect it to take in oxygen, burn up, or oxidize, the stored food within it, and throw off carbon dioxide. We know that we take oxygen into our lungs; that this oxygen is used to burn up, or oxidize, the food after it has reached the blood; and that carbon dioxide is thrown off. 
We have already proved in Exercise 20 that germinating seeds take in oxygen. Now what do they give off in exchange for this?

\section{EXERCISE 22}

Object. - To prove that a germinating seed gives off carbon dioxide.

Procedure.- Secure a piece of fresh unslaked, or unslacked, lime about a third as large as an egg, and slake, or slack it by putting it into a quart jar or can of water. Allow it to stand for two or three hours, and pour the liquid into a clean bottle through a piece of filter paper; or if the liquid is perfectly clear, it is unnecessary to filter it. You now have clear limewater, which should be tightly corked if not used at once, as it reacts with the carbon dioxide of the air.

Place a small amount of this water

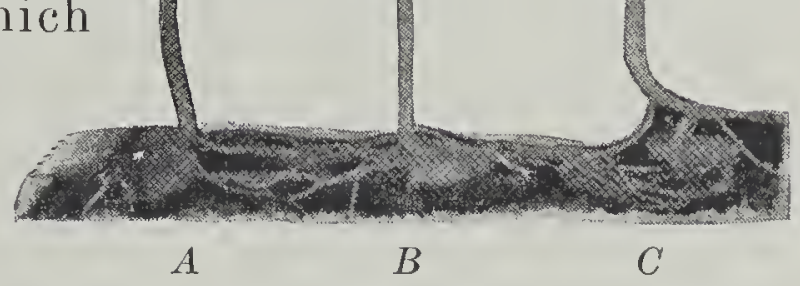

FIG. 20. - Seeds germinating at different temperatures. $C$ has germinated at the optimum temperature, $B$ and $A$ at $10^{\circ}$ and $20^{\circ} \mathrm{C}$., respectively, below optimum. in a second bottle and blow into it through a small paper or glass tube. As the bubbles pass through it, the limewater will turn milky, due to the fact that the carbon dioxide from your lungs unites with the lime dissolved in the water, forming innumerable, minute pieces of limestone, which will not dissolve in the water but which will finally settle. ${ }^{1}$ This is the test for carbon dioxide. It will turn limewater milky, and no other gas will do so.

${ }^{1}$ Limewater contains slaked lime. This consists of calcium oxide, $\mathrm{CaO}$, combined chemically with water, $\mathrm{H}_{2} \mathrm{O}$. When 
Now place a handful of wheat, oats, or other seed in a wide-mouthed fruit jar. Moisten them enough to cause them to germinate. Carefully set a small open bottle of clear limewater in the jar with the germinating seeds. Fasten the lid of the fruit jar on securely. Keep a close

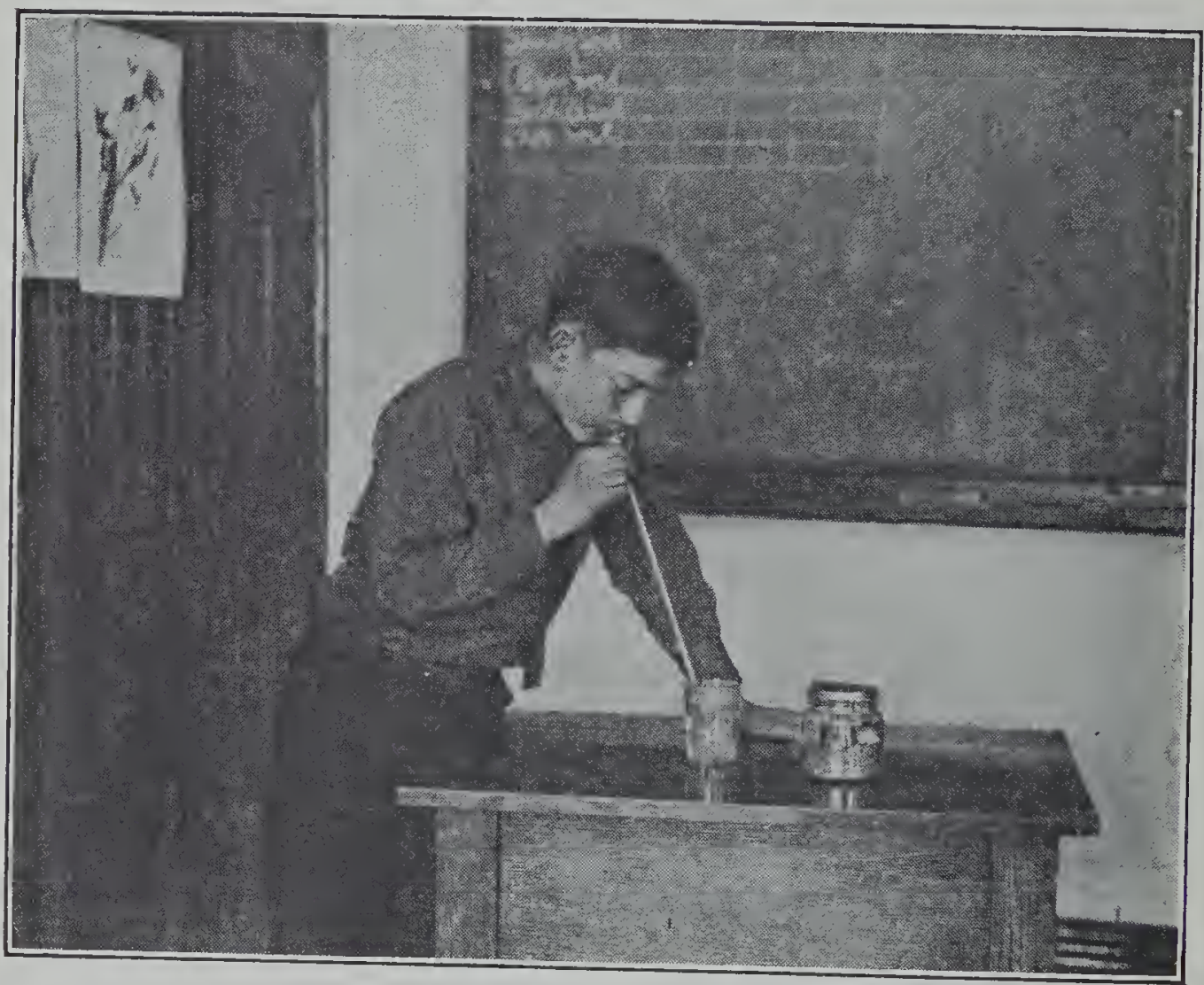

FIG. 21. - The clear limewater becomes milky.

watch from day to day. See the milky film form at the surface of the limewater. Finally, the limestone may form a thin crust like ice over the surface, or it may settle, carbon dioxide, $\mathrm{CO}_{2}$, is passed into limewater, it displaces the water which is combined with the calcium oxide and unites with this calcium oxide, itself. We then have $\mathrm{CaO}$ and $\mathrm{CO}_{2}$ combined,

$$
\mathrm{CaO}+\mathrm{CO}_{2}=\mathrm{CaCO}_{3}
$$


forming a thin, white coating on the sides and bottom of the bottle.

Conclusions. - Would the limewater turn milky if no carbon dioxide came in contact with it? Where must the carbon dioxide in the fruit jar come from? Could any carbon dioxide come off from the seeds in the jar in Exercise 20, which contained the boiled water covered with oil ? Why not? Thinking back over Exercises 10 and 11 and Sections 17 and 49, state (1) what it is that the seed takes from the air ; (2) what becomes of this substance that the seed takes from the air ; (3) what the seed gives up to the air; (4) and four ways of shutting air away from the planted seed. When wood is burning, the carbon which it contains is uniting with oxygen. Why can we not start the fire if the dampers are tightly shut in the stove?

50. Heat generated during Germination. - Whenever carbon and oxygen unite, forming carbon dioxide, heat is generated. In this manner, heat is produced in our bodies when the material containing carbon in the blood unites with the oxygen from the lungs, forming carbon dioxide. So heat is generated when fuel containing carbon in the stove unites with oxygen, forming carbon dioxide. This being true, should we not expect heat to be produced when the stored food, which contains carbon, in the germinating seed unites with oxygen, forming carbon dioxide? Let us prove that this is the case.

\section{EXERCISE 23}

Object. - To show that germinating seeds give off heat.

Procedure. - Boil a large handful of wheat, beans, or other seeds for several minutes to kill the embryos. When the seeds are cool, place them in a medium-sized bottle. 
Place an equal amount of fresh seeds in a second bottle and moisten them slightly to encourage germination. Insert a thermometer into each bottle so that the bulb rests among the seeds. The stem should extend out of the neck of the bottle far enough to be read without disturbing bottle or seed. Plug the neck of each bottle firmly with cotton to prevent the escape of heat. A woolen

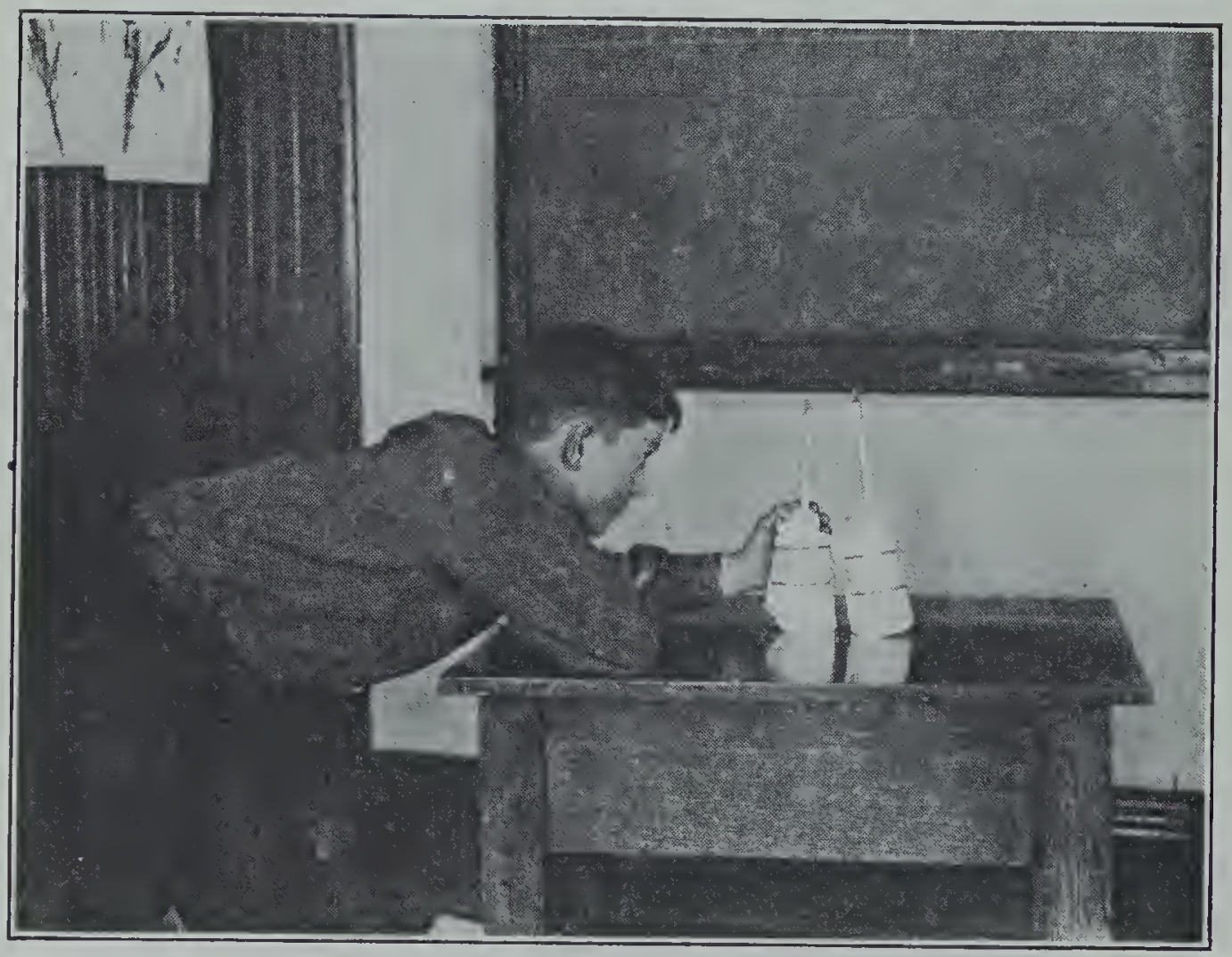

FIG. 22. - Germinating seeds give off heat.

cloth, wrapped carefully about each bottle, will serve to keep the heat within the bottle and about the bulb of the thermometer. Record the temperature in each bottle every day during germination. All seeds used in this exercise should be first immersed for two hours in a solution consisting of one part of $40 \%$ formalin in 320 parts of water. This will destroy the spores of molds. 
Conclusion. - Explain briefly why one thermometer should have shown a higher temperature than the other. If more than one kind of seed is used, tell why large seeds, such as peas or beans, should develop higher temperatures than smaller seeds, such as oats or barley. Why is it that if grain becomes wet in the bin while the weather is warm, it will heat? Name, now, two things which a seed takes in and two which it gives off during germination.

51. How Size of Seed affects Growth of Young Plant. - Now that we have found that germinating seeds give off heat, let us take up the question of how the amount of food stored in the seed affects the amount of heat or energy generated. In other words, since the reserve food in the seed is to feed the embryo, how does the amount stored there influence the strength and vigor of the young plant?

\section{EXERCISE 24}

Object. - To show the use of the reserve food, and how the amount present influences the growth of the young plant.

Procedure. - Carefully cut away the endosperm from four grains of corn, taking care not to injure the embryo: ${ }^{1}$ The cutting is more easily done when the grains have been soaked in water for a couple of hours. Plant these in a row in a cigar box of sand; and in another row, plant four whole grains of corn.

Plant two rows of beans without injuring the seeds in any way. When they have pushed their seed leaves, or

${ }^{1}$ It is a singular fact that mutilation of a seed hastens germination. Even if the embryo is not injured in any way, this operation causes it to germinate quickly and grow rapidly. The effect of the loss of the endosperm is seen later as it weakens from lack of food. 
cotyledons, out of the ground, carefully cut them away from all the plants in one of the rows, so that these plants can draw no more food from their cotyledons.

Keep all the plants properly watered, and measure the

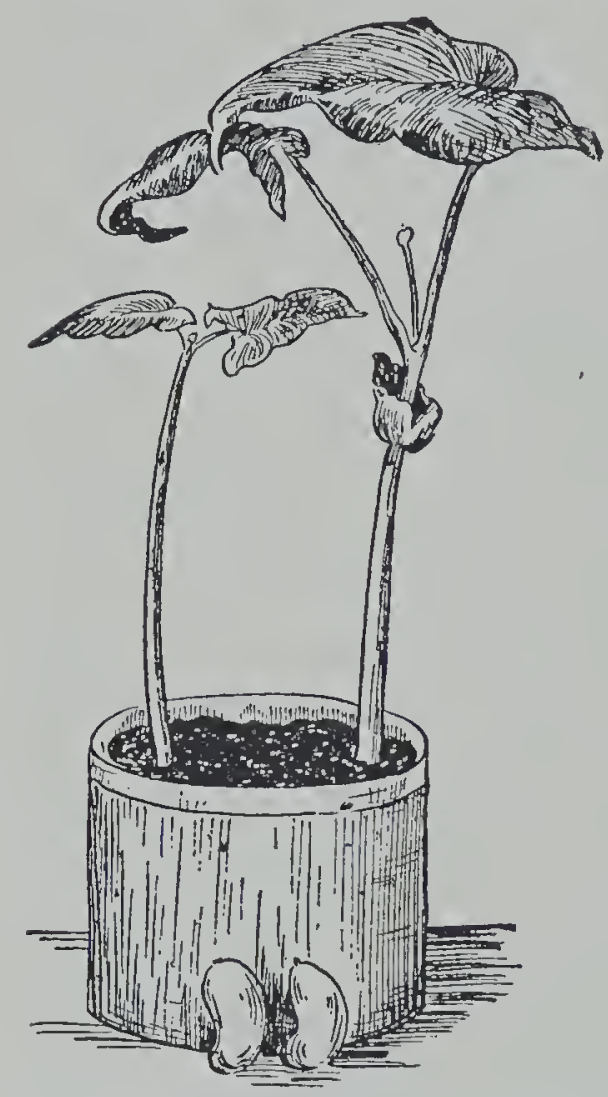

Frg. 23. - Effect of robbing the plant of its stored food. The cotyledons have been removed from the seed of the smaller plant. not been so treated? Why do we usually remove the kernels from the tip of a seed ear of corn?

52. Direction of Growth. - A seed uses its reserve food as the embryo develops into a larger plant. The plumule always grows upward toward the light and the developing root always grows toward the earth. Why this is true remains a mystery. The effort, which either of these 
parts of a plant will make to grow in the right direction, may be interestingly shown in the following manner :

Fill a cigar box with moist chaff or moss, and lay two grains of corn, germ side up, upon this material. A piece of window glass should now be fastened over the chaff and seed, and the box set on edge so the tips of the grains point downward. Moisten and allow them to germinate.

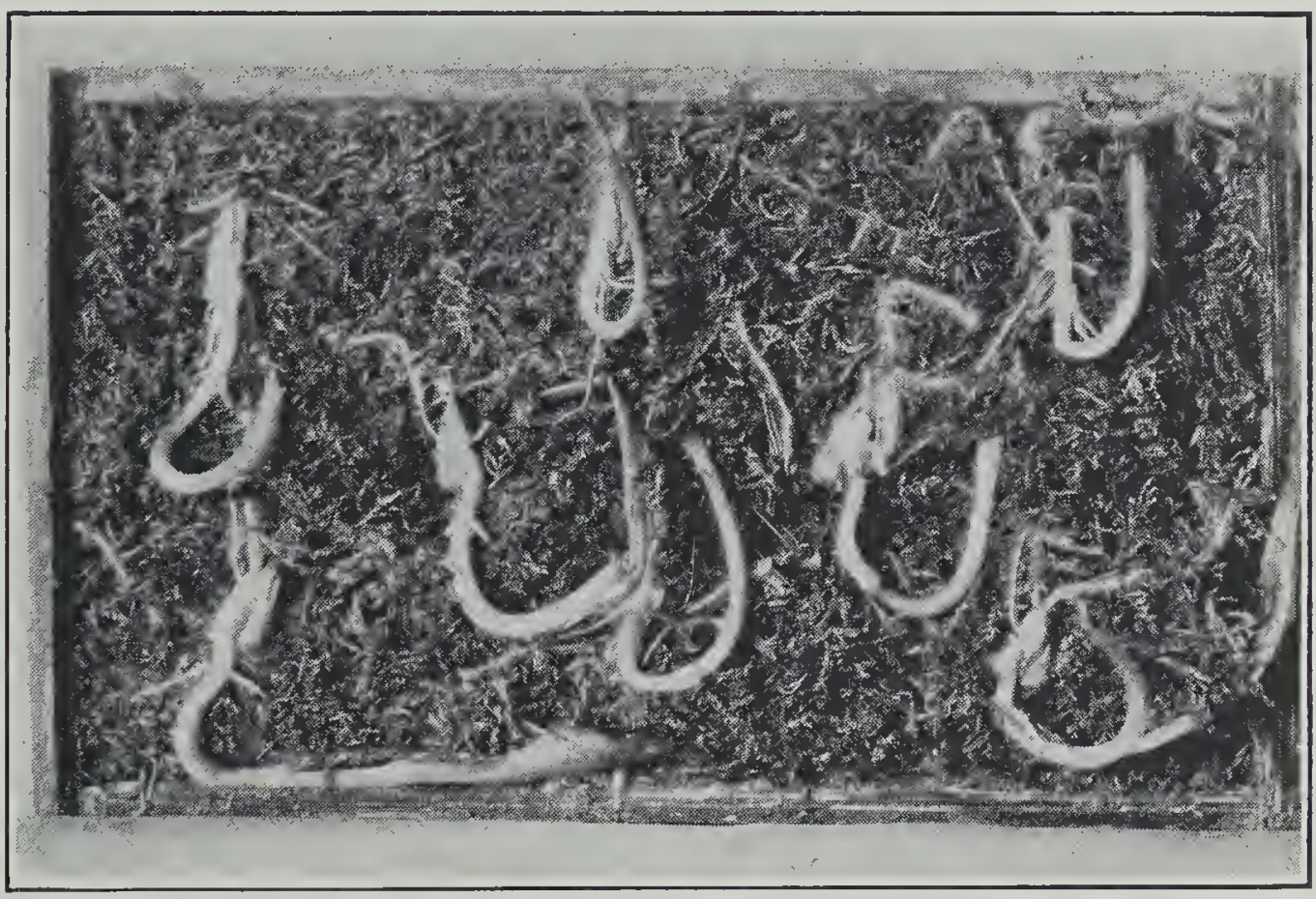

Fig. 24. - Seedling plants trying to grow upward. The box has been turned over and the sprouts have changed their direction of growth.

When the root and stem sprouts have become about an inch in length, turn the box over so that the tips of the grains point upward. Notice how the sprouts turn about, one to grow toward the earth, the other toward the light.

53. The Embryo becomes a Seedling. - An embryo becomes a seedling when it germinates. It remains a seedling as long as it depends upon the reserve food stored for it in the seed. Under favorable conditions for growth, 
the supply of food in a grain of wheat may all be used in ten days, producing a vigorous young plant, which is then able to gather and manufacture its own food. In cold, wet weather, it may take the young plant a month to get established.

It may be stated as a rule that "the shorter the time between planting and germination, the more vigorous the seedling "; and also that the shorter the time between germination and the stage when the plant is able to maintain an independent growth, the more vigorous the plant.

In the early stages of the development of a plant, the root system develops faster than the leaves. This insures the plant a supply of water and anchors it firmly in the ground.

Our next lesson is to be about plant roots.

\section{QUESTIONS}

1. What is a seed?

2. Draw from memory an outline of a grain of corn and name its parts.

3. What is meant by seed germination?

4. What are the conditions necessary for the germination of a seed?

5. How can you prove that a germinating seed needs oxygen?

6. Name three ways by which a farmer may assist oxygen to reach the planted seed.

7. How is heat generated in a germinating seed?

8. How can you prove that a germinating seed gives off carbon dioxide?

9. What is the use of the reserve food stored in a seed? What influence has the amount of reserve food upon the vigor of the seedling?

10. As a seedling develops into a young plant, in what direction do the plumule and the radicle grow? Can you tell why? 


\section{CHAPTER IX}

\section{THE WORK OF ROOTS}

54. What Roots do. - The functions of the roots of a plant are four in number :

First: to gather moisture and plant food and conduct them to the stems and leaves.

Second: to help dissolve mineral plant food.

Third: to hold the plant erect.

Fourth : to act as a storehouse for food.

55. Gathering Food and Moisture. - We have already learned that "roots search for food and moisture in the soil as though they had eyes." No matter how deep or shallow, how extensive or limited the root system, moisture and plant food are taken in. There must be some force, or law, which governs this intake. Let us find out what it is.

\section{EXERCISE 25}

Object. - To determine why moisture enters the roots of plants.

Procedure. - Select a fresh carrot, preferably one an inch or more in diameter. Bore or cut a hole a half inch in diameter downward from the top and extending at least two inches into the carrot. Pour into it a spoonful of sugar and fill it nearly full of water. Plug the hole with a rubber or wooden cork, which fits tightly so that water can not escape around it. There should be a small 
hole through this cork, through which a glass tube is thrust so that the lower end reaches into the sirup in the carrot while the other end extends into the air. Set the carrot

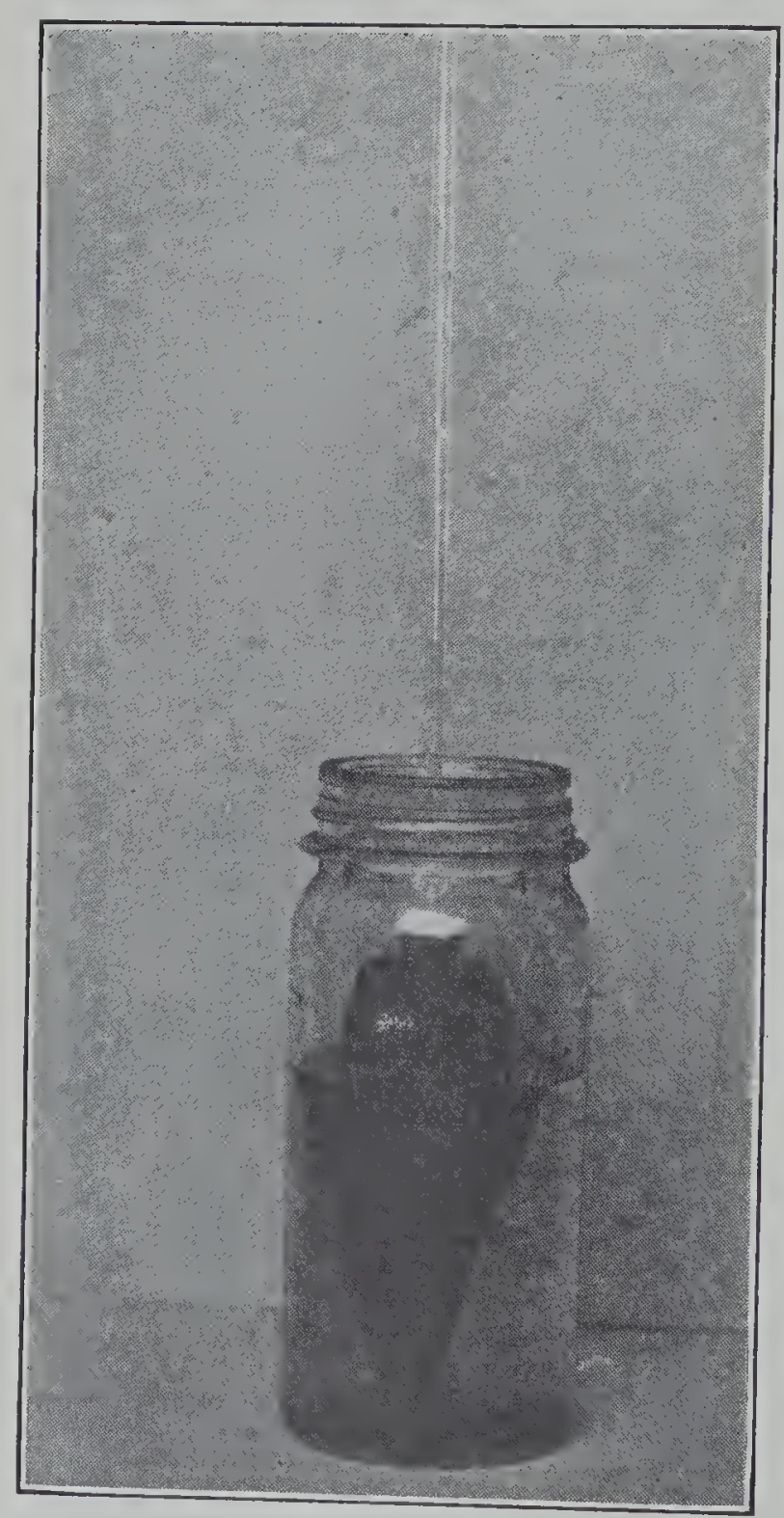

FIG. 25. - A root taking water and forcing it upward through the glass tube. upright in a glass of water, taking care, however, that the upper end of it is not covered with water. Record each day how far the sirup has risen in the tube. Small rubber tubing may be used to connect the glass tube to another one when the sirup has reached the top.

$$
\text { Conclusion.- }
$$

When two liquids are separated by a plant or animal membrane, they tend to mix through it, this phenomenon being known as osmose. The denser liquid, which in this case is the sugar sirup in the carrot, draws the less dense, or the water outside, much more

rapidly than the water draws the sirup. This is known as the law of osmose. Since the dense substance trades only a little of itself for a great deal of the thinner sub- 
stance, it must make room for the surplus gained in the transaction. In the experiment just performed, it crawls up the tube.

The roots of plants, having within them contents which are denser than the soil water, draw this soil water with its dissolved minerals into themselves, forcing it upward through the stems into the leaves.

It sometimes happens that the soil water contains enough dissolved material to make it denser than the liquid contents of the roots. In this case, in which direction would the greater flow of liquid be?

Fields of cotton, corn and other crops wilt during times when the rainfall is light if too much of commercial fertilizers has been previously added to them. Why is this true?

Tell in your own words how roots gather moisture and plant food from the soil. Also, tell under what conditions roots may lose their moisture.

\section{Roots are Able to select the Minerals which they} need. - The roots of a given plant not only draw from the soil their mineral plant food dissolved in water, but in some way which we do not yet understand, they choose, or select, those elements which they need, leaving others unabsorbed. This is shown by the fact that the clover plant when in flower and the barley plant in flower contain about the same amount of mineral matter, yet the clover contains almost six times as much lime as the barley, while the barley contains about eighteen times as much of the mineral of which white sand is composed as does the clover.

Grain crops remove large quantities of phosphorus from the soil, while the root crops remove much potassium. Timothy requires plenty of nitrogen. The best system 
of rotation not only takes into account the water-holding capacity and the mellowness of the soil but also the feeding requirements of the preceding crops.

57. The Origin of Roots. - Since roots not only gather moisture and dissolve mineral matter, but also conduct them upward to the stems or leaves, we might be led to suppose that a plant has two kinds of roots. Such is the case.

Only the young, tender portions, near the tips of the roots, and the root hairs which grow out from these new portions, can absorb moisture. These are known as absorbing roots.

As the root becomes older, the root hairs disappear and the surface becomes covered with almost waterproof, woody layers. It serves then only to hold the plant erect and to conduct the moisture from the soil to the leaves. Such roots are known as anchorage roots. Since they are sometimes called upon to hold against the terrific force of the wind, they must have a firm grip upon the roots from which they grow. We shall soon see that they originate, or branch, from the strong central portion of the root, called the central cylinder. These anchorage roots often tend to contract in length, thus fixing, or holding the plant more firmly in position. The crown or rosette of leaves of the dandelion, for example, which seems to be trying to escape being cut off by the lawn mower, is really being drawn into the soil by the contraction of its large anchorage root.

The absorbing roots, which, as has been said, consist of only the youngest portions of the anchorage roots and the multitudes of root hairs which grow from them, increase the absorbing surface of the young root from five to twenty times. Later, as the absorbing roots become anchorage roots, losing their root hairs and becoming 
covered over with layers of wood, other root hairs form in profusion on the still newer portions which are of course located in other feeding grounds.

\section{EXERCISE 26}

Object. - To study the origin of root hairs and anchorage roots.

Procedure. - With the aid of a blunt knife or paddle, remove with some of the soil surrounding it a young radish seedling which has been growing in the sand for several days. Note how the soil clings to the roots. Carefully wash the clinging particles away. Examine the roots at once with a hand lens, or better still, with a microscope. See if you can find where a single cell in the surface of the root has elongated into a root hair as shown in Figure 26.

Split a parsnip or carrot lengthwise and see how the anchorage roots originate or grow out from the stringy central portion, the central cylinder, of the parent root. If any other root is split in the same way at the point where the anchorage root joins the parent root, its union with the central cylinder of the larger root may be as easily seen.

Conclusion. - Which roots will be more easily torn away when a plant is transplanted, - the absorbing or the anchorage roots? Why? Which class absorbs moisture and mineral plant food? Leaves throw off large quantities of water when in direct sunlight. Why do we shade a cabbage, tomato, or other young plant when it is first set out? How long is the shade necessary? Why do we often remove, or cut away, the twigs or leaves of a tree or shrub when transplanting it?

58. How Roots work their Way through the Soil. A young root must work its way through the soil, avoiding 
obstacles, seeking for food and moisture. It must therefore follow a somewhat snakelike indirect course. Even so, this wandering sort of growth would be impossible were not the root peculiarly adapted for it in two ways: (1) The end of the root is protected by a sort of cap.

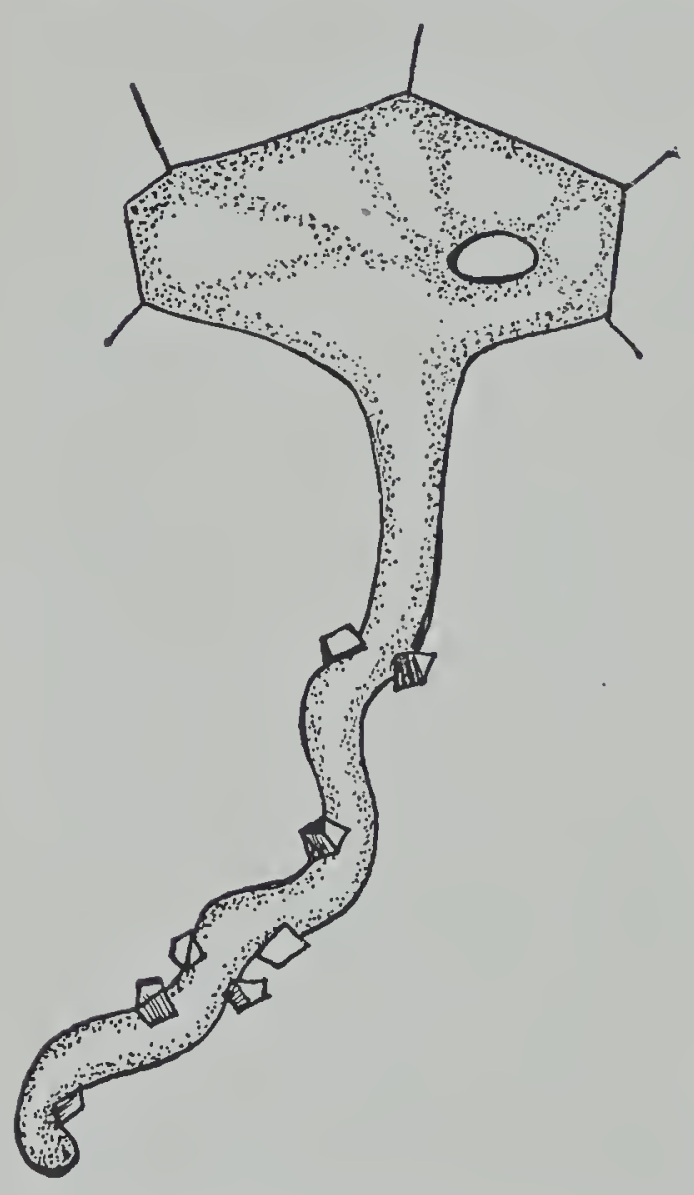

FIG. 26. - A root hair in contact with soil particles (very much enlarged).

(2) Growth in length takes place only in the region just back of this cap.

This arrangement enables the young root to "feel" its way among the soil particles with the delicate cells at the end protected; and it is not shoved or pushed forward, as it would be if growth in length took place at any considerable distance back from the tip.

The root hairs appear only in the region of growth. They grow in the moist air between the particles of soil, with which they come in contact and against which they flatten themselves that they may take up the film of moisture with which these particles are covered.

59. The Extent and Depth of Roots. - The first thing to know in the cultivation of any crop, after learning the soil and seed bed requirements, is the nature of the root system of the particular plant. Shall we give deep culti- 
vation while the plant is young, and shallow cultivation later, or shall we follow just the opposite plan? "But," you say, "how can we study the root systems of plants when they are out of sight beneath the ground?" Let us try to do it.

\section{EXERCISE 27}

Object. - To study the root systems of the corn and bean.

Procedure. - Plant in a wire basket several kernels of corn, and in another basket several beans. These baskets should be at least six inches square, have the same depth, and be made of very fine woven wire. Wrap a piece of cheesecloth very carefully about each one to prevent the dirt from sifting through the sides and bottoms, and fill them with fine garden soil.

When the seeds have sprouted well, remove all but one of the strongest. When the corn plant is six or eight inches high, remove the cheesecloth from this basket, and also from the one containing the bean and thrust pieces of rather fine wire through the sides of the basket and through the soil. These wires will hold the roots in their natural position when the soil is washed away. Now place each basket in a pan or bucket of water and move it slowly back and forth until all the soil falls away, leaving the roots exposed.

If you have larger baskets, the roots may of course be studied when the plants are older.

Conclusion. - You will find that the long, or temporary root of the corn plant has withered or is withering away, and in its stead, quite close to the base of the stem, a mass of fine fibrous roots is developing. This mass of fibrous roots is formed in all the cereals just beneath the surface of the ground regardless of the depth at which the seed is planted. 
In the dicotyledon, the bean, you will see that the first root is a permanent one and grows downward rather deep into the soil. Bear in mind these characteristic root habits when you come to study the cereals and legumes. The roots of the clovers and alfalfa penetrate deep into the subsoil, bringing up plant food which is left near the surface when these crops are plowed under. The shallowrooted cereals and grasses which follow them are thus benefited.

Draw in your notebooks the root systems of the corn and the bean.

60. How Roots help dissolve Mineral Matter. - In Section 7 we learned that certain mineral elements are essential to the growth of any plant. These elements are found in the soil, and it is a part of the work of roots, by the excretion of acids, to help dissolve them.

\section{EXERCISE 28}

Object. - To show that roots give out, as well as take in. Procedure. - Fill a small bottle almost full of water, and add a few drops of ammonia water, or dissolve in it a grain or two of ordinary lye. Drop a slip of pink litmus paper into it, and its color will begin to change. In a short time it will have become blue. This shows that the solution is alkaline, for alkalies turn pink or red litmus paper blue.

Now add a littie acid of any kind, - vinegar will do, and presently the slip of blue paper will begin to change in color again, turning this time from blue to red. Finally, its color will be about the same as it was at the beginning. This shows that the solution is now acid, for acids turn blue litmus paper red. We are able by this test to tell whether any solution is acid or alkaline. 
Now empty the bottle, rinse thoroughly, and fill again nearly full of water. Put into it a slip of litmus paper which you have made blue as you did the one above.

Wash the dirt from the roots of a seedling plant and lower them into the bottle of water. Fasten some paper about the bottle to exclude the light from the roots. About forty-eight hours later, examine the litmus paper to see if its color has changed.

Conclusion. - Would you say that the roots must have given off some acid into the water? How does the litmus paper show this? Acids dissolve many minerals. What is the use of this acid given off by the roots? Since roots of different plants feed at different depths, why is the rotation of crops beneficial?

Write out how acids and how alkalies change the color of litmus paper.

61. How Roots hold Plants Erect. - One of the important functions of the roots of a plant is to anchor it in the place where it is to develop, that its leaves and stems may be held upright in the air. Some plants have a much firmer grip on the soil than do others, and may for this reason be called soil binders. Large areas of sandy soil along Lake Michigan were in former years almost devoid of vegetation. The shifting of the sands by the high winds destroyed nearly all young plants before they could become established. By the use of beach grass and other grasses, the shifting of parts of this soil has been stopped; and the land that was formerly waste, is now of use. The western wheat grass is much used by railroad companies to bind embankments. Large tracts of land on mountain sides have in the past been stripped of their trees. The roots soon decayed, and great scars, gullies and cañons were washed out, making the land worthless 
for a second crop of trees. If a few of the trees only had been removed, this injury to the soil would have been avoided.

Land that tends to wash may well be sown to some perennial crop which does not require cultivation.

The grip that roots have on the soil is well shown by the stump puller. The power required to pull even a small plant from the soil is indeed surprising.

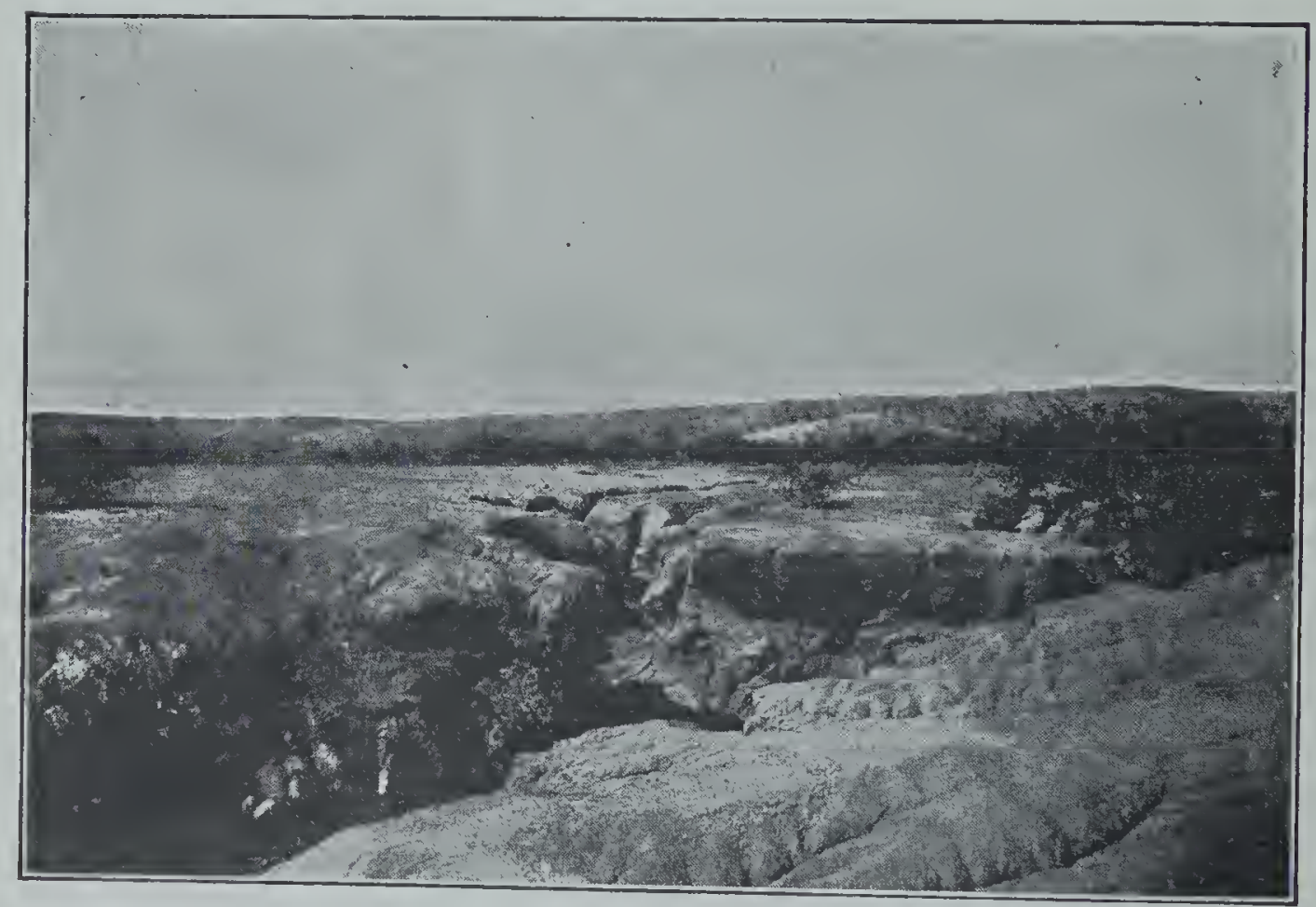

Fig. 27. - Denuded and gullied land. This was onee pasture land.

\section{EXERCISE 29}

Object. - To demonstrate the hold which roots have in the soil.

Procedure. - Secure a potted plant which has a wellestablished root system and a tough stem. Fasten a small wheel in the end of an upright stick, and pass a string over it, forming a pulley. Wrap a piece of paper about the stem of the plant and tie one end of the string firmly 
about it. Pass the string over the pulley, and tie a bottle or other container on the end. Now put shot or sand into the bottle, a little at a time, until weight enough has been secured to pull the plant from the pot. Weigh both shot and bottle.

Conclusion. - Why is it that such rivers as the Ohio, Mississippi and others in the Central West carry so much greater quantities of mud at present than in an early day when the land which they drain was in native grasses and timber? Why do railroad companies and land owners plant willows along the banks of encroaching streams? From this experiment, would you say that the roots of plants bind the soil quite firmly together? Why does the government often prohibit the cutting

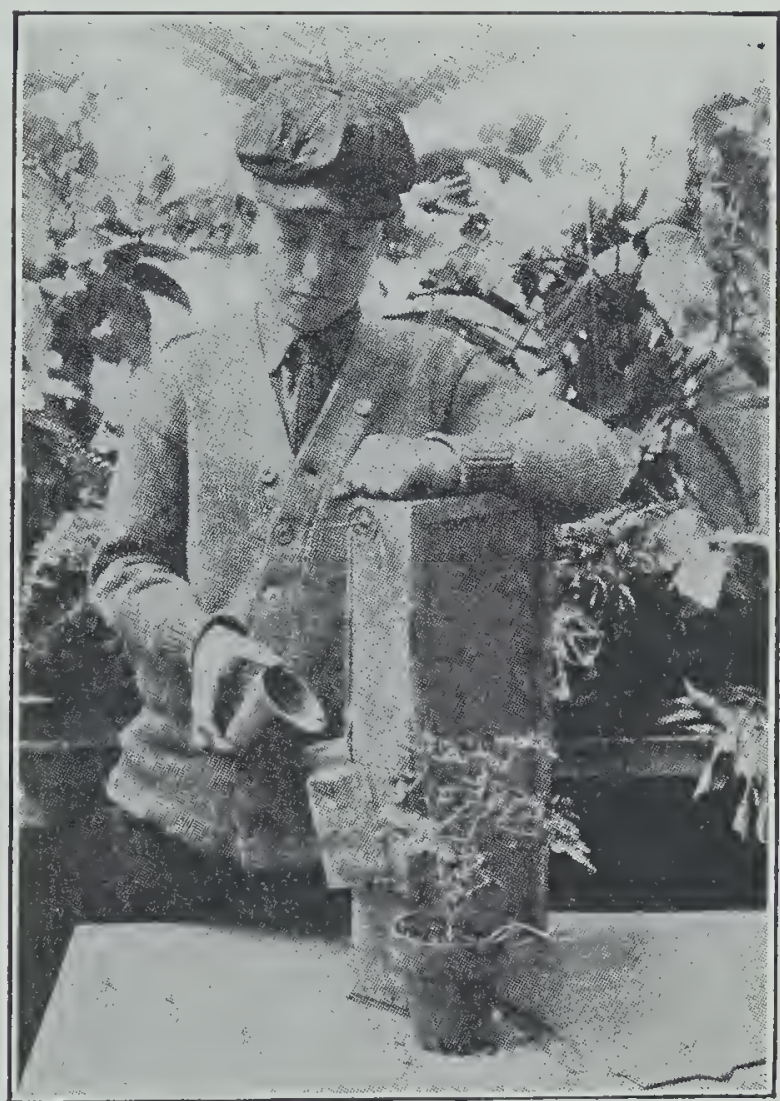

Fig. 28. - Pulling up a plant by means of a pulley and weight.

of timber entirely off from hill and mountain sides on public lands?

62. The Root a Storehouse of Food. - Every plant stores in its stems and roots certain amounts of reserve food to be drawn upon in time of need. The members of one great class of plants which live two years and are 
therefore called biennials spend one whole season in storing food in their roots to be used the following season in producing seed. The carrot, parsnip, beet, turnip, mangel wurtzel and sugar beet are excellent examples of this class of plants.

63. Benefits of Roots. - In performing the functions for which Nature intended them, roots assist in a remarkable way in maintaining a permanent agriculture :

They loosen the soil by their deep and ramifying growth. They bind the soil and thus prevent washing and blowing.

They offer a home for friendly bacteria, which are known in certain cases to gather nitrogen from the air, thus adding to the store of plant food in the soil.

They enrich the soil when they decay.

\section{QUESTIONS}

1. Name four functions of roots.

2. By what law do roots gather moisture from the soil?

3. Under what conditions do roots lose moisture?

4. What two classes of roots do plants have? What is the function of each?

5. Why does a cabbage wilt when transplanted? Why do we protect newly planted vegetables from direct sunlight?

6. Where does growth take place in a young root?

7. Compare the root systems of the corn and bean.

8. How do roots help dissolve mineral plant food? soil?

9. How can you prove that roots have a firm grip on the

10. Name four benefits of roots. 


\section{CHAPTER X}

\section{THE WORK OF LEAVES}

Certain plants reproduce themselves without seeds. Some get along without stems. None of the important higher plants, however, can exist without roots and leaves.

64. Functions and Uses of Leaves. - Leaves are of use to man as food, for the shade which they afford, and for beauty. These benefits are incidental, however, to the three functions which Nature has given them to perform. These functions are:

First: to manufacture out of the water from the soil, and the carbon dioxide from the air, starch for the plant. This is known as photosynthesis. ${ }^{1}$

Second: to give off the surplus water taken in by the roots. This is called transpiration.

Third: to act as a storehouse for food.

65. The Manufacture of Starch. - The.phenomenon of starchmaking takes place only in the green leaves and green twigs of plants. Just how carbon dioxide, an invisible gas existing in the air, can be made to unite with water to form starch, liberating oxygen at the same time, we can not say. Yet upon the fact that it does so in the green leaves of plants, all life in the earth depends.

1 The term photosynthesis is derived from photo, meaning light, and synthesis, the act of putting together. It means, then, the act of putting together, or building up, by light. The reaction is :

$$
6 \mathrm{CO}_{2}+5 \mathrm{H}_{2} \mathrm{O}+\underset{89}{\mathrm{Light}}=\mathrm{C}_{6} \mathrm{H}_{10} \mathrm{O}_{5}+6 \mathrm{O}_{2}
$$


66. The Green Leaf likened to a Mill. - The process may be likened to the work in a mill where corn and oats, we shall say, are ground together to make the "grist." The water from the root corresponds to the corn; the carbon dioxide from the air, to the oats; the green leaf, to

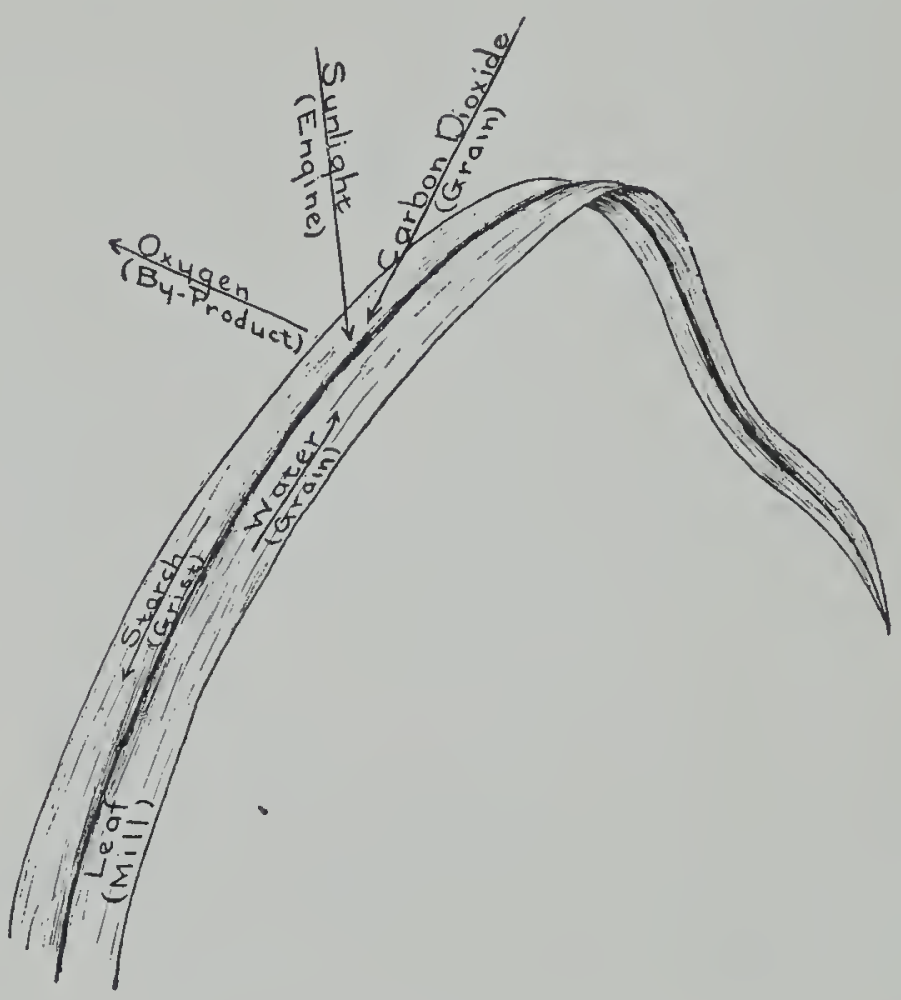

FIg. 29. - The green leaf as a mill. the mill ; the sunlight to the engine; and the starch formed, to the grist. If any part is lacking, no grist can be produced.

\section{EXERCISE 30}

Object. - To learn how and when food is manufactured in the leaves.

Procedure.Place a few grains of starch in a saucer and cover with two or three teaspoonfuls of water. Add a drop of tincture of iodine, and note that a blue-black color appears. This is the test for the presence of starch. Secure a potted plant, or use any growing plant in the schoolyard. Provide several corks and pins, a small pan of wood alcohol and some tincture of iodine. Place slices of cork on opposite sides of a leaf and thrust a pin through both to hold them snugly and firmly against the leaf so that no sunlight can reach it where they are held against its surface. The remainder of the leaf will be exposed to the light. Prepare several leaves in this way. 
Set the plant in the sunlight, and after it has been there several hours, remove the leaves to which the corks are attached. Remember that the exclusion of light from the portions of these leaves between the corks has probably put a stop to the work of starchmaking there.

Place the leaves of the plants in a dish of water and boil them for about one minute to break down the tissues. Transfer them to a bottle of alcohol. Cork tightly and set away for a day or more. If this does not remove the green coloring matter, transfer them to a dish of alcohol and boil them in it until the coloring matter is dissolved and the entire leaf is white. In this case, use the utmost care that your alcohol does not boil over, take fire and burn up your leaves.

Now put the leaves into some tincture of iodine, diluted with water. Allow them to remain in this solution three or four minutes. Remove and wash them with fresh water and spread them out on clean sheets of paper.

Test fine pieces of potato, crushed corn and powdered rice or wheat flour for starch. Tell how and where this starch was manufactured.

Conclusion. - Describe fully the results secured with the leaves and explain. If weeds, or other plants, cut off the sunlight from growing plants, what part of the "mill " indicated in Figure 29 is shut off? Why are plants which are crowded often spindling in growth? Why do sprouting potatoes in the cellar grow toward the light of the window?

67. How Other Foods are made. - The starch, manufactured in the green leaves, is one of the chief food materials of the plant, but it is of the utmost importance for still another reason. With starch as a basis, the plant makes many other kinds of foods, such as sugars, fats, 
oils and proteins, using, when needed, those essential elements which come to it in the soil water.

It is from the various food materials, made in this way, that the plant derives the energy that makes its own growth possible. It is from them that all of its tissues are built, whether wood, bark, fiber, blossoms, fruits or grains. Moreover, animals depend upon these food materials made by the plant just as does the plant itself, for it is from them that animals derive all of their heat and energy and tissue-building material.

Thus we see that out of the raw materials - the ten essential elements which come to them from the soil and air - plants are able to make the food supply not only for themselves, but for all animal life as well. That is to say, while man may eat the flesh of animals, he may be sure that these animals were in turn dependent upon plants for their existence, or upon other animals, perhaps, whose food supply was drawn from plants.

As the Father of Waters, the great Mississippi, may be traced to its source in the highlands of Minnesota, so the food supply of the world can be traced back to its source in the green leaves of plants where carbon dioxide and water, and minerals from the earth, by the power of the sun, unite to form the food substances that make it possible for plants and animals, including man himself, to live.

68. Amount of Water, Food Material and Ash in Plants. - The weight lost by plants in drying represents the water held in the tissues. The weight lost in burning represents the food manufactured in the leaves. The ash remaining after burning contains all of the minerals which come from the soil except the nitrogen, which escapes into the air in the process of burning. 


\section{EXERCISE 31}

Object. - To determine how much food is manufactured in the leaves.

Procedure. - Cut into very fine pieces one hundred grams of potato, grass, apple or any grain. Weigh again after cutting to make sure that your original weights are accurate. Set the pan or dish containing your material on the back of the stove or in an oven. When perfectly dry but not burned, weigh again.

Put the dried material into a dish which will withstand heat, and carefully burn it over a hot fire. When nothing but white ashes remains, take the final weight.

Conclusion. - How much water did the material which you used contain? Where did it come from? Will it get back to the soil again? If so, how? How much food material and how much ash did the substance which you used contain? Where did each come from? What element came from the soil but escaped into the air? Give two reasons why cornstalks and straw should not be burned. (Sections 4 and 68.) How do your results compare with those of others who used other material? Why do grains produce more flesh and energy in animals than the same weight of green forage, potatoes, beets or other root crops?

69. The Water given off by Leaves. - The minerals which a plant takes in are really received in a very weak solution. In other words, a great deal of water is absorbed to get a small amount of phosphorus, potassium or any other element required from the soil. The excess of water must escape, and it does so through the leaves. On the under side of leaves, and to a limited extent on the upper side also, are found numerous tiny openings, called stomata. These stomata are guarded on either 
side by cells, known as guard cells. When there is more than enough water to unite with the carbon dioxide to form starch, and when the sun is shining, these cells draw apart and allow the water in the leaf to escape and the carbon dioxide to enter. This escape of water, which is in the form of invisible vapor, through the stomata of the leaves is called transpiration.

The roots of a plant must absorb from two hundred and twenty-five to nine hundred and fifteen pounds of water for every pound of dry matter, or food material produced. In times of drouth, the stomata are partially or nearly closed, so that transpiration becomes slower. During the night, the stomata are closed, but the roots absorb moisture in the darkness as well as during the daytime. It follows that when moisture reaches the leaves in the night, it can not escape, but accumulates both in the leaves and back in the stem, making them turgid. This explains why plants look fresh in the morning and why corn will break under the cultivator in the early morning but not at noon.

We are able by a very simple experiment to determine how much water escapes from the leaves.

\section{EXERCISE 32}

Object. - To determine how much water the leaves of a plant throw off.

Procedure. - Cover with melted paraffin the outside and bottom of a flower pot containing a healthy plant. Put a cork in one end of a glass tube and thrust the open end into the soil in the pot. Cover the surface of the soil with melted paraffin which has cooled enough to do no injury to the stem of the plant.

Notice that no water can now escape from the soil in the flower pot except by passing out through the plant; 
and since little or none escapes from the stems of plants, we may say that that which is lost from the pot is given off by the leaves.

Carefully weigh the flower pot and plant. Remove the cork from the glass tube each day, pour water through

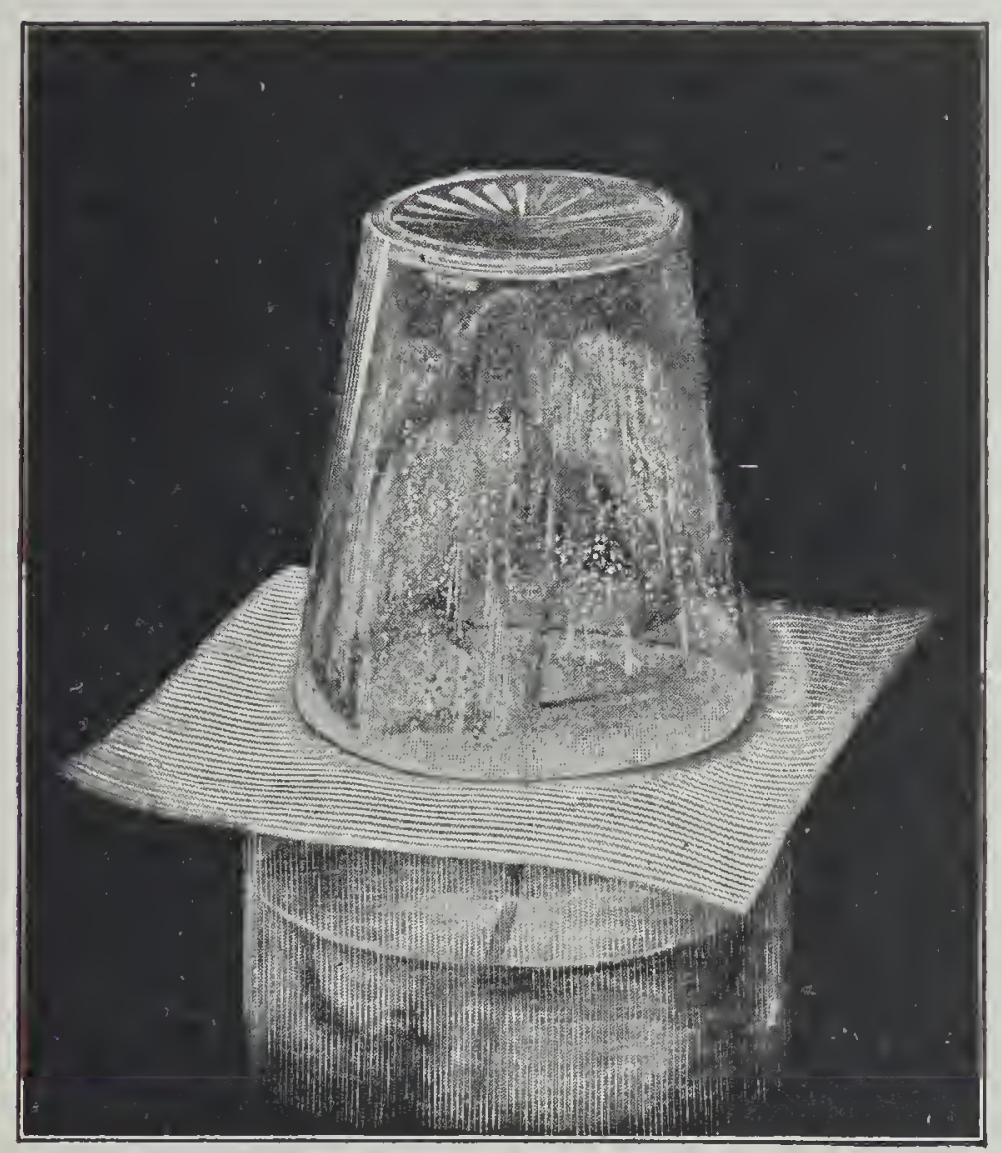

FIG. 30. - The water lost by leaves.

it into the soil, keeping an accurate record of the weight of the water so added, and being careful to replace the cork each time. At the end of a week, weigh the plant and pot again, and from the figures which you will now have, determine the amount of water given off by the leaves during that time. Measure as accurately as possible the number of square inches of leaf surface on the plant. 
Conclusion. - Determine how many grams per square inch the plant has given off during the week. Reduce it to ounces, considering that twenty-eight and three tenths grams are equal to one ounce.

How many tons of water will the velvet weeds in a ten-acre field remove in one hundred days if each weed throws off as much water per square inch of leaf surface per day as the plant with which you have worked? The average leaf surface on each weed is two hundred square inches and the average number of weeds is two on each square rod.

70. Storage of Food in the Leaves. - The food which is manufactured in the leaves is used by the plant in three ways:

First: to supply the plant with energy with which to carry on the processes of growth.

Second: to build the tissues of which its body is composed.

Third: It may be stored away for time of need, such as drouth, dormant season, or to nourish the seedling after germination.

We have already seen how roots may be used as storehouses of food. Leaves, like those of the cabbage, or those which make up such bulbs as the onion, become filled with reserve food, and for this reason are useful to man.

\section{QUESTIONS}

1. Give three functions of leaves.

2. Draw from memory a leaf considered as a mill, showing how food is manufactured within it.

3. Tell briefly and clearly how you proved that a leaf manufactures starch, and that sunlight is necessary.

4. Why will plants always reach for the light?

5. Name two reasons why stareh is important. 


\section{THE WORK OF LEAVES}

6. Where do the water, the food material, and the ash of a plant come from?

7. How does water escape from the leaves?

8. Why will corn break under the cultivator in the early morning but not at noon?

9. How can you find out how much water a plant gives off?

10. State three ways in which the plant may use the food which it manufactures. 


\section{CHAPTER XI \\ THE WORK OF STEMS}

71. The Functions of Stems. - The three functions which Nature has given stems to perform seem to be:

First: to hold the leaves up to the light that they may manufacture food.

Second: to conduct the water and dissolved minerals from the roots to the leaves.

Third: to conduct the food manufactured in the leaves back again to the roots and other parts of the plant.

72. The Forms of Stems. - In the effort to hold their leaves up to the light, stems grow in three fairly distinct forms; (1) prostrate, or trailing, (2) climbing, and (3) erect.

73. Prostrate Stems. - Plants which form this kind of stems are often overshadowed by those with erect stems. Notwithstanding this fact, a large number of plants have prostrate stems. Such plants as the prostrate pigweed, purslane, sweet potato and the dooryard weed, or knotweed all have this form of stem. Because of their clinging closely to the ground, these plants require less moisture than they would if the stems were higher in the air. The stems themselves act as a mulch to prevent the escape of moisture from the soil while often at the joints roots are formed.

Even when these plants grow among the erect plants as the purslane or crab grass grows among the corn, the 
prostrate stems creep, turn and twist to reach the beams of light, which filter through between the blades. When we remember the troubles we have had in hoeing these weeds from our gardens or fields, we conclude that prostrate stems may get along very well in competition with other kinds.

74. Climbing Stems. - Such plants as the morning glory, the grape, and the five-leaved ivy, or Virginia creeper, twine their stems around any support they can find and thus raise their leaves up to the light. Plants with this class of stems are excellent for covering over trellises, arbors and fences which may screen buildings and unsightly places. When some of these plants, such as the wild morning glory and the black bindweed, grow among our field crops, they become serious pests. Their roots take from the soil, moisture and plant food needed by the growing crop, and they interfere with the harvesting of the crop as well. Moreover, their stems twine about the stems of the corn and other plants, which makes them extremely hard to destroy.

75. Erect Stems. - The great majority of plants have this kind of stem. They may be short or long, depending upon the environment in which they grow. On the plains the grasses and prairie flowers have short stems, but they are mostly erect. In the forest, the trees form stems of remarkable length and strength, and because of this, yield us our supply of lumber. Most of our cultivated crops have erect stems. For this reason, we are able to cultivate the ground close around them; the binder and header can be used to harvest them; the mower can be used to cut them down; and the stems themselves in addition to the leaves often make excellent forage. Those 
which are harvested or gathered by hand, as the cotton and corn, are held up at a convenient height to pick.

76. Study of the Forms of Stems. - Nothing will fix in our minds the habits and uses of stems so well as a

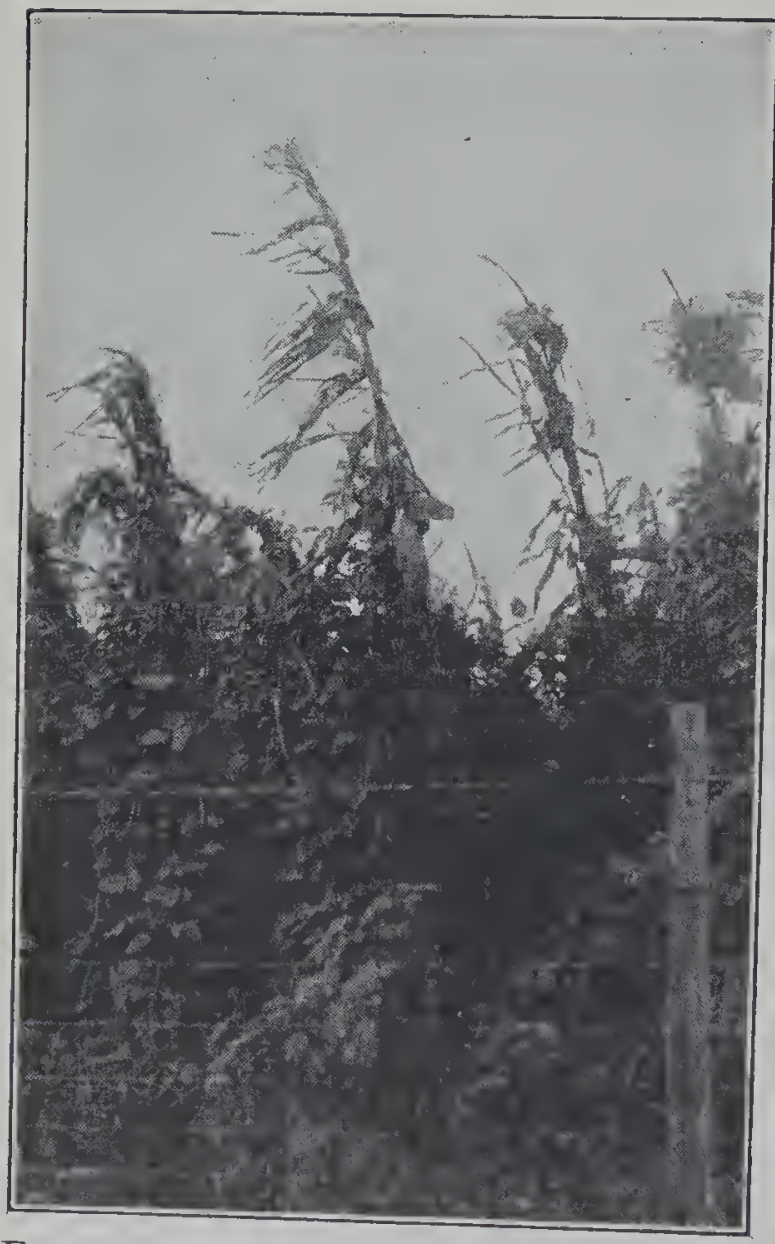

FIG. 31. - Cornstalks with an extra burden. field study and a collection of them.

Gather at least three specimens of plants with prostrate stems, three with climbing stems and three with erect stems. Record in your notebook where each was gathered, that is, whether in pasture, cultivated field, orchard, or elsewhere; also, tell what chance it had to get plenty of light, and what is the use of the plant to man.

\section{EXERCISE 33}

Object. - To become familiar with the character of stems.

Procedure.-Place the stem of a mature corn plant, a mature, dry morning glory vine and some prostrate plant, as the purslane or the prostrate pigweed, on the table before you. Notice the joints, or nodes, on the cornstalk; also that there are joints on the other stems, though they are different in appearance from those of the corn plant. 
Conclusion. - Where do the leaves grow out from the stems of each of the plants? Are the leaves of the corn plant arranged on opposite sides of the stem, or are they arranged spirally? How are they arranged on the morning glory? Of the three kinds of stems, which would need to be most rigid? Why? Do you find it so? Which would need the strongest anchorage roots? Why?

Name three cultivated plants with erect stems, three with climbing stems and two with prostrate stems. In what kind of fields is each grown, and how is it cared for?

77. How Water travels from Roots to Leaves. - We have seen how the roots draw water, containing dissolved mineral substances, from the soil. We have learned the uses to which this water is put in the leaves. How does it pass upward from the roots to the leaves?

In every plant, extending continuously from the ends of the roots to the leaves, are tiny tubes, which are more or less connected. These are the water-carrying vessels, and united with them are the food-carrying cells which we shall study shortly. The two are joined in such a way as to form strands, or threads, called fibro-vascular bundles.

We noted in Section 45 that the common plants are divided into two classes, the monocotyledons and the dicotyledons. The stems of these two classes are very different. In the monocotyledons the bundles described above are scattered irregularly, either through the pith as in the cornstalk, or through the walls of the hollow stems, while in the dicotyledons, they are regularly arranged in a circle or circles about the central pith.

\section{EXERCISE 34}

Object. - To study how the water travels from the roots to the leaves. 
Procedure. - Wash the dirt from the roots of a corn plant and of a bean plant, each about six or eight inches high. Put the two plants in a glass of water containing a few drops of red ink. After an hour remove them, and with a razor blade cut each plant off at the lower end of the stem. Make a thin section of the stem at this point, and examine it with a hand lens to see where the water has moved upward. Keep cutting thin cross sections up the stem until you reach the point where only the water-carrying tubes are stained.

A common house plant, the Sultana, has a very clear stem, and the colored water may be watched as it moves upward through it. Either the narcissus, or the Chinese sacred lily, which you have probably grown in water in

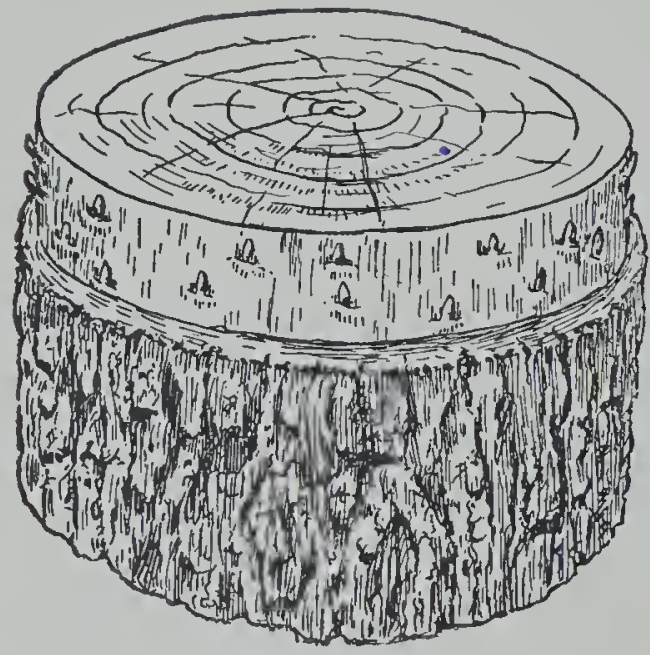

Fig. 32. - Annual rings. the schoolroom, may have its blossoms colored by adding dye or ink to the water in which it stands.

Conclusion. - Describe briefly how the water-carrying tubes differ in arrangement in the corn and bean plants.

78. How to tell the Age of a Tree. - In the spring, when there is an abundance of water, the water-carrying tubes are very large. As the season advances and the rainfall becomes less, smaller and smaller tubes are made, until in the fall they are so small and compact that they look like a ring of denser, harder wood. In trees, therefore, which grow from year to year, this circular line between the small water-carrying tubes of the fall and the large ones of the spring is so plain that 
we are able to tell the age of the tree, limb or twig by counting the rings in its cross section.

79. How Food travels from Leaves to Roots. - The food made in the leaves has three uses. (Section 70.) In order that it may be used in any of these ways, it must first be conducted from the leaves to the different parts of the plant. We have already learned that it takes several hundred pounds of water to produce one pound of dry matter or food material in the plant. (Section 69.) It is evident, then, that the vessels through which the manufactured food travels from the leaves to other parts of the plant need not be so large as those by which the soil water travels from the earth to the leaves. The tubes, called sieve tubes, which carry the manufactured food to different parts of the plant, are very small indeed; and no careful study can be made of them without specially prepared material and a compound microscope. It is enough for us here to know that in the dicotyledons, these sieve tubes are outside of the water-carrying vessels just beneath the bark; while in the monocotyledons, they are connected with the water-carrying vessels, forming the fibro-vascular bundles, as explained in Section 77 . These bundles, which are seen as threads, running through the pith of the cornstalk, have the double function, then, of carrying water from the soil to the leaves, and manufactured food from the leaves back to other parts of the plant.

You have perhaps noticed that where a notch has been cut in a tree, a callus is formed above, but not below, the cut. This means that the food on its downward path has found a place where the "bridge is out" and has piled up on the bank on the side from which it has come. Girdling a tree is simply the cutting away of the bark and the sieve tubes just beneath it. This stops the current of food and 
starves the roots. A girdled tree does not sprout from the stump.

80. The Flow of Sap. - We have perhaps heard that the sap flows upward in the spring and back downward in the fall. This is not the case. The roots absorb water throughout the growing season and this water moves up-

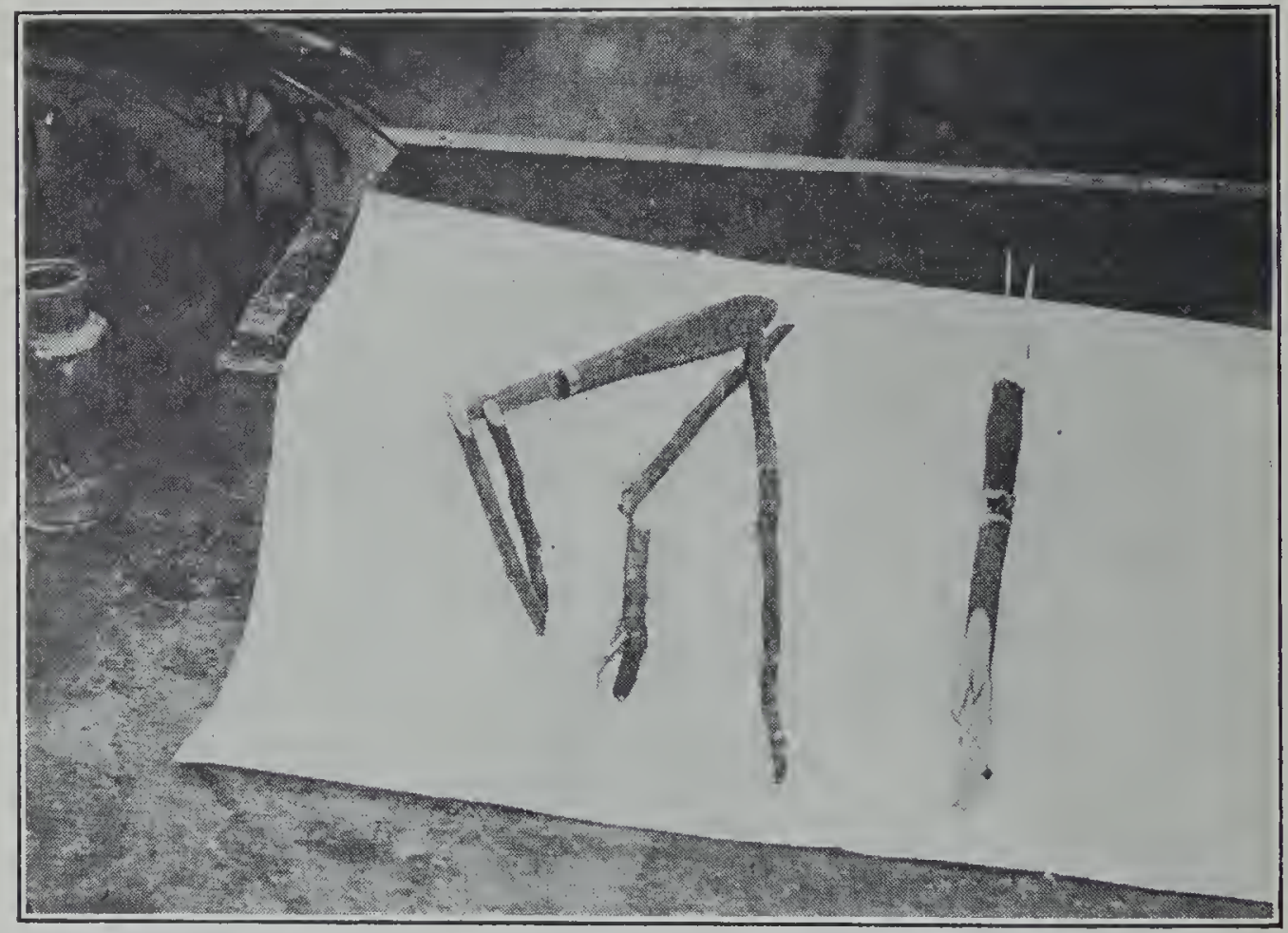

FIg. 33. - How a graft is made and how it grows together.

ward rather rapidly through the water-carrying tubes to the leaves where food is manufactured; and throughout the growing season, the food manufactured in the leaves oozes back downward through the sieve tubes to all parts of the plant.

81. The Cambium Layer. - In the dicotyledons, there is a layer of cells between the water-carrying vessels and the sieve tubes which lie outside of them. This is known as the cambium layer. It is the thin, wet, slippery layer 
which we find when we remove the bark from a tree or twig. It is here that all growth takes place and that new sieve tubes or water-carrying vessels are formed as the plant has need of them. When we reach the subject of grafting, we shall have to remember that the cambium layers of the root and the twig must be actually touching each other or the two will not grow together.

82. Rope, Twine and Linen Material. - We can not conclude our study of stems without learning something of the spindle-shaped cells, called bast fibers, which often make up a part of the outer portion of the stem. They give it strength and flexibility.

The bast fibers of the hemp and flax, which are grown in different parts of the United States; of the Manila hemp, which is a small tree of the banana family found in the Philippines; and of the century plants of Mexico yield us our chief supply of rope, twine and linen thread material.

The stems of the hemp and flax are allowed to soften by partial decay in the field, or hot water is used, and the wood removed, leaving the long fibers, which are bleached and spun into the material desired. These fibers may be found in the wild hemp nettle which grows along creeks and in low places. If the stem is broken in winter, the long strands of bast fibers may be secured and woven or braided.

\section{QUESTIONS}

1. Name three functions of stems.

2. Name three forms of stems.

3. Name two weeds with prostrate stems, two with climbing stems, and two with erect stems.

4. How does water from the soil reach the leaves?

5. Why does a callus form above, but not below, a cut in the bark of a tree? 
6. Why will girdling kill a tree?

7. How does the arrangement of the water-carrying vessels differ in the corn and bean? Of what do the threads in the pith of a cornstalk consist?

8. Describe the flow of sap.

9. What is the cambium layer? How could you find it in a twig?

10. How, and from what part of hemp and flax do we get our linen thread, rope and twine? 


\section{CHAPTER XII}

\section{THE WORK OF FLOWERS}

83. The Work in which All Parts join. - All parts of the plant work together to do these two things:

First: to provide for the needs of the growing plant.

Second: to provide some way by which another generation of the same kind of plants may be produced.

84. What the Flower does. - Nearly all plants are propagated, or continued from generation to generation, by seed. It is the business of flowers to produce this seed.

Each part of the flower plays some part, directly or indirectly, in the production. of seed. We shall soon see why some are attractively colored; why some are green and unattractive; why some are fragrant and some odorless; why it is necessary for bees or other insects to go from clover blossom to clover blossom or from strawberry blossom to strawberry blossom; why, if they fail to do so, the clover plants produce no seed and the strawberry plants no fruit; why the corn lifts its tassel high in the air and why the cane produces its seed on the top of the stalk.

Let us proceed step by step to find out some of these interesting and important facts and to get a glimpse also of hidden changes, which take place within the flower before the seed begins to form.

The first step will be to learn the parts of the flower. 


\section{EXERCISE 35}

Object. - To become familiar with a flower and its parts. Procedure. - Lay on the desk before you (1) the flower of a dicotyledon, such as the apple, pear or petunia ; also (2) the flower of a monocotyledon, as a head of cane, foxtail or millet, which is just in bloom. Beginning at the stem, compare the flower of the dicotyledon before you with the drawing in Figure 34.

At its base, you find five stiff, green leaf-like organs. These are the sepals; and all of them taken together are

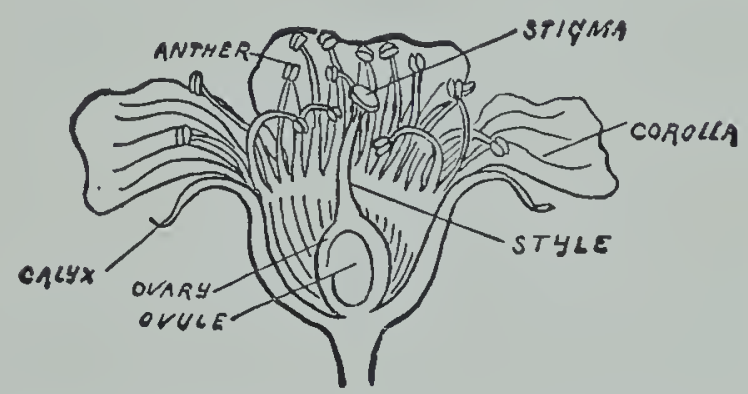

Fig. 34. - Parts of a dicotyledonous flower. called the calyx. They afford protection to the blossom before it opens.

Next above these, we find the petals, pure white or bright in color. Whether united, as they are in the petunia, or separate, as in the apple or pear, the petals make up the corolla. These serve to attract insects.

Next, just inside the corolla, we find a number of small, usually yellow, oblong or round bodies, held erect on tiny stems. These are the stamens. The tiny, thread-like stem of each one is the filament, the body at its tip, the anther, and inside the anther, is a powdery substance called the pollen.

Lastly, and usually in the center of the flower, we find a part, expanded or divided at the top, and joined by a thread-like stem somewhat larger than the filament with little seed cavities in the base of the flower. The whole of this central portion is called the pistil; the upper divided or expanded part is the stigma; the lower portion, 
containing the cavities in which the seeds will form, is the ovary; and the connecting portion, or stem, is the style.

Let us turn now to the other class of flowers before us.

We must look upon each head of these monocotyledons, not as a single flower, but as a mass of flowers arranged in groups of two along a central axis. That is, we find two flowers together against this axis, then, a little higher and on the opposite side of it, we find two more, and so on.

Study each group now a little more closely. You find no sepals. Instead, you find at the base of each group two stiff, husk-like organs which are called glumes. Above these glumes are the two flowers.

At the base of each of these flowers are two thin, husk-like organs, one of which is smaller and thinner than the other and partly inclosed by it. The large one is called the flowering glume,

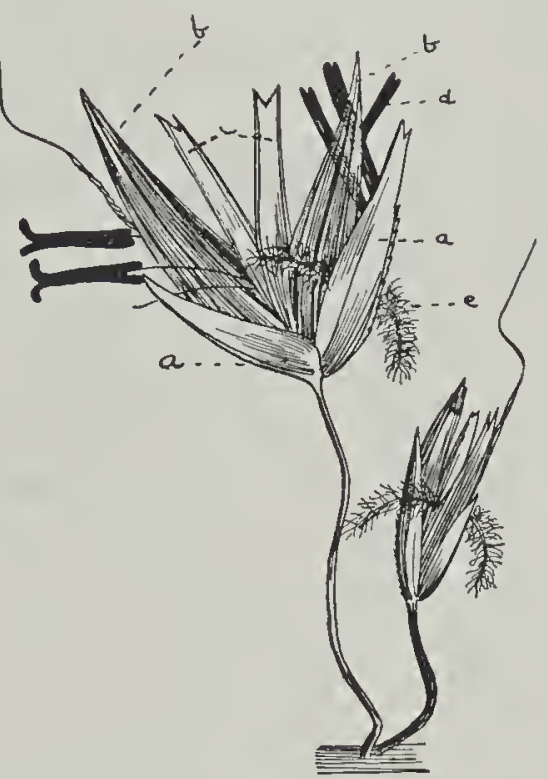

FIG. 35. - Parts of a monocotyledonous flower.

$a$, glumes ; $b$, flowering glumes; $c$, paleas; $d$, stamens . $e$, stigmas.

the smaller one, the palea. Inclosed by these two are three stamens, while at the center is a rounded ovary, from which rise two long, feathery stigmas.

Compare now, part by part, these flowers with those of the dicotyledons already studied. Point out and name all parts of each flower.

If you can do this, you may take pride as well as pleasure in the achievement. It is from flowers like these that all grains, fruits, and seeds are produced. Very many people are content to become familiar with only the flowers of the 
first group ; yet all of our common field crops have flowers of the second kind.

Conclusion. - Write a careful description of the flowers with which you have been working, naming and describing each part. State whether the flower is fragrant and give the color of its corolla. After you have studied Sections 87 and 88 , complete your notes here by telling whether the pollen from the flower is scattered by the wind or insects, and state how you know.

85. Parts of the Flower on Separate Plants or on Different Parts of the Same Plant. - The flowers of the plants we have chosen to study have all their parts together; but from this it does not follow that the parts of the flowers of all plants are so arranged. In the corn, for instance, the tassel at the top of the stalk produces all the stamens, while the ear, which is a collection of pistils, is borne about midway on the stalk. Similarly, there are two kinds of flowers on every pumpkin vine, - one, which bears stamens and is therefore called staminate, while the second one bears the pistil and is called a pistillate flower. You can easily recognize the pistillate flower, for at its base a small pumpkin is beginning to form. In certain varieties of strawberries, all the flowers are pistillate; and unless another variety is near which bears stamens, no fruit will be produced. In mulberries, persimmons and some other trees, the staminate and pistillate flowers are borne on separate trees.

86. How the Pollen gets from One Plant to another. Hold the ripe anthers of the petunia against the palm of the hand and they will leave a purple-gray mark. If you had a microscope to examine the spot, you would find it made up of very many minute grains, which we call pollen. 
Examine the stigma of the petunia to see if it is sticky. Touch it to your tongue to learn if it is sweet.

Before a seed will form, a pollen grain must alight on the stigma. This is the first step in seed formation, which we call pollination.

It is a rule of Nature that the flowers of few plants care to receive their own pollen. There are very few plants but that have adapted themselves so that they receive pollen from other plants of the same kind. The principal agents in carrying pollen from one plant to another are insects and the wind.

87. The Flowers which depend upon Insects to carry Pollen. - Plants which depend upon insects to bring them pollen or to transport their own have :

(1) Bright colored flowers, which attract the bees and other insects.

(2) A perfume, or fragrance, as in the case of the clover or plum blossom, which invites the insect.

(3) Glands bearing nectar, which is gathered by insects and made by bees into honey.

(4) Pollen, which is gathered by insects for food and which is called beebread when found in the cells of the honeycomb.

(5) The stigmas so placed that they come in contact with the insect's body.

(6) Pollen, which sticks to the insect's body.

(7) Stigmas, which are expanded and sticky to receive the pollen which the insect may bring from other plants.

88. The Flowers which depend upon Wind to carry Pollen. - Plants which send their pollen by the wind or catch that which drifts through the air have:

(1) Exposed flowers with no sepals or petals to stop the drifting pollen. 
(2) Enough pollen produced to allow for enormous waste. A single corn plant may produce as many as fifty thousand pollen grains. Scarcely one in a thousand reaches the stigma of a flower.

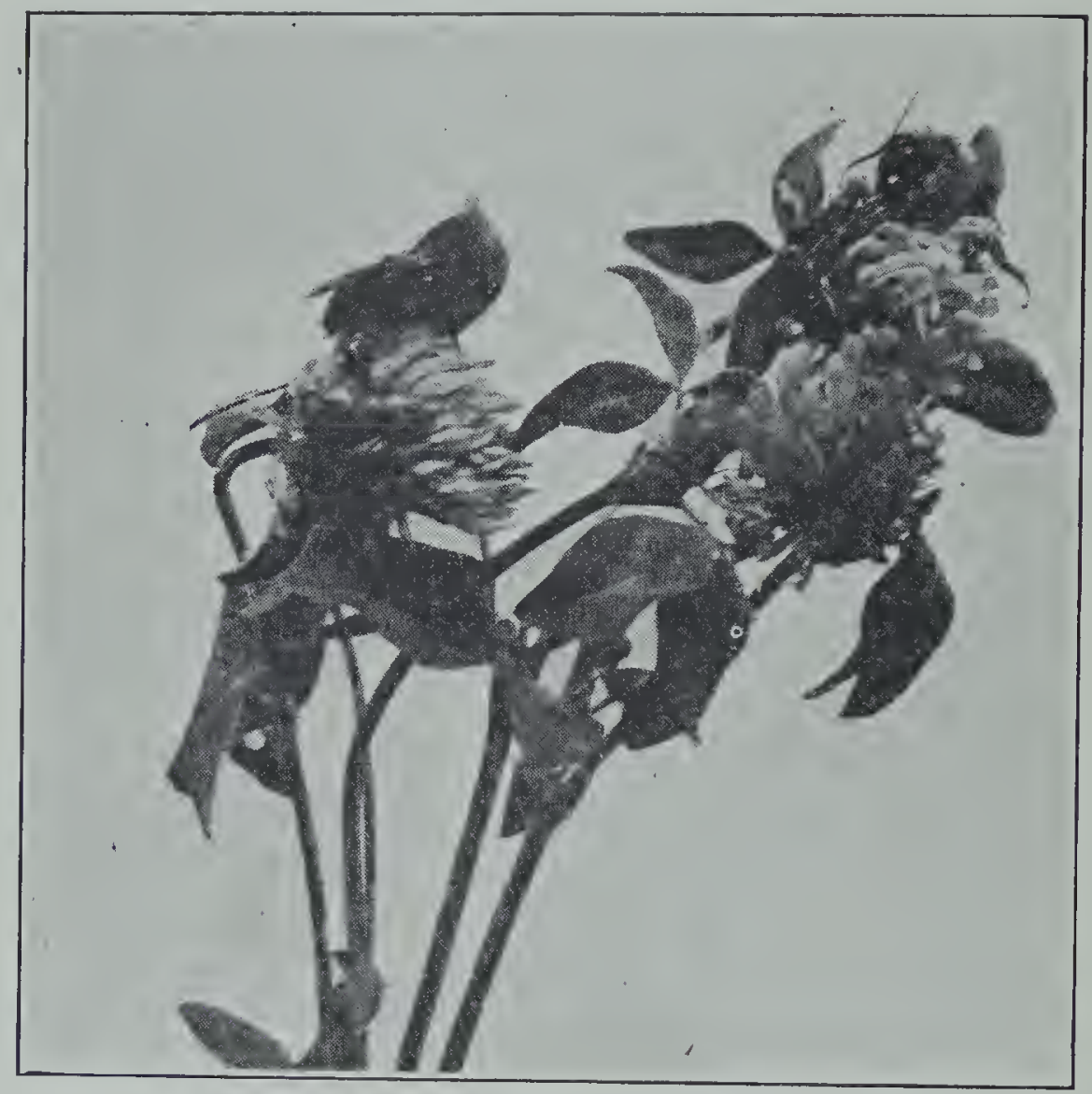

Courtesy Iouca State College.

FIG. 36. - Bees in clover blossoms.

(3) Dry, powdery pollen which floats easily in the air.

(4) Flowers for the most part on top of the stalk or stem where they are exposed to the wind.

(5) Stigmas in the form of feathers, as in Figure 35, or like the silks of corn. Both of these easily catch the drifting pollen.

89. What happens after the Pollen reaches the Stigma. - As we have said, pollination is the first step in the formation of seed after the flower has opened. 
If we place the pollen of the sweet pea blossom in a very small glass dish containing slightly sweetened water, in less than an hour we can see with the aid of a microscope the pollen grains beginning to germinate. In perhaps two hours a long slender tube will extend far out from the original pollen grain.

When a pollen grain falls upon a stigma, it absorbs moisture and nourishment from the latter and sends out a tube, just as do those of the sweet pea in sweetened water. This tube pushes its way down the style into the ovary. Here in a small organ, called the ovule, a sperm cell from the pollen tube and an egg cell within the ovule unite, and a seed begins to form. This union of sperm and egg cells, which is the second step in seed formation, is called fertilization.

90. Cross-Fertilization the Rule. - As a rule, crossfertilization, in which the pollen of one plant fertilizes the ovules of another plant, produces the greatest number of seeds capable of germination. Self-fertilization, in which the pollen of a plant fertilizes its own ovules, tends to produce no seeds at all or small seeds of which few or none are capable of germination.

There are a few important exceptions to this rule, some notable ones being the oat, wheat, barley and cotton plants. As might be expected, the seed from a selffertilized plant is less subject to variation than the seed from one which is cross-fertilized.

91. Cross-Fertilization by Hand. - It is possible for us to secure the pollen from a plant, place it on the stigma of another plant, and thus know both parents of the seed we. secure. If the flowers of the plant which is to receive the pollen contain both stamens and pistils, the stamens must be removed with a small pair of scissors and the 
flower covered with a paper or mosquito netting bag to prevent self-fertilization or its receiving any other pollen than that which we have selected. If the pistil is produced

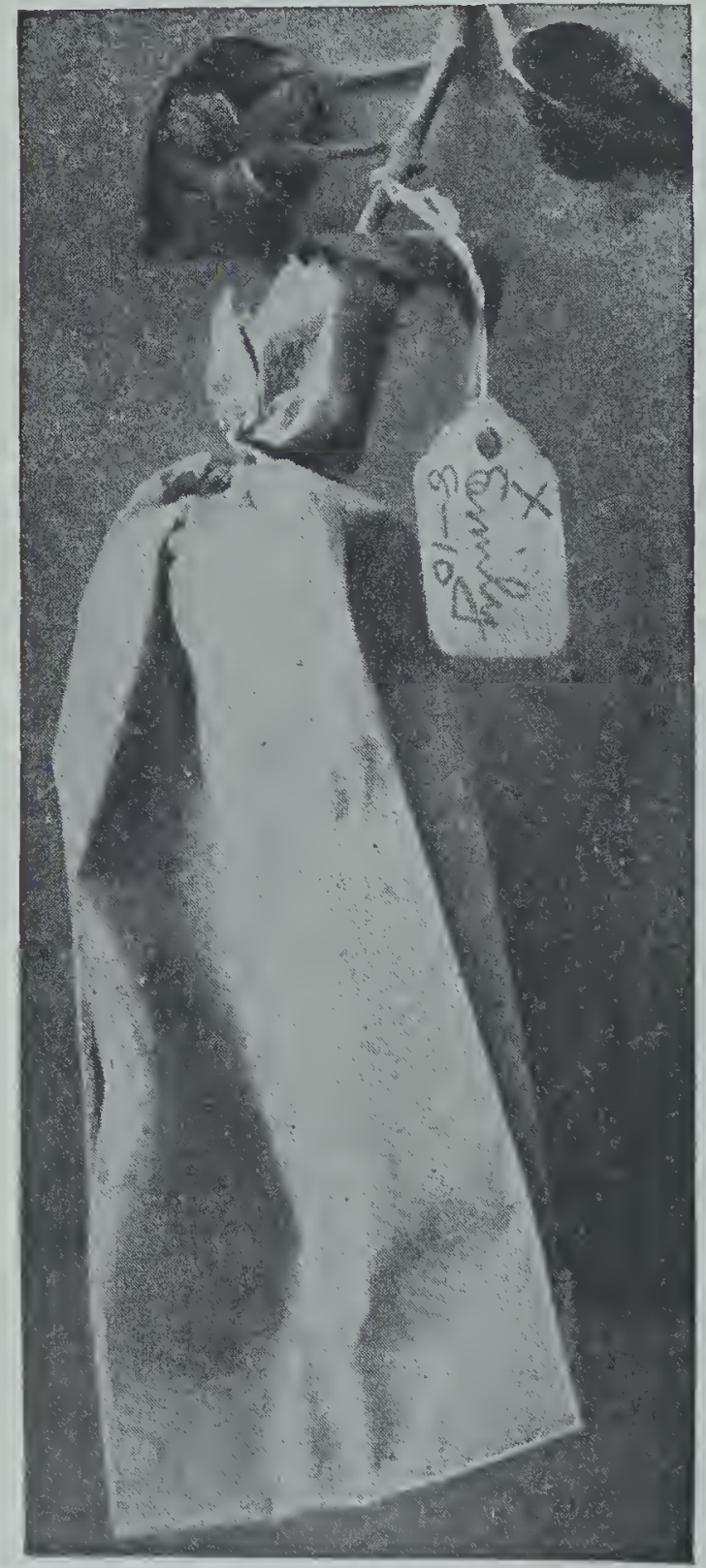

FIG. 37. - Blossom fixed for crossing. on a separate plant, it must be covered also except when we are placing pollen upon it. When the pistil is ready to receive the pollen, we select and carry it to the plant bearing the pistil, remove the sack gently, shake the pollen on the stigma, or better still, place it there with a fine camel's hair brush, tie the sack securely about the blossom again and the deed is done.

Ordinarily no results from this cross are seen in the first crop of seed secured. The plants which come from this seed, however, often present a variety of form and flowers, some resembling one parent and some another with many intermediate types.

Fertilization by hand properly belongs to a kind of work called plant breeding, and requires special knowledge. As amateurs, we can not expect great results from it. 
This matter of cross-fertilization, however, has a striking application in the case of the corn plant. The best development of the ear of corn is seen only in case the seed from which it grew was fertilized by pollen from another plant;

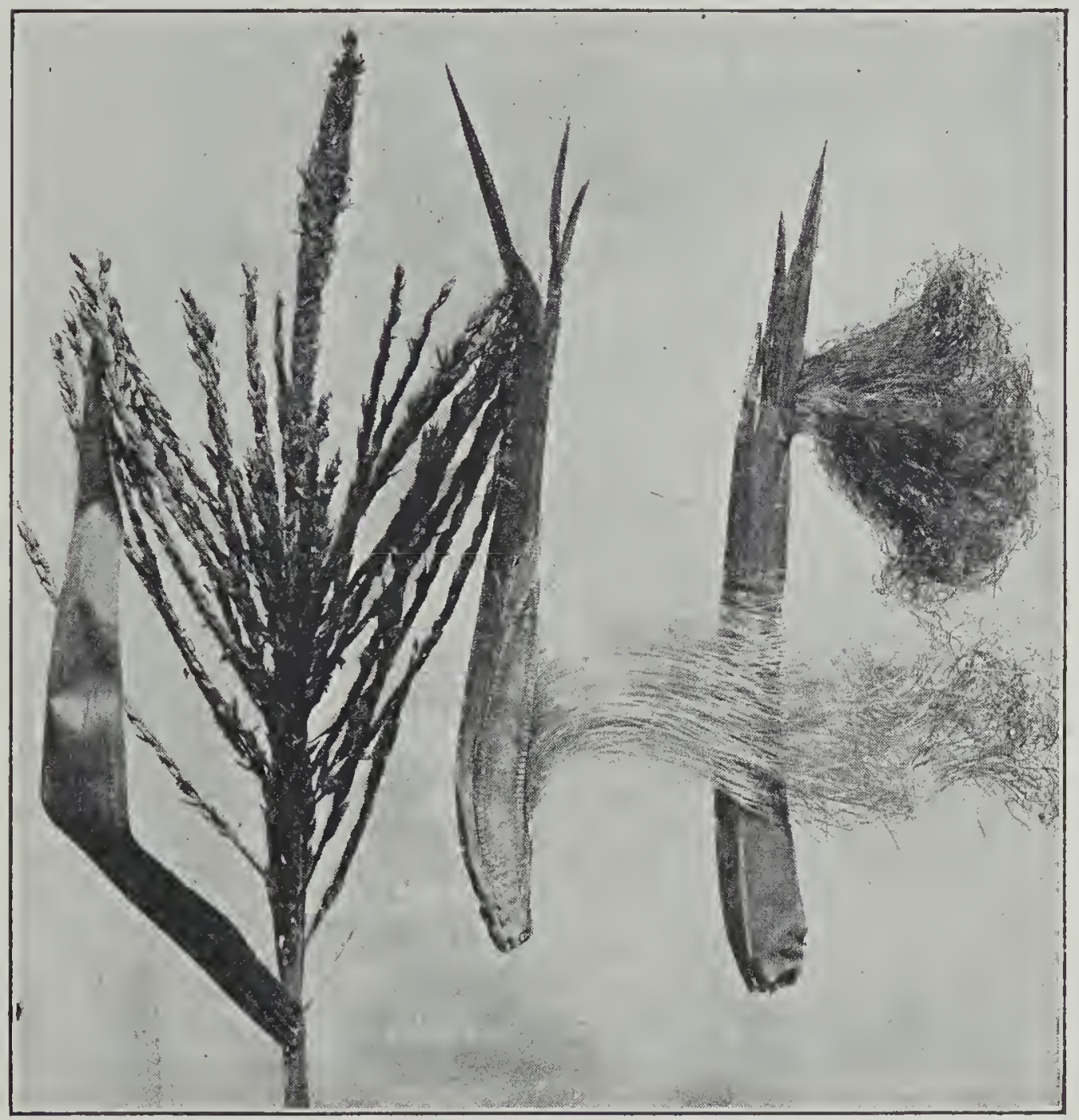

FIG. 38. - Flowers of the corn plant.

but since the tassel which bears the pollen is directly above the silks which receive it, self-fertilization very often takes place.

By going through a field of corn when the tassels are just coming out and cutting them off as they appear in 
every other row, we are able to secure cross-fertilized ears in the detasseled rows since their own pollen is destroyed and they must be fertilized by that from other plants.

If, now, the corn from the detasseled rows is used as seed, it will ordinarily produce more vigorous plants and likewise a larger yield per acre than will seed which has been fertilized in part by its own pollen. This is true, however, only of the first year's crop as after this much of the seed is again self-fertilized.

Next summer, suppose you make an experiment of this sort by detasseling every other row in a part of your field at home. The following spring plant some of the seed from these detasseled rows and compare the yield secured with that from other seed.

\section{QUESTIONS}

1. What is the business of flowers?

2. From memory, draw a diagram of the flower of a petunia and name its parts.

3. Name two cultivated plants which have their flower parts on different parts of the plant.

4. Name several cultivated plants which have both stamens and pistils in the same flower.

5. Define the term pollination.

6. What are the two agents by which plants secure crosspollination?

7. Name four ways by which plants adapt themselves to wind pollination.

8. Name four ways by which plants adapt themselves to pollination by inseets.

9. Define the term fertilization, and trace the steps after the pollen grain reaches the stigma.

10. Tell briefly how you could cross by hand one blossom with another. 


\section{CHAPTER XIII}

\section{THE FORMATION AND DEVELOPMENT OF SEED}

As soon as the sperm cell from the pollen tube and the egg cell in the ovule have united as explained in Section 90 , the development of the seed begins.

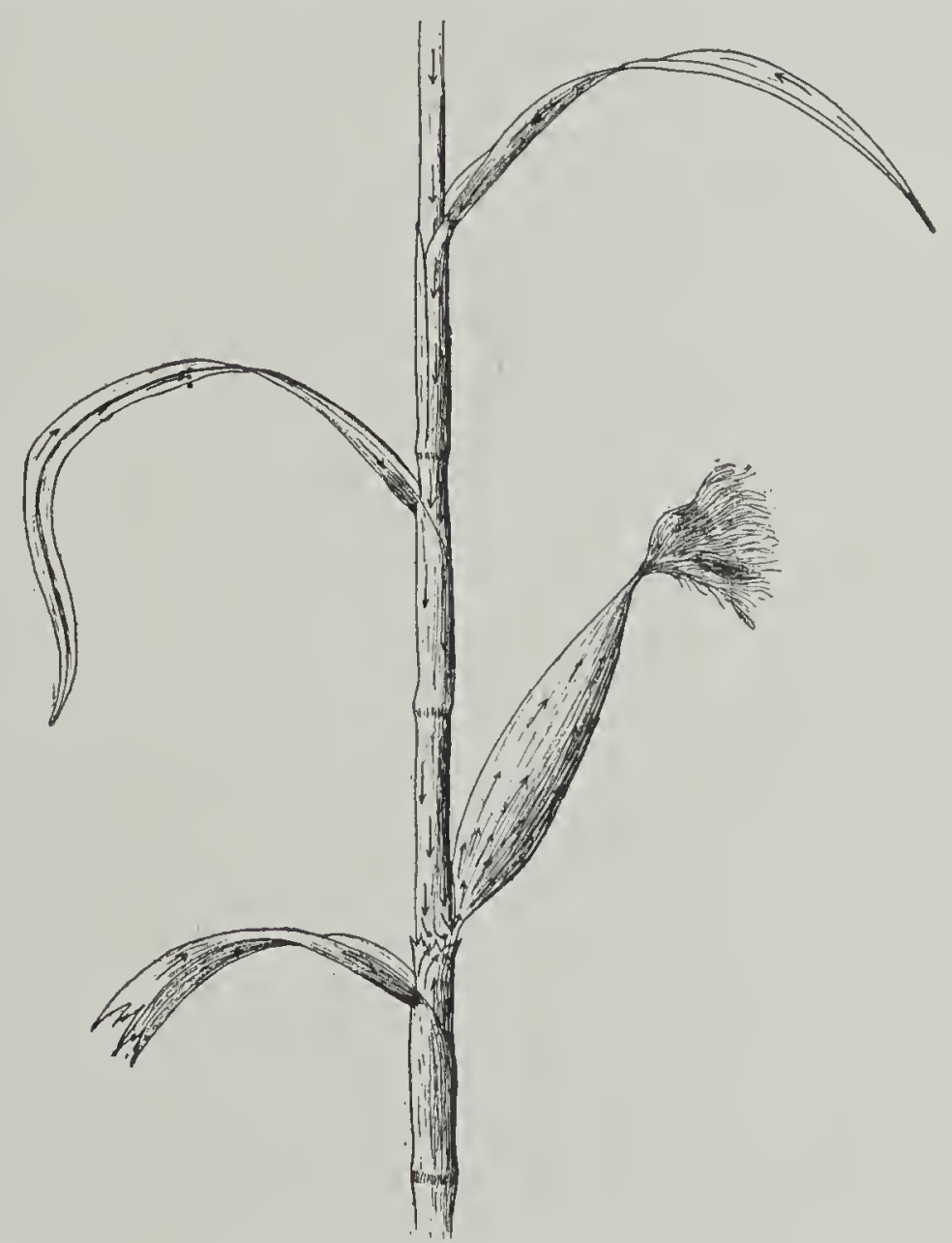

FiG. 39. - How food travels from the leaves to the seed.

92. How the Food is stored in the Seed. - We have noted how starch is formed in the green leaves (Sections 
66 and 67 ), and how by a process we do not fully understand, this starch is converted into other food compounds, including fats and oils, or how it may in other cases be combined with mineral elements from the soil to form proteins.

As the seed develops, it draws this food from other parts of the plant and stores it within itself. Around the tiny plant which is developing within the seed, is built layer after layer of cells stored with starch, sugar, fats and proteins. In the accompanying drawing (Figure 39 ), the arrows indicate the currents of food moving toward the seed where food accumulates.

93. How Man may thwart Nature's Plan. - It will thus be seen that the whole plant is working to produce this seed. If, before the seed is fully formed, the plant is harvested, much of the food will be retained in the leaves and stems since it will not have had time to reach ' the seed, and so these parts will be useful as forage for animals, or even as food for man. If we want oat hay, we cut the crop while it is yet green. On the other hand, alfalfa or clover straw, from which the seed has been threshed, has little food value, and you can readily see why this is true.

Grasses are cut, dried only enough to prevent their molding, and then stacked in the field or stored in barns that animals may use the food that is stored in their leaves and stems. For the same purpose corn plants are cut before they are fully mature, and the leaves and stalks are chopped together into short, small pieces, which will pack solidly into the silo.

None of us enjoys roasting ears when the kernels are very small and consist principally of water; neither do we enjoy them when so much food from the leaves has ac- 


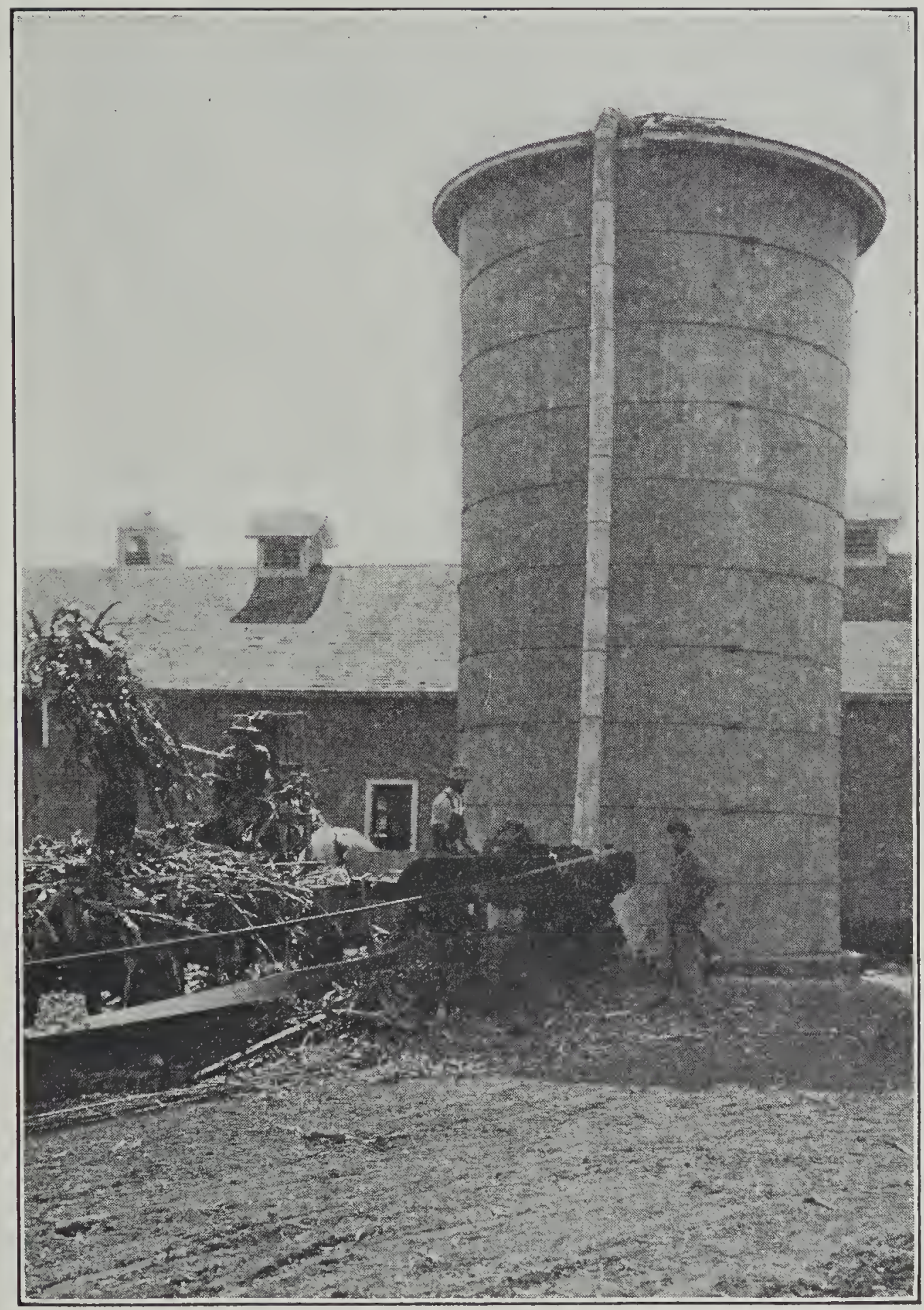

Courtesy Iowa State College.

FIG. 40. - Filling a silo. 
cumulated in the kernels as to make them hard and doughy.

\section{The Forms and Uses of the Various Food Materials} in the Seed. - As the food accumulates within the seeds, part of it assumes the form of grains, or granules, which often resemble to some extent minute oyster shells; and inclosed in certain parts of some seeds, oil may be seen in the form of tiny droplets. A person who has made a careful study of the subject can detect adulterations in

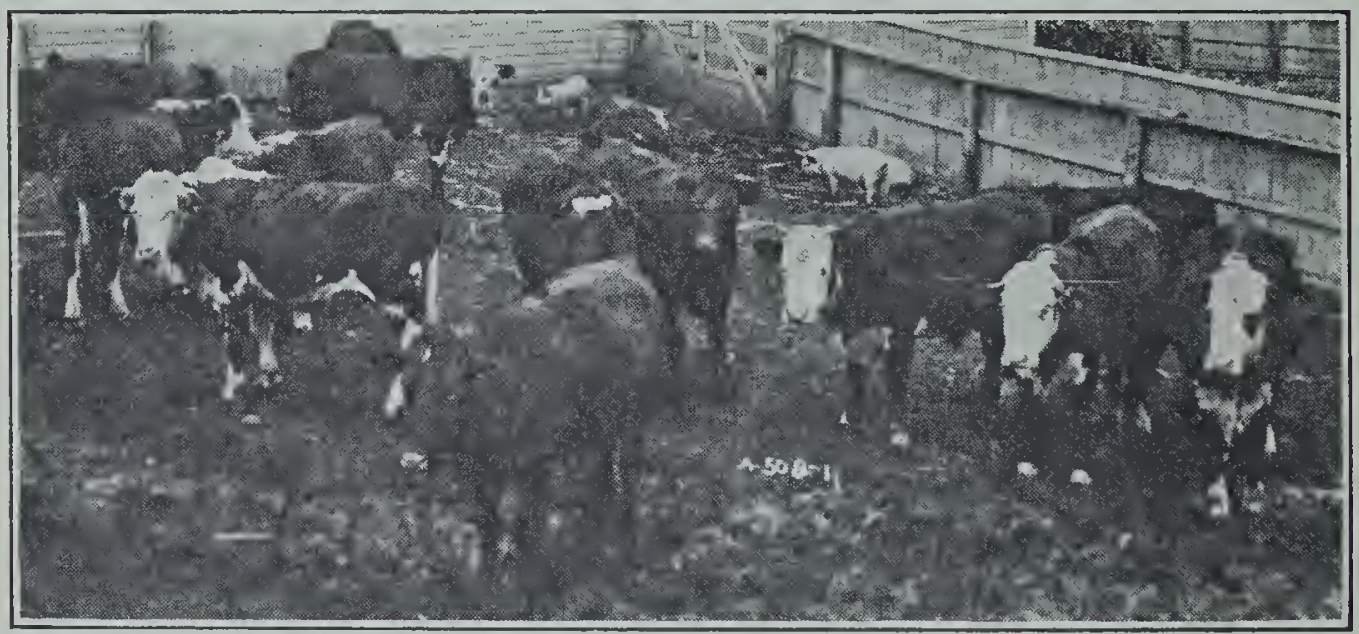

Courtesy Iowa State College.

FIG. 41. - A feed lot scene.

foodstuffs, such as corn meal in wheat or buckwheat flour, or ground peas or beans in ground coffee, by the form of the starch and protein grains.

A good stock raiser knows the use of the various kinds of food stored in the seeds. He knows that protein builds tissue, and must be provided in considerable amounts for growing animals and milch cows; and furthermore, he knows that foods containing starch, sugars, or fats and oils, yield heat and muscular energy and produce fat if fed in excess, - but that they will not build tissue.

The ration for his growing pigs and milch cows includes 
such feeds as the outer layers of wheat grains, or wheat middlings, or perhaps flaxseed or oil meal, for these are rich in proteins, and proteins produce new tissue or milk. The ration for the hogs in his fattening pens will consist largely of corn, for it is rich in the foods that produce fat. His growing calves get a considerable amount of such feeds as ground oats, oil meal or wheat middlings along with their corn meal; and even his fattening steers get in addition to corn some such protein feed as cottonseed meal. 


\section{CHAPTER XIV}

\section{THE PROPAGATION OF PLANTS}

To propagate plants is to cause them to multiply, spread or continue by natural generation or other means, as a species or variety. In Nature, we see each plant, from the tiny one that causes the mold on bread to the

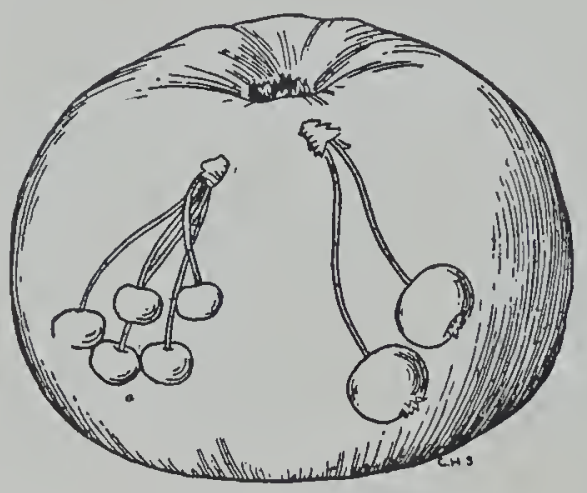

Fig. 42. - The Bismarck apple and its wild parents. gigantic oak of the forest producing its seeds or spores that the species may be continued.

Man has selected from among these wild plants those which are adapted to his use and has cultivated and improved them until it is often with difficulty that we recognize the wild type from which they came.

Nor has man been content with only those species which he has found growing in his own immediate country. He has - and this is especially true of the American through the work of the United States Department of Agriculture - searched the uttermost parts of the earth for new plants and seeds to be introduced into his own native land.

95. How Plants are propagated. - Plants are propagated in three ways: 


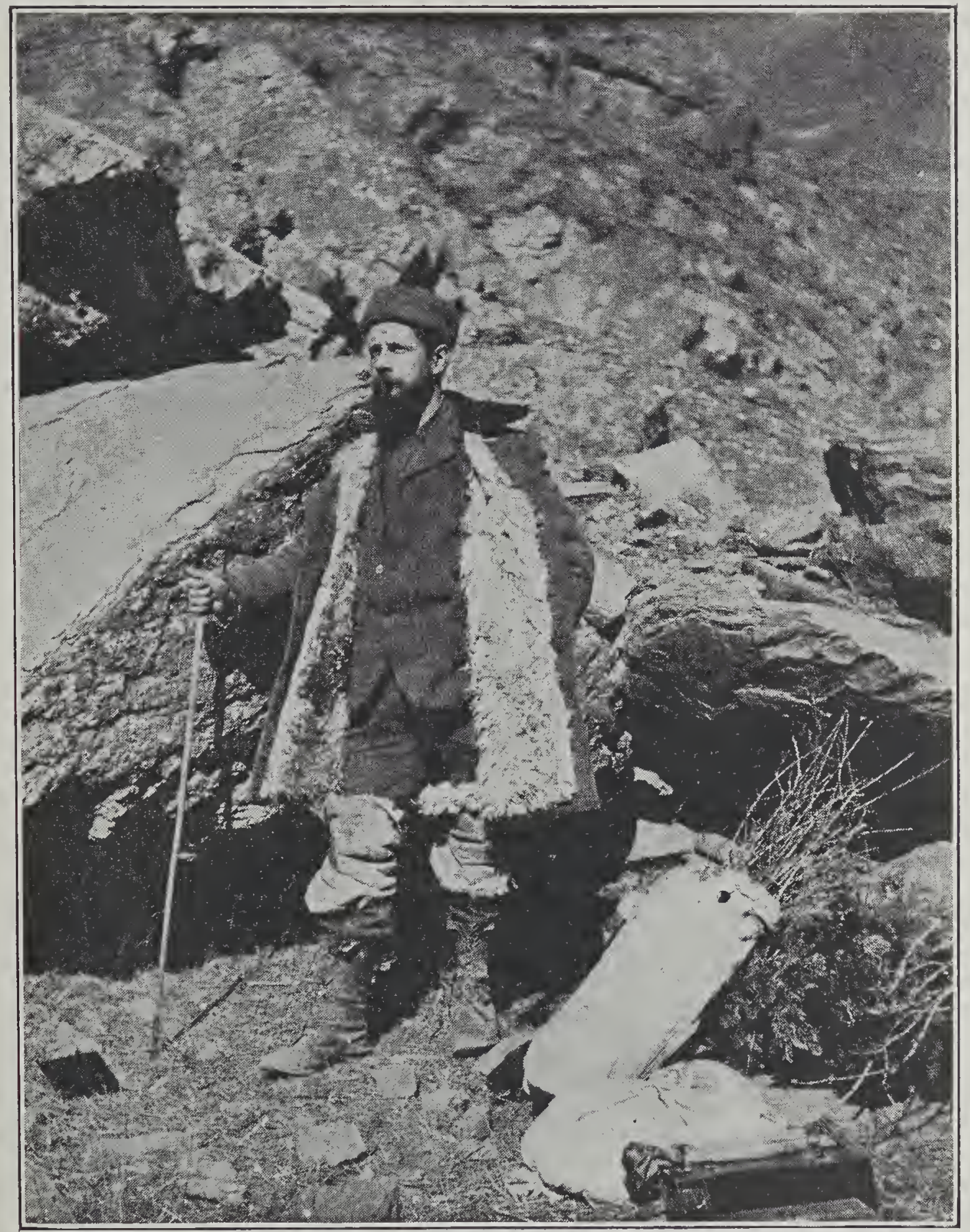

U. S. Dept. of Agriculture.

FIG. 43. - Mr. Frank N. Meyer, an agricultural explorer sent out by the United States Department of Agriculture, returning from a successful trip into the high mountains of China where he has secured new varieties of plants to be tried in the United States. 
First: by spores (minute bodies, which are borne by lower plants, such as the puff ball or the corn smut, and which correspond to the seed of the higher plants).

Second: by seed.

Third: by some part of the parent plant other than the seed or spore.

The beginning point of all plants is the seed or the spore. Every seed contains, as we have seen, a tiny plant, which under the proper conditions will unfold and expand, becoming more and more complex until it produces flowers and finally seeds like the one from which it grew.

It must not be understood, however, that all higher plants in their natural state are propagated entirely by seed. The wild strawberry produces runners; the wild plum, sprouts or suckers; and the snap willow loses many live branches which serve as cuttings. Many plants have wholly or partially lost their ability to produce seed, and depend upon bulbs, tubers, etc., to perpetuate the species.

A few of our cultivated plants, such as the seedless orange, produce no seed, while almost none of our fruits come true to seed. That is to say, the seed of a Jonathan apple will not produce a Jonathan tree, nor will a tree grown from a Bing cherry produce the same kind of cherries. Man must secure some part, as a leaf, a bud, a stem or a root of the original tree or vine, or one of these parts from a plant which came from the original. All the vines bearing Concord grapes have come in this way from a single vine still growing at Concord, Massachusetts.

96. Propagation by Spores. - The plants which are propagated by spores are of two classes:

(1) Those like the ferns, the mosses and the green pond scums, all of which contain green coloring matter and can 


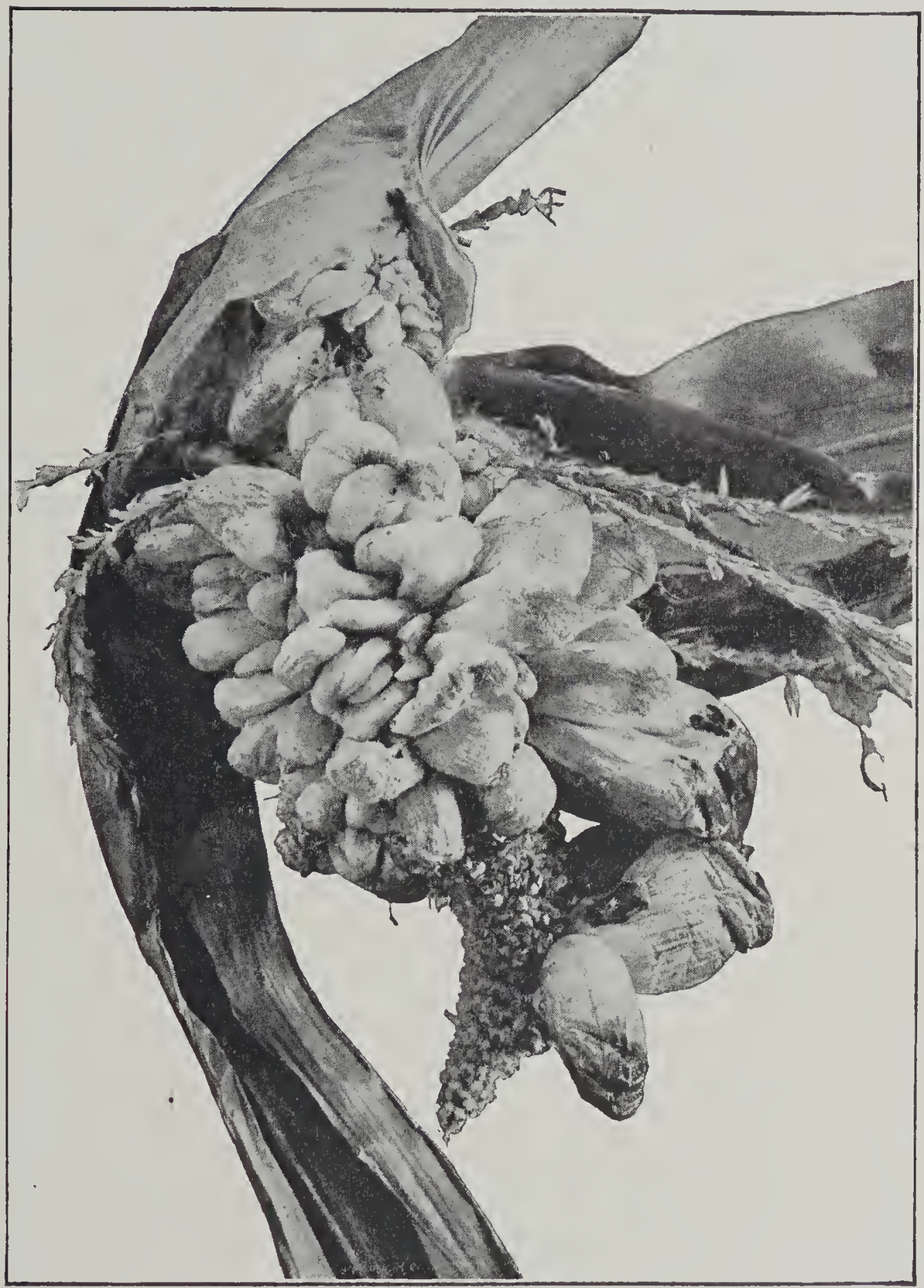

Fig. 44. - Smut on an ear of corn. 
therefore manufacture their own food. (Section 66 and Exercise 30.)

(2) Those like the corn smut, the cotton wilt, the wheat and oats rust, the potato scab, the apple blight, the mushroom and the toadstool. These contain no green coloring matter, can not manufacture their own food and must therefore draw their nourishment from living or dead plants of other kinds. In so doing, they often cause either diseases or decay.

We are familiar with the destructive effect of plant diseases and with the rotting of apples and potatoes. We must not on this account, however, condemn all plants of this second class. Many cause no injury, while a multitude of them are beneficial and absolutely essential to soil fertility and plant growth. The bodies of dead plants must be broken down into simpler substances. This necessary work is done by plants of this class, such as molds and bacteria. (Section 5.)

Place a piece of moist bread in any open, shallow dish and set it aside for a few days. The whole surface will become covered with common bread mold, a fuzzy growth of minute plants, which develop when the spores floating through the air fall and germinate upon the surface. With a common hand lens, we can see dotted through this growth the tiny round black bodies which bear the spores. If it were not for the foul smelling gases, coming from the decomposing proteins, which these plants set free, we could leave the bread in the dish until the simple substances which molds invariably produce would alone remain.

A striking illustration of the way in which the spores of these minute disease-producing plants may exist is shown in the common loose smut of oats. The smut spores are carried with the seed oats from infested fields. When the 
oats germinate in the soil the following spring, the spores germinate also and send slender, thread-like organs upward in the tissue of the oat stem as it develops. Thus we actually have one plant growing at the expense of and within the tissues of another. About the time the oat begins to flower, these thread-like organs push their way into the base of the flower. Here they take the nourishment which was intended for the seed (Section 92 and Exercise 24), prevent its development and develop instead a mass of loose, black spores. The loss to farmers of the United States in a single year, caused by this smut plant, has been over twenty million dollars. We shall consider shortly how to prevent the spread of this disease.

97. How Spores are spread. - As agricultural students, we are not particularly interested in the spores of plants like the fern and the moss, but the manner in which the spores of the disease-producing plants are spread is of vital interest to us. The different ways by which spores may be spread, or disseminated, may be grouped as follows :

First: on seeds, which are carried from place to place. Oat smut, stinking smut of wheat, potato blight, anthracnose of beans, and many other diseases are spread in this way.

Second: in the soil. The spores of the root rot of cotton, potato scab, root rot of the beet, and many others live through the winter and spread more or less through the soil.

Third: on dead leaves, stems, roots, weeds and grass. Many spores of the disease-producing plants pass their winter stages on this kind of material. When the warm weather of spring comes on, the spores develop, spread and attack growing plants.

Fourth : by diseased and fallen fruit. The old, withered plums, which hang on the trees all winter, harbor the 
spores of the brown rot of the plum. The apple scab is spread from diseased fruit and leaves.

Fifth: by insects. Insects, which come to attack the plants, often bring with them from other plants the spores of disease. The first step, then, in the control of such diseases is to destroy the insects.

98. How to prevent the Spread and Growth of the Spores of Disease. - (1) Spores on the Seed. - The first step in preventing propagation by spores clinging to seeds is seed selection. Since many diseases are spread in this way, a careful farmer tries to select clean seed from clean fields. It is of course impossible to examine each seed of the oats or wheat as might be done with potatoes. In this case, something must be applied which will kill the spores but not the seed. The methods used for the control of oat smut will illustrate this.

\section{EXERCISE 36}

Object. - To learn how to treat oats for loose smut.

Procedure. - Put a peck of oats in the bottom of a box. Make a solution of formalin in water by adding 5 cc. of 40 per cent formalin to 1600 cc. of water. This is in the proportion of one pint of formalin to forty gallons of water.

With the hands, sprinkle one quart of this solution over the oats in the box and stir them thoroughly with a fire shovel or stick so that every kernel will become moist. Now cover them with a gunny sack or otherwise so as to prevent the escape of the pungent gas which is given off by the formalin. After four or five hours, remove the cloth and spread the oats out on a floor, table or other surface until thoroughly dried. 
Conclusion. - State carefully in your notebook just how you treated this peck of oats to kill any spores of smut that might have been on the seed.

In actual farm practice, the oats are spread on a clean floor, a sprinkler is used, the solution is applied at the rate of about one gallon to each bushel, and the grain is then covered for several hours, after which it is quickly

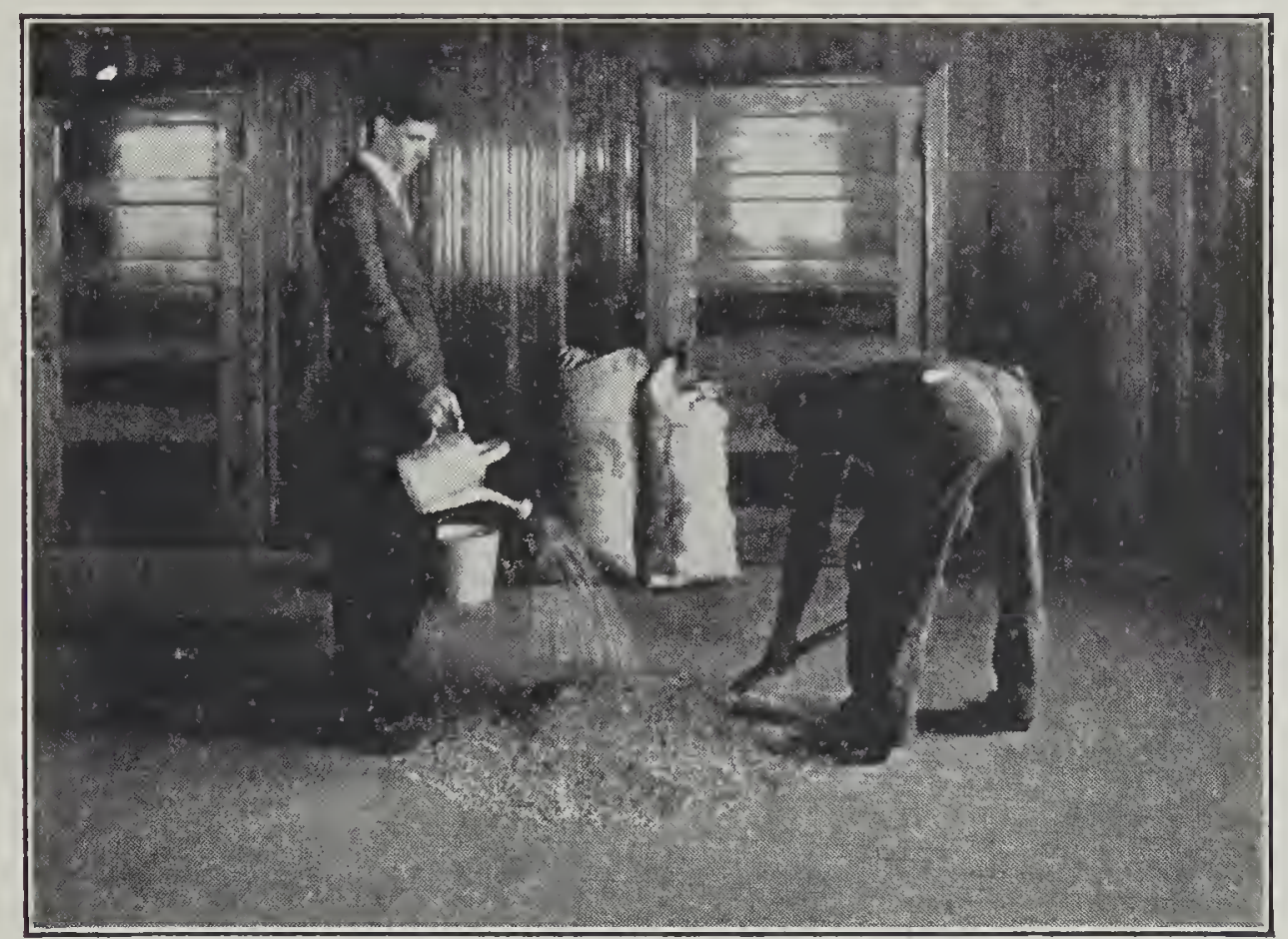

FIG. 45. - Treating seed oats for smut.

but carefully dried. If not sown at once, it must not be allowed to heat or freeze.

In 1906, eight per cent of the oat crop of the United States was destroyed by loose smut. At this rate what would have been the total reduction in bushels in the yield of a thirty-acre field, which produced forty-six bushels per acre, but the seed for which was not treated for smut? If the formalin to treat the seed had cost one dollar and the oat crop was worth thirty-five cents per bushel, 
how much would the owner have made by treating his seed?

The scab of potatoes may be controlled in a similar way by allowing the seed to remain for two hours in a solution of one pint of formalin in thirty gallons of water.

(2) Spores in the Soil. - Soil, which has become infested with the spores of such diseases as the potato scab or onion smut, should be planted to some other crop for several years until the ground becomes free from the spores of the disease. Crop rotation, then, becomes an important step in disease control as are also thorough drainage and deep cultivation.

(3) Spores on Dead Plants. - Most disease-producing plants have two kinds of spores: those which are able to withstand the severe cold of winter, called winter spores; and others which are produced during the warmer months and are called summer spores. These are formed much more rapidly than the winter spores but are more easily destroyed. Owing to the presence of winter spores, it is exceedingly important that all of the preceding year's plants in infested fields be destroyed before seeding time arrives. The dreaded black rust of wheat has been shown to live over the winter on old grass and weeds. Field sanitation, then, is an important matter.

(4) Spores on Diseased and Fallen Fruit. - The winter spores are not usually directly responsible for the rapid spread of disease on fruit. When a winter spore germinates, a tiny plant develops. This little plant in turn sends up a mass of summer spores, and from these summer spores come the plants which really produce disease.

There are certain chemical mixtures which will destroy both winter spores and summer spores when they begin to germinate without injury to the plants upon which 
they are lodged. The principal one of these mixtures, which is known as Bordeaux (pronounced bordo), is made as follows:

\section{EXERCISE 37}

Object. - To learn how to make Bordeaux mixture.

Procedure. - Dissolve four ounces of blue vitriol in a stone jar or wooden bucket - a tin one will be destroyed by the vitriol - containing three and one eighth gallons of water.

Place four ounces of fresh unslacked, or stone lime in another bucket or jar containing the same amount of water.

When the lime is thoroughly mixed with the water, pour the contents of both buckets or jars into a third jar or wooden bucket large enough to contain all of it.

You have now made the standard Bordeaux mixture at the rate of four pounds of lime and four pounds of blue vitriol to fifty gallons of water.

If you place a clean, bright knife blade in the blue vitriol solution before adding it to the lime mixture, a coating of copper will form over its surface. This should not occur in the Bordeaux mixture. If even a slight copper coating appears when the knife blade is placed in it, you should add more lime, as otherwise the mixture will "burn" the leaves of your potatoes or apple trees when it is applied.

Conclusion. - By applying this mixture when the buds of the apple are just showing pink, the destructive apple scab may be controlled.

If this mixture is applied to potatoes when they are about six inches high, and every two weeks thereafter, the dry rot, or late blight, will be held in check. In the year of 1905 , this disease caused a loss of fifty million dollars in the state of New York alone. 
The dreaded black rot of the grape can be controlled if Bordeaux mixture is applied when the buds are just swelling, again when they unfold, and two or three times after this at intervals of about two weeks.

The most effective means we have of preventing the

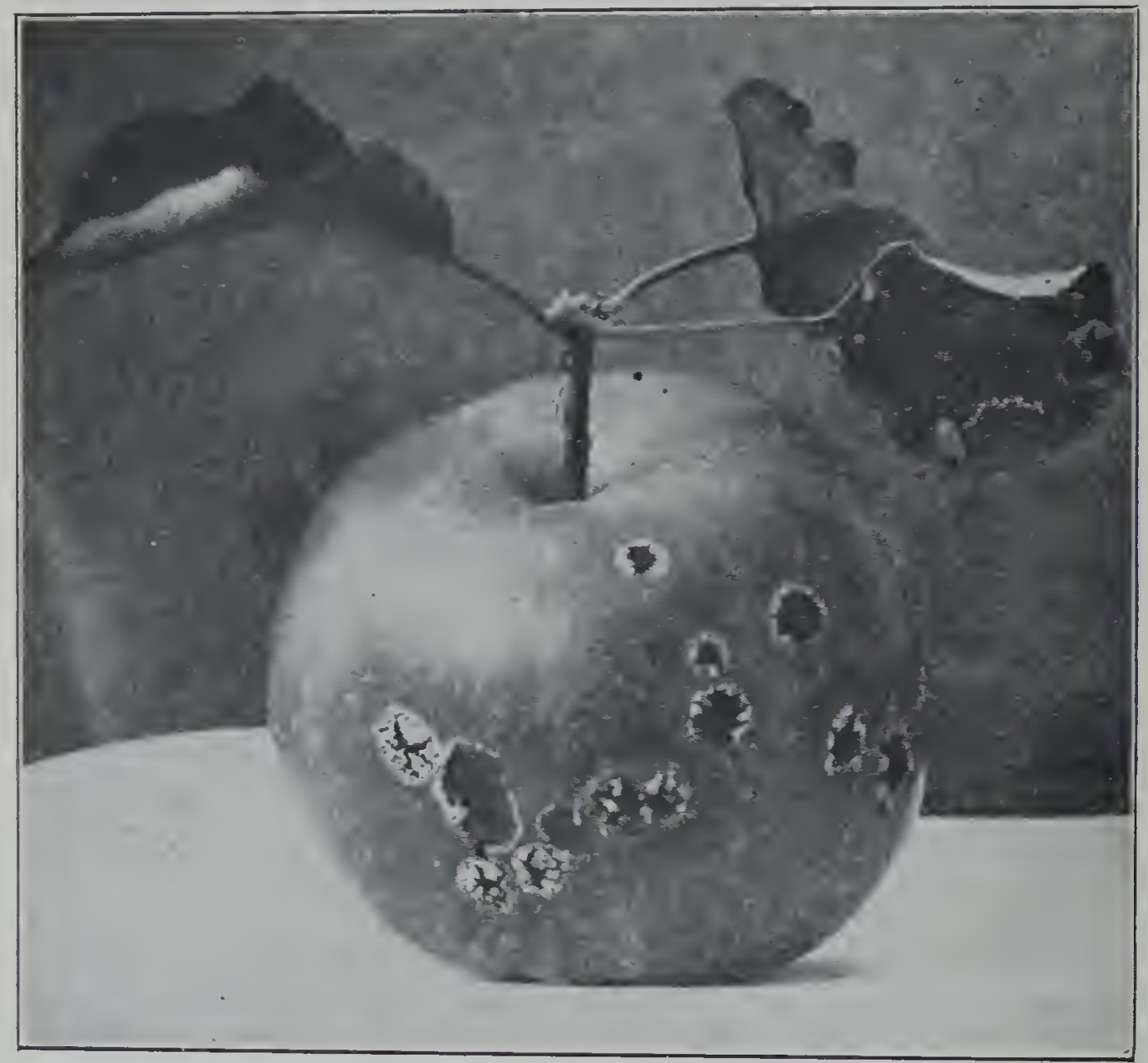

Frg. 46. - The apple scab.

germination and growth of spores is the Bordeaux mixture. It should not be applied during rainy weather; and for stone fruits, such as the cherry, peach and plum, it should be used in only half strength.

By the addition of three pounds of arsenate of lead to fifty gallons of Bordeaux mixture, both biting insects and diseases can be controlled. 
99. Conditions which favor the Entrance and Growth of Spores. - (1) Unhealthy Condition of the Plant which they attack. - Plants that are weakened by drouth or by the attacks of insects, or those that have become shaded by weeds are more liable to be destroyed by disease than others. The disease, in other words, makes the greatest progress when the plant is in an unhealthy condition.

(2) Moisture. - Moisture favors the growth of spores. In low, damp places, in dark, wet cellars, where fruit and vegetables are stored, the spores of disease and decay thrive. In Section 43 we learned that the greatest enemy of stored seeds is moisture. This is partly due to the fact that it favors the growth of molds which may eventually cause the death of the embryo.

(3) Darkness. - Direct sunlight will do much to prevent the propagation of spores. We therefore destroy weeds, leave sufficient space between our plants, and prune our trees to let in the sunlight.

(4) Heat. - Spores spread and grow best in warm places. This is why we put fruit and regetables in cool cellars, in cold storage or in the refrigerator.

(5) Careless Treatment. - By bruising or breaking the skin of fruit or vegetables, we may open the way for the entrance of spores, and decay will follow. Similarly, by careless pruning or cultivating, we may allow the spores of disease to gain entrance into living plants.

100. Propagation by Seed. - The higher plants are commonly propagated by seed. Howerer, this means of propagation will be considered in detail in the chapters on special crops. In Chapters VII and VIII, we have already learned essential facts concerning selection, storing and germination of seeds. 
101. Propagation by some Part of the Plant other than Seed or Spore. - The methods of propagation other than by seeds or spores may be placed in three groups:

(1) Plants may be formed while still attached to the parent plant. This may be by (a) runners, (b) tip layers, (c) layers, or $(d)$ suckers.

(2) Plants may be formed from portions detached from the parent plant. This includes propagation by $(a)$ bulbs, (b) tubers, and (c) cuttings.

(3) Plants may be formed by the union of two plants as by (a) budding and (b) grafting.

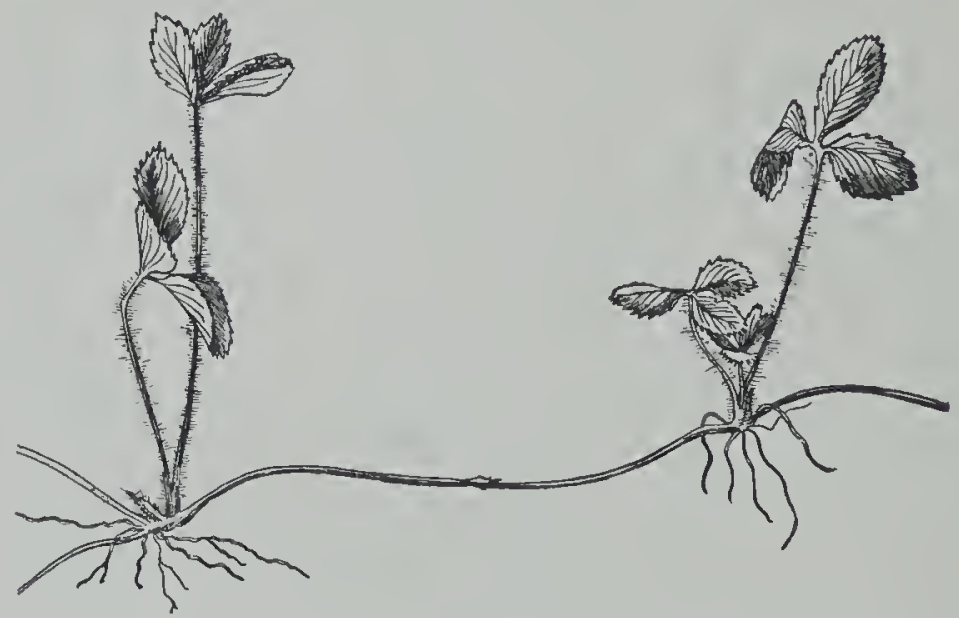

FIG. 47. - Runner on a strawberry plant.

102. Plants formed while still attached to the Parent Plant. - Such plants draw nourishment from the parent plant until they are able to maintain an independent growth. After this, the young plant is usually separated from the older one by the death of the part connecting the two, though this is not always true of suckers.' Some plants, such as the strawberry, send out long, prostrate stems from which, at either the ends or the nodes, roots develop and new plants form. Such a prostrate stem is called a runner. 
The stems of a few plants, such as the black-cap raspberry, tend to curve toward the ground. Roots will form at the tip if it is in close contact with the soil or

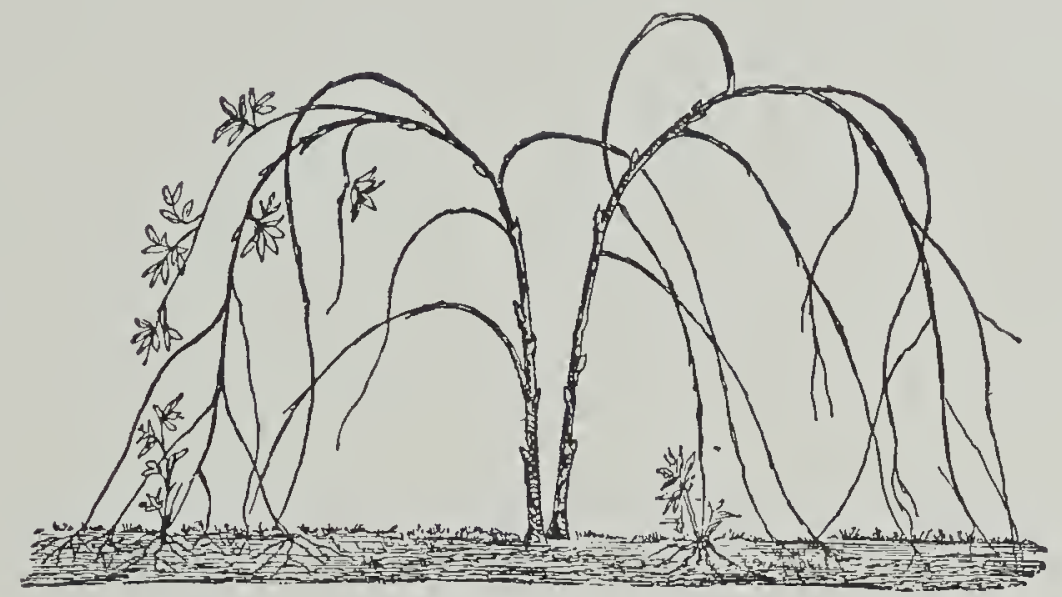

FIG. 48. - Propagating a plant by tip layers.

covered by it. The new plant thus formed is called a tip layer. If the ground is kept free from weeds and the soil loose and mellow, the formation of both runners and tip layers is favored.

Plants like the grape, the snowball and the rambler rose, whose stems do not naturally curve toward the ground, may be layered. This is done by bringing a stem carefully to the ground and holding it in place by covering it with earth. Roots then grow out from

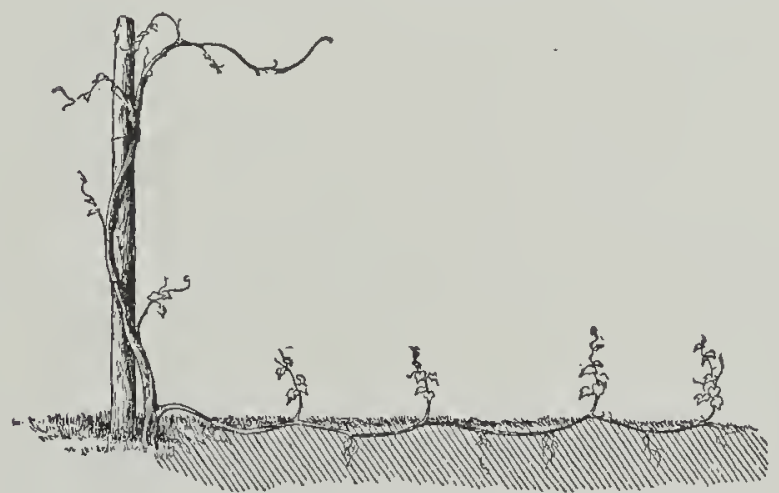

FIG. 49. - Propagating a plant by layers. the buried stem, and the new plant which forms at this point is called a layer.

The roots of many plants send up sprouts which are called suckers. Such plants do not develop good root 
systems, owing in part to their connection with the parent plants, and they show a tendency to produce new suckers. The red raspberry is propagated entirely by suckers.

103. Plants formed by Portions which become detached from Parent Plant. - Some plants which are accustomed to long periods of inactivity, for example, those in arid regions, or in wet countries subject to overflow, lose their power to produce seed and form bulbs instead. A bulb is in reality a very short underground stem, having leaves closely crowded about it, which are filled with nutriment to feed the young plant when it begins to grow.

\section{EXERCISE 38}

Object. - To learn how to care for bulbs and how plants are developed from them.

Procedure. - Secure from some seed house or local merchant a dozen or more of each of the following kinds of bulbs: paper white narcissus, tulip, Roman hyacinth and crocus; also procure a few bulbs of the Chinese sacred lily. Secure two boxes about two feet long, one foot wide and four inches deep.

Cover the bottom of one of the boxes with one inch of rich, fine soil. Over this put one half inch of fine sand. Press the bulbs of the Roman hyacinth slightly into the sand about two inches apart. Add more fine soil to the box until the bulbs are completely covered. Set it aside in some convenient part of the room where it does not get direct sunlight, and see that the soil does not dry out.

Place the bulbs of the narcissus in the other box in the same manner. Instead, however, of keeping the box in the room, place it outside in some cool, well-drained and 
shaded place and cover it with about six inches of soil and six inches of leaves.

Thoroughly spade up the soil in some protected corner of the school grounds to a depth of about twelve inches. Plant the tulips and crocuses in this bed about four inches deep. When cold weather sets in, cover the bed with two feet of leaves or hay.

All of the planting, both in boxes and beds, should be done by the first of October. In about six weeks bring the box of narcissus bulbs into the room, place it and the box of hyacinth bulbs in a warm, sunny window and watch the development of leaves and blossoms.

In the early spring, remove the leaves or hay from the bed of tulips and crocuses.

If desired, the bulbs of the Chinese sacred lily and some of those of the narcissus may be placed in glass dishes containing water and enough clean stones to hold the bulbs erect. The development of the roots may then be studied as well as that of stems, leaves and flowers.

Conclusion. - Only the roots developed while the bulbs were kept out of the sun by deep covering or otherwise. What started the development of the leaves and blossoms? Tell briefly how to have flowers from Thanksgiving until Easter.

Why may not this exercise be the beginning of an effort to make the school grounds more attractive and beautiful by a general plan of landscape gardening, which should include the planting of shade trees and hardy shrubs as well as bulbs?

Tubers. - A tuber is a short, thickened, underground stem. Buds form on these stems just as on any others though we ordinarily speak of these buds as "eyes." Such plants as the potato, dahlia and others are propa- 
gated by planting the tuber whole or by planting pieces of it. The young plant is developed from the bud, and, of course, if a piece should have no buds, or eyes, it will not grow.

Cuttings. - Such plants as the willow, poplar, grape

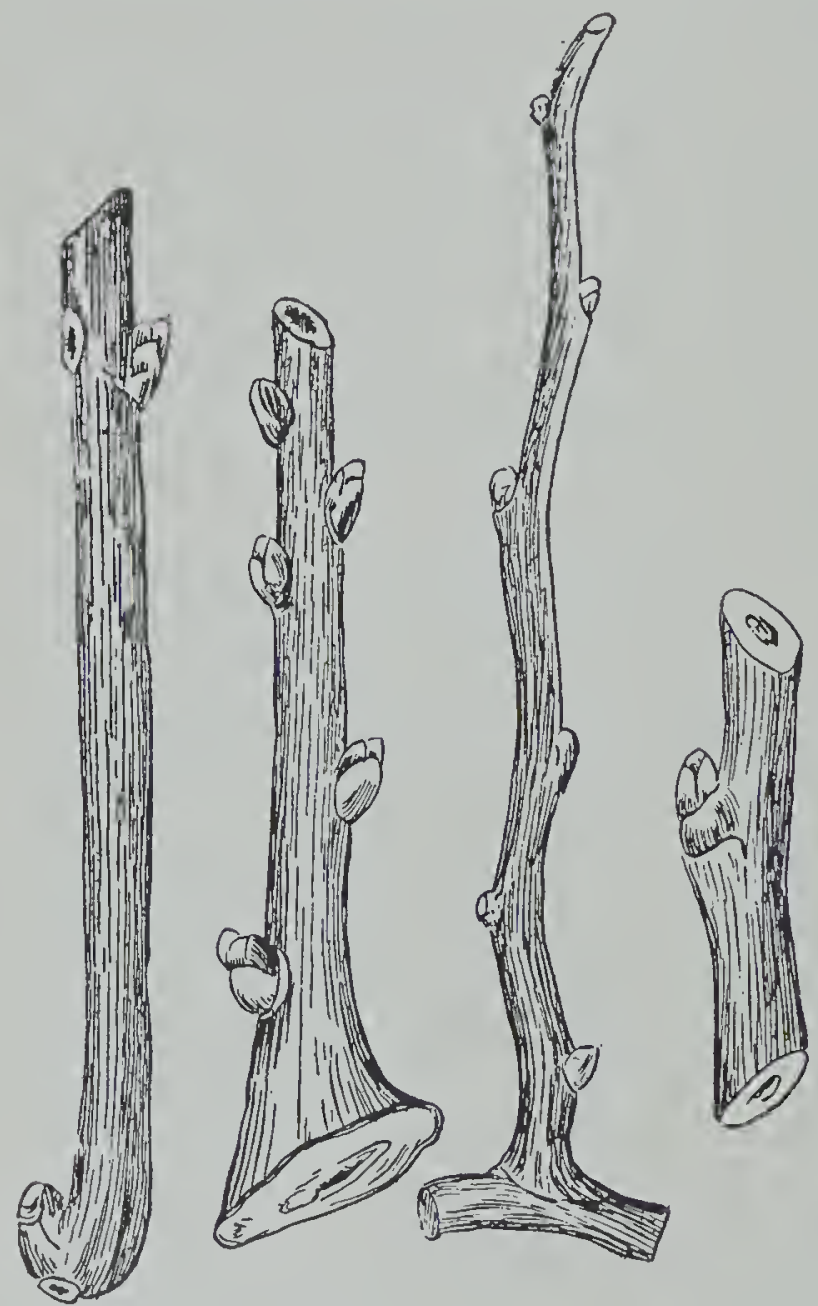

FIG. 50. - Cuttings of various kinds of wood. vine, spiræa and bridal wreath may be propagated in the following manner :

Secure in the late autumn some fresh, firm young twigs of the same season's growth. Cut them into pieces about six inches in length and store them in the ground as you did the tulip and crocus bulbs in the last exercise. In the spring, at garden planting time, set these cuttings out in rows, leaving only one or two buds above the surface of the ground.

104. Plants formed by the Union of Two Plants. None of our choice varieties of fruit come true to seed. This is a fact of vital consequence in fruit culture. We can not reproduce a desirable variety of fruit by planting the seed. Furthermore, not many of our fruit trees can 
be propagated by cuttings. Hence the necessity of the third method commonly practiced, - that of uniting two plants.

A bud or twig of the variety desired is united with a root grown from a seed, called a seedling root, so that the two grow together, forming a single plant. The upper part of the tree so formed will then bear the desired variety of fruit.

If a twig and root are caused to unite in this way, the process is known as grafting, the root being referred to as the stock while the twig is known as the cion. If a bud is inserted in the stem and allowed to develop until it becomes a part or all of the top, the process is known as budding.

\section{EXERCISE 39}

Object. - To learn how to propagate plants by grafting.

Procedure. - Procure from some nursery company as many apple seedling roots, or stocks, as you wish to make grafts. Gather some fresh, firm twigs of last season's growth from the apple tree you wish to propagate.

Provide strips of old muslin or calico, which has been dipped in a hot wax made as follows: Melt together in an old pan or other dish resin, 4 parts; beeswax, 2 parts; and tallow, 1 part. After the cloth has cooled, tear it into strips about one eighth of an inch wide and six inches or more in length.

The cion and stock to be joined together should be equal in diameter and small. The former should be cut back to a length of five or six inches if it is longer than this. Both should be cut off obliquely, the bevel, as well as the length of the cut, being the same on the two pieces. Each should now be split at a point near the middle, the split, 
however, extending but a short distance back from the bevel surface. When this is done, it will be found that the two pieces will fit together in the manner shown in Figure 51.

Care must be taken that the cambium layers (Section 81) of the two pieces coincide, as otherwise they will not grow together. If, however, the two pieces are of the same size, and if the bark of each joins the other perfectly, the cambium layers are quite certain to be in contact.
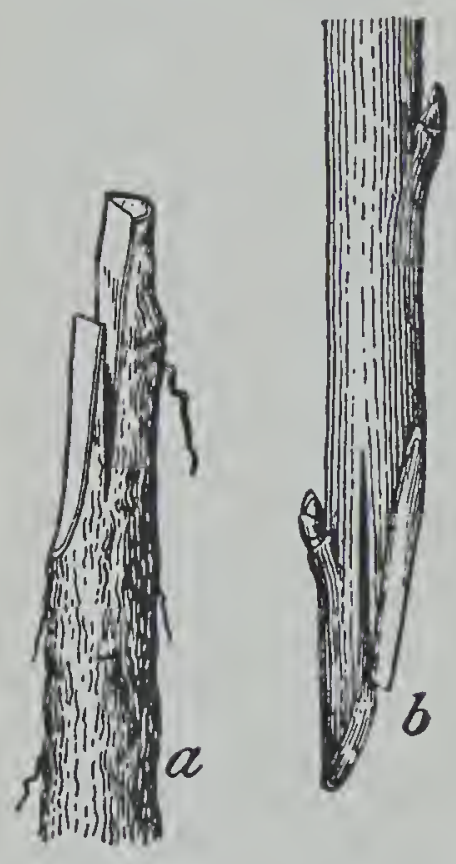

FIG. 51. - The whip graft.

About the joint, or splice, wrap enough of the waxed cloth to hold the two pieces firmly together.

'This work should be done in winter; and when it is finished, the grafted plants should be stored in sand outside the schoolroom and covered with about a foot of straw, hay or leaves. In the spring at garden planting time they should be removed and set in the open ground.

Conclusion. - This graft is called the whip graft. Tell in your notebook just how it is made or make a drawing to illustrate it.

It must not be understood from the above that all roots and twigs will unite regardless of kind, or species. Only members of the same family will unite, and these will not 
always do so. Among the stone fruits, the plum will unite with the peach, or either of these will unite with the apricot. Among the fruits which form seeds, as the apple, the quince will unite with the pear. The apple will unite with crabapple and with the different varieties of large apples, but it is only in very rare cases that it will unite with any other plant than these.

Grafting may be done on mature trees as well as on young ones but we use a different graft. This will be shown in the next exercise.

\section{EXERCISE 40}

Object. - To show how the character of a grown tree may be changed, or how several varieties of fruit may be grown on the same tree.

Procedure. - Secure a smooth, straight piece of the limb of an apple tree about the size of a broom stick and from eight to ten inches in length; some twigs from bearing apple trees, such as were used in Exercise 39 ; and a ball of the wax used in that exercise. Before this wax is handled, the hands should be rubbed with tallow to prevent the wax from sticking to them.

Split the end of the limb down about one and one half inches, using a piece of wood as a mallet and a knife blade as a chisel. Cut two of the twigs to a length of about six inches and wedge-shaped at the larger end. Thrust one of these sharpened twigs into either side of the cleft in the larger piece, making sure that the outside of the limb and the outside of the twig are flush, or even. Cover the wound and exposed parts with wax so that neither water nor fungi can enter and cause rot.

Conclusion. - Describe in your own words just how this graft is made, or make a drawing that will show it clearly. 
Small twigs can be grafted upon the larger limbs of trees in this way, and the twigs and branches will unite, the joint becoming quite smooth. In fact, this graft is often used on mature trees to grow a different variety or perhaps several varieties of fruit upon the same tree. This work should be done in the spring just as

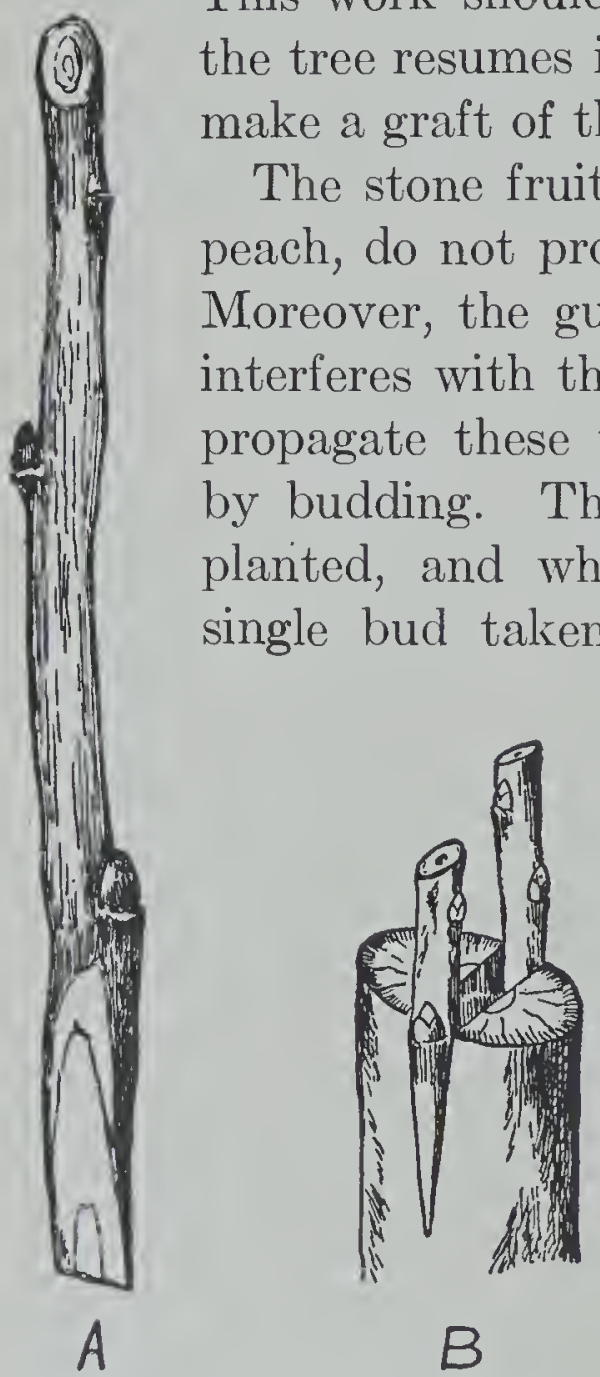

FIG. 52. - The cleft graft.

\section{EXERCISE 41}

Object. - To learn how plants are propagated by budding.

Procedure. - Procure some fresh twigs of an apple or peach tree, a sharp pocket knife and some common wrapping cord. Place the twigs in water for twenty-four hours in order to make the bark slip easily. If this work is done in the spring, soon after the leaves have expanded, the twigs may be used as soon as gathered. Cut the cord into pieces . from eight to ten inches in length. 
Take one of the twigs, and with your knife make a cut through the bark on one side directly across the grain of the wood. Next make a cut through the bark downward from the center of the one already made so that the two will form a letter $\mathrm{T}$.

Remove a plump bud with a little of the bark from another twig and insert it in the first twig where the cuts
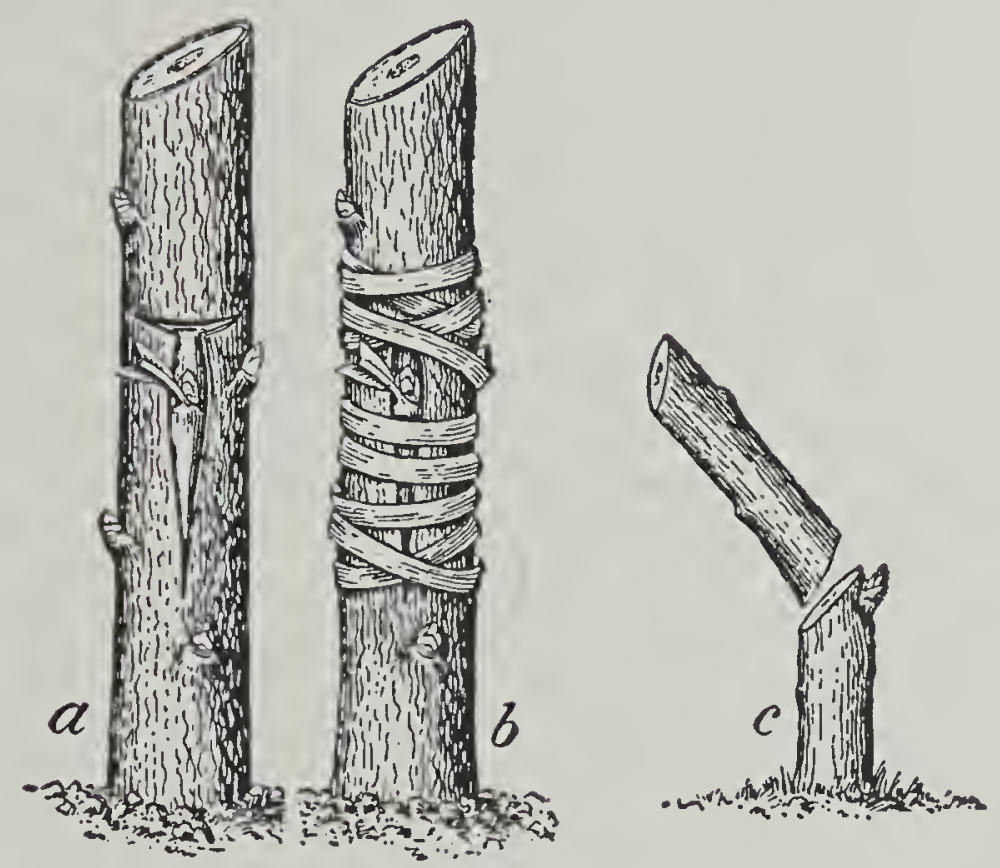

FIG. 53. - How the bud is inserted. The top is removed after the wound has healed.

have been made. In doing this, lift the bark of the twig on both sides of the downward cut, and thrust the little piece of bark to which the bud is attached underneath, leaving no part of the bark exposed. Now press the bark of the twig firmly down over the inserted bud by wrapping the twig with string above and below, but not directly across the bud.

If the leaves have expanded, this exercise may be performed out of doors upon trees of plum, peach, apple, or any shade or forest trees. 
Conclusion. - Briefly, this is the story of a "budded" peach tree, - and all peach orchards consist of budded trees:

A peach pit or seed was planted and allowed to grow one season. Near the close of the growing season, perhaps in the latter part of August, a bud from a tree bearing the desired variety of peaches was inserted in the trunk of the seedling near the surface of the ground just as you have inserted the bud in the twig above. During the following ten days or two weeks, the little bud grew rapidly. The string was then removed. Nothing further was done until the following spring, when the top of the seedling was removed and the inserted bud became a twig, and finally, a new top. This was allowed to grow where it stood for another year and was then transplanted to the orchard.

Suppose you had a plum tree of a choice variety and wished to propagate it in order that you might have a number of trees of the same kind. Tell in your notebook exactly how you would do it.

\section{QUESTIONS}

1. Define the term propagation.

2. Name three ways by which plants are propagated.

3. How do plants, which contain no green coloring matter, obtain their food? What do they cause?

4. Name five ways by which spores that cause disease are spread.

5. Tell how to treat seed oats for smut.

6. Name five conditions which favor the entrance and growth of spores.

7. Tell briefly how to secure flowers from bulbs from Thanksgiving until Easter.

8. Tell briefly how to propagate apple trees, using the whip graft.

9. Tell the story of a peach tree from the time the seed is planted until the tree is set in the orchard. 


\section{CHAPTER XV}

\section{WHY MAN CULTIVATES PLANTS}

THERE are about two hundred thousand known species of plants in the world. When we compare this vast number with the few that man has chosen to cultivate, we are led to ask: Why are these few useful to him, and what part or parts of them are deemed so desirable that he is willing to labor diligently and patiently often for months or even for years in order to secure them?

105. Classes of Plants according to the Parts for which they are cultivated. - We may classify plants roughly according to the portions from which the useful parts come. Most of those that are cultivated by man may be grouped under five heads as shown in the outline below :

I. Plants cultivated for their Grains which furnish Food for Man and Domestic Animals. — These plants include:

(1) Corn.

(This crop will be studied in Chapter XVI.)

(2) Wheat.

(3) Oats.

(4) Barley.

(5) Rye.

(6) Rice.

(These crops will be studied in Chapter XVII.)

II. Plants grown for Forage and Pasture for Domestic Animals, the Useful Part coming from the Stems and 
Leaves. - Some of these plants are also used for lawns. They include :

(1) Grasses.
(a) Wild Grasses.
(b) Timothy.
(c) Redtop.
(d) Brome Grass.
(e) Blue Grass.

(These will be studied in Chapter XVIII.)

(2) Clovers, or Legumes.
(a) Alfalfa.
(b) Red Clover.
(c) Alsike Clover.
(d) White Clover.
(e) Sweet Clover.
$(f)$ Field Peas.
(g) Cow Peas.
(h) Soy Beans.

(These will be studied in Chapter XIX.)

III. Plants cultivated for the Fiber, which is found either in the Stems or in the form of Lint on the Seeds. These plants may also yield food and oil. They include:
(1) Cotton.
(2) Flax.
(3) Hemp.

(These plants will be studied in Chapter XX.)

IV. Plants cultivated for their Fruits. - These plants include :

(1) Seed, or Pome Fruits.
(a) Apples.
(b) Pears.
(c) Quinces. 
(2) Stone, or Prune Fruits.
(a) Cherries.
(b) Peaches.
(c) Plums.
(d) Prunes.
(e) Apricots.

(3) Grapes.

(4) Small Fruits.

(a) Strawberries.

(b) Raspberries.

(c) Blackberries and Dewberries.

(d) Currants.

(e) Gooseberries.

(5) Citrus Fruits.

(a) Oranges.

(b) Lemons.

(c) Grapefruit.

(We shall study these fruits in Chapter XXI.)

$V$. Plants known as Vegetables, which are cultivated for their Leaves, Seeds, Fruits and Underground Parts. -

(1) For the Leaves.
(a) Lettuce.
(b) Cabbage.
(c) Spinach.
(d) Celery.

(2) For the Seeds.

(a) Peas.

(b) Beans.

(c) Corn (Sweet).

(3) For their Fruits.

(a) Tomatoes.

(b) Melons.

(c) Pumpkins and Squashes.

(d) Cucumbers. 
(4) For the Underground Parts.
(a) Potatoes.
(b) Sweet Potatoes.
(c) Onions.
(d) Carrots.
(e) Beets.
(f) Turnips.
(g) Parsnips.
(h) Radishes.

(These plants will be studied briefly in Chapter XXII.) 


\section{CHAPTER XVI}

\section{CORN}

THe leading cereal crop of the United States is Indian corn. It was cultivated in a rude way by the Indians long before the white man dreamed of such a country as America. The earliest settlers recognized its value and at once commenced to raise it. Forests have been cut down to make room for fields of it; and swamps and lowlands have been drained that its production might be increased. If the corn fields of the United States were placed together, they would cover entirely the states of Maine, New Hampshire, Vermont, Massachusetts, Rhode Island, Connecticut, New York, Pennsylvania, New Jersey, Delaware and Maryland, with many large fields remaining.

106. Uses of Corn. - Corn is used in four rather distinct ways :

(1) As a grain ration for domestic animals.

(2). As fodder, or roughage, for domestic animals.

(3) As food for man.

(4) In manufactured products.

As the grain, with which to fatten the animals that constitute our meat supply, corn stands practically alone.

If the corn plants, both stalks and ears, are cut while the leaves are still green and the kernels are just becoming hard, they make an excellent rough forage for domestic animals. 


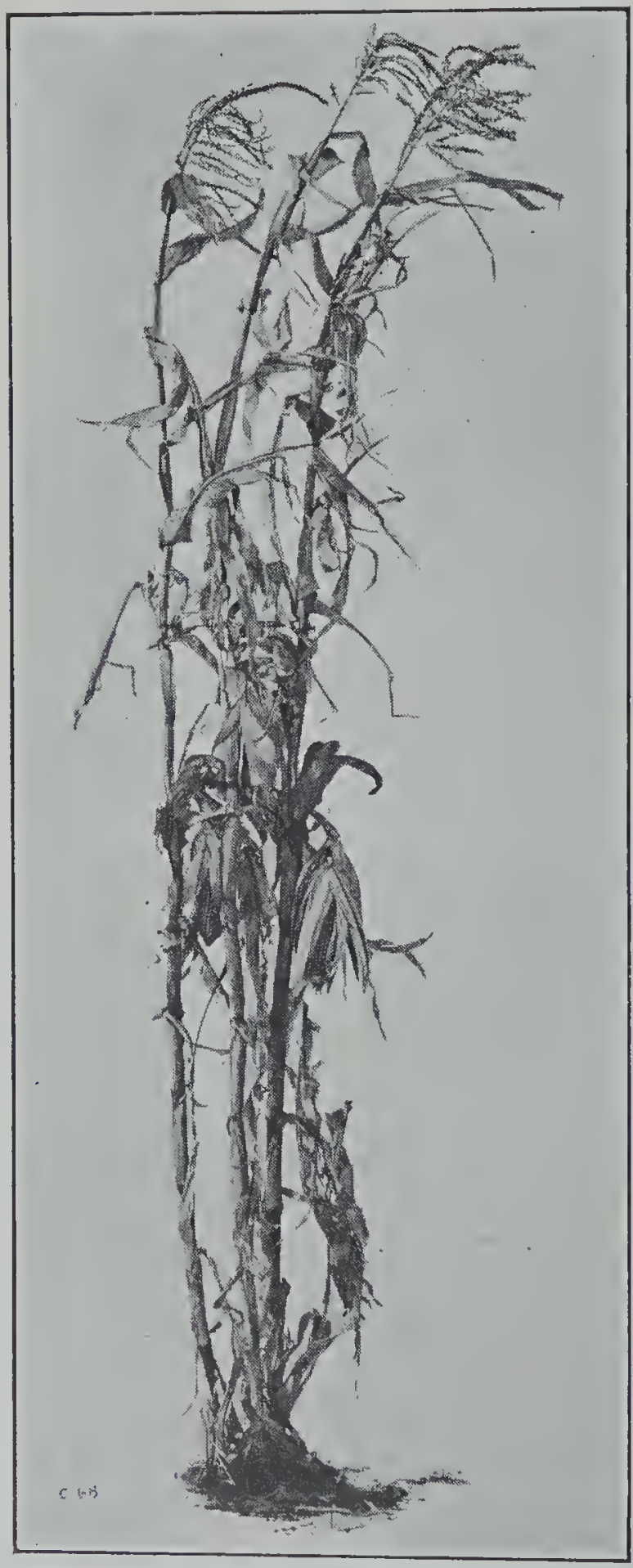

Fig. 54. - An ideal hill of corn.

Corn is used in a variety of forms for human food, as corn meal, hominy, breakfast foods, canned corn, roasting ears, etc.

The number of manufactured products made from corn is increasing year by year. Among them are glucose, corn sirup, corn starch, oil, gum, rubber substitutes and alcoholic products.

\section{Distribution} of Corn. - Corn is a native of Mexico. When we study its habits and requirements carefully, we shall see that it still retains many of its subtropical characteristics although the plant has pushed its way steadily northward even into Canada.

Corn is grown throughout the southern states. It is succeeding in New England. Minnesota and North 
Dakota are producing surprising yields. The cultivation of the crop is extending into the western states where it was formerly thought that the corn plant would not thrive. "It may be in fact that the time will come when we shall quit talking about a corn belt as though corn were something that could be

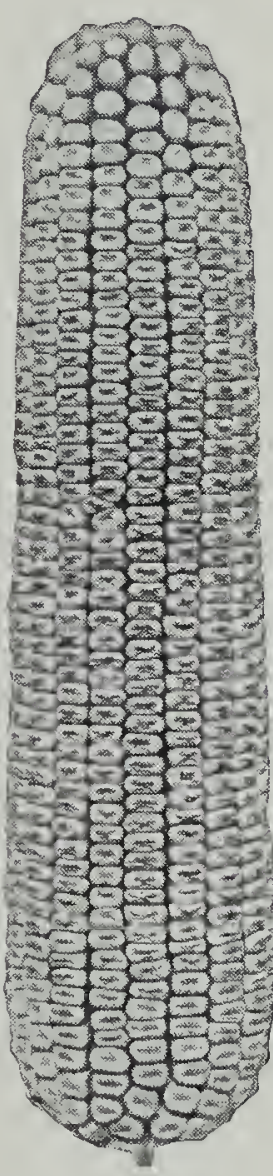

Fig. 55. An ear of dent corn. grown only in a limited section from east to west, and that corn will be grown in every section where farming is possible." 1

The corn belt, just referred to, includes the states or parts of states where the production of corn is now largely centralized; viz., Ohio, Indiana, Illinois, Iowa, southern Minnesota, the eastern parts of South Dakota, Nebraska and Kansas, and the northern part of Missouri.

\section{How the Corn Plant} has changed as it has moved Northward. - In the South, if the soil conditions are favorable, the stalks are tall

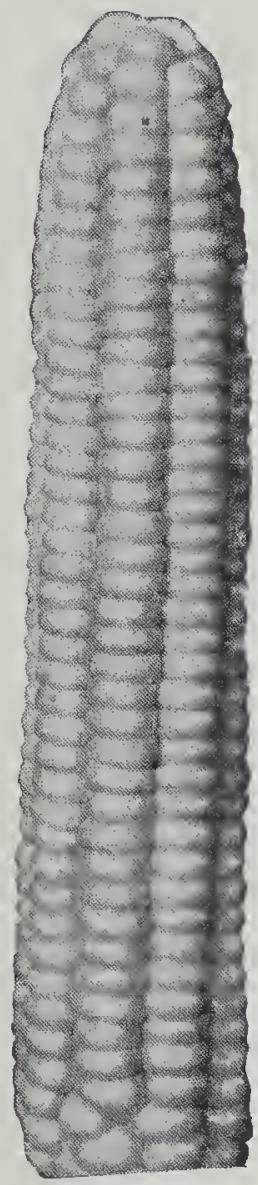

Fig. 56. An ear of flint corn. and massive, the ears are

large, and the kernels are large and deep with much white starch, while the dent on the crown of each one may be so deep that its sides become pinched together. As we go northward, we find the stalks becoming smaller and less

${ }^{1}$ Wallace's Farmer, January 21, 1915. 
woody, and the ears likewise smaller, while the kernels are shorter, more flinty and less deeply dented, until at last we encounter the characteristic flint corn of the northern regions.

Notwithstanding the fact that the corn plant has adapted itself in a truly marvelous way to grow in a wide range of climate, it is still extremely sensitive to even slight changes in climatic conditions. Thus we frequently find that if the seed is sent or taken to a distance no greater than forty or fifty miles from the locality where it was grown, it will not produce at all well for a year or two, or until it has had time to adapt itself to the new climatic conditions. Corn growers are for this reason extremely cautious about procuring seed from other localities than their own. We may truthfully say that there is not only a corn for each climate but for every locality as well.

109. Climatic Requirements of the Corn Plant. - Certain climatic conditions are necessary to the best growth of corn wherever it is cultivated.

The soil must be warm when the seed is planted and it should remain warm thereafter. While the growing season may vary in length, the average temperature of both day and night must be high.

While the seed is germinating, and the plants are yet small, much wet weather is detrimental. It makes the ground cold, excludes oxygen, and the stand may be poor owing to the rotting of the seed. If the seeds germinate under this condition, the little plants form shallow root systems and so become unable to make a vigorous growth or to withstand dry weather. Wet weather, moreover, interferes with cultivation and allows weeds to become established.

The months of July and August represent the critical 
period in the life of the corn plant as regards weather conditions. The rapidity of growth at this time as compared with that of other plants is amazing; and because of this,

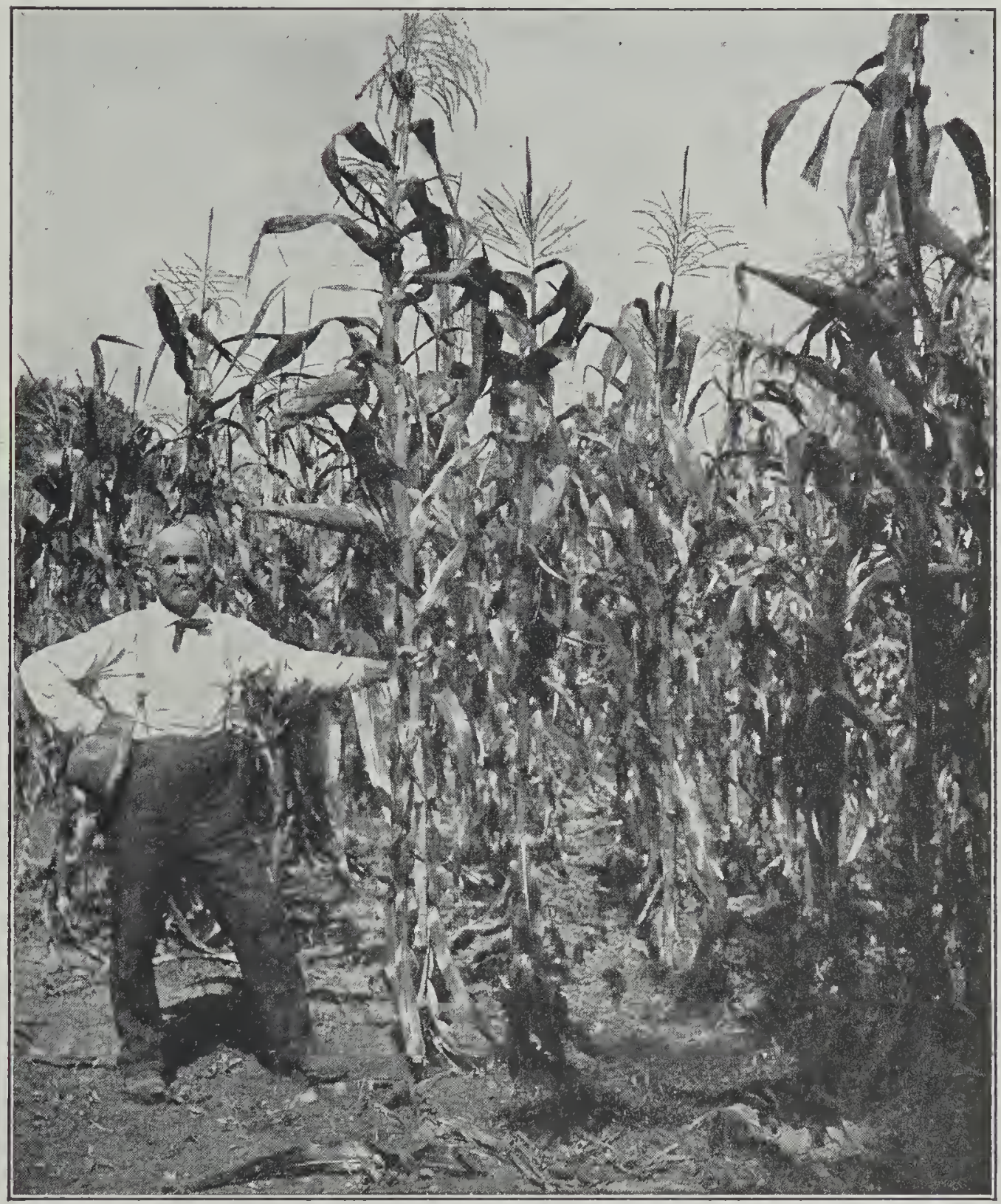

FIG. 57. - Cornfield scene.

it needs very much water. Frequent warm rains at this time are exceedingly important in determining the yield of the crop. 
As the ears become well developed, the supply of moisture should diminish. This, too, is a matter of importance since continued rains after this time prolong the season of growth. In wet seasons, therefore, the crop is frequently injured by early autumn frosts.

110. Soil Requirements of the Corn Plant. - Corn requires a fertile, well-drained soil, containing a large amount of humus. Owing to its vigorous growth, it demands large amounts of the essential elements mentioned in Section 7. Nitrogen, in particular, is rapidly removed by it from the soil. Unless some means of renewing the supply of nitrogen is provided, the yields of the succeeding crops gradually decrease. In fact, we may say that the rainfall of July and August and the supply of nitrogen in the soil are the two factors which commonly influence the production of the corn crop throughout the Corn Belt.

111. The Production of Corn. - The production of corn may be studied under eight important heads :

(1) Selection of the Seed.

(2) Storage of the Seed.

(3) Testing the Seed.

(4) Grading the Seed.

(5) Preparing the Seed Bed.

(6) Planting the Seed.

(7) Cultivation of the Crop.

(8) Harvesting the Crop.

112. Selection of the Seed. - In Chapter VII, and particularly in Exercise 18, we learned some of the important points to look for in an ear of corn and in the stalk which bore it. We must now take up a more critical study of the ear which we wish to use for seed. 
We shall doubtless be surprised that there are so many ways in which ears of corn may differ, and that so many points must be considered in the selection of those that are to be used as seed.

In general, the selection of seed corn is a process of elimination, or casting out of the unfit; and we may reject an ear either because of some condition indicating impaired vitality or because it shows one or more characteristics which we deem undesirable and do not wish to perpetuate. In the selection of seed corn, then, we generally consider:

First: the soundness and maturity of the ear.

Second: the characteristics of the ear as a whole.

Third: the characteristics of the kernels.

The three exercises which follow, if carefully performed, will make clear the points for which one should look when seeking a seed ear of corn.

\section{EXERCISE 42}

Object. - To learn how to recognize immaturity and unsoundness in an ear of corn.

Procedure. - Select from any crib or field eight ears of corn as directed below. Do not break any ear, nor remove more kernels than necessary in order to determine with certainty its condition.

(1) An ear whose kernels are mouldy at the cob.

Mouldy kernels usually indicate dead germs or embryos. Such an ear is, of course, of no value as a seed ear. (Section 99.)

(2) An ear whose kernels are so loose on the cob as to rattle when the ball of the thumb is drawn lightly along the row.

This condition is called chaffiness, and is due to immaturity. Kernels from such ears may sprout, but they will produce weak seedlings. 
(3) An ear too heavy for its size and easily twisted, owing to the presence of excessive moisture.

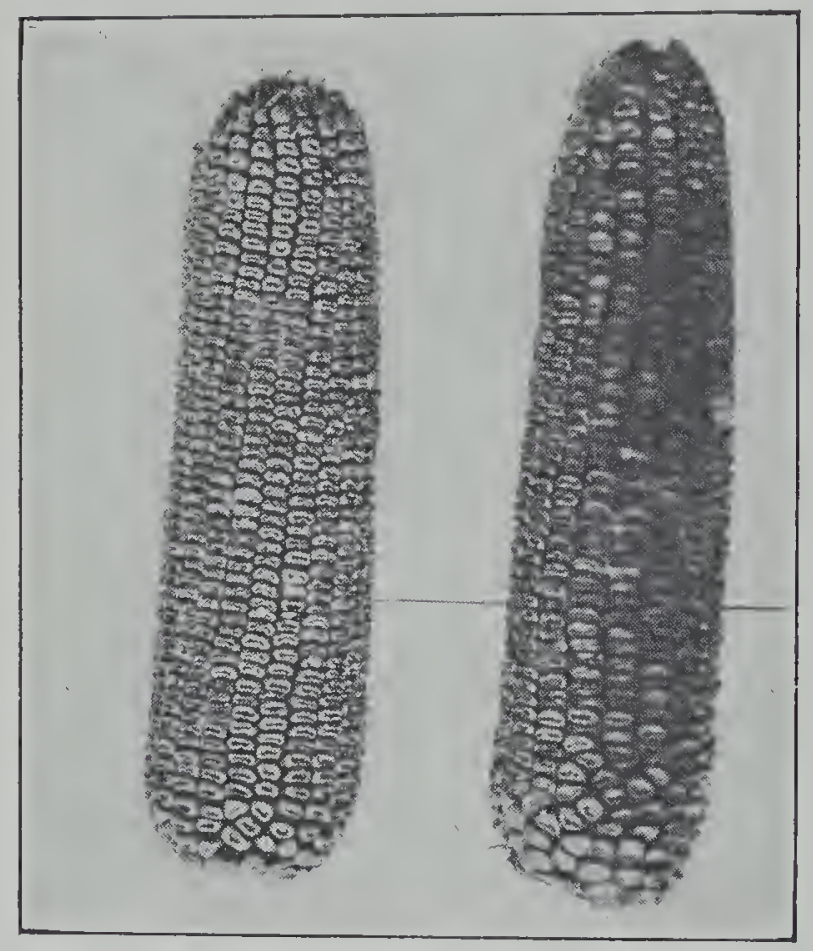

FIG. 58. - Mouldy corn.

This is called sappiness. When such seed is stored, we know what an enemy this moisture will become. (Sections 35 and 43.)

(4) An ear showing blistered germs.

This again indicates immaturity and makes its vitality questionable.

(5) An ear showing discolored germs, varying from yellow to black, when the seedcoat is opened with a knife blade.

Such discoloration is an indication of a weakened or dead germ.

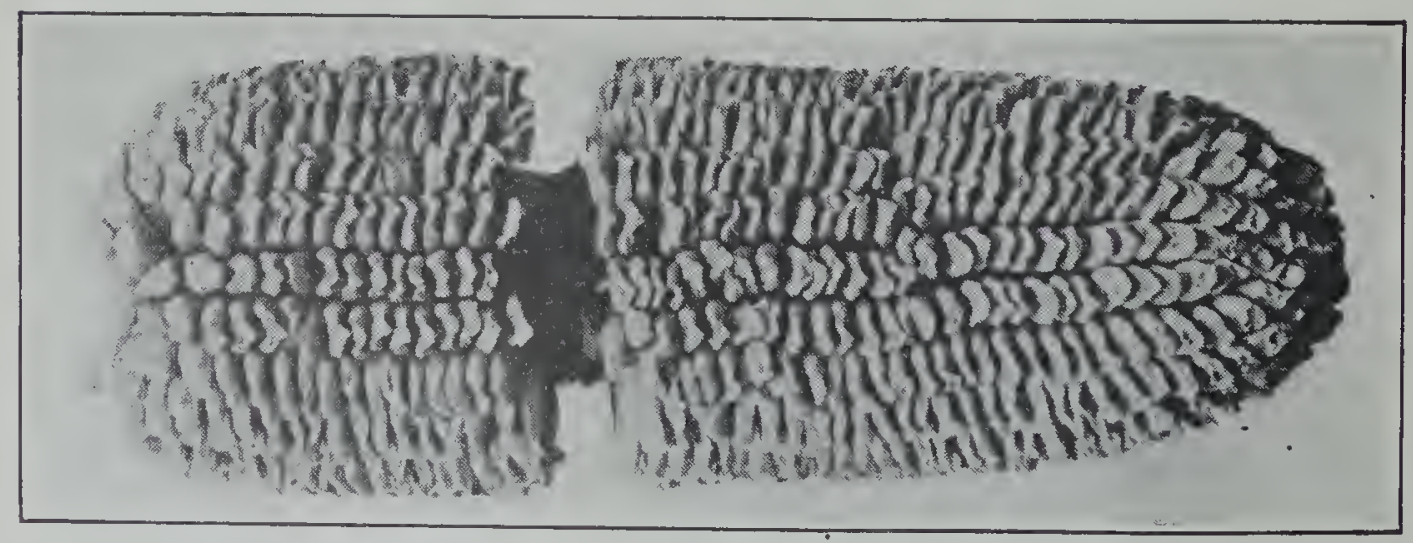

FIG. 59. - A chaffy ear.

(6) An ear showing either at the crowns of its kernels or down their backs a white color in patches. 
This is called starchiness and usually, though not always, indicates immaturity. A small amount of starchiness is allowable at times, but much is to be avoided.

(7) An ear whose kernels are blistered elsewhere than on their germs.

This again is a sign of immaturity even more serious than blistered germs.

(8) An ear which is firm and dry, and which shows none of those indications of

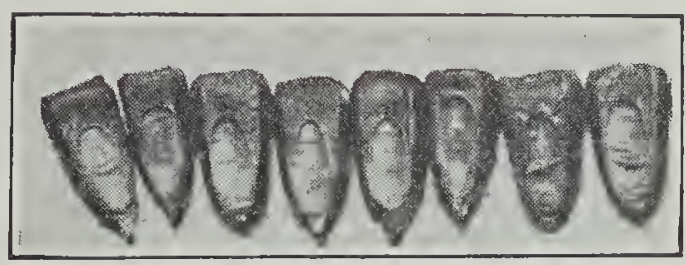

FIG. 60. - Kernels with blistered germs. immaturity or unsoundness named in the preceding paragraphs.

Such an ear may be regarded as sound and mature.

Conclusion. - Write in your notebook the points which you have studied in connection with immaturity and unsoundness, and tell precisely what each condition indicates.

\section{EXERCISE 43}

Object. - To learn to recognize the desirable and undesirable characteristics of an ear of corn which we wish to use for seed.

Procedure. - Select and bring to the schoolroom thirteen ears of corn, each of which is sound and mature and shows vitality. No ear may be considered in this exercise or for seed purposes at any time which shows any evidence of low vitality.

In addition to the foregoing, each of these ears must show either a desirable or an undesirable characteristic as required below. Those which illustrate desirable characteristics are given first and in italics. Note carefully the reasons given for the desirability or the undesirability of the respective ears. 


\section{Stze of EAR}

(1) An ear between eight and ten inches in length. Its circumference should be about three fourths of its length, the measurement being

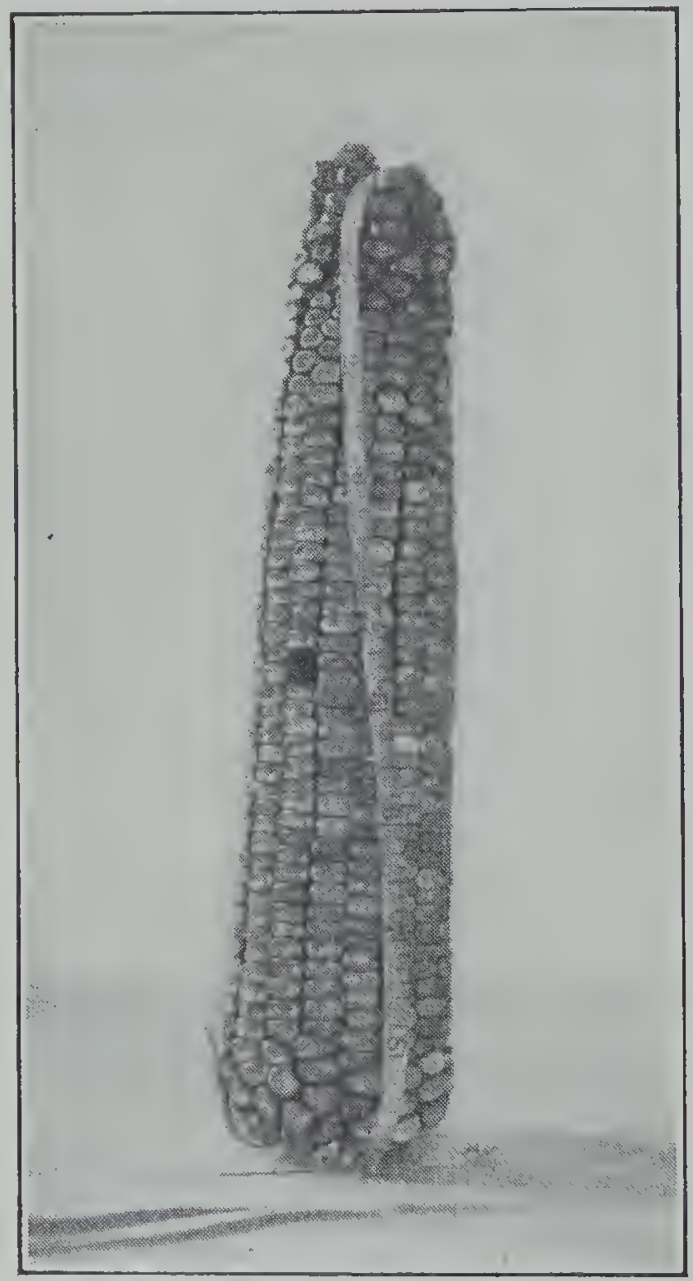

Fig. 61. - An ear of desirable size. taken one third of the distance from butt to tip.

(1) An ear more than eleven inches long and another less than seven.

The best corn breeders and growers do not now try to raise large ears of coln as has been commonly done in the past. It has been found that the size of ear which can safely be raised in any locality depends very largely upon the length of the growing season. The longer the growing season, the more time the plant has to manufacture food, and the larger the ear will probably be. Therefore ears in the South are of greater average size than those in the North, provided both are raised under like soil conditions. In Iowa and Illinois, the two leading corn states, the dimensions given first above are considered to be about right. It is clear, however, that in states farther south the standard of size should be somewhat greater. 


\section{SHAPE OF EAR}

(2) An ear nearly cylindrical, but very slightly tapering, and having straight rows from butt to tip. This ear must be full in the middle and of the desirable size given in (1).

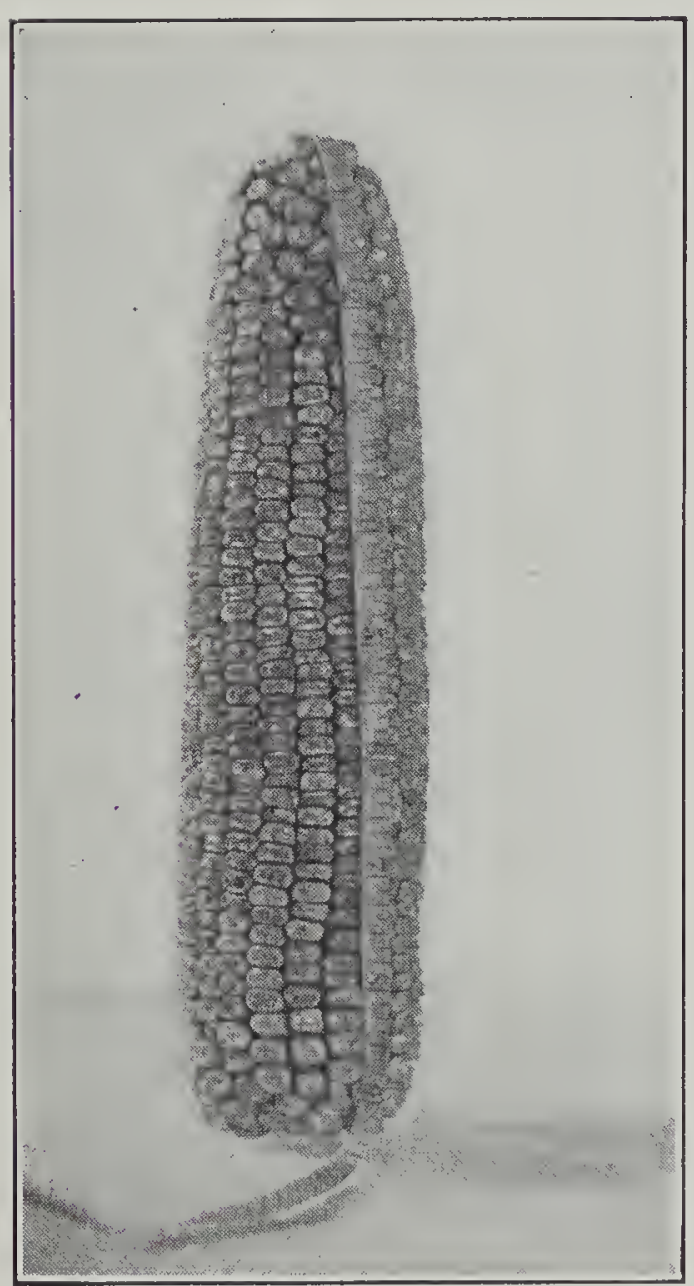

Fig. 62. - An ear of desirable size and shape.

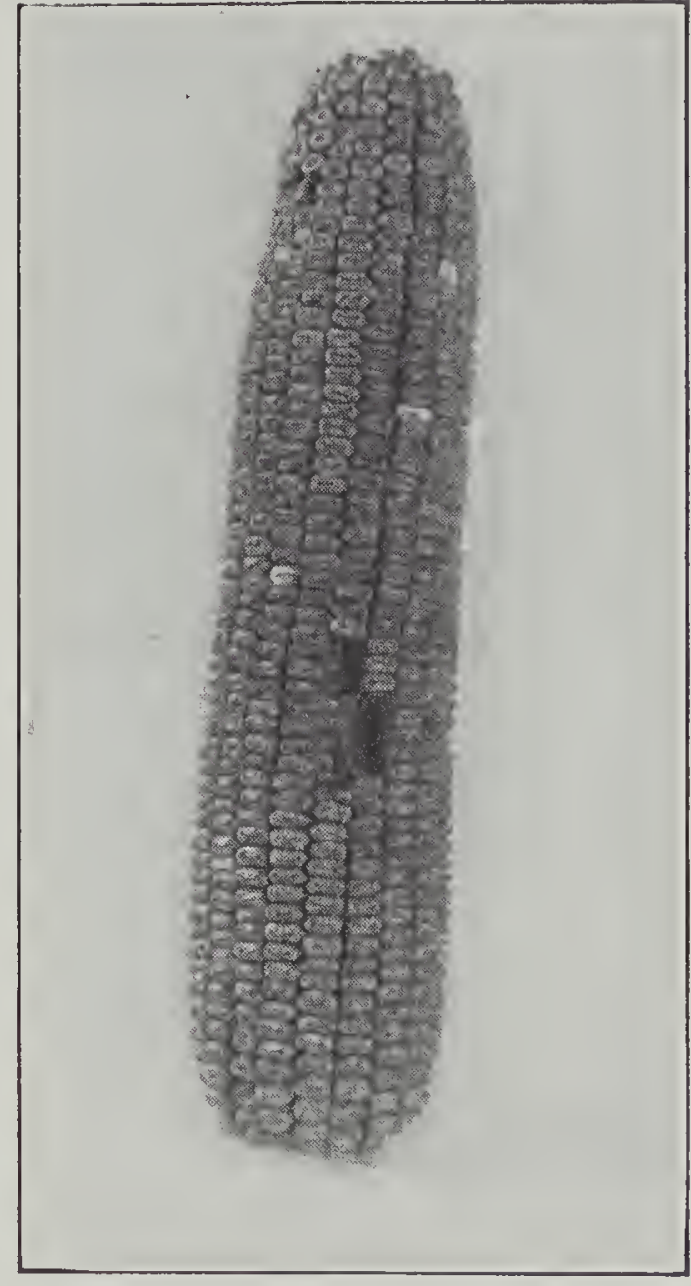

Fig. 63. - An ear of desirable size and shape, having a desirable butt.

(2) An ear in the form of a cylinder about two thirds of its length, then sharply tapering; another sharply tapering from butt to tip; and still another with extremely crooked rows.

The kernels are more uniform in both size and shape in the nearly cylindrical ear, and also in those ears whose 
rows are straight than in other ears. This is important for the reason that uniform kernels drop evenly from the planter, thus insuring a uniform stand.

\section{THE BUTT}

(3) An ear whose butt is covered with kernels of nearly the same shape and size as those of the body of the ear.

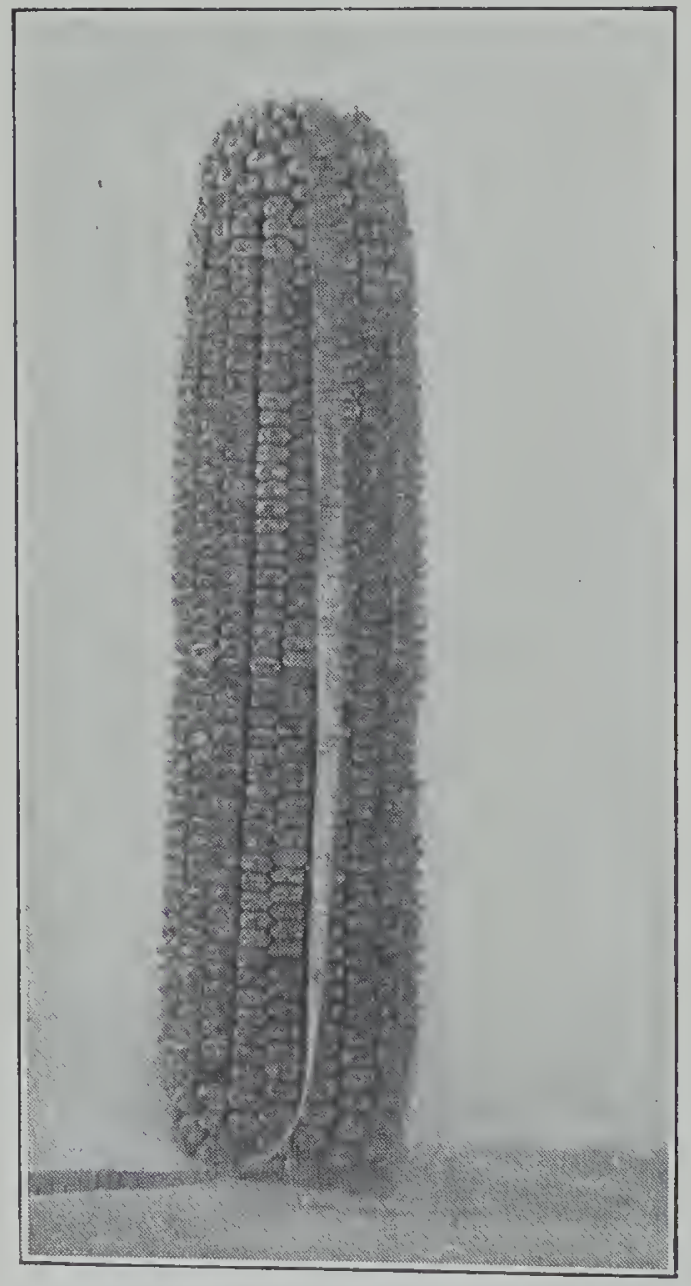

Frg. 64. - An ear of desirable size and shape, having a desirable butt and tip.

less waste space between the kernels both because of the greater uniformity of kernels in size and shape and because of their close arrangement about the shank. uniformly arranged and fit closely about the shank.

This ear should be of the desirable size given in (1) and of the desirable shape given in (2), since it represents simply another step toward the ideal ear which we hope at last to find.

(3) An ear whose butt is covered with irregular or "blocky" kernels which do not fit closely about the shank.

A butt of the desirable kind described in (3) insures greater uniformity in the size and shape of the kernels of the ear, the importance of which has already been stated. Moreover, in a butt of this description there is

These kernels should be (n) 
This in turn increases the proportion of corn to cob, the shelling percentage.

\section{THE TIP}

(4) An ear whose tip is completely covered, or whose cob is only slightly exposed between the kernels. Most of the

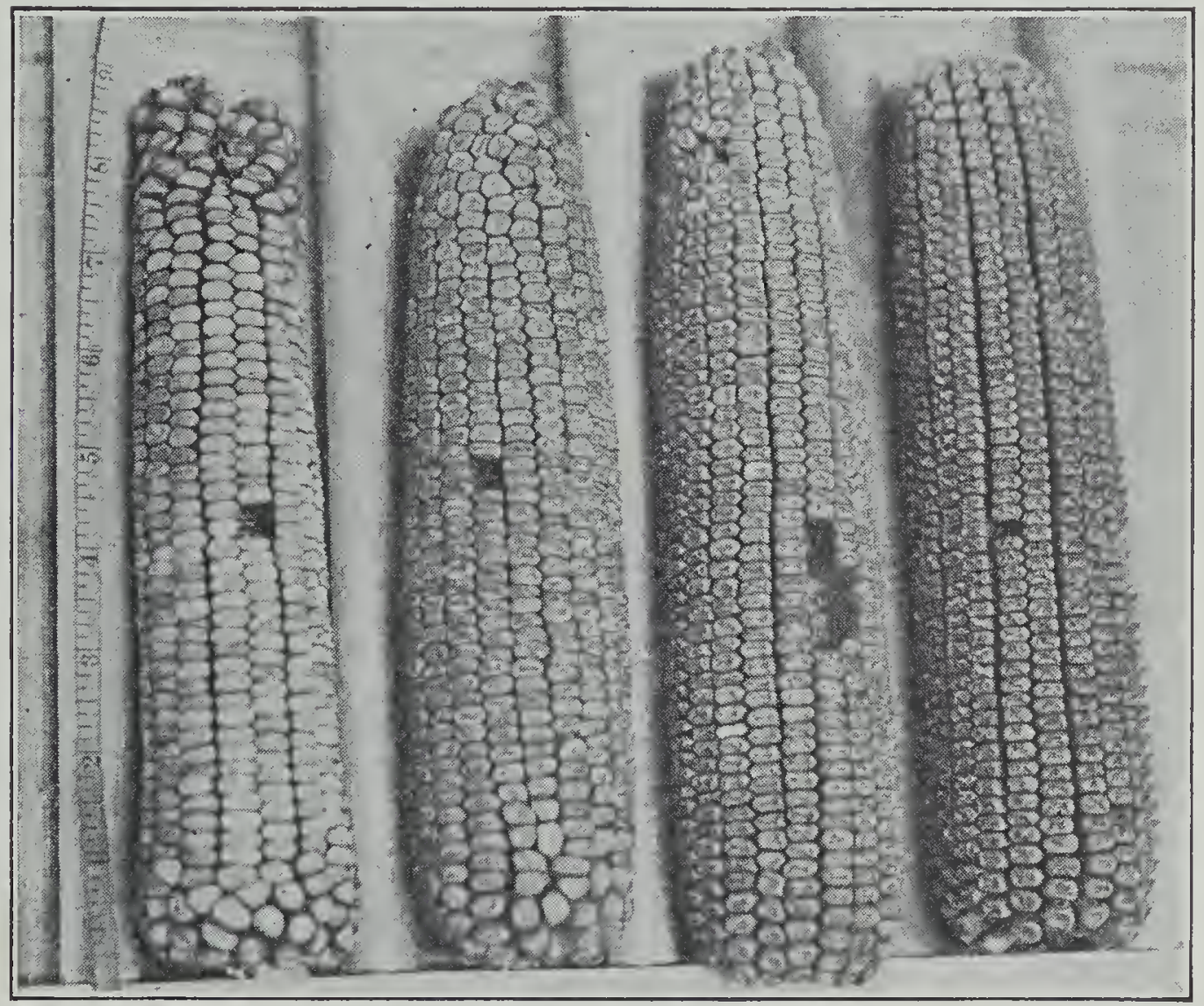

FIG. 65. - Improving step by step.

kernels about the tip should be dented and rather deep. This ear should be of the desirable size given in (1), the desirable shape given in (2), and it should have as nearly as possible the desirable butt given in (3).

(4) An ear whose cob is exposed for half an inch or more at the tip, and surrounded by round or shot-shaped kernels. 
The desirable tip insures greater uniformity in size and shape of kernels and also a higher shelling percentage.

\section{DEPRESSIONS IN THE ROWS}

(5) An ear whose rows show no depressions throughout their length. This ear should be of the desirable size and shape given in (1) and (2), and it should have as nearly as possible the desirable butt and tip described in (3) and (4).

(5) An ear whose rows show numerous depressions. Depressions in rows are another cause of non-uniformity in size and shape of kernels, which we are seeking to avoid.

Conclusion. - State carefully in your notebook the points that are regarded as desirable in an ear of seed corn and give reasons. Name the undesirable characteristics.

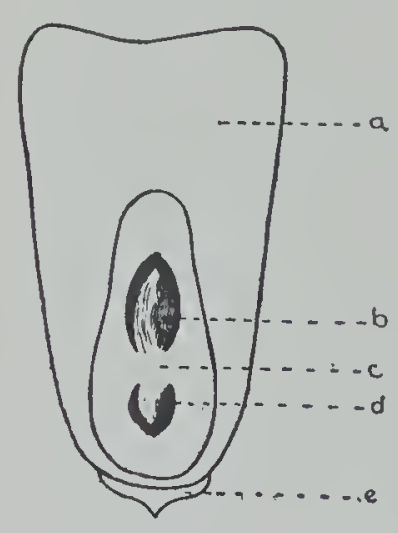

Fig. 66. - The parts of a corn kernel.

$a$, the endosperm; $b$, the plumule; $c$, the germ; $d$, the hypocotyl, also called the radicle; $e$, the tip cap.

\section{EXERCISE 44}

Object. - To learn to recognize the desirable and undesirable characteristics of the kernels of a seed ear.

Procedure.- Select ten ears of corn whose kernels show the desirable and undesirable characteristics named below. Again the desirable characters are in italics.

Since the kernels must be examined carefully, it is necessary to remove two or three from each ear about midway between the butt and tip. After this, keep each ear, together with the kernels which came from it, separate from the other samples. 
(1) An ear most of whose kernels are keystone-shaped; that is, slightly wider at the crown than at the base. They should be of only medium depth and average about six to the inch in the row. This ear, as well as all others required in this exercise, must be sound and mature and show vitality; and if pos-

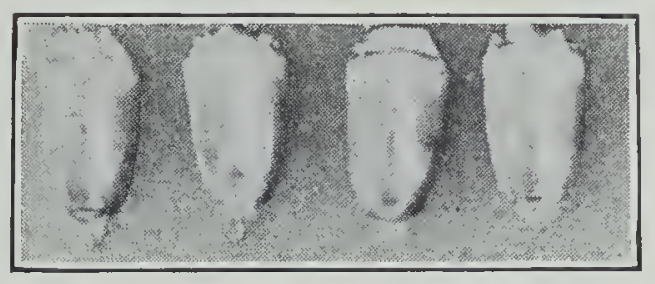

Fig. 67. - Kernels of keystone shape. sible, or as nearly as possible, it should possess all the desirable characteristics brought out in Exercise 43.

(1) An ear whose kernels are very shallow and nearly square, that is, practically as wide at the base as at the crown; also one whose kernels are sharp and pointed; another, whose kernels are very deep but about equally wide at base and crown ; and still another with "shoepeg"

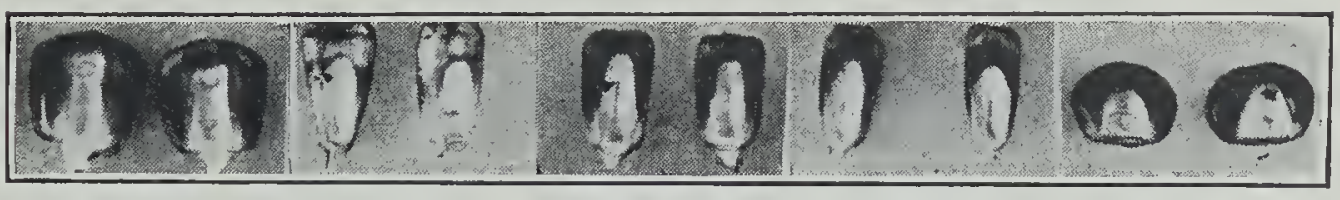

Square.

Pointed.

Rectangular.

Shoepeg.

Round.

Fig. 68. - Kernels of undesirable shapes.

kernels, that is, kernels which are unusually narrow and very deep.

As will be seen by the illustrations, kernels of keystone shape fit one against the other without unnecessary loss of space between them or between the rows at either top or bottom. This means that the shelling percentage is high.

The depth of the kernel, like the size of the ear, depends as a rule upon the length of the growing season. The shorter the growing season, the shallower the kernels. 
In Missouri, for instance, it is safe to grow a type of corn with a deep kernel, while one of only medium depth can be safely grown in Minnesota.

Very shallow and nearly square kernels mean a low shelling percentage. If square blocks, for example, are placed around a circle, their tops are slightly pulled apart. Square kernels about a round cob will be separated at the top in the same way, causing a loss of space between the rows. Moreover, since the kernels themselves are shallow, the proportion of kernel to cob is still further reduced.

If the kernels are sharp and pointed, there will be waste space at the base both between the rows and between the kernels in the row. If the kernels are very deep and equally wide at base and crown, (1) they are liable to be starchy, owing to immaturity, which in turn is due to the long growing season required; also (2) there is waste space between the rows at the crown, just as in the case of square kernels.

When the kernels are "shoepeg" in shape, there is again a loss of space between the rows and a poor development of germs. Moreover, because of their depth, there is a strong tendency to starchiness due to immaturity.

\section{SIZE OF GERM}

(2) An ear whose kernels have germs which are large and thick. This ear should have if possible, or so far as possible, all desirable characters given up to this time.

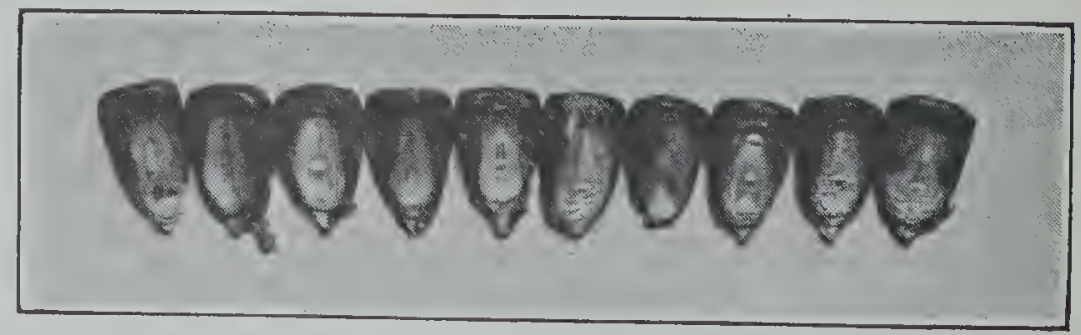

FIG. 69. - Kernels with large germs. 
(2) An ear whose germs are unusually small.

Large germs are considered desirable, owing to the fact that they are rich in oil and protein and therefore high in feeding value.

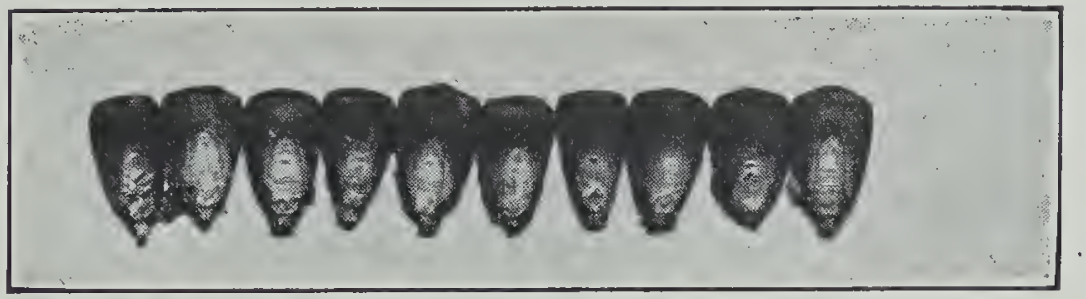

FIG. 70. - Kernels with small germs.

PURITY OF KERNELS

(3) An ear having no mixed kernels. This ear should have as nearly as possible all the desirable characters hitherto studied. If the ear which was used in (2) of this exercise has no mixed kernels, it may be used here.

(3) A yellow ear, having one or more mixed kernels; also a white ear, having one or more mixed kernels.

A mixed kernel on a yellow ear is known by the fact that its upper half shows the pure white of ordinary white corn. On. the other hand, a mixed kernel on a white ear is known

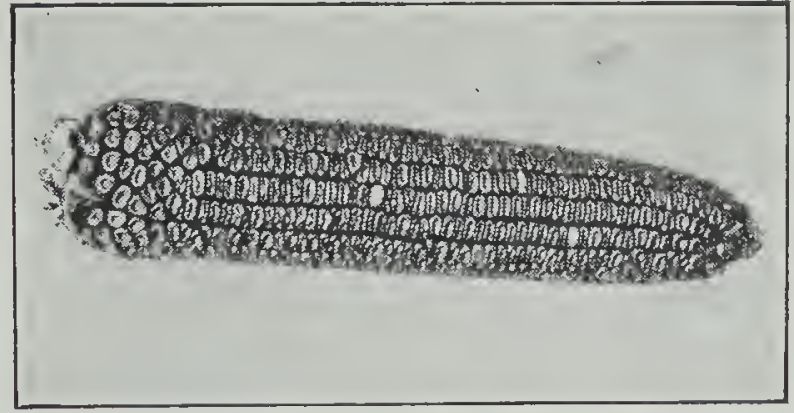

Fig. 71. - An ear showing mixed kernels. by the fact that its lower half shows the yellow of ordinary yellow corn. By looking closely, this last may be seen between the rows of a white ear if mixed kernels are present.

Mixed kernels show that pollen from another variety of corn has fertilized certain kernels on the ear, that is, they 
indicate a crossing of varieties. For this reason, an ear showing mixed kernels, like one showing evidence of impaired vitality, must be barred from all judging contests of seed corn.

We must not understand that the variegated kernels of such varieties of corn as the "calico" are mixed kernels in the above sense.

Conclusion. - List carefully and fully in your notebook the desirable characters of a kernel of corn and give your reasons. List also the undesirable characters and tell why they are undesirable. Go over in your mind again and again the important points already given - fifteen in all - under (1) Soundness and Maturity, (2) The Ear and (3) The Kernel, that you may think of them in logical order while selecting and judging the ears to be used in the next exercise.

Can you rank these fifteen points in order of importance, giving good reasons for placing them as you do?

\section{EXERCISE 45}

Object. - To find and award a blue ribbon to a prizewinning ear.

Procedure. - Select and bring to the schoolroom an ear which approaches the ideal as nearly as possible. This ear should be taken from among those which you selected and stored away for this purpose some time ago as required in Section 41, unless you are able to find a better one elsewhere.

Bring it securely wrapped in paper so that other members of the class may not know to whom it belongs. Leave it with the teacher, who will attach to it a numbered tag and keep a record of the owners of all ears entered in this way in the contest.

Remember that this ear must be sound and mature, 
showing no evidence whatever of impaired or doubtful vitality and that it must be free from mixed kernels.

The ears should be laid on a table, two or three kernels removed from each one, and kernels and ears placed side by side, - some of the kernels being laid with the germs up and the remainder with the germs down. After this, they should not be shifted to other positions, or the ears and kernels will become separated.

The entire class will now act as judges, and will proceed as follows:

Begin by ranking all the ears according to size, as this was the first point studied in connection with the ear. By ranking, we mean deciding which one is best, or should rank first, as regards the point which is being considered, which one should rank second, which one third, and so on through the entire class of ears. If all of the ears, however, prove to be of the right size, as is frequently the case, this point may be omitted; or if two or more are equally good in this or any other point, give them the same rank. Record the ranks given the respective ears in each point in the manner shown below:

\begin{tabular}{|c|c|c|c|c|c|c|}
\hline & $\begin{array}{l}\mathrm{EAR}_{\mathrm{AR}} \\
\text { No. } 1\end{array}$ & $\begin{array}{l}\mathrm{E}_{A R} \\
\text { No.2 }\end{array}$ & $\begin{array}{l}\text { EAR } \\
\text { No. } 3\end{array}$ & $\begin{array}{l}\text { EAR } \\
\text { No. } 4\end{array}$ & $\begin{array}{l}\mathrm{E}_{A R} \\
\text { No. } 5\end{array}$ & $\begin{array}{l}\text { EAR } \\
\text { No. } 6\end{array}$ \\
\hline Size & 3 & 1 & 2 & 6 & 5 & 4 \\
\hline Shape . . . . . & 1 & 3 & 5 & 2 & 6 & 4 \\
\hline Butt . . . & 5 & 4 & 1 & 3 & 2 & 6 \\
\hline Tip & 2 & 5 & 6 & 4 & 3 & 1 \\
\hline Depressions in Rows & 3 & 6 & 2 & 1 & 4 & 5 \\
\hline $\begin{array}{l}\text { Shape and Size of } \\
\text { Kernels }\end{array}$ & 6 & 3 & 2 & 1 & 4 & 5 \\
\hline Size of Germs . & 2 & 3 & 6 & 1 & 4 & 5 \\
\hline & 22 & 25 & 24 & 18 & 28 & 30 \\
\hline
\end{tabular}


Note that the above record, which was for a class of only six ears; means that, as regards size, ear No. 2 ranked first, No. 3 ranked second, No. 1, third, No. 6, fourth, No. 5, fifth and No. 4, sixth. As regards shape, however, the rank was very different, No. 1 ranking first, No. 4, second, and so on.

Remember that only one point is to be considered at a time and the rank of all the ears in this one point is to be recorded before another point is taken up. The ears should not be handled while this judging is being done.

You may find it somewhat difficult to judge the ears in regard to some one point, especially if there is a large number of ears instead of merely six as in the case above. If you have trouble of this kind, search out the poorest one and rank it lowest on your record; then find the poorest one of those still remaining, ranking it next lowest, and so on until all are placed. In this way, you will find the ranking of the ears on any given point quite a simple matter.

When the ears have been ranked on all the points, add the columns in the manner shown above to find the total score of each ear.

The one with the lowest, or smallest, total score wins first place in the contest; for in order to get the lowest score, the numbers in its column must be smaller than those in other columns, thus denoting higher average rank. The ear with the next lowest score takes second place in the contest, etc.

The judging of these ears should be done without assistance from any one else. Indeed, you should make it a point not to compare notes with others.

When you have made the final placing of all ears according to their total scores, write the result on a slip of paper, stating which ear is given first place, which one second 
place, and so on through the list. Then sign your name to the slip and hand it to the teacher, who will make the final decision as to how the ears should rank in the contest.

Remember that there is abundant room for difference of opinion in this judging, as well as in any other, but that there is no ground for offense on the part of any one. It is much more important that you should be able to judge accurately, recognizing and naming the ears that are really best in the class, than that your own specimen should win the contest.

A blue ribbon should be attached to the best ear, a red ribbon to the next best and a white ribbon to the third best.

Conclusion. - Hang the prize-winning ears in some convenient place in the school-

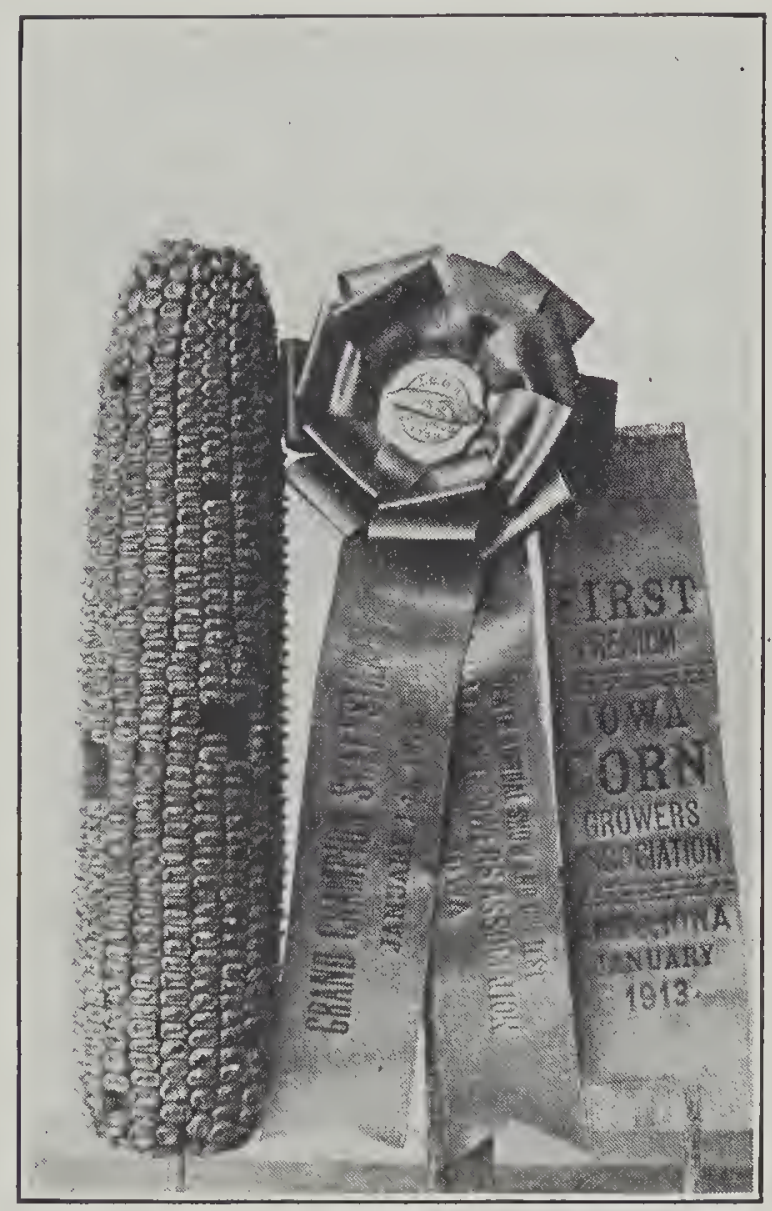

Contesy Iowa State College.

Fig. 72. - A grand champion ear.

room where they may be seen by visitors. Write a criticism of these three ears, stating in what respects each one is particularly good and in what respects it is poor.

113. The Selection of the Seed Supply. - Nature allows for a prodigal waste of seed each year. On the other hand, the careful farmer is anxious to have every seed he selects 
for planting capable of germination. Several different methods of selecting a supply of seed for the ensuing year's crop are used throughout the leading corn states. Among those commonly practiced are the four given below :

(1) The farmer may go into his fields before the first killing frost of autumn and gather the seed ears in a sack or basket. The advantages of this method are:

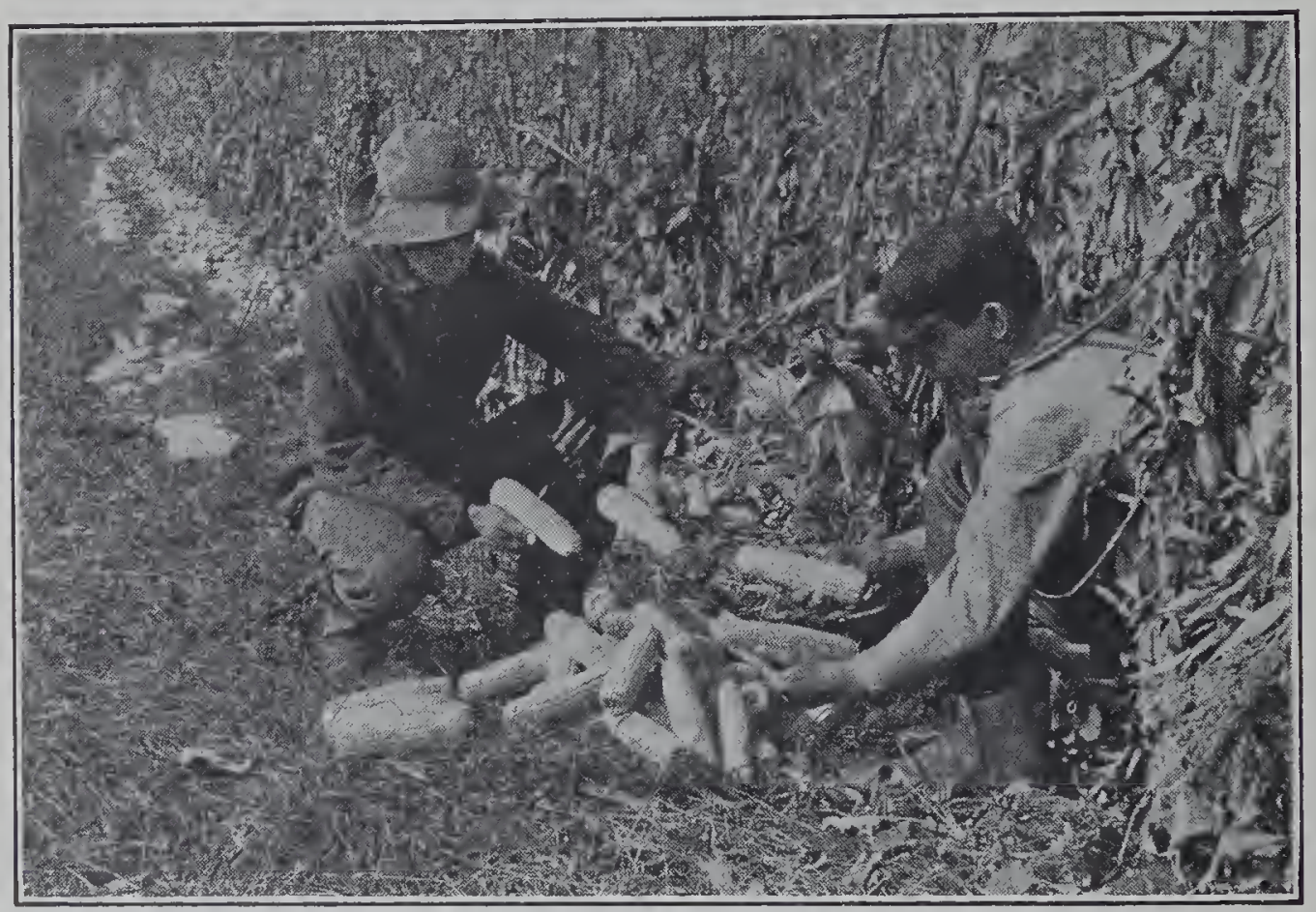

FIG. 73. - Boys gathering seed corn.

(a) He is able to select those ears which mature early, thus securing early maturity in the following season's crop.

(b) He is able to study the parent plant and its environment, just as we have done in Exercise 18.

(c) He is able to study the characteristics of the ear and kernels, precisely as we did in Exercises 42, 43, and 44 .

(d) He is able to preserve the vitality of the seed, since it is gathered before the frost has had a chance to injure it and may be properly cared for thereafter. 
(2) He may select it while husking, putting it into a box or basket attached to the wagon for this purpose. The advantages of this method are:

(a) He may study the parent plant and its environment.

(b) He may study the characteristics of the ears and kernels.

(c) He is able to preserve the vitality of the seed as he finds it.

The disadvantages of this method are:

(a) He is unable to select early-maturing ears with any degree of certainty.

(b) The vitality may have been already impaired by severe frosts.

(c) Corn husking is done too hurriedly to permit of a careful examination of parent stalks, ears or kernels.

(3) He may select seed ears while unloading the corn from the wagon. The advantages of this method are as follows :

(a) He may study the characteristics of ears and kernels.

(b) He may preserve the vitality of the seed as he finds it.

On the other hand, this method has the serious disadvantages named below:

(a) He can not study the parent plants nor their environment.

(b) He can not determine which ears will yield earlymaturing seed.

(c) The vitality may have been already impaired.

(d) There is not enough time to examine the ears properly.

(4) He may leave the selection of seed until late winter or spring and then take it from the crib. There is little 
to be said in favor of this method, save that the characteristics of ears and kernels may be seen. The chief objections to it are:

(a) Nothing is known as to the parent plant or its environment.

(b) It is impossible to determine which ears will yield early-maturing seed.

(c) The vitality has very probably been seriously impaired. This will be certainly true unless the corn was thoroughly dry when stored in the crib.

114. How Selection of Seed may influence the Yield. From the foregoing comparison of methods, it is evident that that of selecting seed corn from the field before the first severe frost occurs in the fall is greatly superior to any other.

The farmer who selects his supply of seed in this way may reasonably expect to be rewarded by more vigorous plants, a more uniform stand, and consequently by increased yields.

This is particularly true if he has previously taken the precaution to detassel alternate rows in a part or all of his field in the manner explained in the latter part of Section 91 , and if he now selects his seed supply only from the detasseled rows.

115. Drying out the Seed. - Even though seed corn is mature and has been gathered in favorable weather, it should be dried as thoroughly as possible.

This is brought about by putting it in a dry, well ventilated place where there is a free circulation of air about each ear. At this time the ears should not be allowed to be in contact at any point.

Unless the ears are thoroughly dried out, moisture, 
which is known to be the chief enemy of stored seeds (Section 35), may lead to the death of the embryo in two ways :

(1) It favors the growth of destructive molds, as explained in Section 99.

(2) It makes the seed incapable of withstanding freezing.

The drier the seed, the more freezing it will endure. This

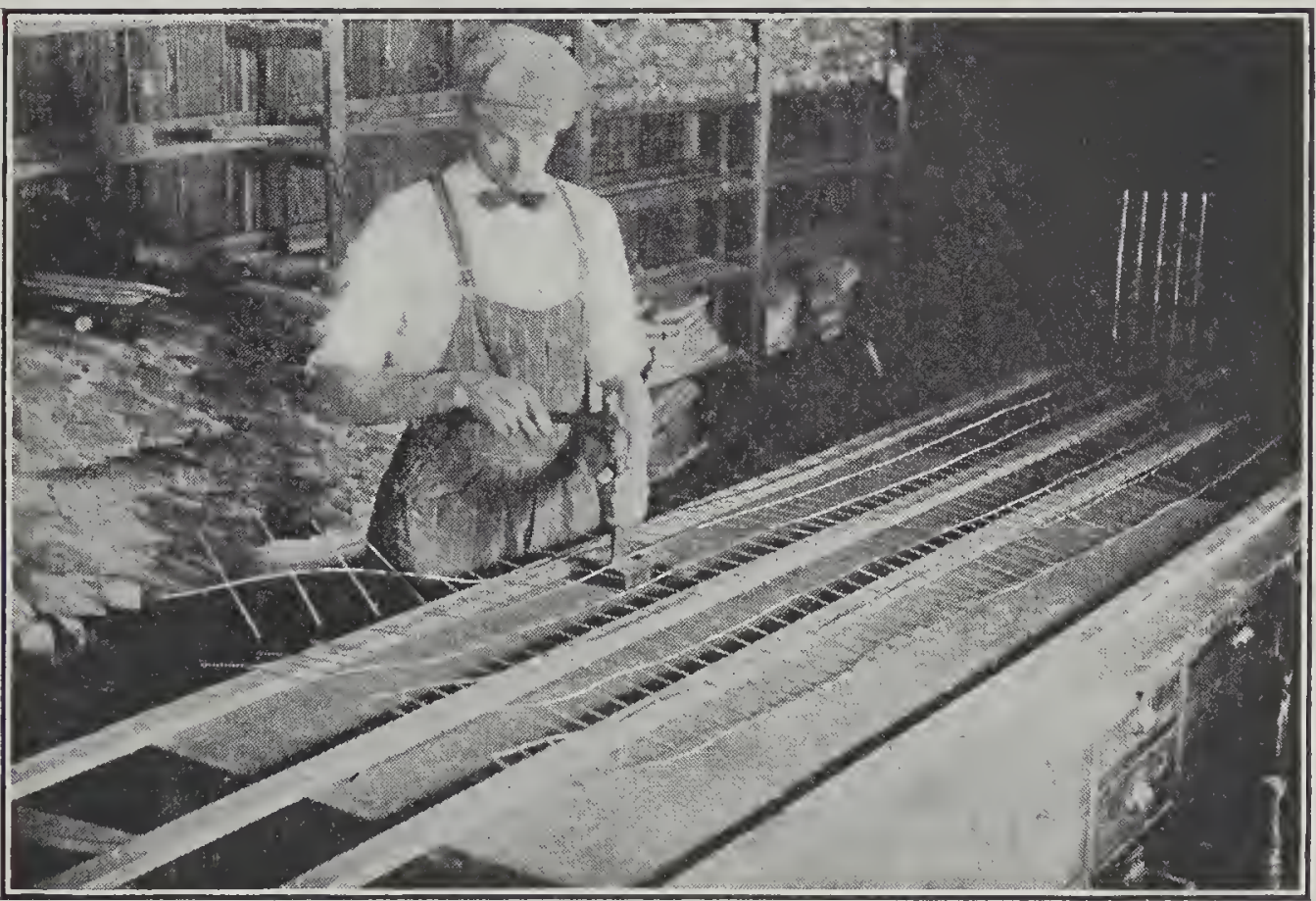

FIG. 74. - Making a seed corn holder.

fundamental principle must be kept constantly in mind in drying seed corn.

116. Storing the Seed. - After the seed corn is thoroughly dried out, it should be stored where the following conditions are provided:

(1) Protection from rain and snow, or dampness of any kind. 
(2) Protection from insects, rats, mice and other animals.

(3) Free circulation of air.

(4) Protection from extremes of heat and cold.

(5) A convenient and simple arrangement of ears for spring seed testing.

There are very many different methods of storing seed corn, whether on nails, on strings, in racks or otherwise. One method, which seems to be meeting the approval of
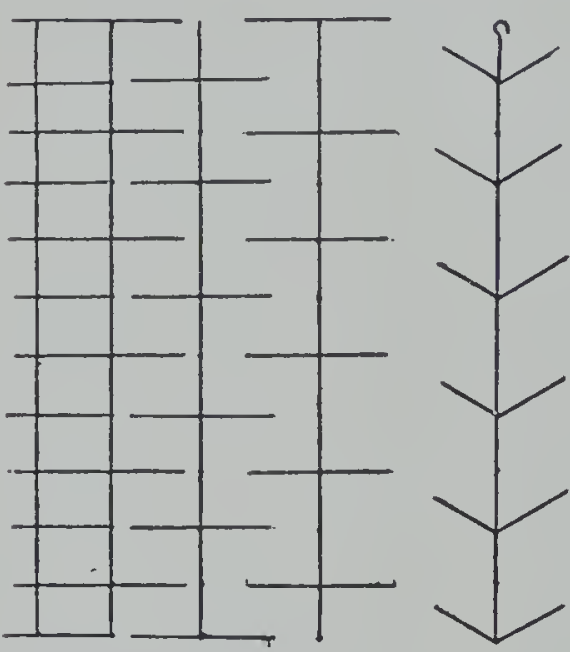

FIG. 75. - How the wire is cut. many of the best farmers, is to cut a sort of pole ladder out of rather heavy wire fencing, having square meshes and the wires soldered, or "welded" together at the intersections. Such fencing is easily procured at any store handling goods of this class.

One of the vertical wires is followed from top to bottom and cross wires cut away from it at every other intersection so that it resembles a pole with steps nailed on it. The drawing and pictures show clearly how this is done.

The ears are put on these holders, which are then hung up in some such place as the garret of a dwelling house where the conditions mentioned at the beginning of this section prevail.

117. Testing the Seed. - No matter how carefully the seed has been selected and stored, we can not be certain of our stand in the field without testing specimen kernels from each ear. While we are able in certain cases to de- 
tect dead kernels by an examination of the germs, yet we can not always do so with any degree of certainty; and as for those which are alive, we are wholly unable to distinguish in this manner the kernels of strong vitality from those which are weak. It follows that we can not be sure of the vitality of our seed corn save by an actual germination test.

There are many methods of testing seed corn, although the same principles underlie all of them :

First: Cloth, or any other material which touches the seed, should be boiled or some other method used to kill the spores of molds which may otherwise destroy the vitality of the seed.

Second: The material in contact with the seed should be uniformly moist, but not wet. (Section 47.)

Third: The seed should be kept at a fairly uniform temper-

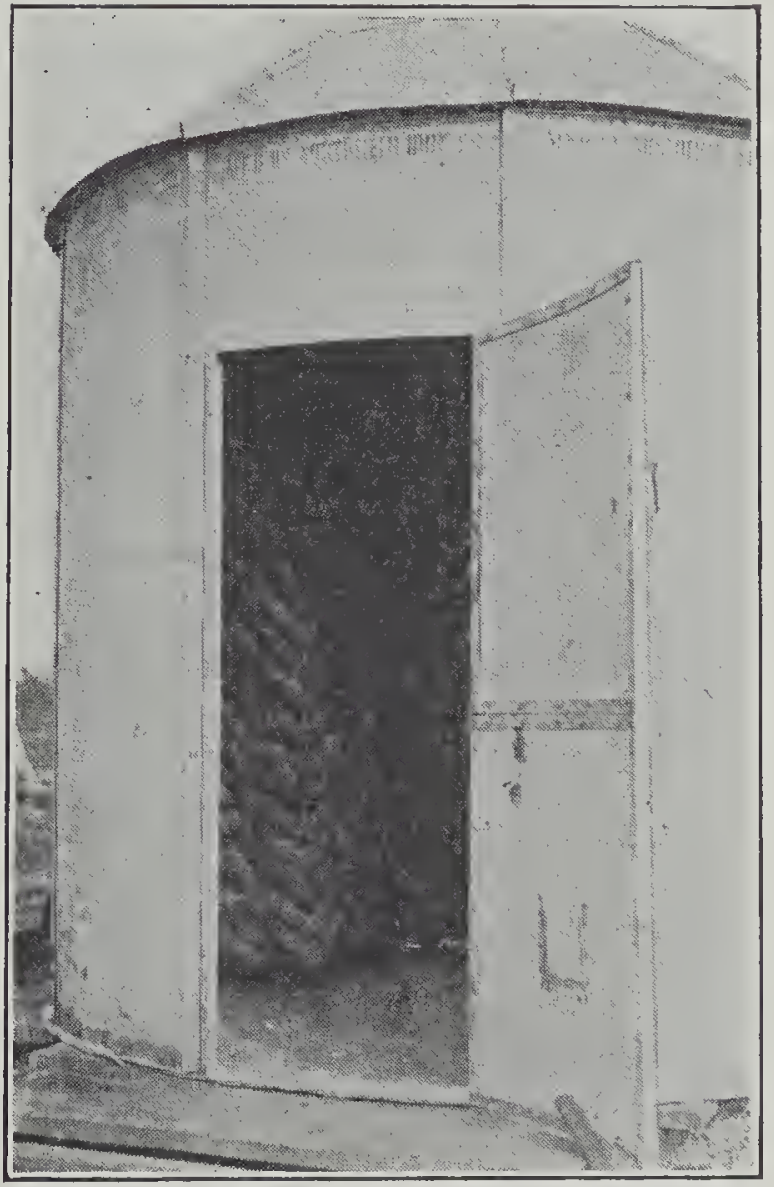

Fig. 76. - A good way to store sced corn. ature of about seventy degrees Fahrenheit; that is, at about ordinary room temperature. (Section 48.)

Fourth: The seed must not be so closely confined as to exclude oxygen. (Exercise 20.)

A few weeks before planting time in the spring, germination tests may be made for as many patrons of the school as the space and time will allow. 


\section{EXERCISE 46}

Object. - To determine the percentage of germinable kernels in twelve ears of corn.

Procedure. - Each student should have a seed corn holder, made from soldered wire fencing as shown in Figure 75 and described in Section 116. If this can not be conveniently procured, however, a holder, or rack, of any other kind may be used.

Bring to the schoolroom twelve ears of corn, which are to be used in the spring for seed. Place them on your holder, numbering the samples according to their position in some order that is not liable to become confused. If there is any danger of getting the ears disarranged, they should be numbered by placing a rubber band about each one and fastening to the band a small numbered tag, or by driving a tack and numbered strip into the butt.

Each student should have a piece of muslin of good quality about nine inches wide and thirty-six inches long; and he should write upon it plainly his name, the name of the farmer for whom the seed corn is tested and the date of making the test.

Lay your strip on a desk or table. Using a soft pencil - not indelible - mark it off as follows :

(1) Draw a cross line; that is, a line at right angles to the length of the strip, eight inches from the left end. This eight-inch space is to be left vacant.

(2) Draw a line lengthwise along the middle of the cloth from this cross line to the other end.

(3) Draw six other cross lines at right angles to this long line and four inches apart.

There are now fourteen squares on yoúr cloth. However, the two at the end will not be used and may be disregarded. Number the others with your pencil so that 
the numbers will correspond in position if possible to those of the ears on the holder. This numbering should begin with the squares next to the eight-inch vacant space.

Wet the strip and spread it out upon a desk or table or upon a smooth board. Now remove six kernels from ear number one, one from opposite sides near the butt, one from opposite sides at the middle, and one from opposite sides near the tip, - but no two from the same row. Place these kernels, germs upward, in square number one. They may be arranged in two rows of three kernels each, and with tips all pointing in the same direction, preferably away from the vacant space at the end of the cloth.

Place six kernels, taken in the same manner, from ear number two in square number

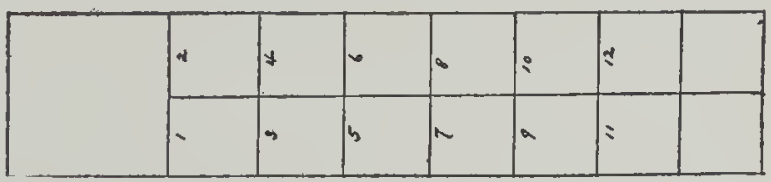

Fig. 77. - How the cloth is marked. The squares may be numbered otherwise if desired to correspond to the position of the ears in the seed corn holder.

two. Proceed in this way until the kernels that are to be tested from each ear are properly arranged in their respective squares.

Lay a light stick about nine inches long at the end where the vacant space was left. Roll the cloth loosely but carefully about it until all the kernels are inclosed, taking care not to get them out of their respective squares.

Tie a string or place a rubber band loosely about each end of the "rag doll" you have just made. The doll should now be placed in a pail of water at the temperature of the room for eight or ten hours. If it is put in the water at or before the opening of school in the morning, and removed from it at the close, the kernels will have taken up enough water to give a good test.

When the rolls are removed from the pail, take off the 
strings or rubber bands, place them loosely in a box of moist sawdust or in folds of clean, wet gunny sacks, and set them in a warm place for five or six days. If there is danger of freezing in the schoolroom, the box should be taken to some home until the rolls are to be opened and the count of the germinable seeds is to be made. The box should be covered with a screen to prevent the mice from entering; and the sawdust or the folds of sacks should not be allowed to dry out.

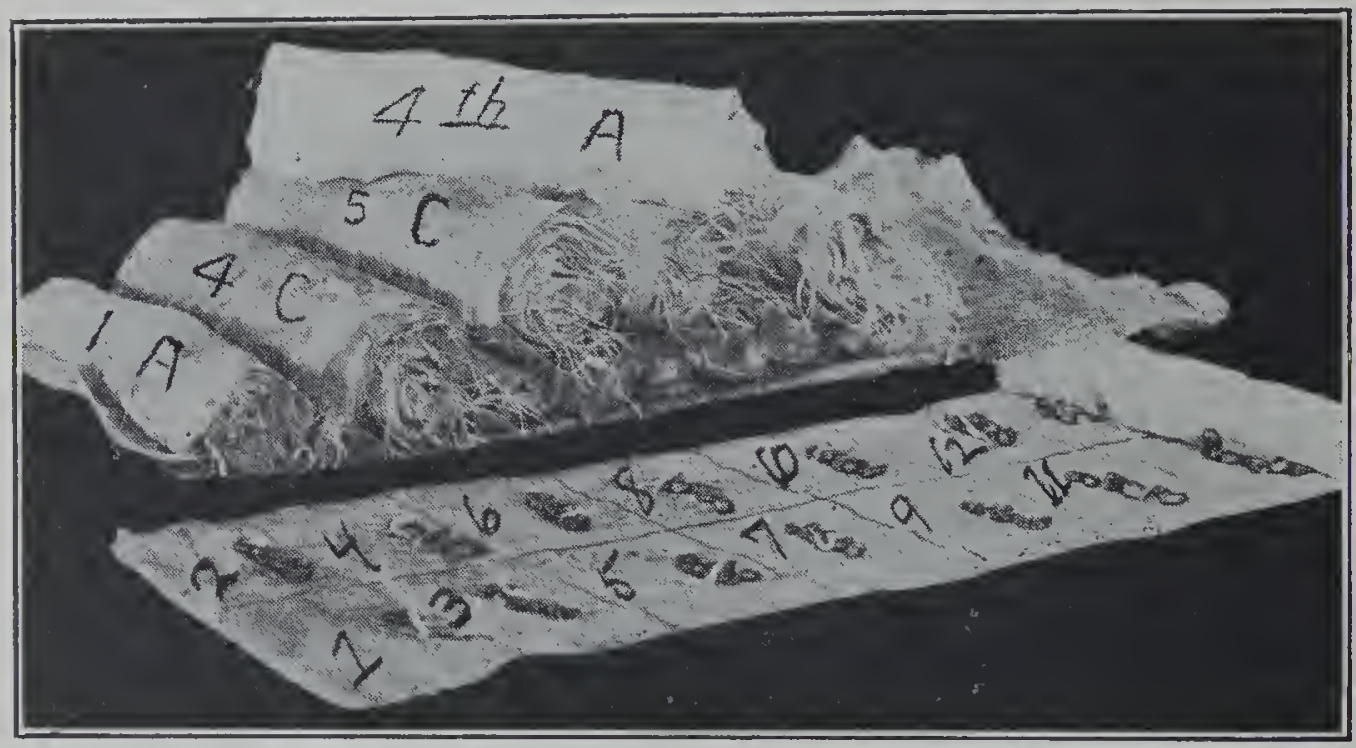

FIG. 78. - Some rag dolls.

Couriesy Iowa State College.

After five or six days, carefully remove the rolls from the box and unroll, taking care again not to displace the kernels from their respective squares.

Conclusion. - Arrange in your notebook a table as shown on page 179 .

Figure the percentage of strong, weak and dead seed in each ear, and also in the twelve ears, which you have tested, taken as a whole.

If a perfect stand from strong seed yields sixty bushels of corn per acre, at what rate should your twelve-ear 
sample yield, provided the weak kernels develop into weak plants, yielding only thirty bushels per acre.

\begin{tabular}{|c|c|c|c|}
\hline EAR No. & $\begin{array}{l}\text { KERNELS WITH } \\
\text { StroNG Sprottis }\end{array}$ & $\begin{array}{l}\text { KERNELS WITH } \\
\text { WEAK SPROUTS }\end{array}$ & $\begin{array}{l}\text { KERNELS WITH } \\
\text { NO SPROUTS }\end{array}$ \\
\hline 1 & . & & \\
\hline 2 & & & 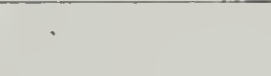 \\
\hline 3 & & & \\
\hline 4 & & & \\
\hline 5 & . & & \\
\hline 6 & & & \\
\hline 7 & & & \\
\hline 8 & & & \\
\hline 9 & 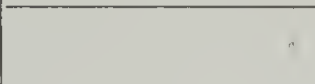 & & \\
\hline 10 & & & \\
\hline 11 & & & \\
\hline 12 & & & \\
\hline
\end{tabular}

Compare your results with those of others of the class, inquiring as to how each sample was selected, dried and stored, and see if you can find out why some samples test better than others.

118. Grading the Seed. - In the selection of seed ears, we have endeavored in every way possible to secure uniformity in size and shape of kernels in order that the planter might drop the seed accurately, which in turn should result in an even stand in the field.

We may be sure, however, that the kernels will not be 
so uniform as we desire, no matter how carefully the seed ears have been chosen. There are three reasons for this :

(1) The kernels near the tips will be small.

(2) The kernels about the butts will be large and more or less irregular in size.

(3) The average size of kernels on different ears will vary surprisingly.

Because of the first two facts, the kernels about the

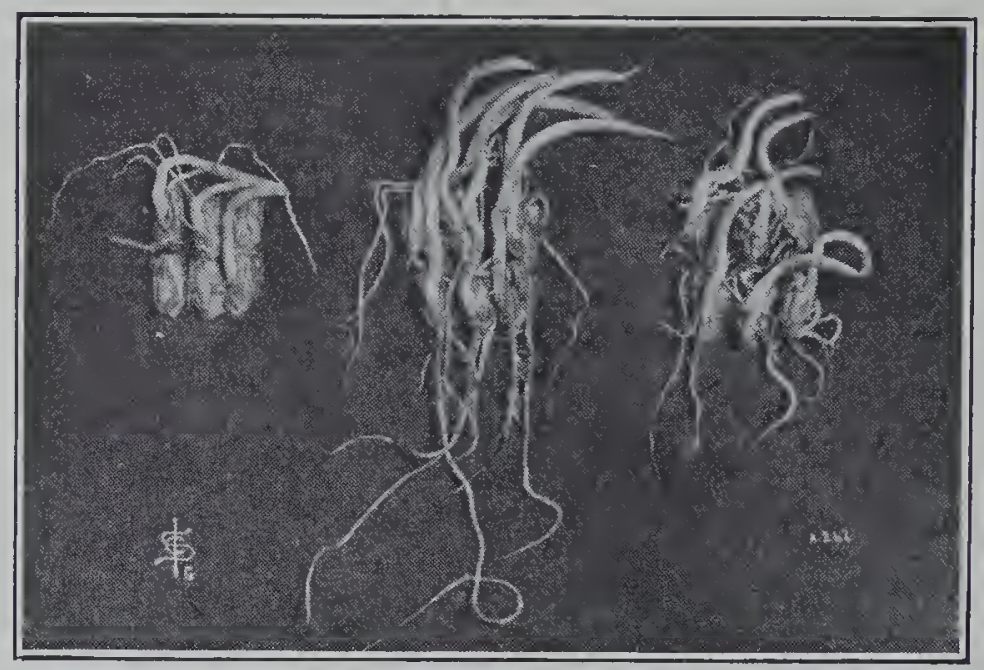

FrG. 79. - Strong, weak, and dead kernels. Note that kernels lacking the root sprout are accounted as dead, since they could not grow. They would be regarded in the same way if the stem sprout were lacking.

butt and tip of each ear are shelled off and discarded before removing the coln from the bodies of the ears.

After this is done, it is necessary to grade the remaining kernels as they are shelled. In doing this, three boxes or measures are provided, in the first of which are to be placed large kernels, in the second, kernels of medium size, and in the third, those which are small. The ears are shelled separately into a pan, usually with a hand sheller; a glance is then sufficient to show whether the kernels are of large, medium or small average size; 
and they are placed in the box in which they are seen to belong.

When the shelling is finished and the seed has been graded in this way, we have three sizes of seed. Even planting then becomes merely a matter of changing the plates in the machine when changing from one size of seed to another. If the planter does not drop the seed evenly, the grading, not the machine, should be blamed.

119. The Ideal Seed Bed for Corn. - The ground in which the seed is planted is known as the seed bed. An ideal seed bed for corn may be described as follows:

First: It should contain an abundance of available plant food.

Second: It should be finely pulverized.

Third : It should be loose and mellow so that the particles may lie closely and compactly against the germinating seeds and yet allow air and moisture to move freely through it. (Sections 46 and 47.)

Fourth: It should be reasonably free from weed seeds.

Fifth : It should be free from injurious insects.

Sixth: The surface should be made smooth to allow the easy movement of machinery.

The methods to be employed in securing these conditions depend chiefly upon the character of the preceding crop and the condition in which it has left the ground. Corn is usually planted, -

(1) In sod ground; i.e., land previously in grasses or clovers.

(2) In cornstalk ground, or land previously in corn.

(3) In stubble ground; i.e., land previously in small grain. 
120. Preparing a Seed Bed in Sod Ground. - If sod ground is to be prepared for corn, it should be (1) plowed in the fall unless it is badly needed for fall pasture; (2) allowed to crumble and disintegrate through the winter (Exercise 15); (3) disced well early in the spring; (4) disced and harrowed thoroughly and repeatedly later when getting the seed bed ready for planting; and finally (5) harrowed until the ground is finely pulverized.

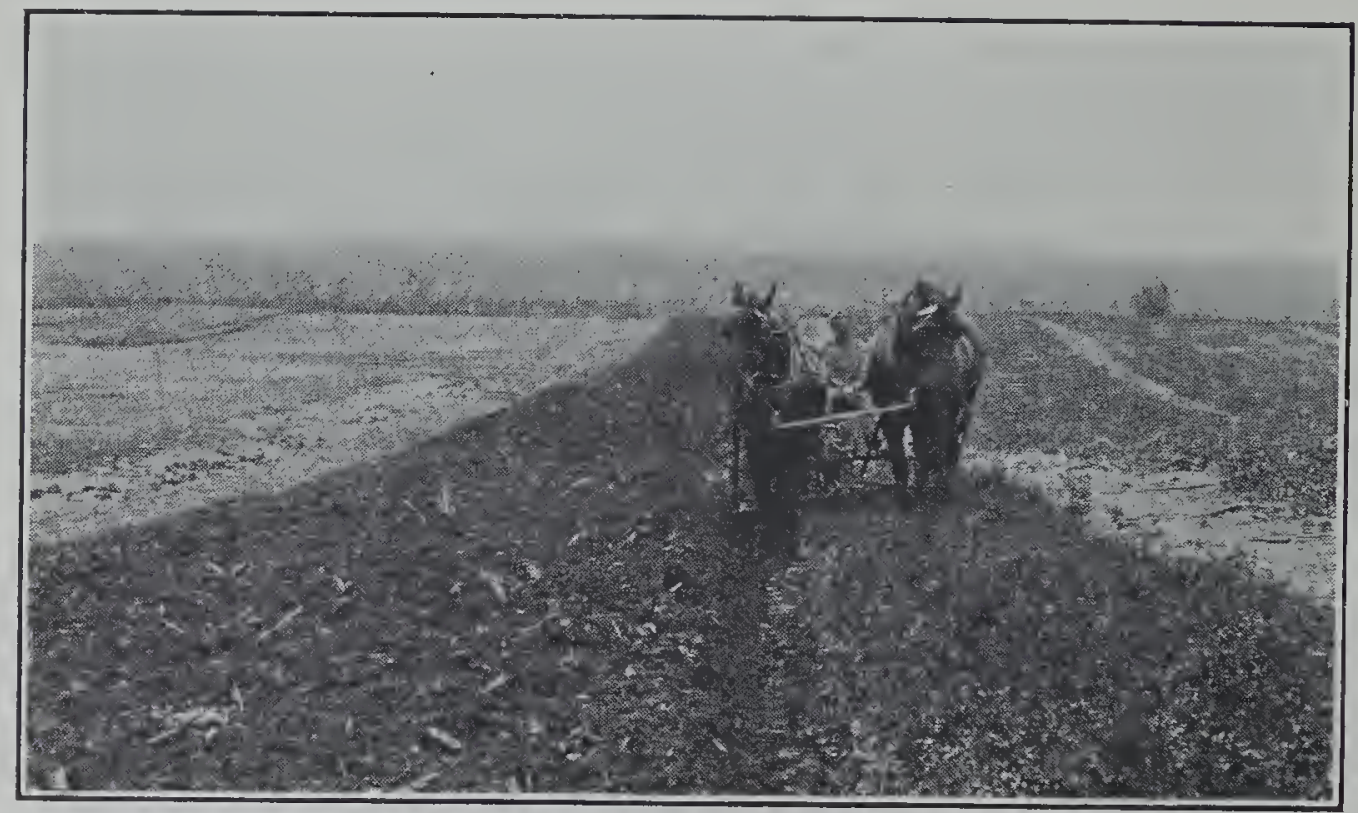

FIG. 80. - Getting the ground ready for corn.

The advantages of fall plowing of sod, which should be rough, or ridged, not smooth, are:

(a) Crumbling and disintegration, due to freezing and thawing, can take place.

(b) There is ample time for decay, which makes plant food available.

(c) This disintegration and decay tend to restore capillary connection so that moisture can rise more freely from below.

(d) The hibernating quarters of many injurious insects are destroyed. 
Unless the rough plowed sod is disced down early and well in the spring, it will dry out badly. Discing at this time forms a mulch which conserves moisture; and it also admits air about the roots, thus hastening decay and liberating plant food.

It is common knowledge that corn in sod ground is liable to "fire" during the hot months of summer. This may be expected whenever large pieces of sod are allowed to remain in the seed bed, since the air can circulate so freely through the open spaces about them that the bed is quickly dried out. The corn, then, becomes yellow simply from lack of moisture. To prevent this, it is necessary to disc thoroughly when getting the seed bed ready for planting that these sod masses may be cut into fine pieces; and after this, the harrow should be used until the soil is in the finest possible state of division.

It is sometimes found impossible to plow sod ground for corn in the fall as indicated above. In this case, it should be first disced very early in the spring when the ground has thawed to a depth of only two or three inches. The disc at this time will cut through the sod, chopping it into fine pieces; and when the plowing is done later, the earth will crumble as it turns nearly as well as does stubble ground.

The plowing of sod in the spring should be done early, as considerable time is needed to restore the capillary connection with the subsoil and to liberate plant food by decay. It is a serious mistake to allow the grass to begin to grow before plowing sod in the spring as it consumes available plant food which at this time is deficient; and later, when it is turned under, it prevents the rise of moisture from below. In doing this plowing in the spring, the harrow should follow soon after the plow as it forms a mulch, which prevents the newly turned sod from drying 
out. It is a notable fact that sod ground can be plowed earlier in the spring than any other ground, due to the fact that the abundance of roots in the soil prevents the baking which invariably follows the turning of other ground while wet.

The final preparation of spring plowed sod ground should be similar to that of fall plowed sod, save that discing and harrowing should be even more thoroughly and painstakingly done.

121. Preparing a Seed Bed in Cornstalk Ground. - If corn is to be planted on cornstalk ground, the first step in seed bed preparation is the breaking down of the previous year's stalks. Following this, the land (2) should be plowed - unless the lister is to be used - as early as the condition of the soil will permit; (3) the harrow should follow the plow closely; and (4) when the seed bed is finally prepared for planting, it should be repeatedly disced and harrowed until it has become mellow and well pulverized.

In breaking down the old stalks, the disc is commonly used. It is driven diagonally through the field and may go over the ground as often as necessary, depending upon the growth of stalks. Only in exceptional cases, if ever, should the stalks be raked up and burned, since this results in the loss of both humus and nitrogen from the soil. (Sections 68 and 110.)

The plowing should not be done when the ground is so wet that it turns up "slick," as it will then bake, clods will form, and these may remain in the seed bed throughout the season.

If weeds and grass are allowed to grow before the ground is plowed, they consume plant food, which the young plants are certain to need later. 
The harrow should follow the plow within half a day as a rule. In this way, the formation of clods can be prevented, and the mulch which is formed prevents the seed bed from drying out.

122. Preparing a Seed Bed in Stubble Ground. Small grain in the rotation really ought to be followed by clover or some other legume to restore nitrogen to the soil. Corn, therefore, should not be planted in stubble ground. This rule may be disregarded only in case a liberal application of barnyard manure is made a part of the preparation of the ground for corn.

In this case, the successive steps should be about as follows:

(1) The stubble should be disced as soon as the small grain is removed. This will form a mulch, prevent further loss of moisture, destroy weeds, cause weed and other seeds to germinate so that they will not be present in the ground the following spring, and make the draft lighter for the plow.

(2) Barnyard manure should be applied liberally with a manure spreader.

(3) The ground should be plowed in the fall as its moisture-holding capacity is thereby greatly increased.

(4) It should be disced very early in the spring, as otherwise the rough plowed soil will dry out badly and the corn crop may be injured by the lack of moisture later.

(5) The ground should be disced and harrowed until mellow and well pulverized when the final preparation is being made for planting.

123. Planting the Seed. - There are three common methods of planting corn:

(1) It may be checked; i.e., planted in hills in such a manner that rows are formed both lengthwise and cross- 
wise of the field. This is the common practice in sections having considerable rainfall. The particular advantage is that the corn may be cultivated both ways, thus keeping the weeds in check more easily. In case the corn is blown down by violent summer storms, however, there is further

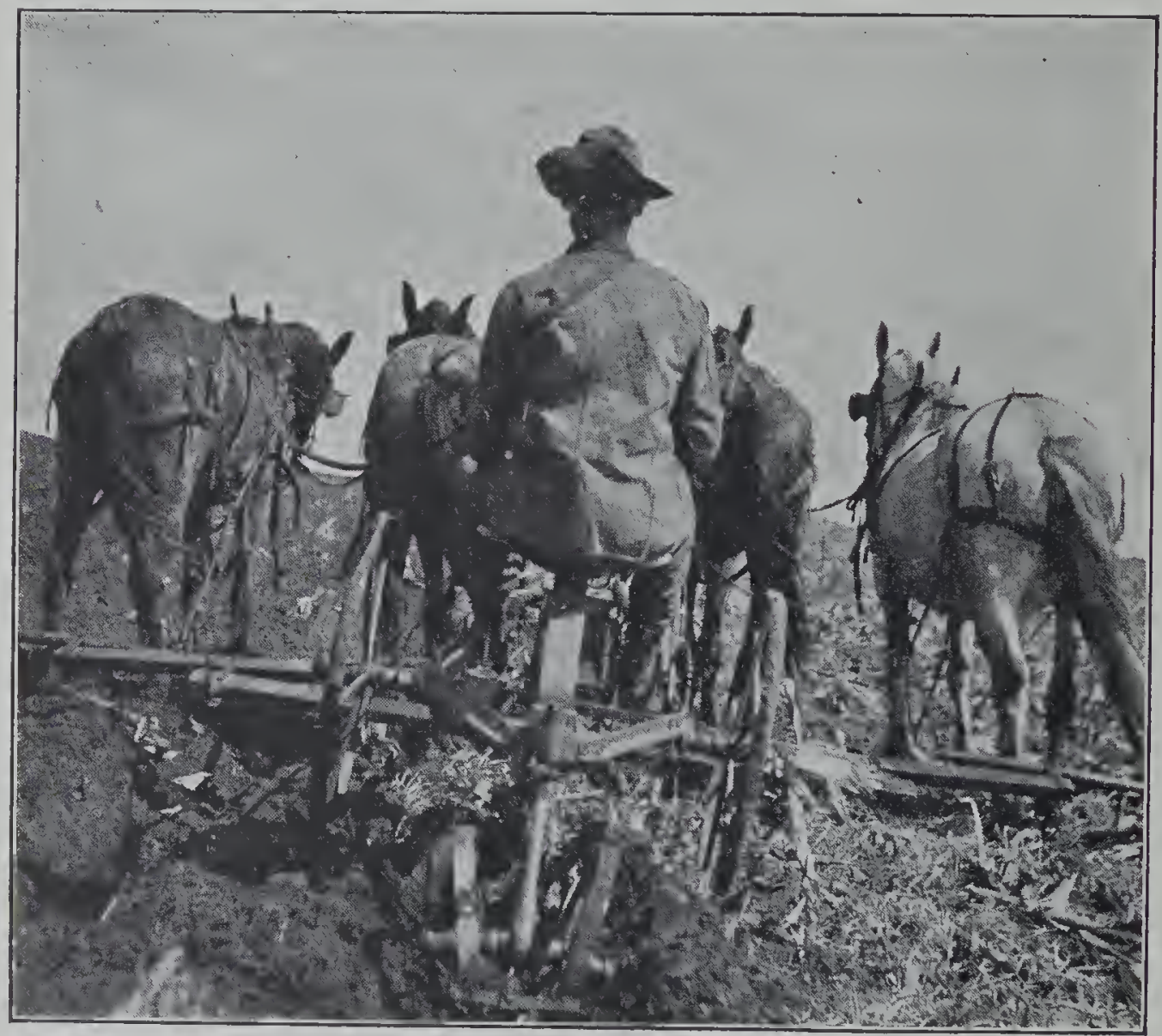

FIG. 81. - Lister at work.

advantage in the fact that the wagon may be driven through in either direction at husking time.

(2) It may be drilled; i.e., planted in continuous rows rather than in hills, a kernel being dropped every few inches.

Drilled corn gives no higher yield than checked corn, provided there is the same number of stalks to the acre 
in the two cases. However, drilling is regarded as preferable if the corn is to be used for silage, as by planting the kernels closer together in the rows, the growth may be made less rank and woody and harvesting machinery will run more smoothly. Drilling may also be preferred in case the field is irregular in shape so that checking is difficult or in case it is notably free from weeds so that cross cultivation is unnecessary.

(3) It may be listed; i.e., planted in the bottom of a furrow, made by a special implement known as a lister, which is really a plow with two mold boards, which turn the ground to right and left. This practice prevails generally in the regions lacking ample rainfall. After the permanent root systems of the young plants have formed, the furrow is gradually filled up and in this way the roots are virtually sent down to moisture. It is a highly successful method, inasmuch as it results in notably increased yields in many parts of the western border of the Corn Belt.

The seed is usually drilled in the lister furrow by a special attachment to the lister, or by a single drill or planter.

124. The Time of Planting. - The date of planting corn in any locality is determined by a number of factors, among which are the following:

(a) Latitude.

(b) Weather Conditions. Cold spring rains frequently delay planting.

(c) Temperature of the Soil. This, rather than arbitrary dates on the calendar, is the most reliable guide as to when planting should be done. In general, the temperature of the ground should have reached at least fiftyfive degrees Fahrenheit.

(d) Quality of Seed. Seed that is known to be capable 
of strong, vigorous germination may be safely planted earlier than that whose vitality is low, because if bad weather follows such seed will not decay so readily.

(e) Insects. These are commonly most destructive early in the season; hence late planted corn is less liable to be injured by them. In sod ground, believed to be badly infested by them, this is to be kept constantly in mind.

The general rule is to plant corn as early as the temperature and other soil conditions will permit. It has been quite conclusively shown that the highest yields are secured by early planting, owing, doubtless, to the greater length of the growing season.

125. The Depth of Planting. - The general rule as to depth of planting is to plant as shallow as the conditions which govern germination will permit; that is, the seed should be put into the ground only so deep as is necessary in order to secure all three of the conditions upon which germination depends, viz: : moisture, oxygen and suitable temperature. (Section 46.)

The average depth of planting is perhaps about two and one half inches. As previously stated (Exercise 27), we do not try to control the depth of the root systems by the depth of planting, since this is impossible. In any given case, the depth of planting is determined chiefly by the following conditions:

(1) Soil Texture and Structure. - In loose sandy soil, it is necessary to plant deep in order to reach moisture. On the other hand, this would not do ordinarily in a heavy clay soil as the seed would be deprived of oxygen, and moreover, after a heavy rain such soil has a tendency to puddle and bake, which prevents the sprouts from pushing through. 
(2) Condition of the Seed Bed. - If the seed bed is poorly prepared, clods form, the surface dries out, and it becomes necessary to plant deeper than if the seed bed were well prepared.

(3) Amount of Humus in the Soil. - If there is a large amount of humus in the soil, the seed bed does not dry out readily (Exercise 5), it contains plenty of air, or oxygen (Exercise 10), and hence corn need not be planted so deep as would otherwise be required.

(4) 'The Depth of the Water Level. - The nearer the level of the gravity water is to the surface, the shallower the seed must be planted.

(5) The Time of Planting. - The later the planting is done, the warmer the soil, and the drier it is as a rule near the surface; hence late planting may be somewhat deeper than early planting.

126. Distance between the Rows. - The distance between the rows varies greatly in different sections. In some parts, especially on new soils, the rows are commonly three feet apart, while in other sections, whose soils are nearing exhaustion, the average distance between rows is upwards of six feet. In Iowa, it is commonly three and one half feet.

The proper distance in any given case is determined, as the foregoing suggests, chiefly by the fertility of the soil. It may depend in certain cases, too, upon the use to be made of the crop. If it is intended that the crop be used as silage, the rows may be closer together than otherwise as the growth will be less woody.

127. The Number of Kernels in Each Hill. - This, too, varies considerably in different localities. In the leading corn states, the number is usually either three or four. 
In any given case, the number that should be planted in each hill ordinarily depends upon several factors. These are as follows:

(1) Quality of the Seed. - If the percentage of germinable kernels is known to be low, the number planted in each hill is usually increased.

(2) Fertility of the Soil. - If plant food is abundant in the soil, a greater number of kernels may be planted in each hill, since a greater number of plants can be supported.

(3) Average Rainfall. - In regions where the rainfall is scant, fewer kernels are planted in each hill than in humid sections.

(4) Insects. - If the soil is infested by destructive insects, it is deemed prudent to increase the number of kernels in each hill.

(5) Use to be made of the Crop. - If the crop is to be used for fodder or silage, the number of kernels in each hill may be increased.

128. The Replanting of the Missing Hills. - If for any reason the stand proves to be poor, the question of replanting arises. This is not at all the simple matter that it appears to be. It is easy enough, of course, to replant the occasional missing hills. The difficulty, however, arises in the fact that the plants in these hills, being younger than those about them, will not put forth flowers until the remainder of the field has passed the flowering stage. Most of the pollen from the older plants will have been shed before the silks of the younger plants are ready to receive it, the usual result being that the pistillate flowers of the latter are but poorly fertilized and small ears, or none at all, are formed. This may be avoided in a measure by replanting with seed of some earlier variety, but the result in this case is a mixture of varieties. For these 
reasons, corn growers regard replanting with disfavor and seek to avoid it so far as possible.

A fairly satisfactory rule to follow is :

If more than twenty per cent of the plants are missing, replant the entire field; if between ten and twenty per cent, replant the missing corn; if less than ten per cent, replant none.

If the replanting is made necessary as a result of the destruction done by insects, the new rows should be planted between the old ones, and the latter should be left standing so that the insects may continue to feed upon them.

129. Cultivation begins with the Harrow. - If the seed has been put in by either checking or drilling, the ground should be harrowed crosswise of the rows as soon as the planting is finished. This will prevent the washing out of the kernels by subsequent showers, the water from which would naturally follow the tracks of the planter wheels.

Even after the young plants are up, the field may be harrowed to advantage, as this will break up any crust that may have formed, thus preventing the loss of moisture; and at the same time it will destroy very many small weeds. This harrowing, however, should not be done in the early morning when the little plants are turgid and therefore brittle (Section 69), as many of them will be broken off. Moreover, the harrow should usually be. driven crosswise of the rows, the teeth should be set slanting backwards, the corn should not be harrowed just as it is coming through the ground, and the harrow should be kept away from wet places.

130. Later Cultivation of the Crop. - For later cultivation, the shovel cultivator is the implement generally used. 
The old-fashioned cultivator with four large shovels, which stirred the ground deeply and left it in a ridged

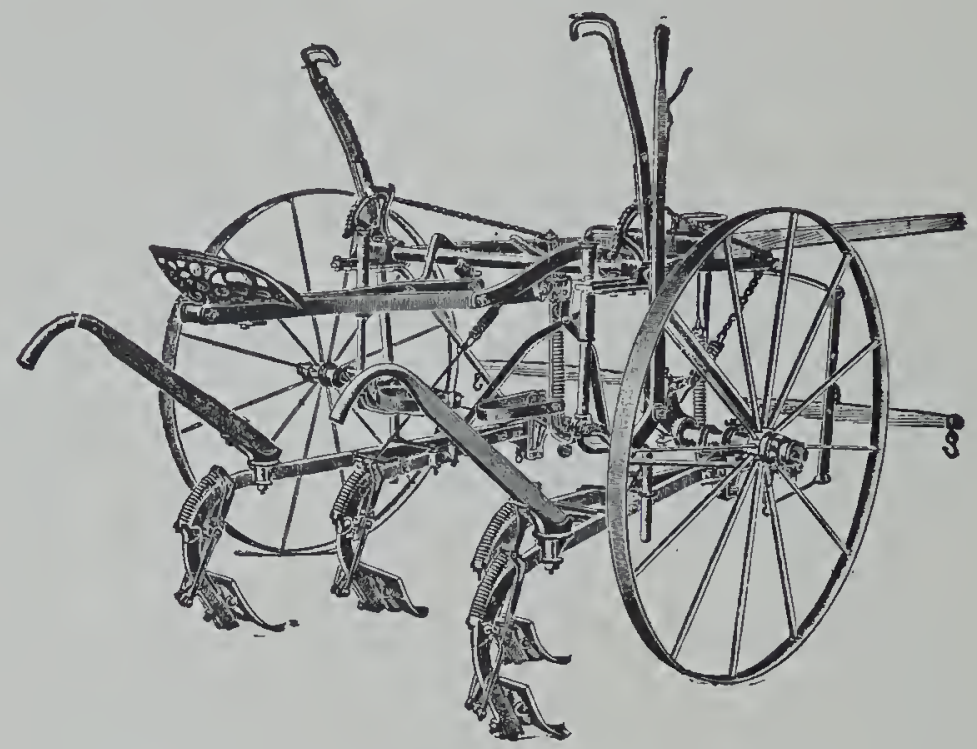

FIG. 82. - Cultivator with large shovels.

condition, is being gradually displaced by others, having six or more smaller shovels. It was formerly held that

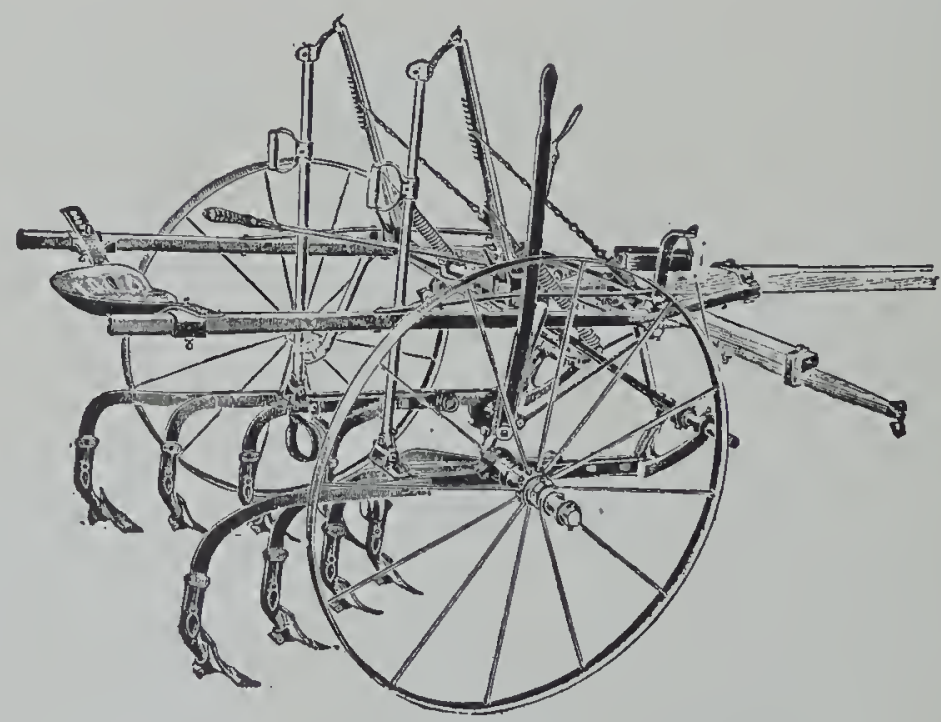

Fig. 83. - Cultivator with small shovels.

the ground in which corn was growing required deep stirring throughout the early part of the season. This 
idea is now being gradually abandoned as many good farmers are coming to believe (1) that the seed bed should be prepared before, not after, planting, and (2) that the severing of roots by deep cultivation works serious injury to the growing plants, especially if this occurs after they have attained considerable size.

131. Depth of Cultivation. - No fixed rule can be given as to the proper depth of cultivation. If the seed

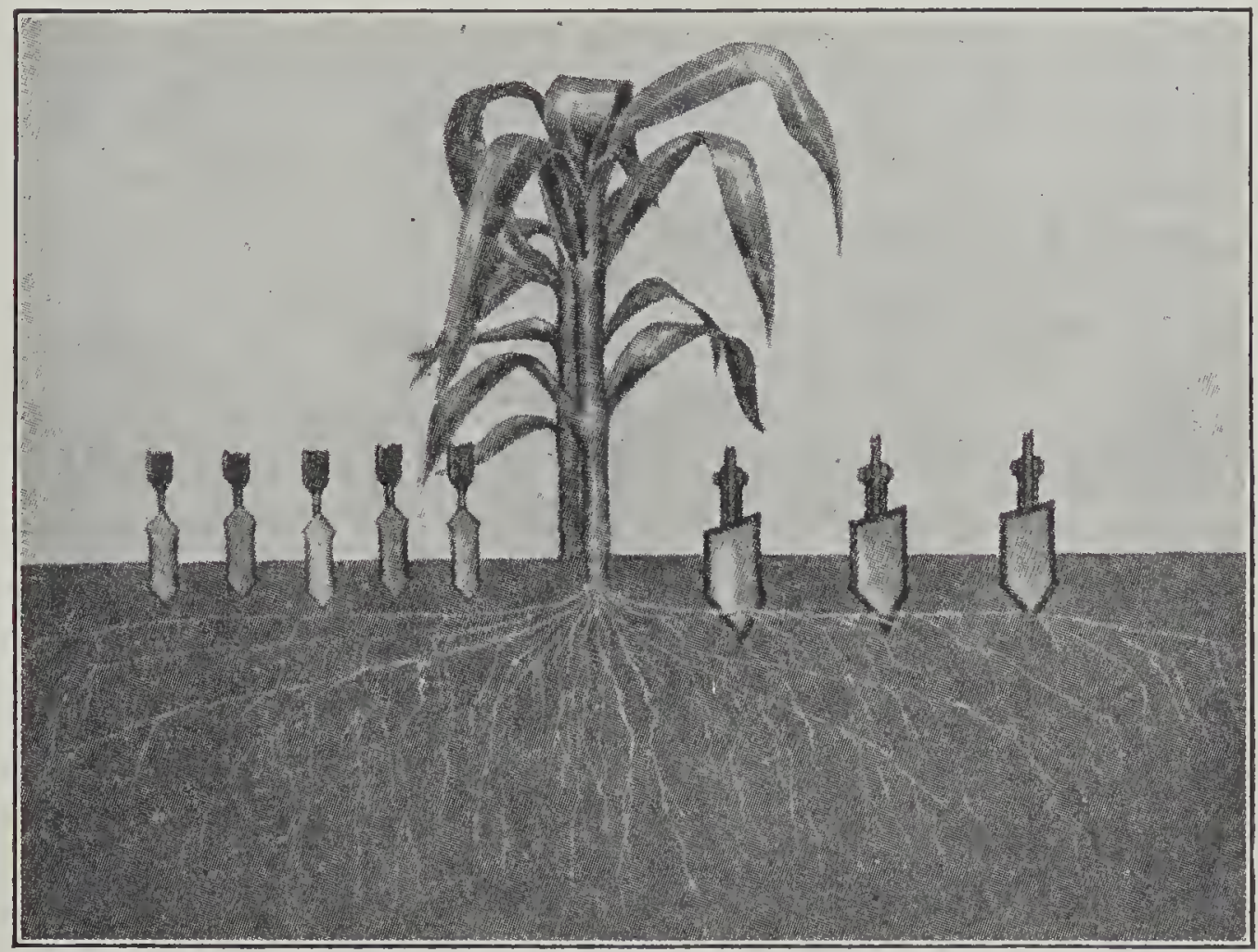

Fig. 84. - Depth of corn roots.

bed has not been well prepared, deep stirring may be beneficial while the plants are small. However, as they become larger, the deep cultivation should be discontinued, as otherwise the shallow, spreading roots are cut off.

There is but one way to tell how deep it is safe to cultivate. This is to make a careful examination to ascertain 
how near the roots are to the surface. After the cultivator has gone through the field once, we should scrape away the earth in two or three places to see if any of the roots have been cut or broken off.

It is in the upper three or four inches of soil that available plant food is most abundant, and this is the feeding ground of many important roots of the corn plant. It is self-evident that they should not be destroyed. It is safe to say that a great deal of the damage that has been sustained by farmers of the Corn Belt in the past as the result of drouths was avoidable in the sense that it was the direct effect of the severing of feeding roots at a time when the plants were unable to withstand this treatment without serious injury.

132. Frequency of Cultivation. - The number of times that corn should be cultivated is determined by certain conditions which are highly variable. Since the purposes of cultivation are mainly to destroy weeds and to conserve moisture, we may say that the frequency of cultivation depends upon the weediness of the field and upon the number of beating rains which it may receive. It is a mistake either to allow weeds to become established in the field or to allow a crust, from which moisture can escape, to form and remain on the surface; and on the other hand it is inadvisable to cultivate soil when it is already free from weeds and its surface finely pulverized.

It should be noted in this connection that mere size constitutes no good reason for discontinuing the cultivation of corn, or, as we say, "laying it by." It is true that when the plants become large enough to shade the ground effectually, the growth of weeds is checked to some extent, but it is also true that much more moisture is needed at this stage than at any other and that its con- 
servation is mole important than at any previous time. The correctness of this principle is abundantly shown by the fact that those farmers, who, in dry seasons, make it a practice to cultivate their corn throughout the hot, dry months whenever a crust begins to form almost invariably secure a very substantial increase in yield. The cultivator used for this work is made to go between the rows. It is fitted with very small shovels, or even with harrow teeth, and is frequently made at home.

A twofold injury results in case a crust is allowed to form upon the surface: the moisture, of which the plants stand in great need, is lost by evaporation; and by the cracking of the dried-out soil, which almost invariably occurs, the roots that occupy the best part of the plants' feeding ground are broken or torn apart in large numbers, this being especially true of the smaller ones.

133. Cultivation of Listed Corn. - Three things must be kept in mind in cultivating listed corn:

(1) The furrows should be opened out while the corn is just becoming established in order that the young plants may receive the maximum amount of sunlight.

(2) The weeds that appear on the shoulder of the ridge and about the young plants should be destroyed.

(3) The furrow should be gradually filled up as the corn becomes older that the roots may be protected from the drying effect of the winds of midsummer. (Section 123.)

The furrows are opened out by discs which work in the bottom and against the shoulders of the ridges. This operation also destroys weeds on the sides and tops of the ridges. Small, curved knives or dises should follow behind and throw a very slight amount of dirt about the 
young corn to bury the tiny weeds and to prevent evaporation of moisture.

As the corn becomes larger, the discs are reversed and the soil is drawn by successive cultivations about the roots of the plants. Shovels are usually substituted for the discs at the second and later cultivations.

134. Harvesting the Crop. - One of the peculiarities of every food-producing plant is that as food material

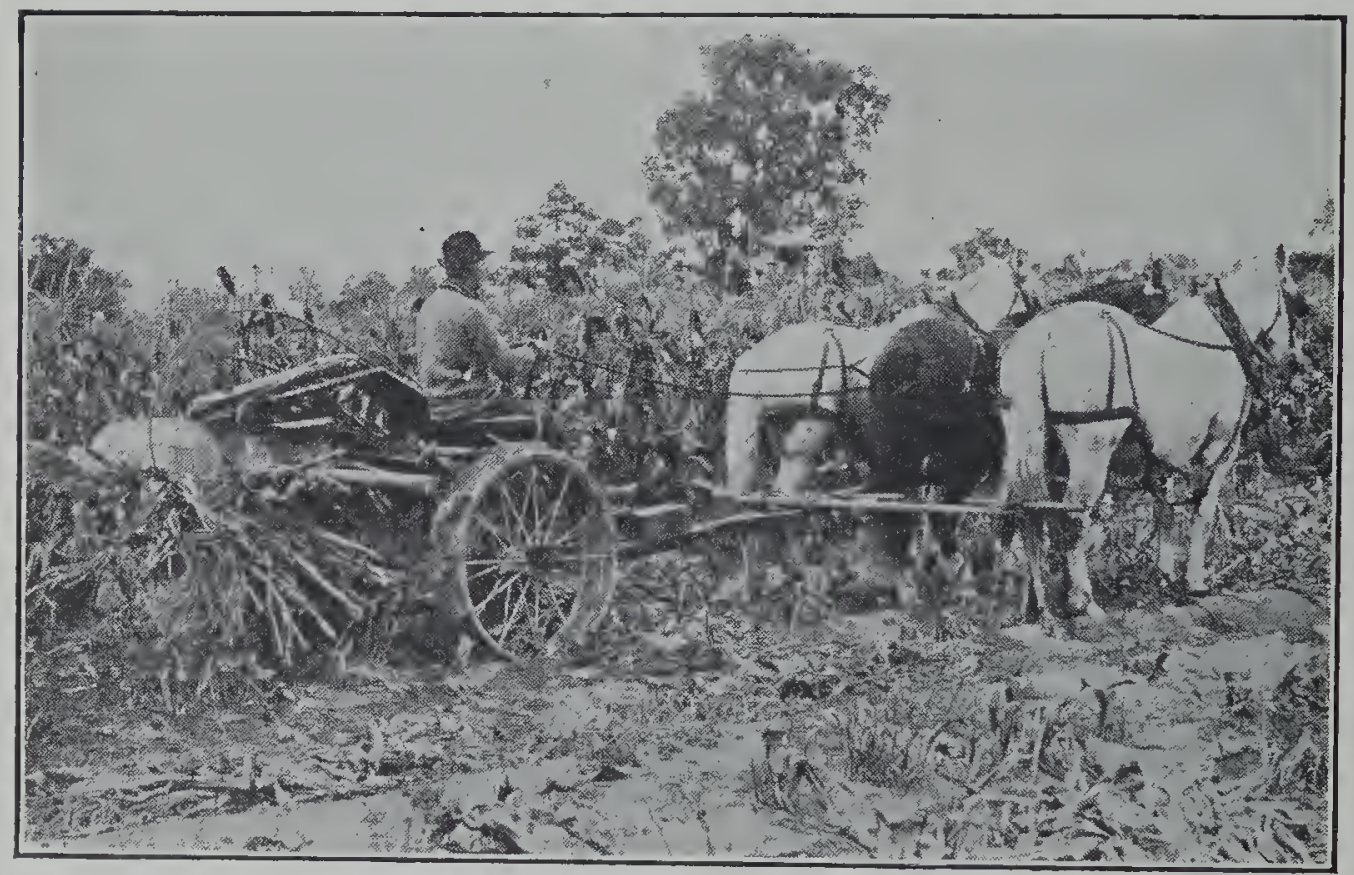

FIG. 85. - Cutting corn with a binder.

is stored in the seed, other parts of the plant become . gradually woody and indigestible.

In the case of corn, for example, we find that while the amount of dry matter in the plant increases steadily until the crop is nearly or quite mature, the amount of digestible matter increases only until the kernels become glazed over and diminishes quite rapidly thereafter. Thus the mature plants on an acre, yielding sixty bushels of 
corn, contain approximately 3300 pounds of digestible food material; but these same plants, at the stage when

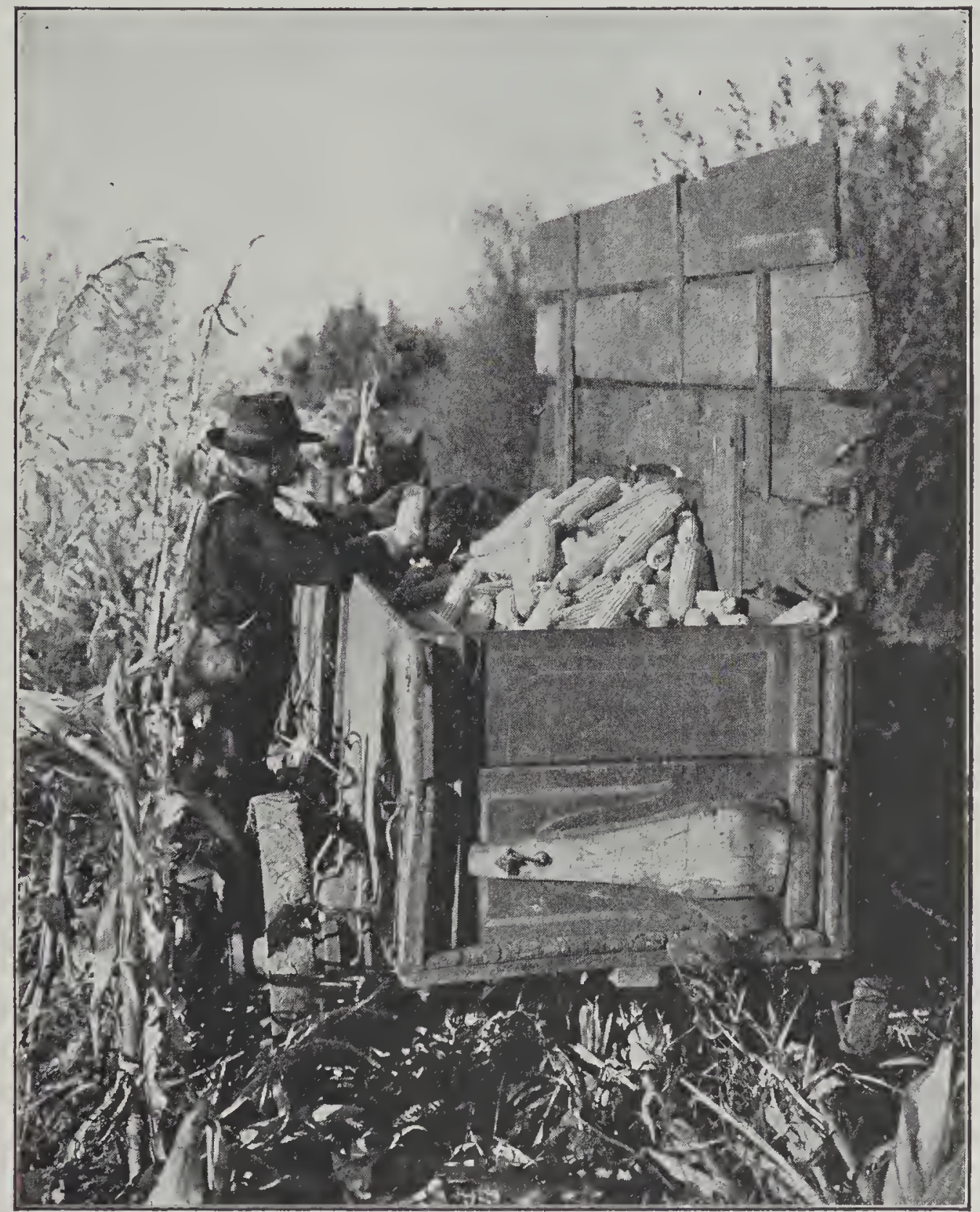

FIG, 86. - Husking in the field.

the ears were in the glaze, contained from 4000 to 4400 pounds of digestible food material. In general we may say that the amount of digestible nutrients in the corn 
plant is at least from 25 to 35 per cent greater when the ears are in the glaze than when the plant is mature.

It is chiefly due to this fact that the practice of cutting corn when the ears are in the glaze, chopping it into fine pieces, and storing it in silos to be fed out later, has proved profitable, though another important reason is found in the fact that a store of palatable, succulent feed is thus secured for winter use. This method of harvesting the crop is undeniably gaining in popularity, and justly so.

The practice of cutting the corn while in the glaze and shocking it to be used as dry fodder later, also has the advantage named above of yielding a greater amount of digestible food material from a given area than will be secured if the plants are allowed to mature and only the ears are taken. However, this method is open to the objection that a considerable amount of the food value is ordinarily lost as the result of molds, weathering and other causes.

Notwithstanding the advantages of other methods, however, it is still true that by far the greater part of the corn crop grown in the central states is allowed to ripen in the field, gathered in wagons and stored in cribs.

135. Crops used as Substitutes for Corn. - In those sections of the West where the rainfall is scant during the hot summer months, corn can not be safely grown. To take its place, other plants which are peculiarly adapted to a semiarid climate have been introduced from foreign lands, and are extensively grown for their grains which are not greatly different from corn in composition. Among these are Kafir corn, milo maize, dura, feterita and others.

These plants are not to be regarded as varieties of corn at all. In fact, they are only distantly related to it, though they are true grasses. They came to us from 
Africa, while corn is a native of southern Mexico. They are sorghums, belonging to the same genus as ordinary sorghum cane; but they are not sweet as we are apt to think all sorghums must be. They all bear their seeds, which are of various colors and more or less round in shape, in heads or spikes, at the tops of the stems. The

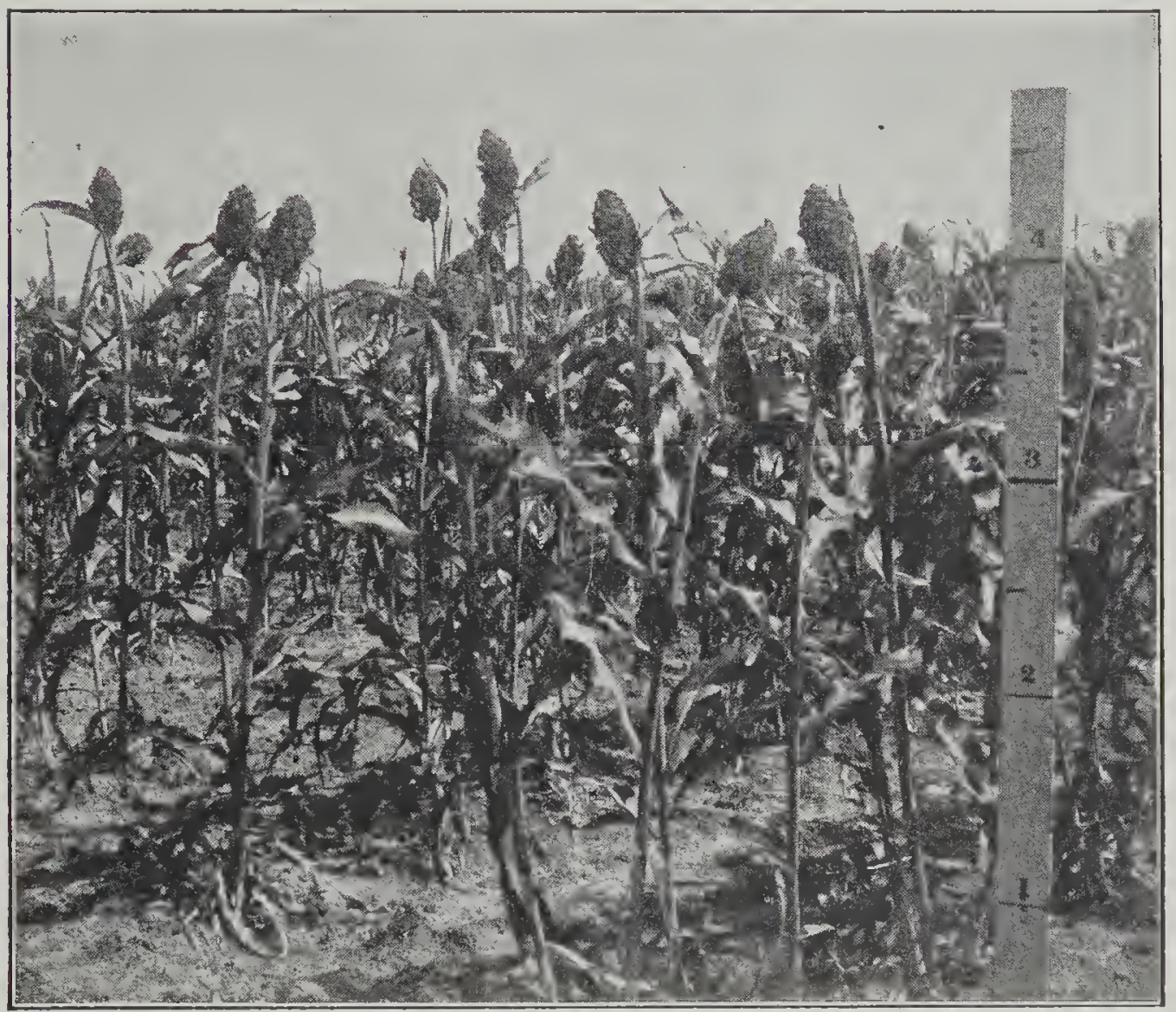

FIG. 87. - Field of Kafir corn.

leaves are coarser, thicker and glossier than those of corn and the yield of grain per acre is somewhat less.

The value of these plants in the semiarid West depends not alone upon the fact that their pollen is able to fertitize the ovules while in a drier condition than is required by that of corn, but also upon their remarkable ability to revive after hot winds or drouth and to continue growth. More- 
over, they are actually able to draw more moisture from the soil than is the corn plant.

Corn which has once been stunted by drouth or by hot winds never fully recovers. The sorghums do recover, usually producing satisfactory crops of grain in spite of these adverse conditions. They have made possible the cultivation of a great deal of land in the semiarid West, which, but for them, could not be made to yield profitable crops.

\section{Planting and cultivating Kafir Corn and Similar} Drouth-Resistant Crops. - Notwithstanding the fact that these crops endure drouth to a remarkable degree, they require a moist, mellow seed bed at the time the young grain is sprouting, and rather exacting conditions as to the way in which the seed is put into the ground. If the ground is too dry, or if the seed is planted too shallow, the young plants will not succeed. If planted too deep, or in a situation where the loose dirt will be washed over them during dashing rains, the young plants can not push their way to the surface, owing to the limited supply of food in the seeds which are comparatively small (Exercise 24.)

Those fields which produce the best yields of Kafir corn and other similar crops are the ones in which (1) the soil has been put carefully into condition to receive and hold the moisture as explained in Sections 30 and 31, and in which (2) the furrows have been opened with the lister in such a way as to prevent so far as possible the water from running down the rows. The latter is accomplished by keeping the bottoms of the furrows as nearly level as possible, as, for example, by following around the hills with the lister rather than simply up and down their slopes. 
The planting is done from one to three weeks later than that of corn in the same latitude. The best plan is to put the seed in with a drill of special design, which leaves the bottom of the furrow slightly ridged along the middle. This prevents such soil as may be washed into the furrow from being deposited upon the sprouting seeds. Dry land farmers, and others who grow Kafir corn, say that more seed is planted too deep than too shallow. Experience and experiments show that seed, covered to a depth of about one inch with moist, mellow earth, germinates and becomes established well.

Care must be exercised during the first cultivation not to cover the young, tender plants. Moreover, they need plenty of sunshine and warmth.

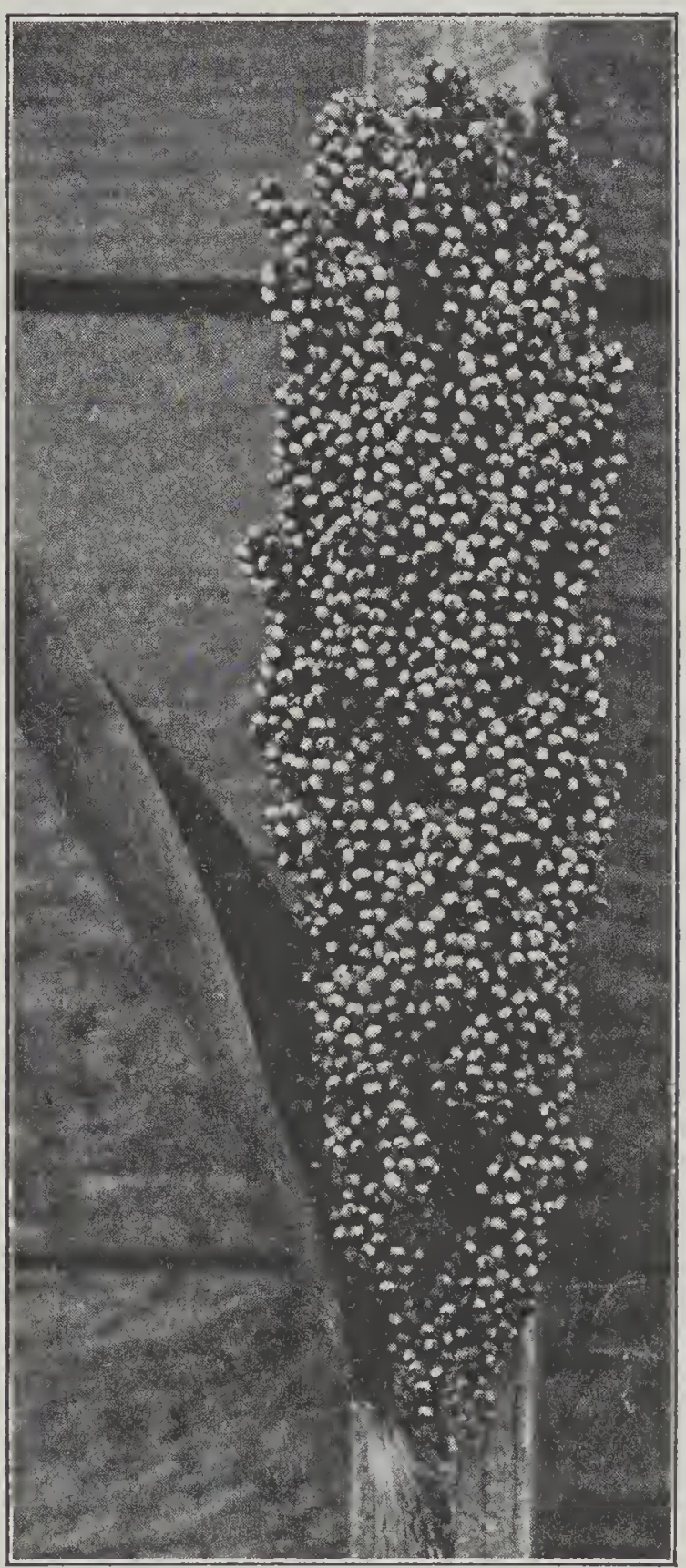

FIG. 88. - Head of Kafir corn. In general, the methods of cultivation are the same as those given for listed corn in Section 133. 


\section{QUESTIONS}

1. Name four uses of corn.

2. What changes do we find in the corn plant as we go from south to north through the United States?

3. Name the two factors which commonly limit the yield of corn throughout the Corn Belt.

4. Name seven indications of unsoundness or immaturity in an ear of corn.

5. Name five important points considered in examining the ear of seed corn. Three in examining the kernels.

6. Name four methods of selecting the seed supply for the following year's crop.

7. State the advantages of the one first given in the text.

8. In what ways may moisture cause the death of the germs of an ear of seed corn?

9. Name the conditions necessary in storing seed corn.

10. Tell how to make a germination test with a "rag doll."

11. Describe the ideal seed bed for corn.

12. Name the steps necessary in preparing such a seed bed in sod ground.

13. What are the advantages of fall plowing of sod ground?

14. State two reasons why the burning of stalks should be avoided.

15. What is the particular advantage of checking corn?

16. What is the great advantage of listing corn?

17. Why do corn growers regard the replanting of missing hills with disfavor?

18. How could you tell how deep it is safe to cultivate a field of corn?

19. Name two injurious results of allowing a crust to form on the surface of the ground while the corn is growing.

20. Name three reasons why the sorghums can succeed in drier weather than can corn. 


\section{CHAPTER XVII}

\section{THE SMALL GRAINS}

THE term cereal is applied both to the plants which yield the grains and to the grains themselves. Cereals, then, include corn, Kafir corn and other sorghums, oats, rye, barley, rice, millet, etc. The cereals are all monocotyledons and members of the grass family. They make up by far the greater part of the food of man and have since the dawn of history occupied very largely his cultivated land.

The leading cereal, or grain crop, varies in different countries. In northern Europe it is rye; in southern Europe, barley; in Asia, rice. In North America, the most important crop is maize, or corn, while wheat occupies second place although it is the chief food of civilized man. Oats rank third.

\section{WHEAT}

137. Why Wheat is so extensively grown. - The Chinese are known to have cultivated wheat for nearly five thousand years. As civilization has moved westward, the cultivation of wheat has moved also in that direction. There are a number of reasons why wheat has always been a leading grain crop and will always continue to be so:

(a) It succeeds in a wide range of soils and climates.

(b) It requires as little tillage as any grain we grow.

(c) It yields quick and abundant returns. 


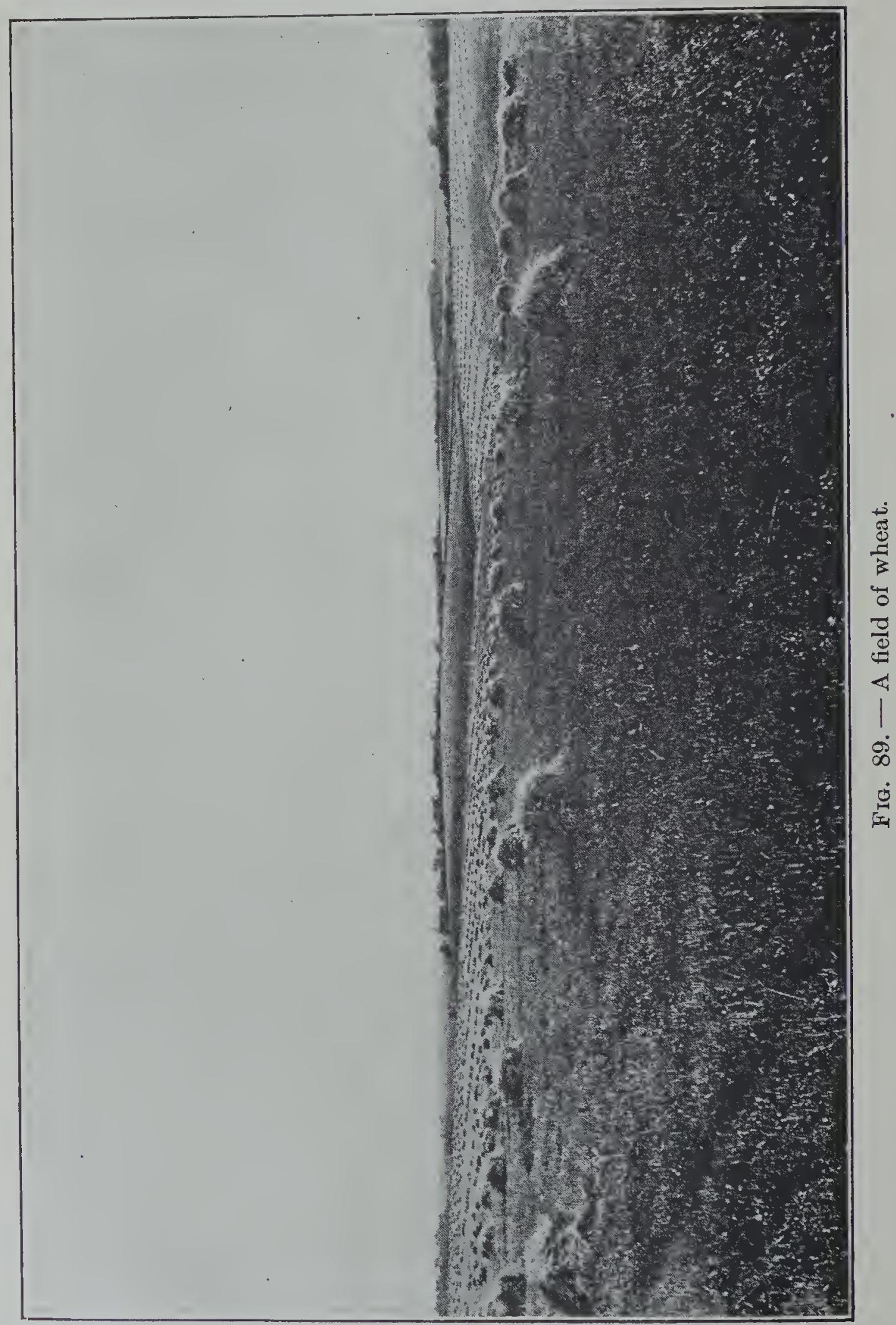


(d) It can be easily transformed into a light, appetizing, wholesome, almost perfect food for human beings.

(e) Valuable foods for domestic animals are prepared from those portions of the grain which man does not use for white flour.

138. Climatic Conditions Favorable for the Growth of Wheat. - In North America, the greater part of the wheat crop is produced where the temperature in January is below freezing. Wheat is grown in California and other portions of the country where cold winter weather does not prevail, but on the whole, the cultivation of the crop is moving northward. The immense wheat fields of Alberta and Saskatchewan in Canada show this to be true.

The best wheat is grown where there is a long, cool spring, followed by a moderately dry, sunny summer season while the grain is ripening.

139. Winter and Spring Wheat. - There are two general classes of wheat: that which is sown in the fall, called winter, or fall wheat; and that which is sown in the spring. In general, winter wheat, which comprises from sixty to seventy per cent of the total wheat crop of the United States, is grown south of the forty-second parallel, while most of the spring wheat is grown north of that line.

Winter wheat is more productive than spring wheat, as a rule, in those sections where both may be grown; and owing to the introduction of hardier varieties, it is being grown, like corn, farther north each year.

140. Systems of Rotation. - Throughout the newer regions of the great wheat belt, wheat follows wheat year after year: The virgin soil, modern cultivating and harvesting machinery, the comparatively low price of land, the satisfactory returns and the scarcity of labor 
have been responsible for this. However, after only a few years, it is found necessary to introduce some system of "rotation," or succession of crops, which will keep up the physical condition and as far as possible the fertility of the soil.

In the older grain states, particularly those of the great central valley, a five-year rotation is often recommended as follows :

First Year, Corn.

Second Year, Oats.

Third Year, Wheat.

Fourth and Fifth Years, Timothy and Clover which have been sown in the wheat the third year.

In those sections of the country, which are given over largely to the production of corn, corn is often grown two years in succession. Oats are sown in the cornstalks the following spring, for the soil is well settled, making a firm seed bed, which is highly desirable. Wheat with which timothy is sown follows the oats; and clover is sown in the wheat field in the spring. The young cloyer takes possession of the land after the wheat is removed, yields a full crop the following year, and the ground is plowed in the fall. The sixth spring, the field goes back into corn again.

Sometimes this rotation is shortened by omitting the oats. Wheat then follows corn. If winter wheat is grown, the corn may be cut for fodder or for silage, or the wheat may be sown between the corn rows with a onehorse drill. Spring wheat is sown with larger drills after the cornstalks have been cut or broken down in the spring.

141. The Seed Bed and how to prepare it. - Successful growers of small grains have learned that these crops 
demand a seed bed that is loose, or mellow, in the upper two or three inches, but firm and compact below this depth.

To secure a seed bed of this description in case wheat is to be grown after oats, the stubble ground may be (1) disced as soon as possible after the oats are removed; (2) plowed, not too deeply, as early as this can be conveniently done; (3) harrowed immediately after plowing to prevent loss of moisture; and (4) harrowed and disced as often as necessary just before seeding time in order to make the surface soil loose and mellow.

The advantages of discing before the plowing is done are as follows:

(1) It conserves moisture by making a dust mulch.

(2) It allows rain to enter the soil instead of running off.

(3) It destroys growing weeds, and starts the germination of other weed seeds in the soil.

(4) It makes the draft lighter for plowing because the soil is loose and mellow.

(5) It pulverizes the soil and works the straw into it in such a manner as to allow the water to rise freely after plowing.

The reasons for early plowing of the ground when preparing it for wheat are :

(1) It gives time for the seed bed to become firm and compact whether from rains, the weight of horses and machinery or other cause.

(2) It gives time for capillary connection to be restored.

(3) It gives time for liberation of plant food by decay.

(4) In the case of winter wheat, winterkilling is reduced because of the greater compactness of the seed bed.

142. Selection of the Seed. - Experiments favor the selection of the large, plump seeds, for the reason shown 
in Exercise 24. These may be secured by running the wheat through the fanning mill, which removes not only the small, shriveled and broken kernels, but many of the weed seeds as well. Uniformity, freedom from weed seed and other foreign matter, soundness, weight per bushel and hardness are all taken into consideration in selecting seed wheat.

We may compare and judge samples, and in this way become familiar with our leading small grain.

\section{EXERCISE 47}

Object. - To compare and judge two samples of seed wheat.

Procedure. - Procure two samples of wheat, each to consist of a quart or more. Mark them "No. 1" and "No. 2."

Compare them with regard to uniformity, freedom from foreign matter, including weed seeds, soundness, weight per bushel and hardness as directed below :

(1) Uniformity. - The kernels should be uniform in size, shape and color; and in judging the sample, the prevailing size, shape and color should be used as a basis. The term color as used here relates to the natural color of the kernels. It follows that we do not hold it against a sample at this stage if discolored kernels are present, for the reason that discoloration of kernels will be considered later under soundness. In determining the prevailing size, shape and color, count out one hundred kernels and sort them out in piles according to the differences which they show in this respect.

The reason for making uniformity an important factor in judging grains is that it is our only reliable guide as to the purity of the variety. If varieties are mixed, we find that the size, the shape, or the color, or perhaps all three, will be variable. 
(2) Freedom from Foreign Matter. - We look for three kinds of foreign matter in wheat. The first and worst one is weed seeds; the second is grain of other kinds, as barley or oats; and the third is inert matter, as sticks, chaff, etc.

(3) Soundness. - This is an important factor to consider in judging seed wheat. The kernels should be plump and bright in color. Shriveled kernels indicate immaturity. The sample should be free from kernels which are decayed, sprouted, musty, moldy, binburnt, broken, shrunken, smutted, bleached, blistered, discolored, damp, or insect injured.

Most of these unsoundnesses indicate that the vitality of the seed has been impaired or destroyed, which accounts for the importance attached to this point in judging seed wheat.

(4) Weight per Bushel. - Plump, well-developed kernels of medium size indicate a high weight per bushel. We consider the sample low in weight per bushel in proportion as we find many shrunken, shriveled, musty, moldy, sprouted or badly weathered kernels, or in case much inert foreign matter is present. In judging samples, weight per bushel is usually determined rather by indications of this kind than by actual weighing, as the latter can not ordinarily be done.

High weight per bushel is desirable in seed wheat, for it means that the kernels are plump, or in other words that the store of food for the embryo in the average kernel is large. (Exercise 24.)

(5) Hardness. - Relative hardness may be determined by biting in two several kernels from each sample, or by cutting them in two with a knife. Hard wheat is best for milling purposes and commands a higher price in the market. 
Conclusion. - State which of the two samples you consider better from the standpoint of uniformity and give reasons for your opinion. In the same way, state which one you believe to be better as regards freedom from foreign matter, soundness, weight per bushel and hardness, giving reasons for your decision in each case. In view of all the answers you have given, which one do you regard

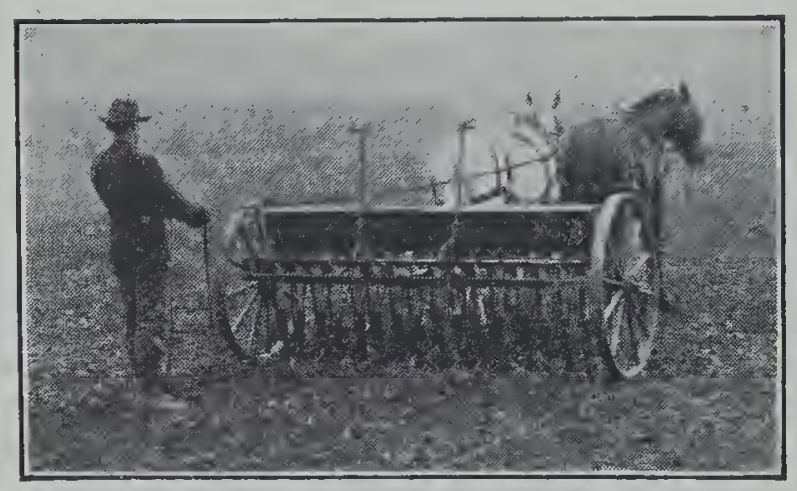

FIG. 90. - Drilling in wheat. as the better of the two samples of wheat? State reasons for your answer fully.

Now weigh equal amounts by measure of each sample, using, for instance, a baking powder can, level full, and see if their relative weights are about as you have judged them to be.

Write in your notebook the reason or reasons why each of the five points named is regarded as important in judging seed wheat.

143. Planting the Seed. - The grain drill has come largely to take the place of the old broadcast method, and on the whole has given much better results.

The time of sowing depends upon the climate, the soil, and, in case of winter wheat, upon the prevalence of an insect known as the Hessian fly. The farther south we go, the later the sowing may be done for winter wheat. In the region of the fortieth parallel, the date of sowing it is about the middle of September. Farther north, where spring wheat is raised, the seeding is done from the latter part of April until the latter part of May, depending upon the latitude or the season. Fall or winter wheat 
may be sown in a fertile soil later than in a poor soil and in a well-prepared seed bed later than in one poorly prepared. The roots must become well established before winter sets in or winterkilling is apt to result. On the other hand, too early sowing may cause plants to "shoot," after which they will be killed by the extreme cold of winter.

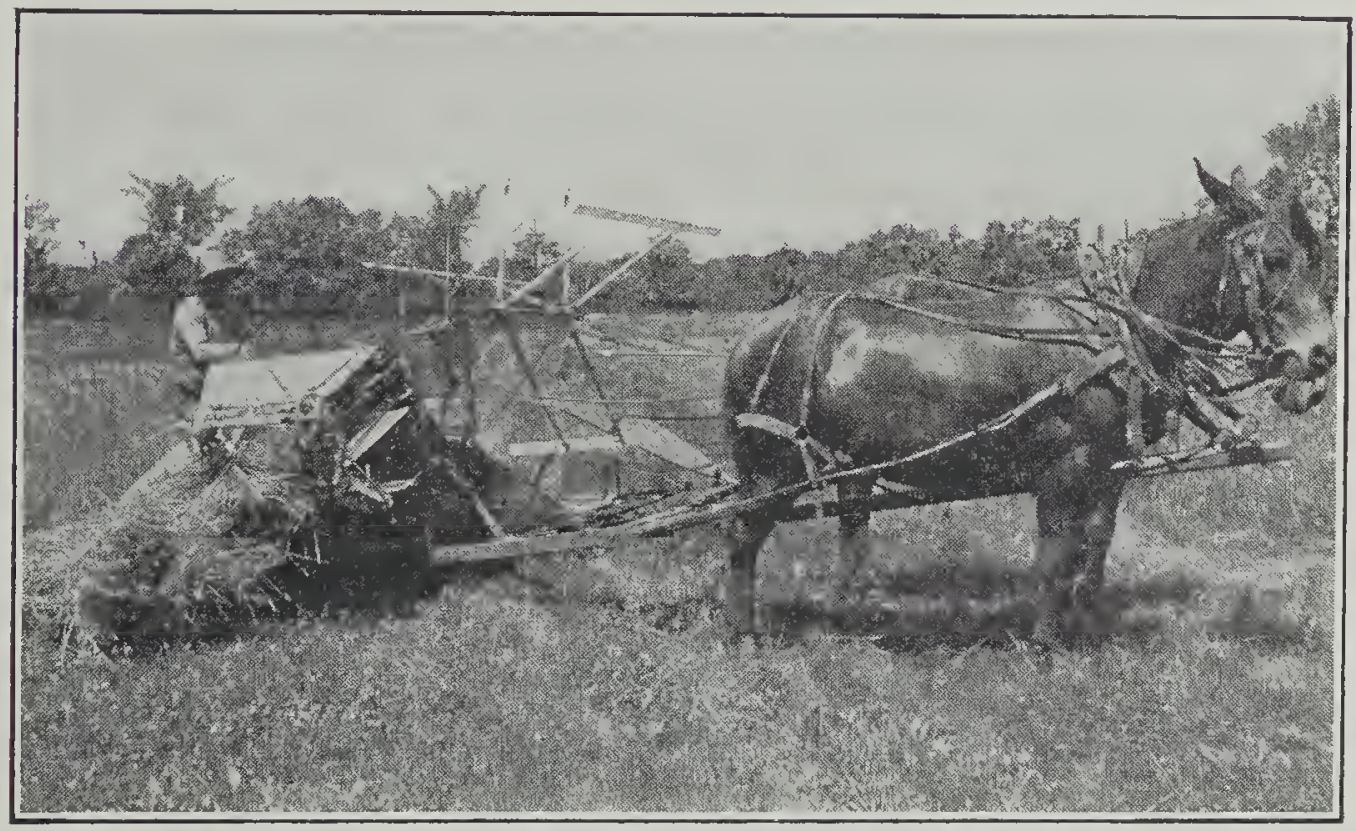

FIG. 91. - Cutting grain with a self-binder.

The Hessian fly makes its appearance known by attacking the volunteer wheat, which comes up after the crop is harvested. When the insect is present in the fields, seeding must be delayed until practically time for frost, for after this time, the eggs are'no longer laid. In Kansas and Oklahoma, wheat planted in the first week in October usually escapes injury from the Hessian fly.

144. Harvesting the Wheat. - The wheat harvest begins in the South in May and moves gradually northward, the crop in North Dakota being harvested in August. 
Laborers are able to follow the harvest and find employment in the wheat fields throughout the summer months.

The time of cutting wheat depends largely upon the kind of machinery with which it is done. Wheat, which is cut with the binder, and placed in shocks, must be not fully ripe or the grain will shatter.

If the wheat is cut with the header, it must be nearly ripe or it will mold when placed in the stack.

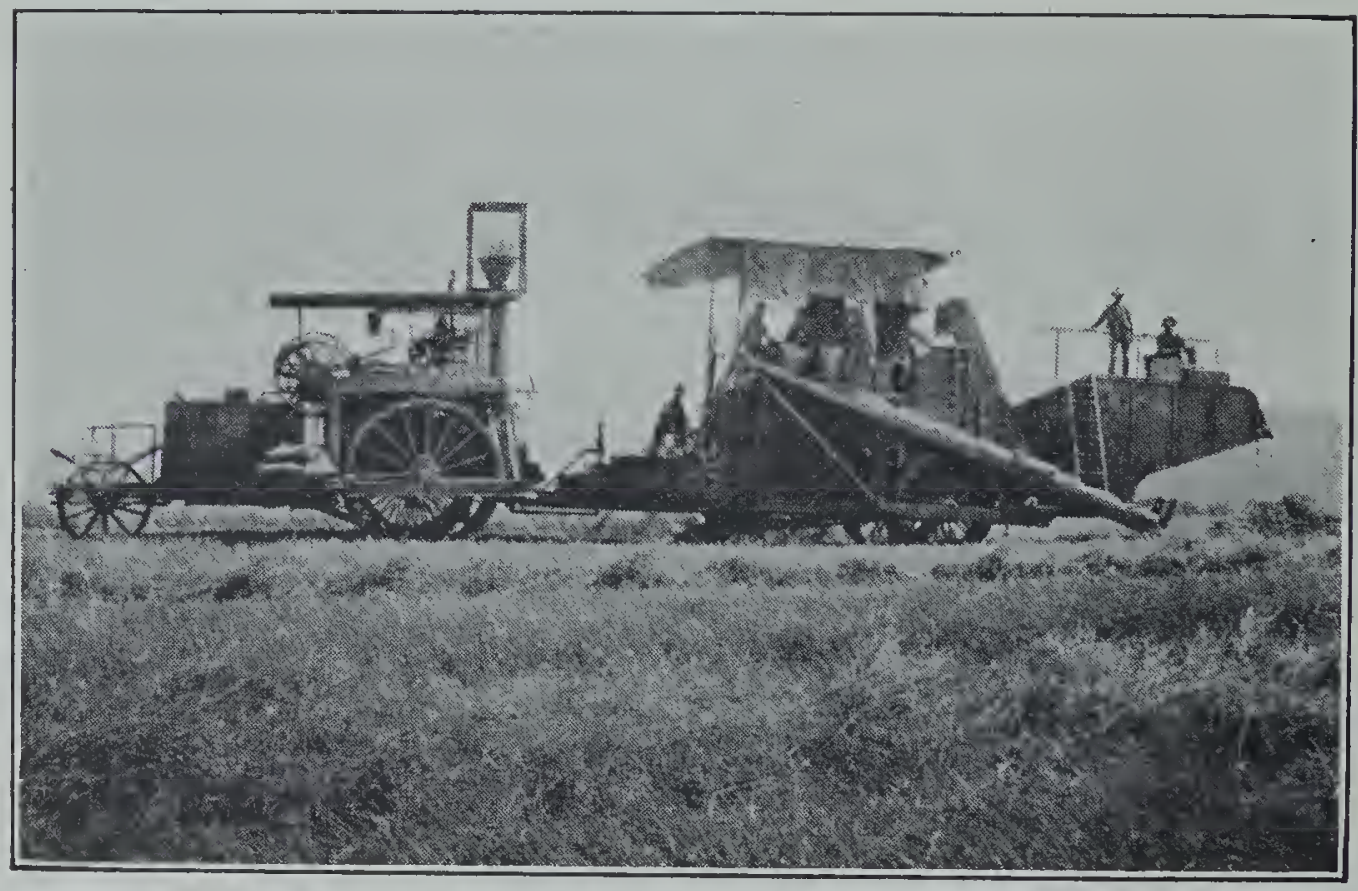

Courlesy International Harvester Co.

Fig. 92. - Combined harvester and thresher.

In California, Oregon and Washington a combined header and thrésher is often used. In this case, the grain must be fully ripe, as otherwise it can not be stored. The varieties of wheat grown there and the dry weather which usually prevails at harvest time, make it possible for growers to allow their grain to stand even for several weeks.

145. The Uses of Wheat. - Unless the price of wheat is very low, whole wheat is not used as a feed for domestic animals. 
The inner portion of the grain is used for flour, the wheat yielding about seventy per cent of this product.

The outer coat of the grain is made into bran, a coarse, light product, which is extensively used as a feed for stock. The embryos and the layers just beneath the bran are mixed usually with the bran itself, forming a product, known as wheat middlings. These portions of the grain are rich in protein, and therefore have a high feeding value. (Section 94.)

If no part of the grain is removed after grinding, the product is known as Graham flour; if the coarser parts are removed, it is called whole wheat flour.

Experiments have shown that the percentage of the different flours that is digestible when used as food is as follows :

White flour .

Whole wheat flour.

Graham flour

$90.1 \%$

$85.5 \%$

$80.7 \%$

Thus we see that a higher percentage of the white flour is digestible than of the others, partially because of its finer state of division, but also because most of the indigestible parts of the kernels have been removed. Because of this greater digestibility, bread from white flour will doubtless long remain, as it is at present, the choice of the great majority of the people.

\section{OATS}

146. Oats a Cool Climate Crop. -- The oat plant is a short season plant. It requires a smaller amount of heat for its development than does barley or wheat; and for this reason, it is grown most successfully in the cooler climates. In Scotland, Norway, Sweden and in Canada, large quantities of oats are grown. The average 
yield per acre steadily increases as one goes northward throughout the United States to Canada, and the average weight per bushel

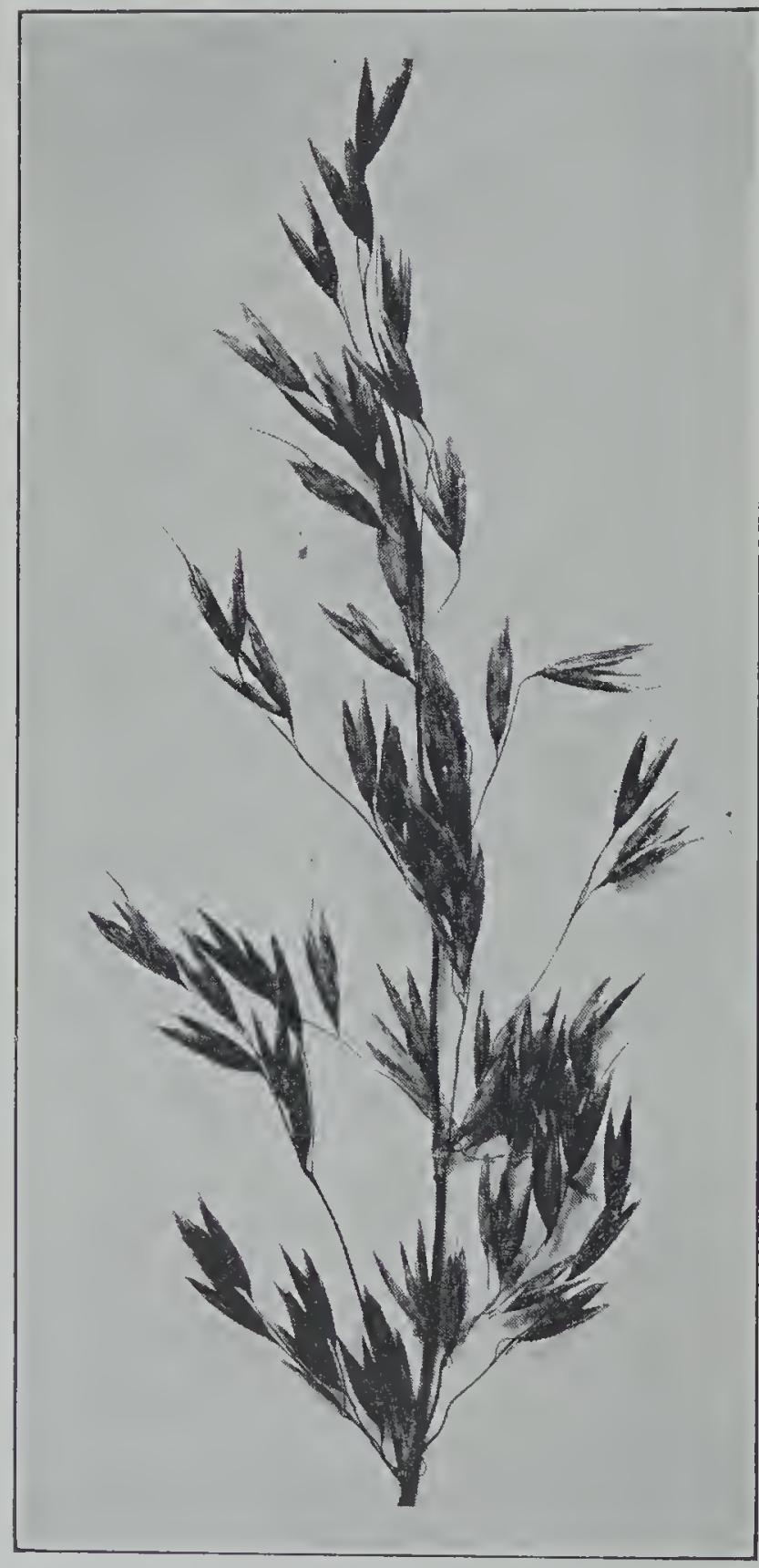

FIG. 93. - Panicle of oats. increases at the same time. In the South, the oats commonly grown are those which, like winter wheat, are sown in the fall. Although not so valuable a crop as some others, oats are grown extensively in the United States because the crop fits well in the rotation.

147. Varieties of Oats. - In color, oats may be white, yellow, red or black, those of the first two colors being most commonly grown.

As in the case of wheat, there are two general classes of oats ; viz., winter oats and spring oats. The former are grown in southern and Pacific states, and, like corn and winter wheat, are gradually moving 
northward. By far the larger part of the oats grown by the civilized world, however, are of the spring varieties.

The variety of oats adapted to any given locality depends not upon the length of the hot, growing season as in the case of corn, but upon the duration of the cool weather in spring and early summer. Thus in Canada, late maturing, varieties of spring oats are successfully grown. In the northern part of the United States, medium varieties of spring oats thrive best, since late varieties can not mature in time as a rule to escape the hot weather. In the same way, early spring oats give the largest yields in the Corn Belt generally, while in the South, where the period of cool weather is short, spring varieties can not be grown successfully, but it becomes necessary to use instead those varieties which make a part of their growth in the fall and hence are able to mature their crop before the hot summer weather comes.

148. Preparation of the Seed Bed.- Oats do not require as deep a seed bed as does wheat. Land which has been in corn the previous year may be thoroughly disced in the spring and the seed planted preferably with a drill; but only in cases of extreme necessity, if ever, may the growth of stalks be burned at this time.

Among the advantages of drilling may be mentioned the following:

(1) The seed is planted at a uniform depth.

(2) A more even distribution of seed is secured.

(3) The crop germinates, grows and matures more evenly.

(4) The yields are larger.

(5) Less seed is required.

If the soil is naturally compact, as is often the case in the eastern states and also in those soils lacking humus, the 
best results are usually obtained by plowing the seed bed before discing. If this is done in the fall, the farmer is able to get his field planted earlier in the spring, and the firm, fine, compact seed bed, which all small grains require, will have had time to form.

149. The Selection of Oats for Seed. - Heavy seed is preferred to that which is light in weight. In Minnesota, the difference in yield between heavy and light seed has been found in some cases to be nearly ten bushels per acre.

The seed should, if possible, be taken from fields free from loose smut, but if there is any indication of the disease, the oats should be treated as explained in Exercise 36 . In fact, some of the most successful growers recommend that all seed oats be so treated every other year.

The desirable characters of seed oats may be well brought out by comparing one sample with another.

\section{EXERCISE 48}

Object. - To compare and judge two samples of oats.

Procedure. - Secure two samples of oats, each to consist of at least two quarts. They should be marked "No. 1 " and "No. 2." Compare them carefully as regards (1) uniformity, (2) freedom from weed seeds and other foreign matter, (3) soundness, (4) proportion of kernel to hull, and (5) weight per bushel, in the manner directed below:

Uniformity. - As in the judging of wheat, we wish the sample to be uniform in size, shape and color. The prevailing size, shape and color are used as a basis, and discoloration of kernels is not held against the sample at this stage as it will be under soundness. In determining the prevailing size, shape and color, count out one hundred kernels and sort them out in piles according to the differences which they show in these respects. 
The importance of uniformity in oats is precisely the same as in wheat, that is, it is our only means of judging purity of variety. A mixture of varieties will show variation in one or more of the three respects named.

Freedom from Foreign Matter. - Foreign matter includes (1) weed seeds, (2) other grains, and (3) inert matter, the first being most objectionable and the last least so.

Soundness. - As in the case of wheat, this is deemed an important point to consider in judging seed oats. The grain should be bright, but not green - as this indicates immaturity - nor yet dull in color. No damp, discolored, weathered, immature, musty, moldy, smutted, badly broken or sprouted grains should be present, as these conditions indicate that the vitality has been impaired or destroyed. We do not, however, regard a slight discoloration as a very serious matter since it is so commonly found and can not ordinarily be taken as an indication of impaired vitality.

Proportion of Kernel to Hull. - A high proportion of kernel to hull is, of course, desirable, as it indicates that the feeding value of the grain is high.

The indications of a high proportion of kernel to hull are (1) a plump kernel, (2) a thin hull, and (3) a short hull without an awn. The opposite conditions, of course, indicate a low proportion of kernel to hull.

Weight per Bushel. - The indications of a high weight per measured bushel are (1) plump grains of medium size, and (2) a high proportion of kernel to hull, determined as shown above.

In general, high weight per bushel means that the oats should produce vigorous young plants when sown, owing to the large stores of food in the plump kernels.

Conclusion. - Which sample do you deem better 
from the standpoint of uniformity? Write reasons for your answer. Which one excels in each of the other four points? Give reasons in each case. Finally, which is the better sample? Write your reasons carefully.

Why is each of the five points given regarded as important in judging seed oats?

150. Harvesting the Crop. - If oats are cut with a self-binder, they should be harvested just as the straw is turning yellow and the leaves are drying up, at which time the kernels are past the "hard dough stage." If cut before this time, the kernels will become shriveled; if later, the oats will shatter badly and much of the grain be lost.

If oats are to be used as hay, they should be cut while the kernels are in the milk stage.

151. Shocking and Stacking Oats. - After the oats are cut, the bundles are usually set together in shocks. The grain which, as stated in the preceding section, is not fully mature at the time of cutting continues to ripen after shocking.

There are two general types of shocks, - the long and the round. Each has its advantages and its advocates. The long shocks permit a freer circulation of air and hence dry out more quickly and thoroughly. This type of shock is preferable if the grain is cut a little too green, or if many coarse weeds are present. On the other hand, the round shocks expose less surface to the elements and are less easily blown down, and they, therefore, afford better protection from the weather, especially if they are capped. The merits of the two types of shocks probably depend more upon the skill and ability of the shocker than upon the shocks themselves. 
No matter which type is used, the oats are certain to be injured if they are subjected to many soaking or beating rains. To avoid the danger of this injury, many good farmers make it a practice to stack their grain as soon as it has ripened and dried out properly in the shock, unless it is to be threshed very soon. The advantages of this practice, provided the stacking is well done, are:

(1) It prevents loss due to injury in the shock, thus yielding grain of better quality than would otherwise be obtained.

(2) It prevents heating and sweating in the bin after threshing.

(3) Less labor is required at threshing time.

(4) The straw is left in a convenient place and is usually of a superior quality.

152. The Uses of Oats. - Oats are used largely as a feed for horses and to a limited extent for cattle and sheep. They are not considered a desirable feed for hogs, other than brood sows, on account of their coarse hulls.

Oat hay is an excellent forage and is used extensively in the southern and Pacific states. It is cared for just as is any other crop of hay, but if handled too much, both leaves and grain are lost by shattering.

Oats are sometimes sown with field peas or with rape. In the first case, the mixture of oats and peas makes excellent hay, while in the latter case, the rape is used for pasture after the oats are harvested.

153. Oatmeal. - Oats, freed from their hulls and rolled, make the most nutritious cereal food we have, though oatmeal was not used as human food until machinery was perfected for removing the hulls. 


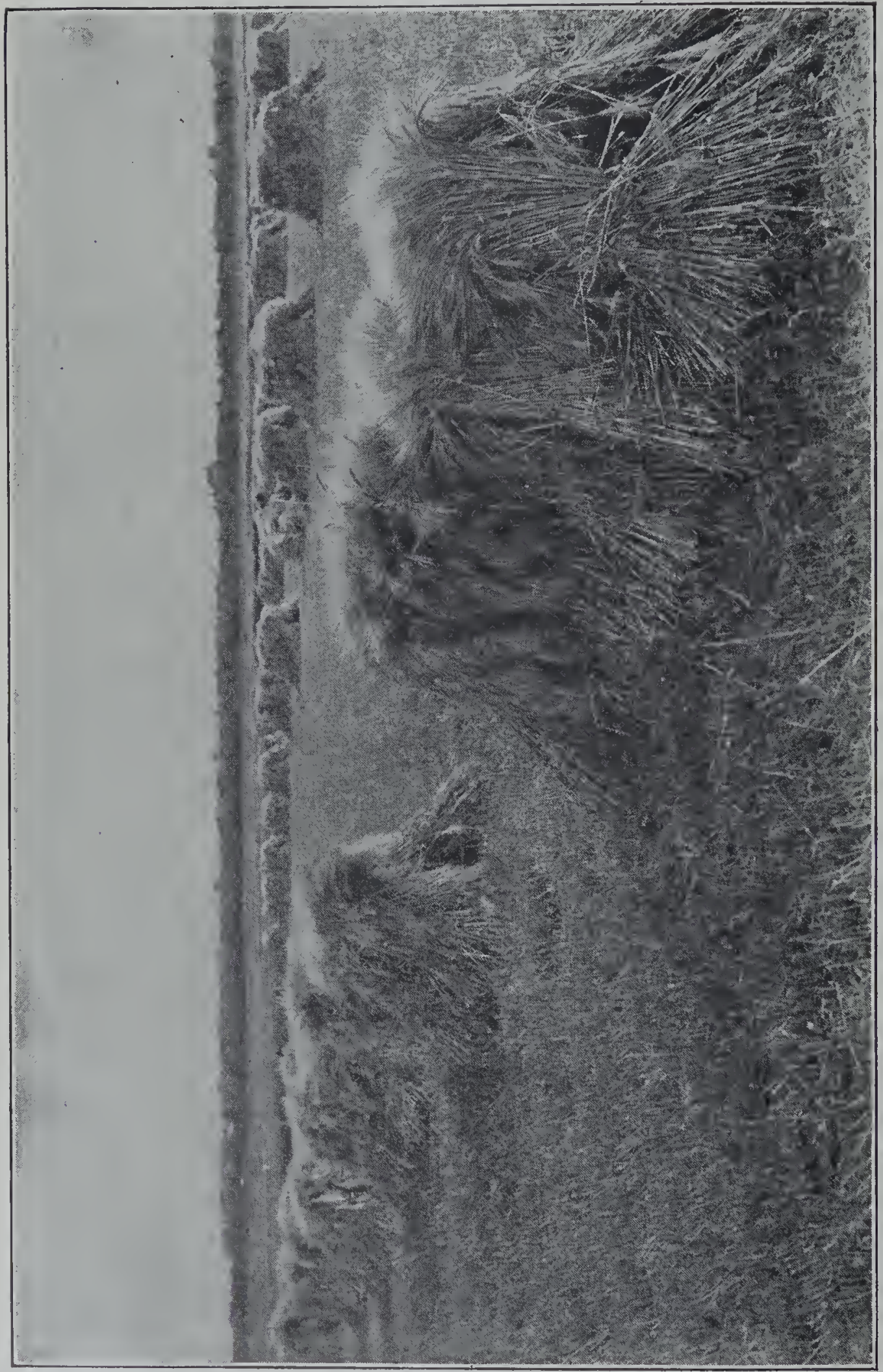


The consumption of this product continues to increase year by year, and, like the Scotchman, the American is coming to be known as an oatmeal eater.

\section{BARLey AND Rye}

Neither of these grains is grown extensively in the United States, at least as compared with corn, wheat or oats. Both are naturally cool climate crops.

154. Methods of Cultivation and Uses of Barley. Barley is grown in a wider range of climate than any other cereal; but in our country, it is produced in greatest abundance in the drier portions of the plains states and in the Pacific states. In those states where oats and corn can not be very successfully grown, as in California, barley has become an important crop and is used for hay as well as for grain.

Barley requires the same seed-bed preparation as does wheat, and the crop is harvested in much the same way.

Aside from its use as a feed for stock, this grain is used for making malt from which certain alcoholic liquors are derived.

155. Soil Requirements and Uses of Rye. - While barley demands a fertile soil, rye will succeed in a very poor soil. Hence rye is grown in soils, as well as in climates, where other grain crops fail.

Rye is used in making flour, particularly in some foreign countries, and also as a feed for domestic animals. The straw is used in the manufacture of paper and as packing material. It is the opinion of some authorities that, were it not for the demand for the straw, the production of the crop would rapidly decrease. 


\section{RICE}

156. The Soil Requirements of Rice. - Rice is consumed more largely by the human race than is any other grain. This is due to the fact that it succeeds well in the centers of densest population, as in India, China and Japan.

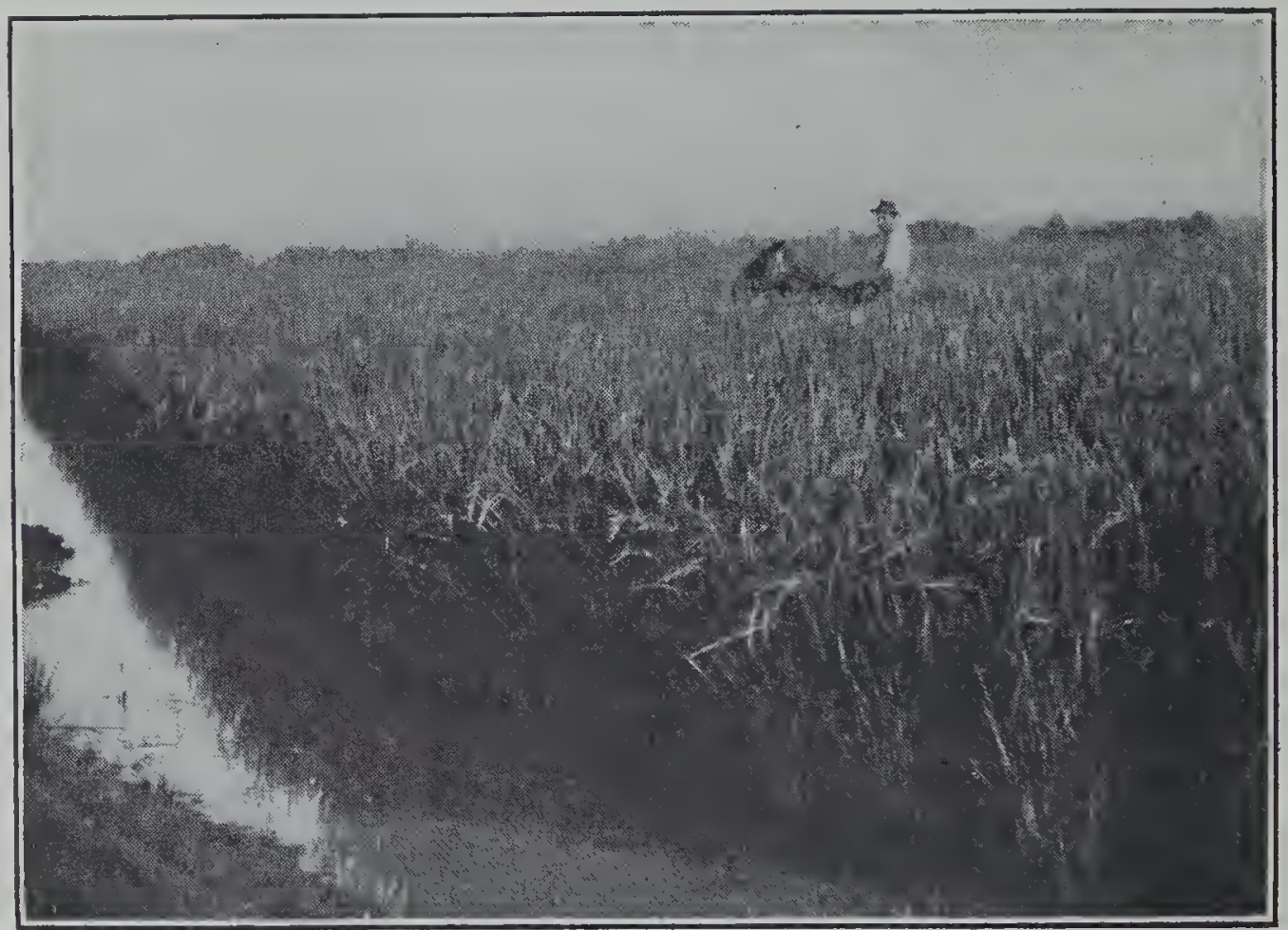

FIG. 95. - A field of growing rice.

The production of rice has increased rapidly in the United States in the last ten to twenty years. Lowlands in the southern part of this country not suited to other crops produce an excellent grade of this grain. It is required that these lowlands be capable of being drained or flooded at will.

157. Preparation of the Seed Bed. - The land is plowed while it is dry in the fall and winter months if the soil is of such a character as to permit of this. Certain types of rice soil, however, can not be worked in this 
condition and must therefore be plowed and harrowed while covered by water.

158. Planting the Seed. - The seed may be planted in the soil while it is submerged. If the land can be cultivated dry, however, the seed is planted while it is in this condition either with a drill or broadcast; and if necessary, it is covered by means of a harrow or otherwise. The water is then turned on the land to start germination, after which it is drained off again until the plants are well started.

159. Caring for the Growing Crop. - When the plants are about six inches high, the field is again flooded and the water kept on it at a depth of from two to six inches for about two months. The water is constantly renewed to prevent its becoming stagnant or the water weeds from becoming established.

When the rice is in the milk stage, the water is drained off and the land allowed to dry while the grain ripens. The crop is cut with an ordinary wheat binder wherever possible though it is necessary in certain places along the lower Mississippi to use the sickle. The bundles of rice are shocked and later threshed with the ordinary threshing machine.

160. How the Grain is prepared for Use. - The rice grains are covered with rough hulls when they come from the threshing machine. At the rice mills, these hulls are removed by rapidly revolving " milling stones," after which the outer coat, or cuticle, of the kernel is removed by special machinery. The grains are then run through machines which polish them by friction against cylinders covered with moose hide or sheep skin. The polished rice has less food value than that which is not polished, 
but its appearance has until recent years given it a higher market value.

161. Uses of Rice. - Rice is used almost exclusively as human food although some is used in the manufacture of starch. The bran and the finely broken pieces, usually called rice flour, are used as a feed for stock, corresponding to the bran, shorts and middlings of wheat.

"Rice straw" hats are not made from rice, but from other grasses. Similarly, Chinese "rice paper" is made from the pith of a tree.

\section{QUESTIONS}

1. Name the six principal cereals of America.

2. What is the leading small grain of America? Of northern Europe? Of southern Europe?

3. Name five reasons why wheat is extensively grown.

4. What is the most favorable spring and summer weather for wheat? wheat?

5. What is the difference between winter wheat and spring

6. What kind of seed bed do small grains require?

7. Name the points considered in the selection of seed wheat and also of seed oats.

8. What are the advantages of long shocks? Of round shocks?

9. Give the uses of wheat, oats, barley and rye.

10. Tell briefly where and how rice is grown. 


\section{CHAPTER XVIII}

\section{GRASSES FOR PASTURES, MEADOWS AND LAWNS}

Is taking up a brief study of the plants under this head, we must keep clearly in mind what true grasses look like. Plants of other families, as for example, the pea, or clover family, are used extensively for pastures, meadows and lawns; but they are not true grasses and will not be studied in this chapter.

162. Characteristics of All the Grasses. - We have studied in different places in the preceding chapters the characteristics of the grasses, which are monocotyledons. Let us now bring them together that we may always know a true grass when we see it.

The roots of the grasses are fibrous, springing from the base of the stem as the first, or temporary root is withering away and finally forming a mass just beneath the surface of the ground, as explained in Exercise 27.

The stems are round and usually hollow, though they are sometimes filled with pith as is the cornstalk. They are made up of nodes and internodes; that is, prominent joints with spaces between the joints.

The leaves envelop the stem by a sheath at the lower portion, are parallel-veined and their upper parts are relatively narrow and lance-shaped. They are arranged alternately on the stem, one springing from each node.

The flowers are greenish in color, inconspicuous, and appear usually at the tops of the stems. We have studied a typical grass flower in Exercise 35. 
The seed is a grain, covered with a thin seedcoat. It is usually longer than wide, the germ being located at one end and on one side.

163. A Peculiar Habit of Growth. - Grasses, particularly those which grow year after year, or perennials,

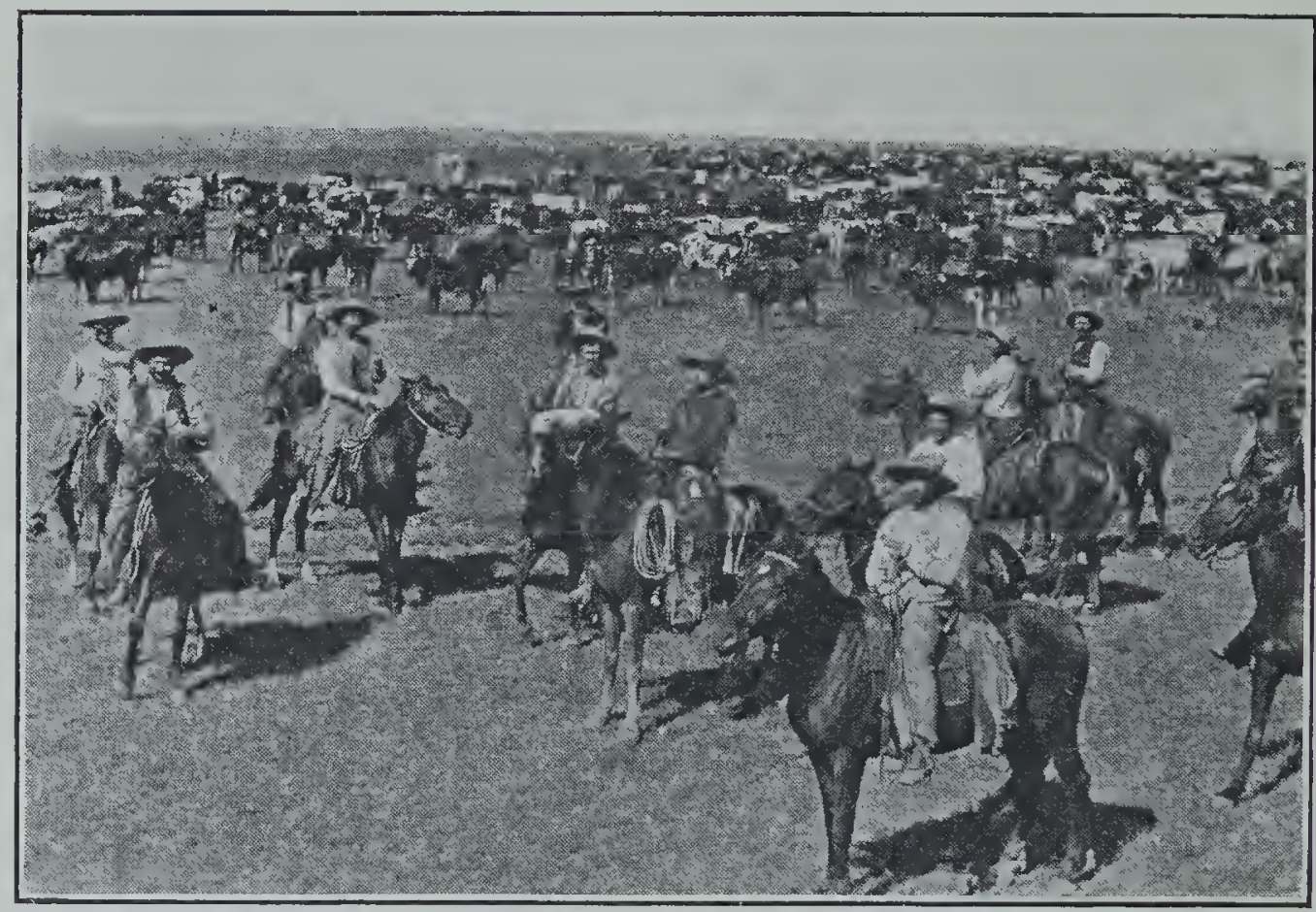

Copyright by Underwood and Underwood.

FIG. 96. - Cattle on the range.

often have creeping underground stems by which the plants spread.

In the small grains, which are not perennials, but annuals, we call this habit stooling. The same tendency is shown even by corn in its habit of forming suckers. These in corn are considered undesirable, while we often watch for wheat to stool with some anxiety as it is a method which the plant has of filling the vacant spaces.

Grasses used for the purposes named in this chapter may be grouped under three heads : 
First : wild prairie and timber grasses.

Second : cultivated meadow and pasture grasses.

Third: lawn grasses.

164. Wild Grasses. - When the white man first began to settle in the territory now known as the United States, the land was covered either with timber or with wild grasses. Gradually the timber has been cut away and the prairie grasses have been broken up to make way for cultivated fields. There yet remain, and will probably always remain, however, vast stretches of prairie in the western plains and in the extreme western parts of the United States where wild grasses are abundant, supporting millions of head of cattle, sheep and horses, and yielding large quantities of wild hay.

165. Cultivated Grasses. - The principal grasses which have come to occupy an important place for meadow and pasture purposes are:

Timothy, the standard meadow grass.

Kentucky blue grass, a pasture grass, which is used also for lawns.

Redtop, which is used for both pastures and meadows.

Brome grass, used for both meadows and pastures. Bermuda grass, likewise used for both purposes.

Millets and sorghums, which are annual meadow grasses.

\section{Tімотну}

166. Where and how Timothy is grown. - This plant occupies first place among the cultivated hay, or meadow grasses of the United States. It is grown largely in the states east of the Missouri River and north of the fortieth parallel, in the high parks of the Rocky Mountain region, and far northward even into Alaska. 
The seed is often mixed with a spring or fall small grain crop, called a nurse crop, from ten to twelve pounds being sown as a rule to the acre. The fall seeding is usually preferred. The crop takes possession of the ground after the small grain is harvested and is allowed to remain for

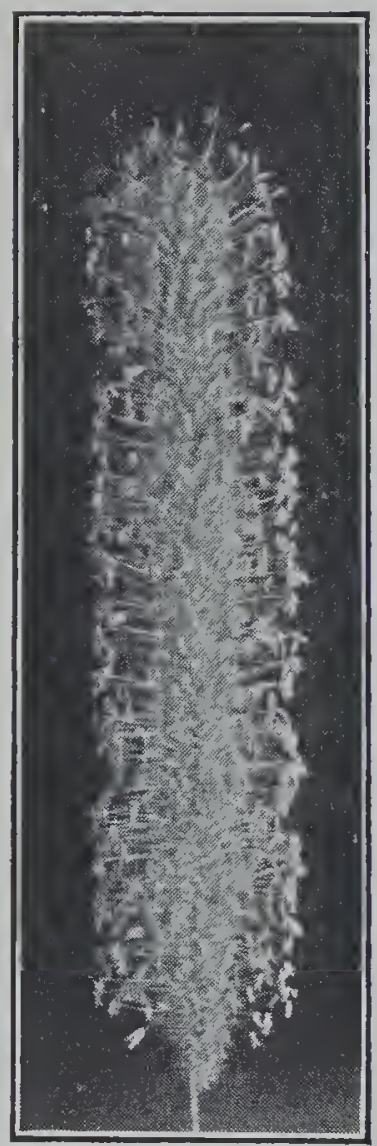

FIG. 97. - Timothy in flower. two or more seasons. If clover is sown with the timothy, as is usually the case, the clover forms seed and disappears in the fall of the second year. After this the field is usually put into some other crop, though if this is not done, the growth the third year is nearly pure timothy as a rule.

167. Advantages and Disadvantages of Timothy. - Since timothy is the leading hay crop of America, we may look for it to possess a number of advantages over other similar crops. Among these are :

(a) It becomes established more readily than other cultivated grasses.

(b) It is easily harvested and quickly cured, thus escaping injury from rains.

(c) The seed is cheap and easily procured.

(d) It may be fed without fear of injurious results, making a palatable hay for horses, especially if cut at the proper time and carefully cured.

(e) It is adapted to a wide range of soils and climates.

(f) There is always a market demand for the hay.

On the other hand, we often hear farmers offering the following objections to timothy:

(a) It yields but one crop a year. 
(b) It can not be pastured without injury to the succeeding crop.

(c) It is less nutritious than alfalfa or other legumes.

(d) It exhausts the soil quickly of its supply of nitrogen.

168. When to cut Timothy. - There are two things to consider in determining the time of cutting timothy:

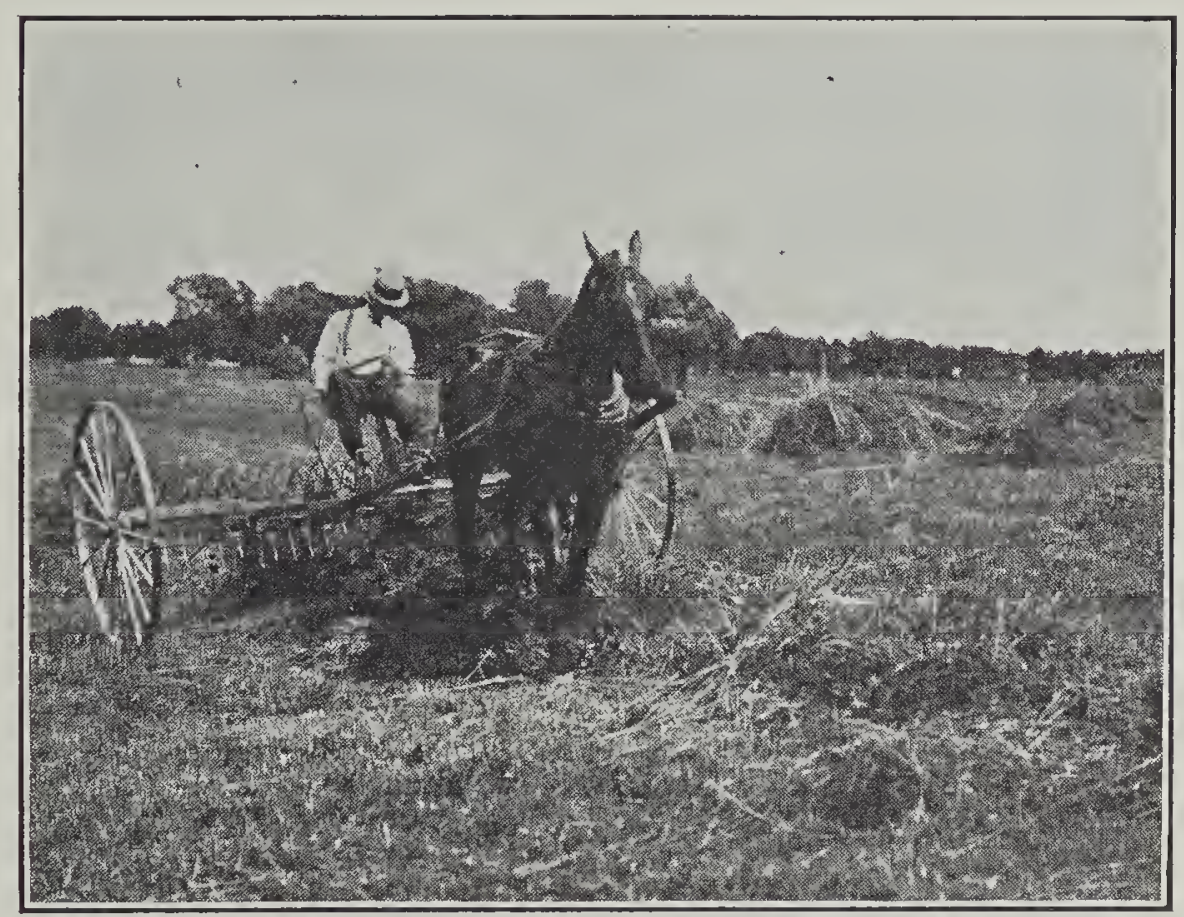

Courtesy Iowa State College.

Fig. 98. - Raking timothy hay.

(1) the yield and quality of the hay, and (2) the effect upon the succeeding crop.

Let us consider the latter point first.

A peculiar characteristic of the timothy plant is that it stores food not alone in the seed but in the stem itself, in one or more internodes near the base. These internodes, which become swollen, are called corms. The store of food which they contain is apparently used the following year in developing new stools, by means of which the plant is thickened. It follows that the plant should not 
be cut until a sufficient amount of food has been stored in the corms to provide for the later, spreading growth. This is usually not until the seed is in the dough stage, or when the purple stamens have all, or nearly all, dropped away. Cutting that is done earlier than this very often results in injury to the succeeding timothy crop, this being especially true in dry seasons, or in regions of scant rainfall. Examine some timothy plants at your first opportunity while haying is going on and find the corms at the bases of the stems. If these corms are eaten by stock, the plants are, of course, injured, - which means that timothy should not be pastured in the fall.

The first point above, that of yield and quality of the hay, is not in conflict with the second one just discussed. If cut too young, timothy will shrink badly; but if it is allowed to become too ripe, the hay is woody and undesirable. Fortunately, at the time when the seed is just formed and in the dough stage, the corms contain enough nourishment to insure proper subsequent growth.

\section{Blue Grass}

169. The Character and Value of Blue Grass. - "Give blue grass credit for having fought its own way alone and unhelped. Without any aid of man, it came to the new clearing; it grew about the cabin dooryard; it carpeted the newly cleared pasture; it enriched and beautified the roadside; it held the clayey hillside and the animals cropped it and waxed fat. Not corn, not wheat, not tobacco, but blue grass, became the chief article of export from the Central West, going out disguised as beef, mutton, or pork, a large part of each being of its making. Of the millions of blue grass pastures in America, only a few have ever had seed of this grass sown upon them." 1

\footnotetext{
${ }^{1}$ Wing's Meadows and Pastures.
} 
GRASSES FOR PASTURES, MEADOWS, LAWNS 231

On lands rich in lime, particularly in the limestone regions of Virginia, Tennessee and Kentucky, blue grass is at its best. The horses, cattle and sheep of those regions have long been famous.

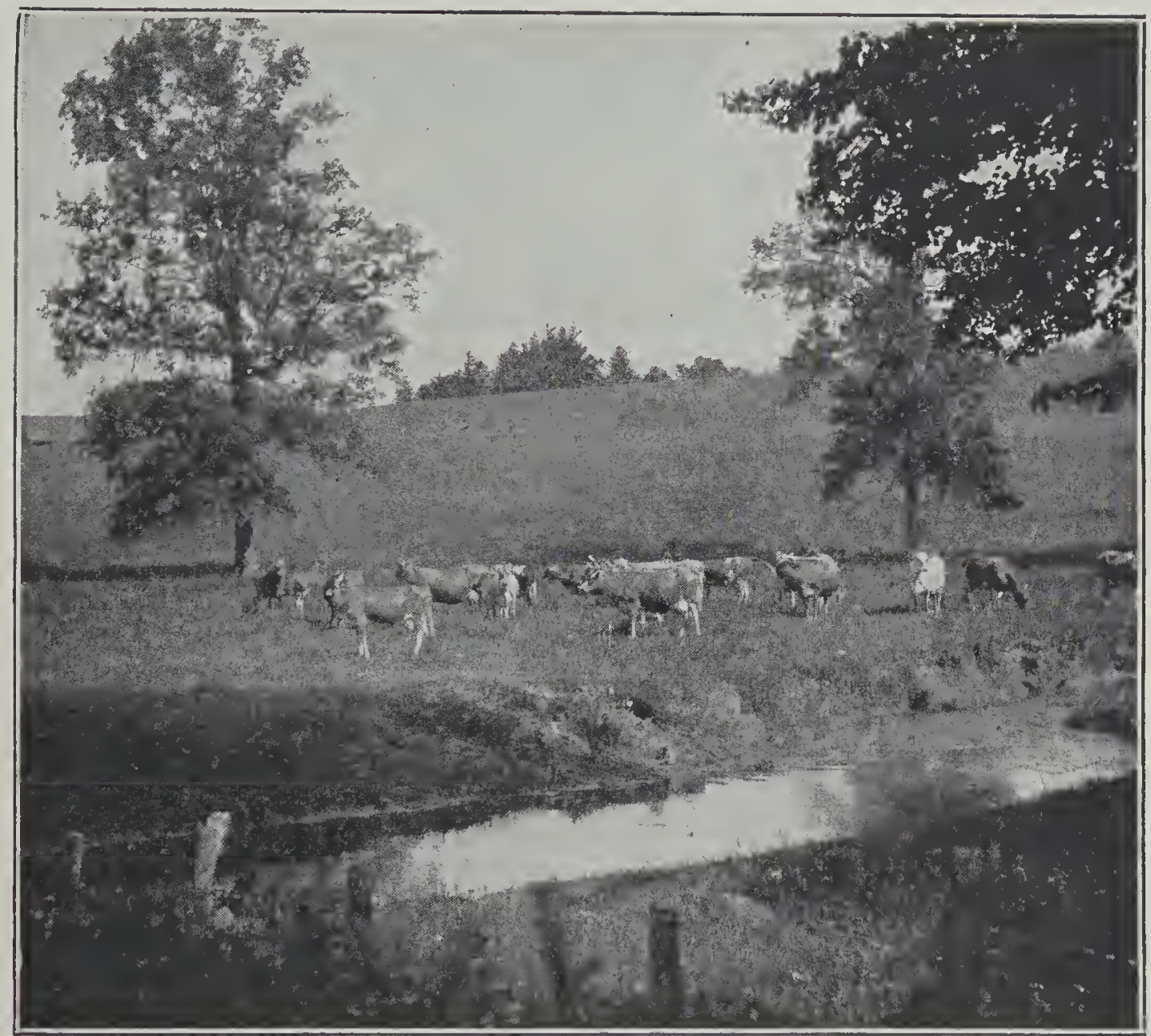

Frg. 99. - A blue grass pasture.

170. The Seeding of Blue Grass. - When it becomes necessary or desirable to sow blue grass seed, the soil should be cultivated until a fine, firm seed bed is formed. The seed does not germinate as a rule unless at some time during the day or night, the temperature falls to near forty degrees Fahrenheit. It follows that seed should be sown in the cool, moist weather of spring or fall. As a 
matter of fact, it is usually sown with some other grass, which establishes itself quickly, but which the blue grass eventually crowds out.

171. Advantages and Disadvantages of Blue Grass. Among the advantages of blue grass the following may be named :

(a) It starts to grow early in the spring and grows late in the fall.

(b) It is highly nutritious and palatable.

(c) It endures close pasturing, as well as clipping with the lawn mower, and hence it is an admirable grass for both pastures and lawns.

(d) It is a persistent perennial.

(e) It spreads rapidly, and it is a useful and beautiful grass along the roadsides and in open timber lands.

(f) It cures well in the field and makes excellent winter pasture.

Many farmers, however, object to blue grass, giving among their reasons the ones below :

(a) It is shallow-rooted and dries up during the months of high temperatures and light rainfall, July and August. It is often of little value for pasture during these months.

(b) It spreads rapidly and often crowds out timothy and clover. In Oregon, men complain that blue grass crowds out other grasses and then dies, itself, of drouth.

(c) It is of little value for hay.

(d) It does not become established as quickly when the seed is sown as do some other grasses, the time required often being two or three years, or even more.

\section{REDTOP}

172. The Range and Character of Redtop. - Redtop grows as far south as Louisiana, and is a very important 
grass in Tennessee and northward to the New England states and Canada. In fact, it has the widest range of any cultivated grass in America.

It resembles in a general way the Kentucky blue grass, but grows taller, blooms a month or more later, and has a narrower, mole divided top.

Like timothy, redtop may be sown with wheat in the fall, or it may be sown in the spring either alone or with a nurse crop of small grain.

173. Its Advantages and Disadvantages. - Among the advantages of redtop may be mentioned those below:

(a) It succeeds on poorer soils than does timothy.

(b) It succeeds on wetter soils than does timothy.

(c) It can be pastured after the hay is cut.

The objections to it, which are commonly urged, are:

(a) It does not make hay of the best quality.

(b) It is not as easily established as timothy.

(c) The seed is more expensive than timothy seed.

(d) Stock do not find redtop as palatable as other grasses.

\section{Brome Grass}

One of the latest grasses introduced by the United States Department of Agriculture is brome grass, or bromus inermis. It has become an important crop in the West and Northwest where the summers are not excessively hot. It is valuable for both pasture and hay. It is one of the first grasses to start in the spring, grows late in the fall, comes on quickly after rains following dry weather, and is exceedingly palatable. These are among its advantages.

On the other hand, the seed is expensive and liable to be mixed with that of quack grass. Like other grasses, it 
exhausts the soil, and when sown with clovers, tends to crowd them out. Moreover, it tends to form too dense a sod even when sown alone, be-

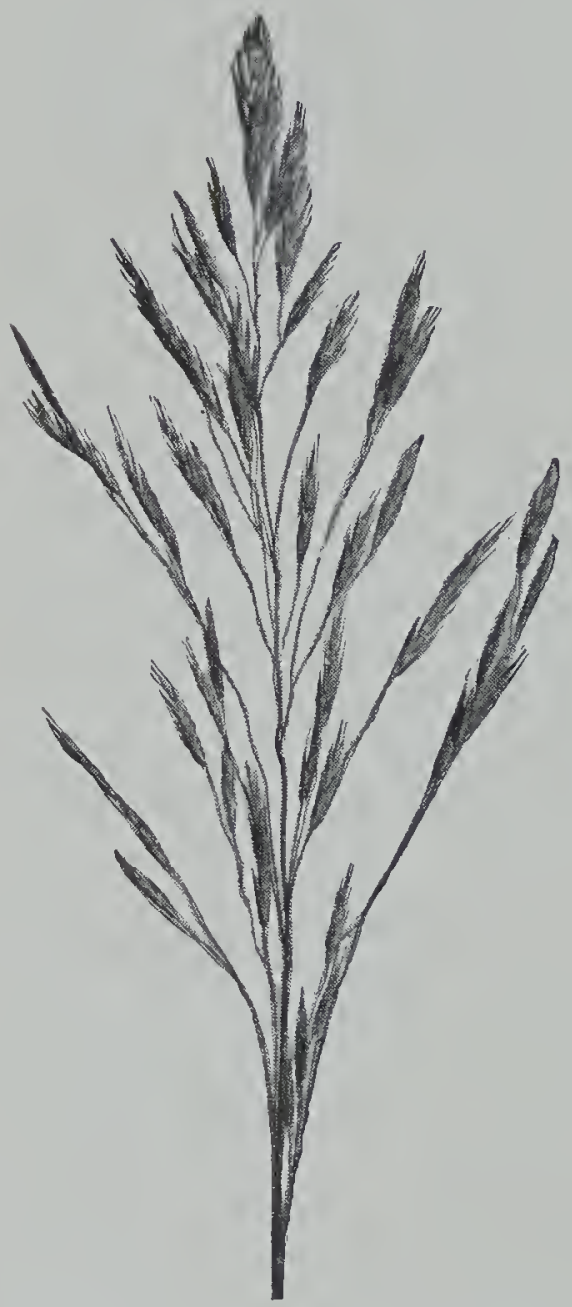

FIG. 100. - Panicle of brome grass. coming "sod bound," and this eventually reduces the yield. And furthermore, it is not an easy grass to eradicate when we wish to put the land into some other crop.

\section{Bermuda Grass}

174. The Range and Character. of Bermuda Grass. - In the southern part of the United States where Kentucky blue grass does not thrive, Bermuda grass is extensively grown. It withstands the hottest weather, endures drouth, and is valuable for both pastures and meadows. Moreover, it is the principal lawn grass of the South.

While this grass may be grown from the seed, the latter is expensive and the results uncertain. Hence the usual method is to scatter or to set out in rows pieces of fresh sod on the prepared soil and to cover them lightly with earth.

175. Advantages and Disadvantages of Bermuda Grass. - Bermuda grass has many advantages for the southern farmer, among them being those given below:

(a) It succeeds in sections where the summers are very hot and often dry as in Oklahoma and Texas. 
(b) It makes a soft, tough sod, for which reason it is often called the blue grass of the South.

(c) It binds the soil together, thus preventing erosion by wind and water.

(d) It stands grazing well - the closer the better, in fact, on rich land.

(e) It succeeds on poor soils, though it responds quickly to feeding with barnyard manure.

The principal ob-

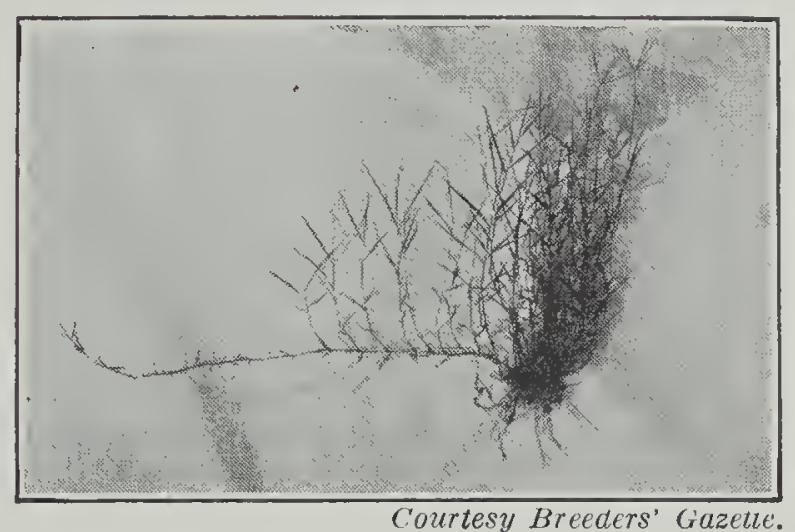

FIG. 101. - A Bermuda grass plant. jections to the cultivation of Bermuda grass are:

(a) The foliage is easily killed by frosts, while severe freezing often kills the roots.

(b) It will not endure shade, and hence is of little value among trees or where tall weeds are allowed to grow.

(c) It is difficult to eradicate when once it becomes thoroughly established in a field.

\section{Millets And Sorghums}

In certain parts of the semiarid West and Southwest where the perennial grasses do not succeed well, the annual grasses are the chief source of forage. By cultivating the land carefully, the moisture is caught and retained in the soil. Millet or sorghum is then drilled into the seed bed with the result that the seeds germinate quickly and the plants mature in favorable years before the driest part of the season comes on.

These crops are not among the so-called drouth resistant ones, such as Kafir corn and milo maize. On account of their early maturity, however, they are valuable in the 
regions of little rainfall. Moreover, they are used for forage to a limited extent in the humid sections.

176. Where each Grass thrives. - It is apparent from our study thus far that each grass has its own peculiar range which should be recognized by farmers generally.

In the Corn Belt and eastward, when a meadow crop is desired, fertile land that is well drained should be put into timothy. If the land is not well drained, redtop thrives better. If a pasture grass is wanted, however, Kentucky blue grass is easily the first choice.

In the gulf states, Bermuda grass is preëminent, while redtop is also grown.

Brome grass is extensively grown in the states of the Northwest because of its peculiar adaptation to the climate and soil.

In the western parts of Nebraska, Kansas, Oklahoma, Texas and New Mexico, as well as in other dry farming regions, annual grasses, such as millet or sorghum, take the place of perennial grasses.

For lawns, Kentucky blue grass is the best where it can be grown; but in the South, Bermuda grass must be used instead.

177. Why Clovers should be grown with the Grasses. Grasses feed largely upon nitrogen, notwithstanding they do not have the means of taking this element from the air as do the clovers. If red clover, then, is sown with timothy, we find that the yield of timothy is ordinarily increased, since the grass obtains a part of the nitrogen which the bacteria on the clover roots gather from the air. In the same way, burr, or white clover, sown with Bermuda grass, causes the latter to thrive better than when sown alone; and brome grass succeeds much better when sown with alfalfa. There are few other classes of plants which 
succeed so well together as do the clovers and grasses. Moreover, the hay produced is more desirable than that of either grasses or clovers alone, since it is more nutritious than the former and cures much better than the latter.

There is, however, another still more important reason why clovers or some other legumes should be grown with the grasses; viz., it is our cheapest and most effective means of preventing the exhaustion of nitrogen from the soil. It is a matter of the utmost importance to maintain this supply of nitrogen for the reasons given in Section 110. To accomplish this under ordinary farm conditions, legumes must be grown in the rotation (Section 140); and there is no time in the rotation when clovers can be conveniently grown save with the grasses.

We may say then that it is always better to grow clovers with the grasses in the rotation.

\section{QUESTIONS}

1. Describe briefly the characteristics of the grass family.

2. Name six cultivated grasses and state the purpose or purposes for which each is grown.

3. Name four advantages and three disadvantages of timothy.

4. When should timothy be eut for hay, and why?

5. Name the advantages and disadvantages of Kentucky blue grass.

6. In what part of the country is redtop grown and in what soils will it succeed?

7. What is the usual method of propagating Bermuda grass?

8. In what sections are the millets and sorghums found most valuable, and why?

9. State where each of the cultivated grasses is chiefly grown.

10. State three reasons why clovers should be grown with the grasses. 


\section{CHAPTER XIX}

\section{CLOVERS AND OTHER LEGUMES}

ONE of the most interesting and useful families of the whole plant kingdom is the Leguminosæ, to which the locust trees, alfalfa, red clover, sweet clover, vetches, peas, beans and other plants belong. In recent years, the term legume has been used principally in referring only to those members of the family which are cultivated in fields and are therefore of agricultural importance.

178. Characteristics of the Legumes. - Leguminous plants, which are dicotyledons, have many lateral roots, which branch from one tap root.

The stems vary from prostrate to trailing, climbing or erect.

The leaves have one central vein with many finer ones branching from it, giving the appearance referred to as netted veined. They are usually round or oval and are arranged spirally about the stem.

Nearly all legumes have rather showy flowers, which attract bees and thus secure cross-fertilization. The form of the flowers helps to distinguish them. Taking the pea as an example, the largest petal, which is uppermost, is called the standard. Below this are two petals, one on either side, known as wings, while the two united petals below the wings form what is called the keel. Have you ever noticed that the oddly shaped flower of the pea resembles very closely that of the sweet clover, or that the head of red clover really consists of a group, or mass, of 
similarly shaped flowers? This peculiar shape is seen in the flowers of all legumes.

The seed is borne usually in a pod, to the side of which it is attached, as in the bean or pea. The seeds, like the flowers, are peculiar in shape, resembling usually an ordinary bean, but in some cases they are more rounded, like the pea. The taste of all raw leguminous seeds is surprisingly the same.

By comparing the points which we have just mentioned 'with those of the grasses as given in Section 162, you will see how radically the two classes of plants differ.

179. How Legumes benefit the Farmer.-The value of these crops to the soil and to the farmer may be stated as follows:

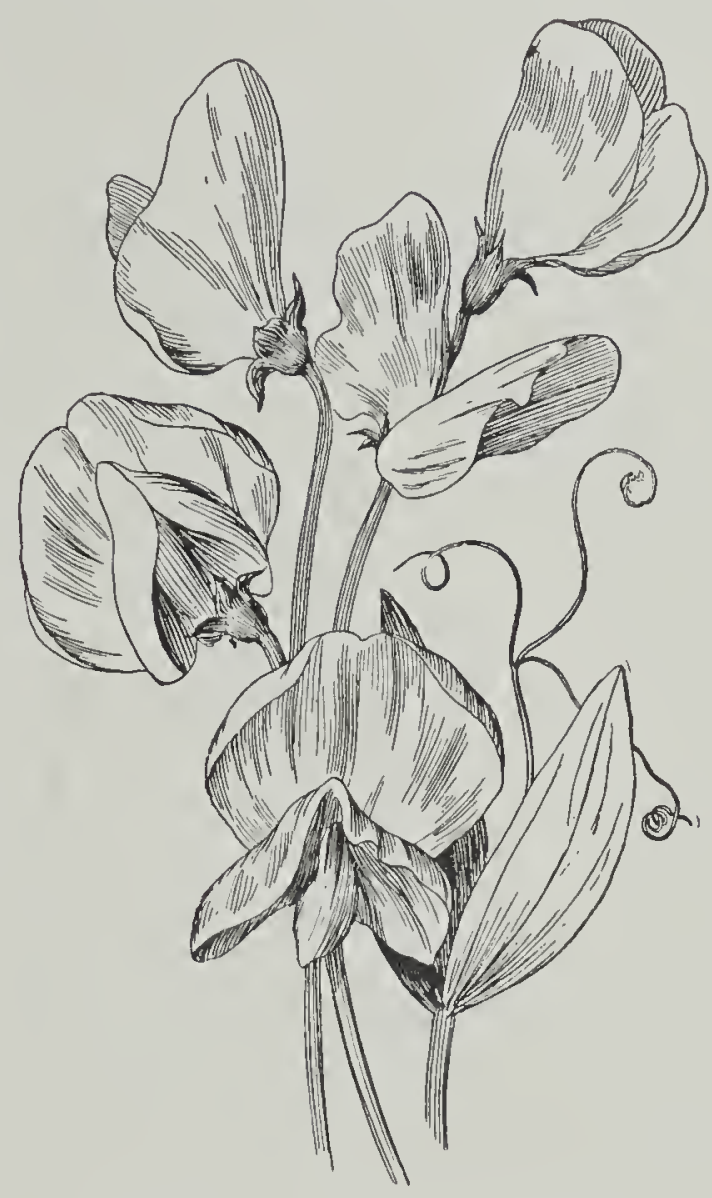

FIG. 102. - Pea blossoms.

(1) They add nitrogen to the soil.

(2) The roots open the soil to a great depth.

(3) They add humus to the soil.

(4) They make other plant food available.

(5) Because of the large amount of protein which they contain, they are valuable in balancing the rations of both animals and man.

(6) They assist by mieans of rotation in the control of insects and fungous pests. 
180. How Legumes add Nitrogen to the Soil. - Legumes and soil fertility are inseparable. Farmers have known for ages that legumes enriched the soil, but it is only in recent years that the reasons for this have been discovered.

On the roots of practically all legumes are found peculiar, whitish knot-like bodies, which were long a puzzle to

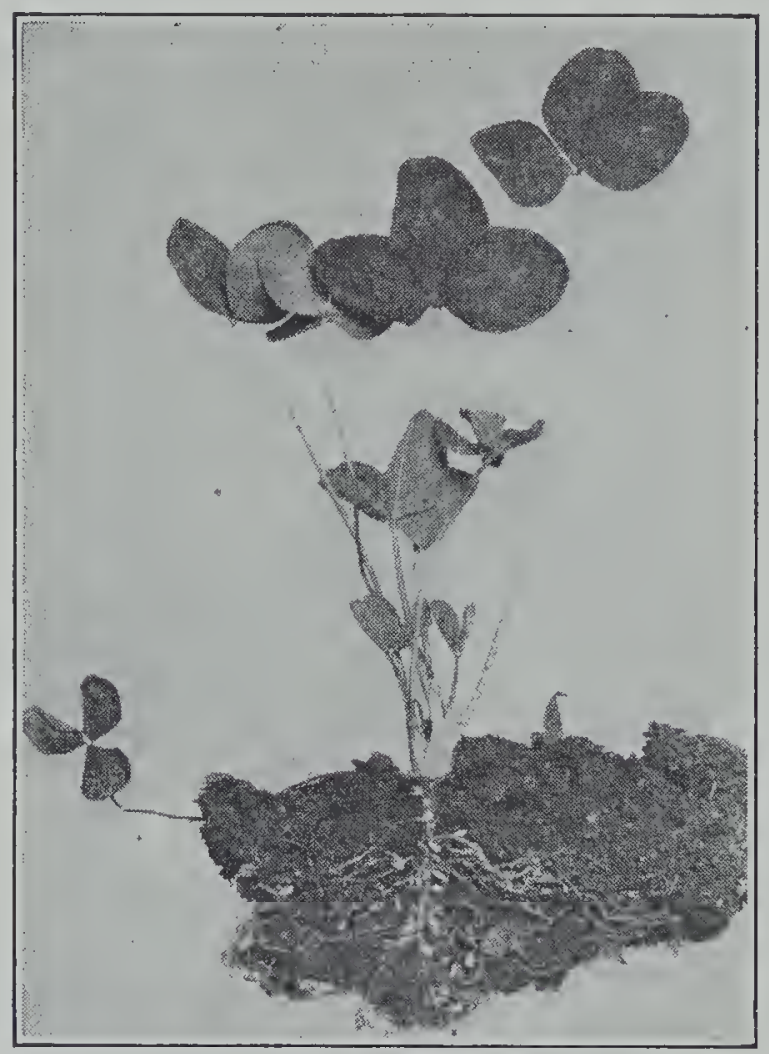

U. S. Dept. of Agriculture.

FIG. 103. - Nodules on roots of red clover. scientists, since they seemed to have no purpose nor function, yet were known to be necessary to the best growth of the plants. At length, however, the puzzle was solved. These bodies, which are called nodules, and which vary in size from that of a pin point to. that of a pea, are the homes of friendly bacteria, which gather nitrogen from the soil air and convert it into plant food. A part of this food is used by the growing legume, but much of it is returned to the soil and used by the crop which is grown upon the land after the clover is plowed under.

It sometimes happens that these nodules do not form on the roots of legumes. This may be due to the absence of the necessary bacteria in the soil ; and unless they are introduced, neither the clover nor the succeeding crops will thrive as they should. 
181. How Roots of Legumes open the Soil. - It is a well established fact that legumes almost invariably leave fields in better condition than they find them. This is unquestionably due in part to their deep rooting habit. Red clover roots may penetrate the soil to a depth of several feet while alfalfa roots have been found thirty feet below the surface of the ground.

When these roots decay, the soil is opened to the passage of both air and water, while the humus made by the decaying roots is a valuable addition to the soil.

182. How Legumes add Humus to the Soil. - The roots of legumes are not the only valuable part of these plants. Clovers, cowpeas, or other leg-

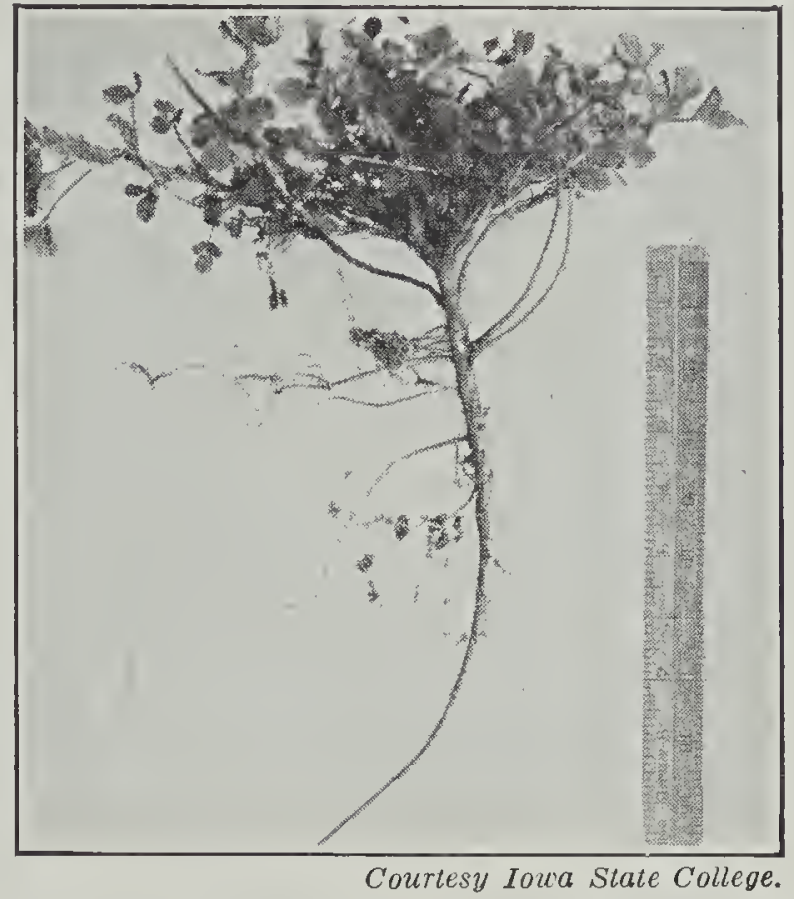

FIG. 104. - Roots of young alfalfa extend deep into the soil.

umes may be plowed under, or they may be fed to animals and the manure returned to the land with the result in either case that the store of humus in the soil is largely increased.

183. How Legumes make other Plant Food Available. - It is apparent that the long roots of the legumes must bring up plant food from considerable depths, and that when they decay, this will be liberated and thus become available to the shallow-rooted cereals. Aside from this, however, the decay of the humus, which these plants 
leave in the soil, produces substances which tend to dissolve mineral elements that are otherwise insoluble.

184. How Legumes balance the Food Ration. - Corn and other grains, used for fattening the animals which yield our meat supply, are generally rich in carbohydrates, which are heat-producing materials, but lacking in proteins, or tissue building foods. (Sections 67 and 94.) The seeds, stems and leaves of the legumes are rich in proteins and therefore are used to balance the rations of our live stock.

In the same way, beans and peas are important articles of food for man since they contain an unusually high proportion of proteins.

185. How Legumes assist in the Control of Insects and Fungous Pests. - Leguminous crops are not subject to the attack of the same classes of insects and fungous diseases as are cereals.

Those enemies, which have been present in a field of corn or wheat, must largely disappear when the land is occupied by clover.

186. Where the Different Legumes grow. - There is no place in the United States where one or more varieties of legumes will not thrive if the soil and moisture conditions are right.

Let us in fancy go to the Gulf of Mexico, and, joining hands in a line from the Atlantic to the Pacific Ocean, travel northward to the Canadian line, finding out what we can that is interesting and instructive about legumes.

Along the Gulf, and extending northward almost to the Ohio River, we shall find the little Japan clover on both poor and rich soils, but more abundantly on the poor soils where the perennial grasses will not thrive. On the river bottom land, subject even to an occasional overflow, 
we may find it as tall as two feet. We will find that it is sometimes cut for hay, occasionally yielding as much as three tons per acre; that animals relish it and thrive upon

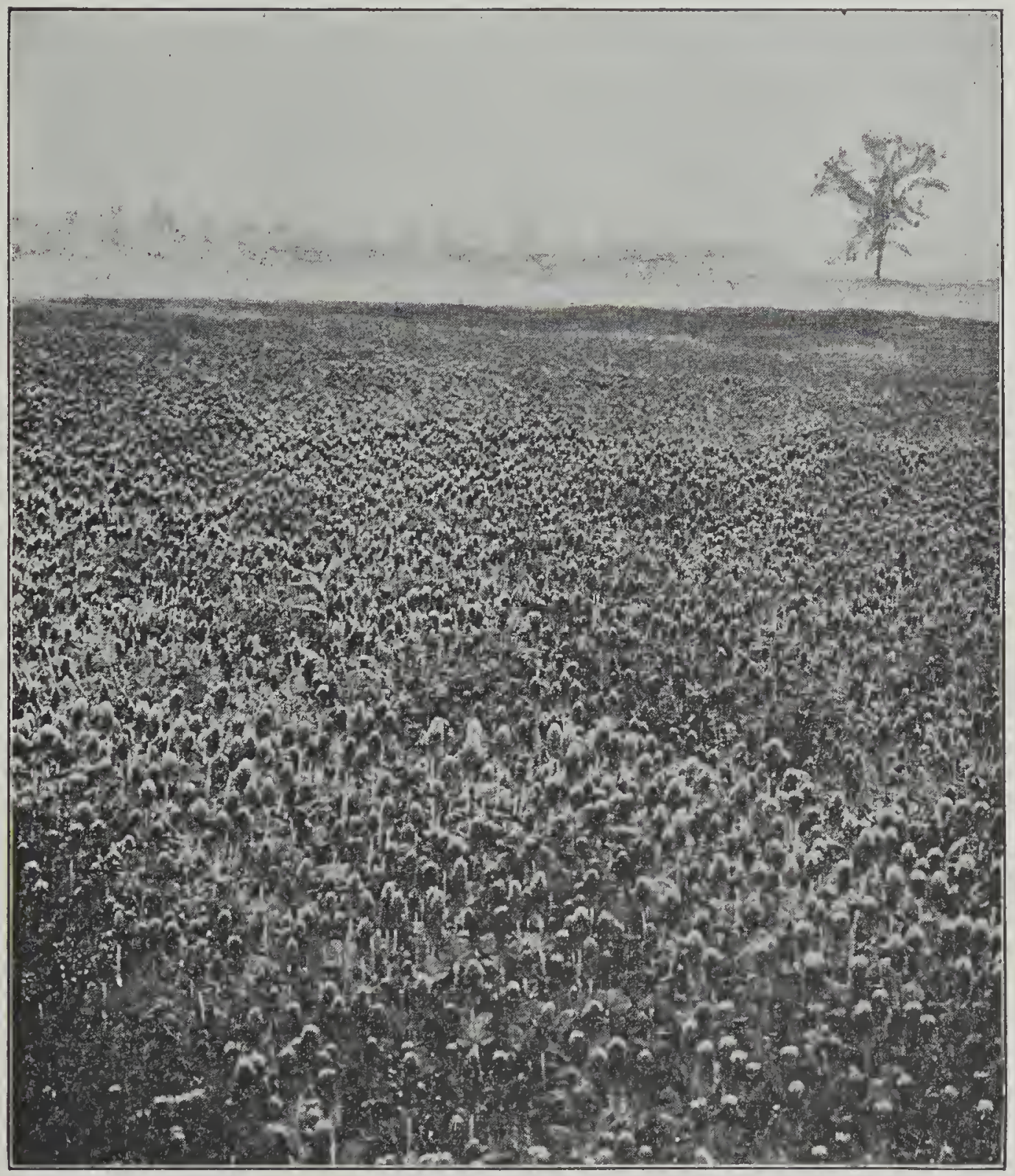

Fig. 105. - Field of crimson clover.

it; and that the soil becomes richer year by year where it is grown.

We shall find, too, that progressive planters in these 


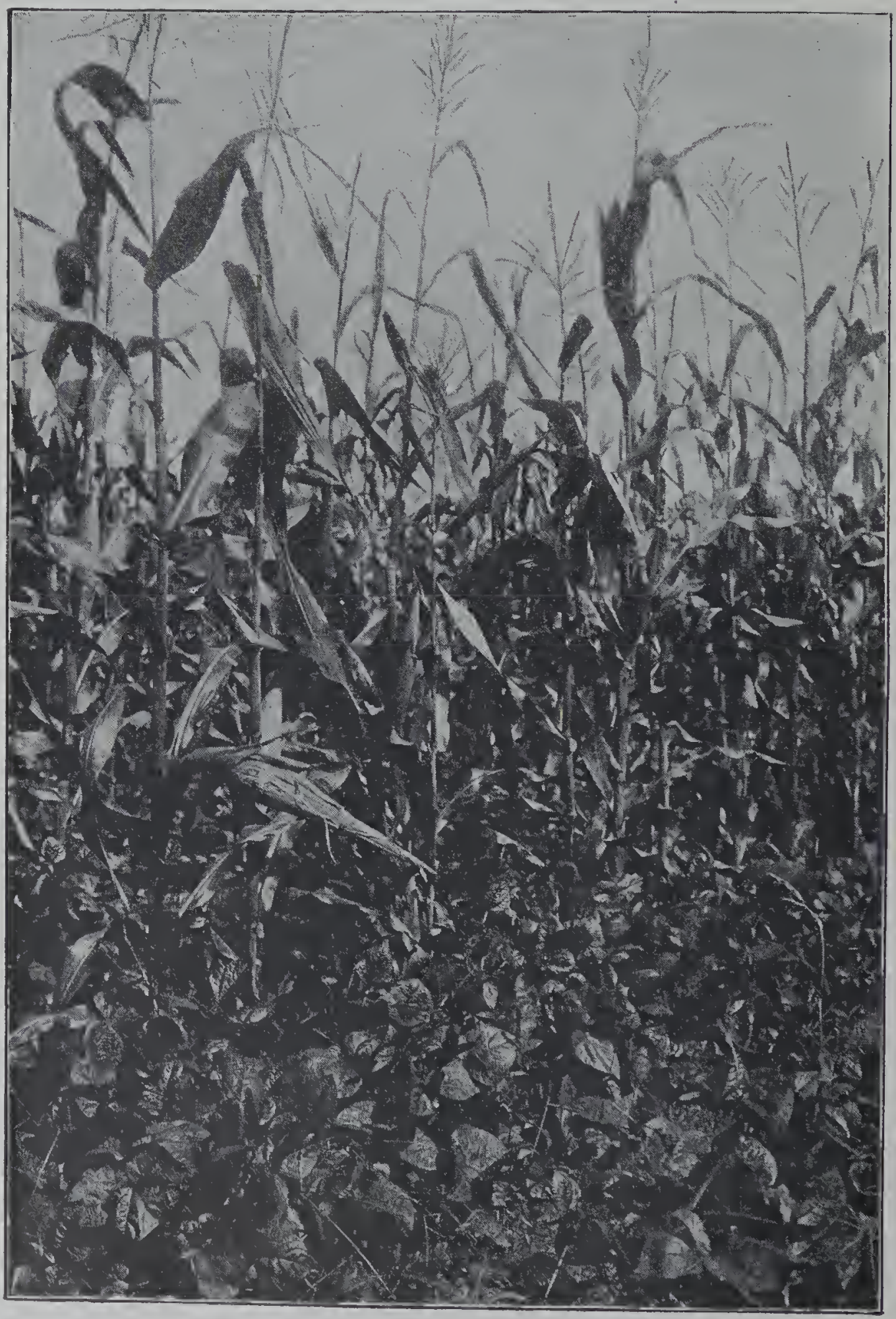

FIG. 106. - Cowpeas planted in corn to make silage. 
gulf states are sowing crimson clover in their cotton and corn at the last cultivation. This wonderful crop will then occupy the ground after the cotton or corn has been removed, will furnish excellent forage for sheep, pigs, and calves, will grow during the mild southern winters, stop the leaching of the nitrogen by the rains of winter, bloom in the early spring, and stand ready to be plowed under to make the soil fertile for another crop. It can not, however, be safely fed as hay after the heads begin to ripen as they are coarse, harsh, and often injurious.

Thoseinterested persons toward the east of the line will doubtless pass along the word that they find the cowpea growing in a variety of places and that it is doing wonders in adding fertility

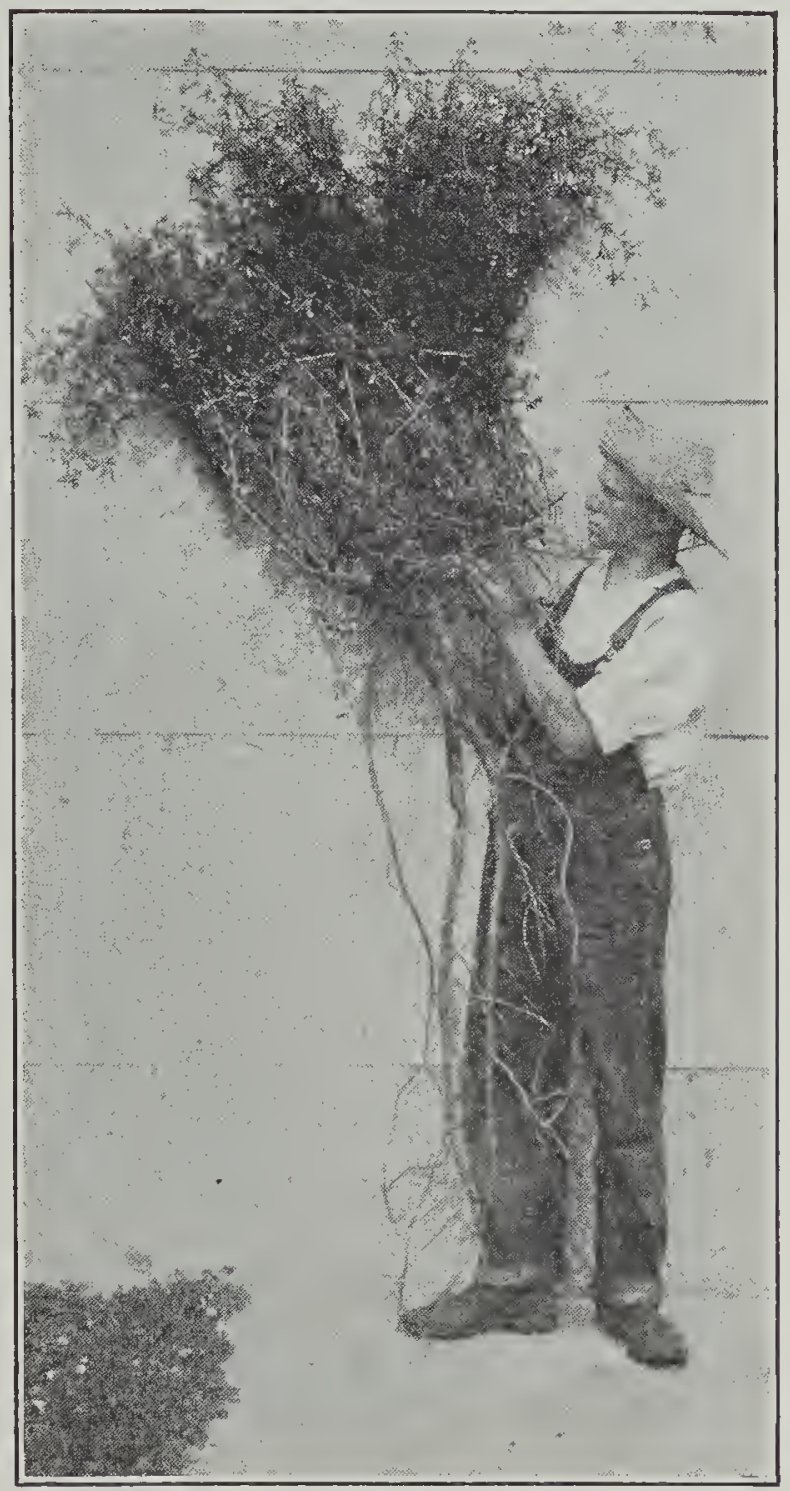

Courtesy Iowa State College.

FIG. 107. - An alfalfa plant. to the soil. They find it in fields with oats, either to be used as hay or to become a pasture for hogs. They find it sown after the regular crop has been removed. They find it frequently sown in corn at the last cultivation and 
making use of the land after the corn is mature ; or it may instead be harvested with the corn, in which case most excellent silage is secured. This crop is grown not only in Florida and Alabama but westward to central Texas and northward to the Ohio River. Here it meets the field pea, or the Canada field pea, as it is often called, which grows northward into Canada.

Here and there through the gulf states, we shall find growing that queen of all legumes, alfalfa. The most

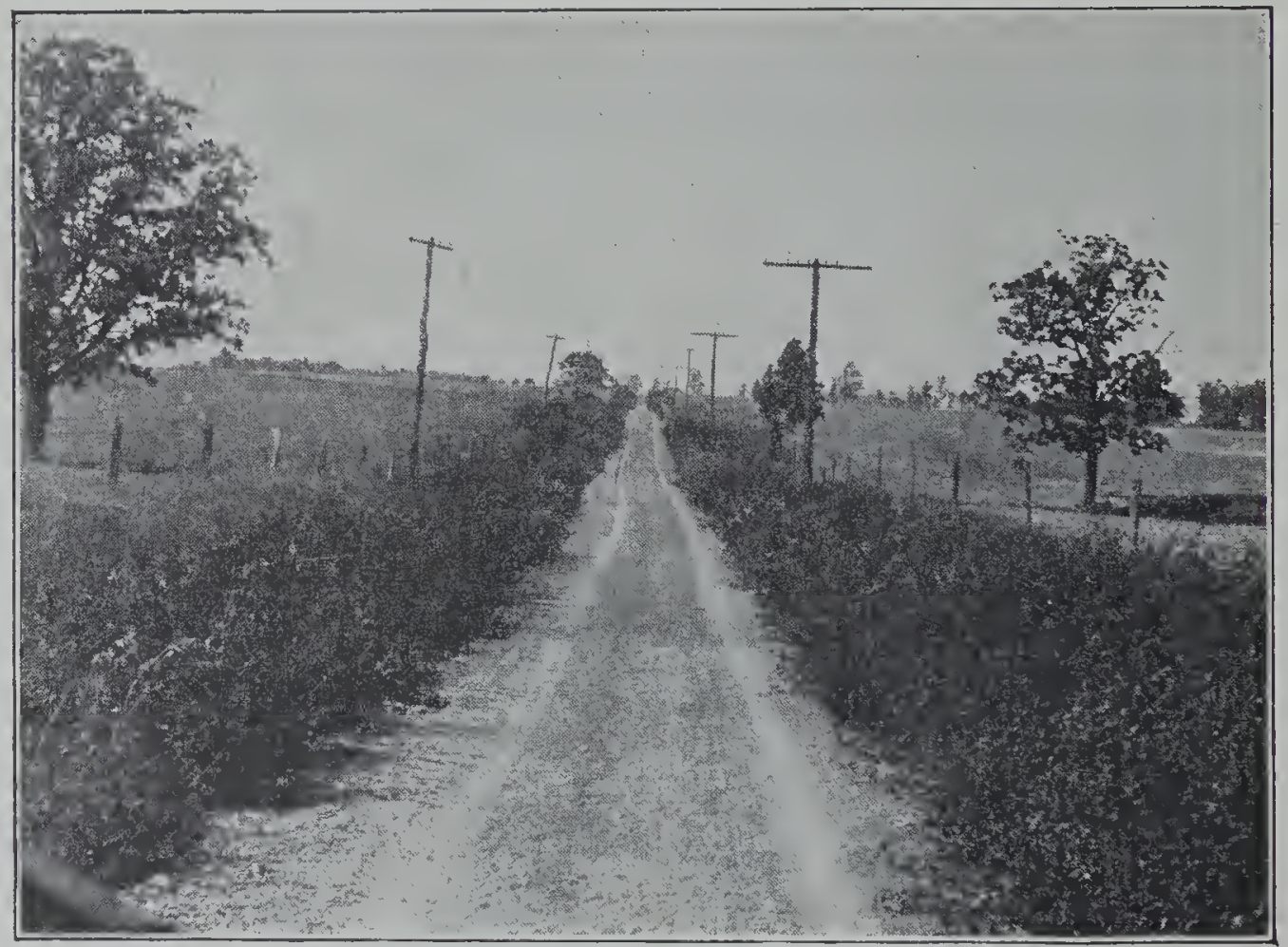

FIg. 108. - Sweet clover growing along a limestone road.

enthusiastic reports regarding it along the whole line, however, will come from those of our number who go into the fertile, irrigated valleys of the Southwest. There they will find this deep-rooted perennial crop producing from four to six cuttings of hay a year and making a richer, more palatable feed as well as a heavier yield than any of the other legumes anywhere. Owing to the fact that its 
roots penetrate so deeply into the earth, alfalfa will be found growing not alone on the irrigated land, but on land on which no water is placed and where the rainfall is even as low as eighteen inches a year. Indeed, it is in regions of scant rainfall that it produces its best seed, though the hay crop is light.

As we move northward, we find still the wonderful fields of alfalfa. Colorado fields are far-famed, more than one half of the area in hay in that state being in alfalfa. A smaller amount of the crop will be found in Wyoming, and even less in Montana, for alfalfa is naturally adapted to a warm, dry climate.

In the northward movement of our line of young investigators, none will encounter more of this splendid crop than those who pass through Kansas

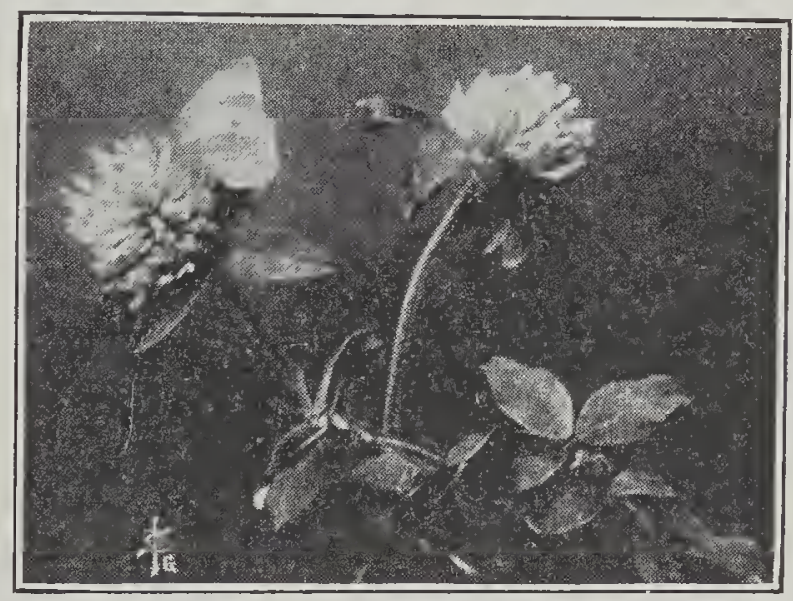

Courtesy Iowa State College.

FIg. 109. - A red clover plant. and Nebraska. Here whole valleys, as the Arkansas, the Kaw, the Solomon, the Little Beaver and the Platte are given over largely to the production of alfalfa hay and seed.

That part of our line eastward from the Missouri River will find that in the Carolinas and Virginia, in Pennsylvania and New York, some alfalfa is grown and successfully; that in Ohio, Indiana, Illinois and Iowa the cultivation of this crop is rapidly increasing as its needs become better known to the farmers; and that even in Minnesota and the Dakotas, a hardy variety, known as the Grimm alfalfa, is being extensively grown. 
Along the highways, on stony hillsides, in neglected places, and here and there in cultivated fields from Alabama to Wyoming, and from California to New Jersey, we find a once rejected plant that is now coming to be recognized as one of the farmer's truest friends. It is sweet clover, - and it is not a weed. Rather it is a valuable forage and pasture crop when stock have once learned to eat it. It is a wonder worker for the soil and it yields honey for the bees. In barren, neglected tobacco fields, in stiff clayey irrigation land, and indeed in nearly any

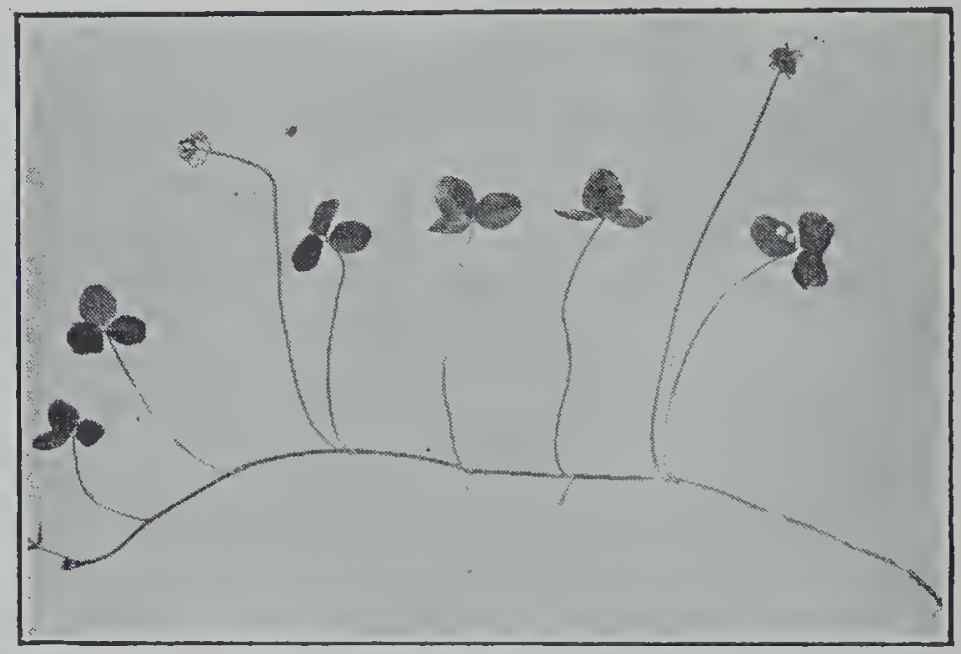

Fig. 110. - The white clover.

soil that is rich in lime, even though it be lacking otherwise in fertility, sweet clover thrives and prepares the way for other crops.

When the portion of the line, which is following up the Mississippi River, reaches the junction of that river with the Missouri, they will find the red clover, which most of us know and love so well, coming into its own. Westward they will find it to Kansas, eastward, to the coast, and northward, to the Canadian line. Those in the far West will also find it on the Pacific coast north of California. Red clover, good farmers will tell you, are 
other words for better agriculture, since it not only fits into the crop rotation, but it is easily and quickly established and makes an excellent forage for live stock.

Throughout this same region and extending to some distance northward, the little white, or Dutch clover is found. In fact it has. a wider range than that indicated, but it is in this region that it is best known. It is a low, creeping clover ; and as we soon discover, it is an unfailing sign of a fertile soil.

In this same region, we find still another clover, a plant, which, because it resembles both red and white clovers, is thought by many to be a cross between the two. It is

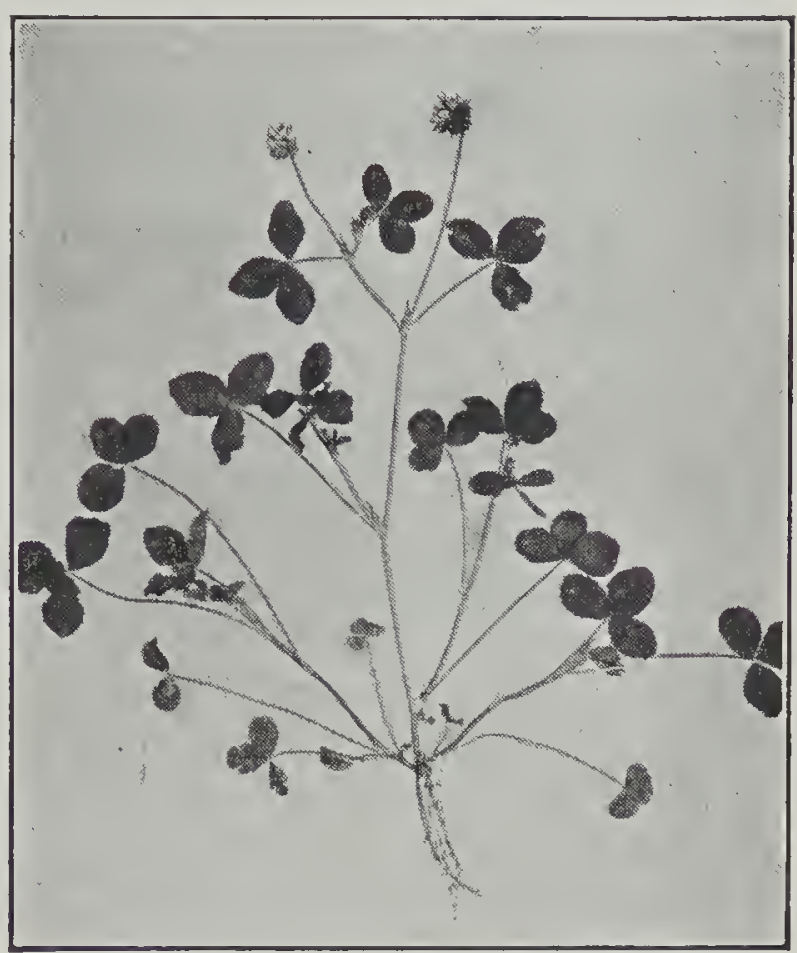

Frg. 111. - An alsike clover plant. known as alsike. We find it on the lower, wetter grounds and on those poorer in lime. It differs from the white clover in that it becomes tall enough to cut for hay, though we find it used principally in pastures.

There are still some other legumes of rather less importance that our line of investigators will doubtless have found. Among these is the soy bean, which thrives throughout the Corn Belt and southward, the peanut, and the vetches, the latter being found all over the South and even as far north as New York.

Notwithstanding the fact that legumes are held in high esteem by farmers everywhere and must in the future 
come to be grown more and more in order to keep up the fertility of the soil, it is still true that these crops are as a class difficult to raise and that the percentage of seedings

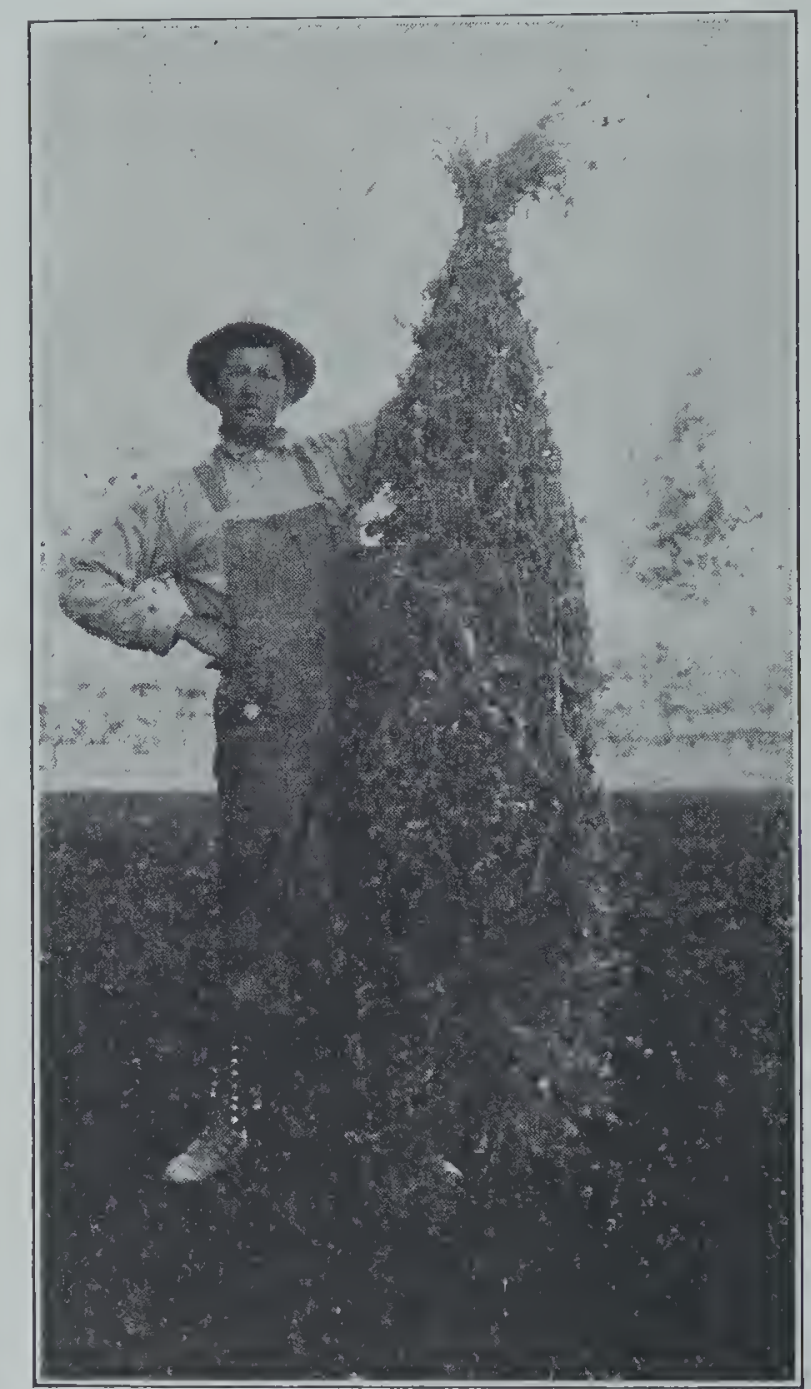

FIG. 112. - Some vines of hairy vetch. which fail is discouragingly high. Let us seek out then if we may some of the principal causes of these failures.

\section{Why Clovers} frequently fail. There are at least seven causes of the clover failures which seem to be growing more and more numerous throughout the leading grain states:

(1) The soil has become deficient in lime, and because of this may, in fact, be acid.

(2) The soil is lacking in phosphorus.

(3) The soil is lacking in humus.

(4) The soil does not contain friendly bacteria.

(5) The nurse crop is not suited to the needs of the young clover.

(6) The seeding, or sowing, is not properly done.

(7) Drouths of midsummer or other unfavorable weather conditions may cause the death of the young plants. 


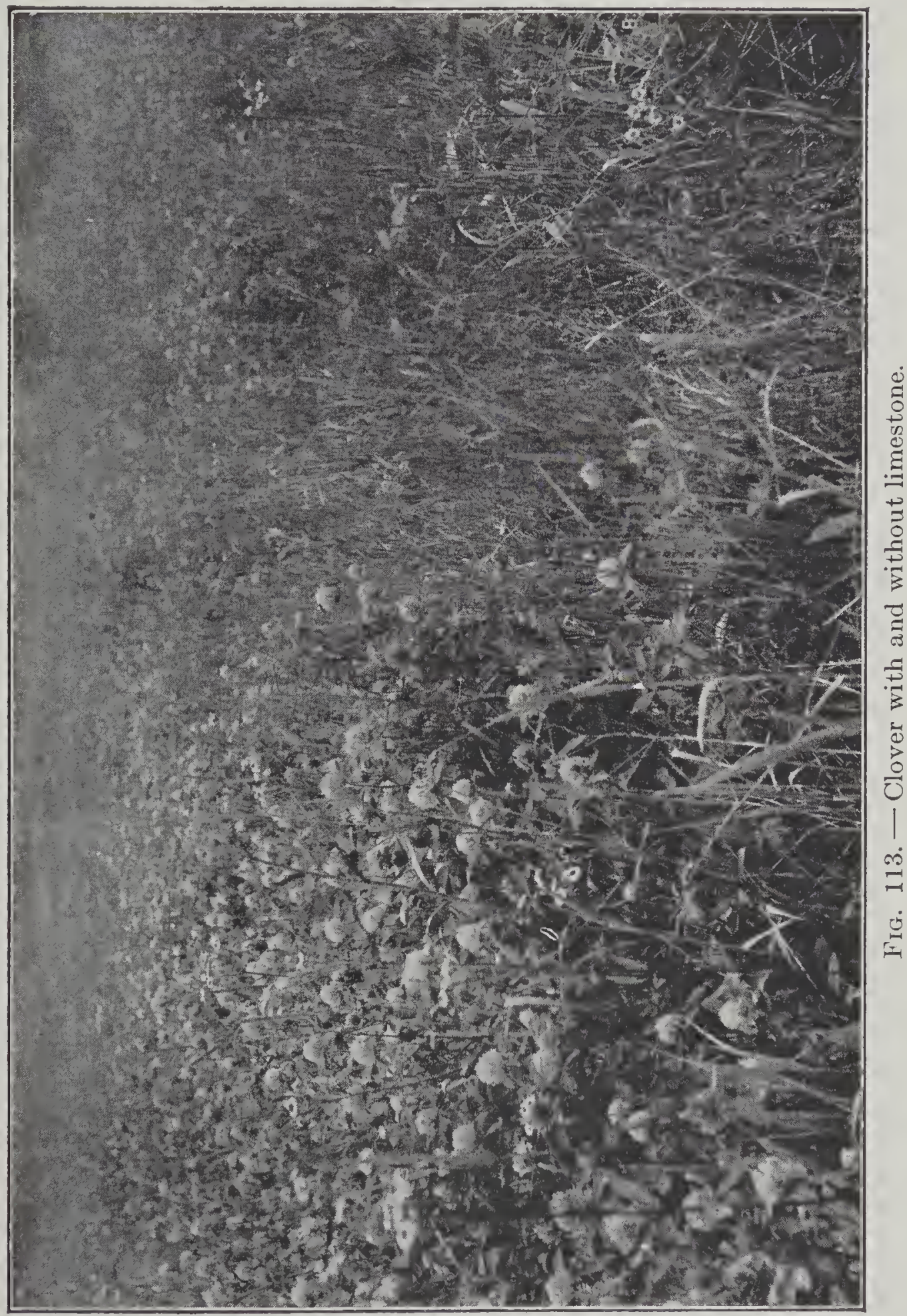


188. How Acid Soil affects Clovers. - Under the system of farming generally practiced in the United States, the soil gradually becomes acid, or sour. We can not, of course, perceive this change in the soil with our senses; and since it comes so slowly, and its effect on cereal crops is not readily seen, it may remain unsuspected for a considerable time, sometimes even for several years.

The clovers generally are singularly sensitive to this acid condition of the soil; and often the first indication we have of it is their feeble and uncertain growth in fields where it seems that they should thrive.

The truth is that it is impossible to grow red clover, sweet clover, alfalfa, or certain other legumes successfully in an acid soil. How long they can survive in it even depends chiefly upon how strongly acid the soil may be. Thus if the acidity is only very slight, the young clover plants may be only somewhat weakened, rather than killed; and the crop may even mature, though the growth will not be vigorous. If, however, a little more acid is present, the little plants will grow still more weakly ; and because of this weakened state, they readily succumb to unfavorable climatic conditions, such as drouth, or perhaps extreme cold, later, in which case the failure is commonly attributed to drouth or winterkilling as the sole cause. It is merely a matter, then, of the degree of acidity as to what the effect upon the clovers will be; and if the soil is strongly acid, we find, just as we should expect, that the little plants usually die soon after the germination of the seed.

It is not at all difficult to detect acidity in the soil. If a slip of blue litmus paper, such as we used in Exercise 28 , is placed in a cup of acid soil which has been made wet with soft water, it will gradually change in color, becoming tinged with pink. Let us make some 
tests of this kind and learn if there is any acid soil in the fields near by.

\section{EXERCISE 49}

Object. - To ascertain if the soils in our fields at home or in other fields near the schoolhouse are acid.

Procedure. - Bring to the schoolhouse, wrapped in a clean paper, about a pint of soil from a field at home. If it is taken from one in which clover has frequently failed, so much the better. This soil should not be taken up or handled with the hands, but with a small paddle or shovel instead. Since other members of the class will also bring samples, there will be a number to be tested for acidity, and they should be marked or numbered to prevent their becoming confused.

Procure, if possible, as many clean cups, glasses or cans as you have samples of soil. Put a sample into each cup, filling it about three-fourths full. Then add soft water while you stir it with a small stick until a stiff mud has been formed.

Now open a slit in this mud with a knife blade, insert a slip of blue litmus paper, and close the wet soil against the paper tightly with the fingers. Insert the litmus slips in the other samples in the same way. Allow them to remain in the wet soil for about an hour; then remove the slips, dip them in soft water to rinse off the dirt, and note the color of each one.

If any given slip is still blue, the soil is not acid; if it is very faintly pink, you will know that the soil is slightly acid; and if it is distinctly pink, the soil is strongly acid.

Conclusion. - Write in your notebook the results of the test of each sample, stating first the field from which it came and then its condition as shown by the litmus paper. 
In making a litmus paper test to ascertain whether clover will probably grow in a given field, we do not usually follow the above method since it is necessary to make many tests in different parts of the field. This is due to the fact that the soil may be acid in some places but not so in others.

The test of an entire field may be made in this manner :

Go into the field after a rather light rain while the soil is in the form of a stiff mud about like putty. If the test is made after a heavy rain, some of the acids may have been washed out of the soil, and this will interfere temporarily with the test.

Beginning at some point in one corner of the field, cut a slit in the soil with a knife blade and insert a slip of blue litmus paper to a depth of from one to three inches, pressing the wet soil firmly against it. Repeat this process at other points about ten rods apart each way all over the field, marking each place by a stake.

After an hour or more, go over the field again, carrying a small pail of soft water, in which to rinse the slips of paper as they are dug from the ground.

Since some parts of the field are liable to be more strongly acid than others, it is better to carry a plat of the field, showing the location of each test, and to record the results on it as the slips are dug up and examined. It is important to have this information when we get ready to correct this acidity in the soil by the method which we shall shortly learn.

It should be understood that soil acidity may or may not extend to the subsoil below.

189. How a Lack of Phosphorus affects Clovers. In many parts of the eastern states, as well as in some sections of the Middle West, the soil is deficient in phos- 
phorus. Moreover, in practically all parts of the United States which are given over chiefly to grain and stock farming, the supply of phosphorus in the soil is being gradually reduced.

Just as clovers will not succeed in an acid soil, so they will not thrive in a soil deficient in phosphorus. When any given farm or agricultural section has reached the stage at which phosphorus is lacking in the soil the successful growing of clovers has because of this fact become impossible until this element of plant food is restored in some form to the soil whether as barnyard manure or commercial fertilizers.

190. How a Lack of Humus affects Clovers. - Contrary to the popular belief, legumes, and particularly clovers, with the exception of sweet clover, are not crops for soils lacking in organic matter. It is a difficult task to get clover established on such soils; and good farmers often tell us to add manure or otherwise increase the humus content of the ground before sowing clover or alfalfa.

A motto which might well be painted on the grain drill is, "Legumes are to be used on this farm to maintain fertility, not as a remedy for abused or ill-treated soil."

191. How Absence of Friendly Bacteria affects the Clovers. - The cardinal virtue of the legumes is that they leave more nitrogen in the soil than they find. This they can not do, however, unless the necessary friendly bacteria make their homes in the root nodules as explained in Section 180.

Unless the soil already contains the particular kind of bacteria needed by a given legume, the bacteria must 
be placed in the ground by the farmer before the legume can be successfully grown. This is known as inoculation.

192. How the Nurse Crop may affect Clovers. - We should keep in mind the fact that clovers are commonly sown in the rotation with a small grain, after the removal of which they take possession of the ground as stated in Section 140. This nurse crop of small grain is not, as its name might be taken to indicate, a help to the young clover plants, but is often very much a hindrance instead.

While there are many good reasons for this practice, it is still true that it is open to some serious objections.

Thus we have found that the small grains, which are shallow-rooted, demand a seed bed that is firm and compact save near the surface. This is not true of the clovers generally, since, owing to their long tap roots, a seed bed that is loose and mellow to considerable depth is better suited to their needs.

Aside from this, it is known that if oats are used as a nurse crop, as is frequently the case, they almost completely exclude the sunlight from the young clover plants, making healthy, vigorous growth impossible, and moreover they take nearly all the moisture and available plant food from the seed bed. It follows that when the nurse crop is finally harvested and the delicate plants, which have made top growth at the expense of root growth, are suddenly exposed, without a proper supply of moisture, to the direct rays of the hot midsummer sun, they must suffer severely if, indeed, they do not succumb.

The same result must follow in case any other small grain is used as a nurse crop if the stand is too dense.

193. How the Method of Seeding may affect Clovers. It is a rather common practice to sow clover seed on the surface of the ground and to harrow or to disc it in. 
The inevitable result is that some of the seeds are covered very deeply while others are hardly covered at all.

Some, of course, will be covered to a proper depth, and these may be expected to grow normally. Not so, however, with the others. The seeds which are on or very near the surface usually fail to germinate because of lack of moisture, while those which are too deeply covered fail to reach the surface because of an insufficient store of food in the small seeds.

194. How Drouth may affect Young Clovers. Just how hardy the normal, healthy young clover plant really is as regards its ability to endure drouth and the heat of the sun in midsummer, - or even the severe freezing of winter - is an important question that has not been satisfactorily settled. Many regard the little clover plants as exceptionally weak and delicate, and hence unable to withstand such adverse conditions as those named. Others maintain, and with a show of reason, that the young clover is in truth sufficiently hardy to survive and establish itself under these severe conditions if other conditions are right; i.e., if the seed has been properly sown in a soil which is not acid, which contains enough humus and enough phosphorus to permit healthy growth, and which contains the particular kind of bacteria that are necessary to the development of the plant.

While we can not say that the loss of young clover from drouth or other unfavorable weather condition is actually preventable simply by making other conditions right, it is unquestionably true that such losses may be largely prevented in this way, especially in those sections where drouths are of comparatively short duration.

Losses may be ascribed to unfavorable weather conditions only after all other conditions have been made favorable. 
195. How to succeed with Clovers. - The farmer who would succeed in growing these virtuous crops, which maintain the fertility of his lands and at the same time yield nutritious forage for his animals, must see to it that the causes of failure are, in so far as it is within his power to do so, removed. It follows that:

(1) If the soil is acid, the acidity must be corrected.

(2) If it is deficient in phosphorus or humus, these must be added to it.

(3) If the necessary bacteria are absent from the soil, it must be inoculated.

(4) A suitable nurse crop must be used.

(5) The seed must be planted at the proper depth in a well-prepared seed bed and uniformly covered.

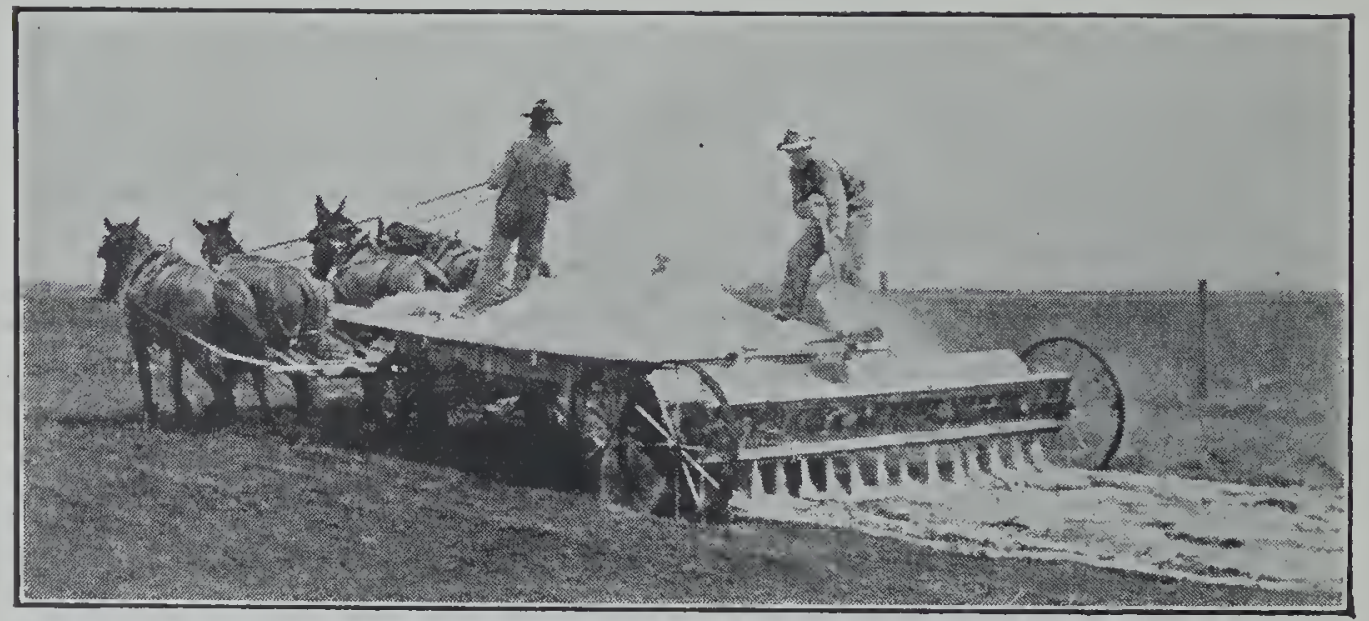

FIG. 114. - Applying limestone to the land.

196. How to correct an Acid Soil. - An acid soil may be corrected by the addition of crushed limestone to it.

This is one of the most abundant rocks found in Nature. It is used not only for making lime, but very commonly for foundations of houses, cellar walls, etc.

When this rock is used to correct the acidity of the soil, at least half of it should be in the form of fine powder, or 
dust. It may be applied with a special machine made for this purpose, or with a manure spreader, the crushed stone being put on top of a layer of manure.

If the soil is only slightly acid, from two to three tons per acre are applied; if it is strongly acid, the application should be increased to five or six tons, or even more, as no harm results from using more than is necessary. The only reliable way to determine the amount required is to make trial of the different rates of application. It should be disced or harrowed into the surface soil but not plowed under.

If crushed limestone can not be procured, lime of any kind may be used. In such case, the application may be not more than half as great as if limestone were used; and, except in the case of air slaked lime, it should not be allowed to come into contact with plants, as injury may result.

197. How to add Humus and Phosphorus to the Soil. In soils that have long been cultivated without a careful system of rotation, humus is deficient; and unless phosphorus has been applied to the soil, it'is probably lacking also. Humus may be added to the land by plowing under green crops; or both humus and phosphorus may be added to it by the application of barnyard manure. If the latter is used, it is advisable to apply with it pulverized rock phosphate, or floats.

At least ten tons of manure should be applied to each acre and not less than five hundred pounds per acre of floats.

198. How Bacteria are added to the Soil. - The soil from a field in which any clover is established and thriving, contains very many of the bacteria which are necessary to that crop. 
By taking some of the soil found in such a field at a depth of from two to six inches and scattering it uniformly at the rate of about three hundred pounds per acre over another field in which we wish to raise the same crop, we may easily introduce the bacteria needed by the clover that we expect to grow.

Since these bacteria die quickly when exposed to direct sunlight, it is necessary to scatter the soil containing them on a cloudy day or in the evening, and it should be harrowed or disced in immediately.

This inoculation is not necessary as a rule in growing certain clovers because the particular bacteria needed are already in the soil. However, in the case of alfalfa east of the Missouri River, it is very frequently a matter of the utmost importance.

199. The most Suitable Nurse Crops for Clovers. As was shown in Section 192, oats are not a suitable nurse crop for clovers.

Winter wheat and rye are perhaps the most desirable small grain crops to use for this purpose since they do not wholly exclude the sunlight and are removed from the ground early in the season. Spring wheat and barley are more objectionable, but these crops are still to be preferred to oats.

The rate of seeding of the nurse crop should not be in any case more than two thirds of what it would be if the clover were not sown; and it is better yet if only a half the usual amount of seed is used, as the thinner stand will admit more sunlight to the young clover plants.

If it is found necessary to use oats as a nurse crop, the stand should not only be very thin, but the oats should be cut for hay as soon as the kernels are in the milk stage. 
200. How the seed should be planted. - The seed bed in which clover is to be sown should be disced and harrowed repeatedly until the surface soil is finely pulverized. It is a serious mistake to sow clover seed in cornstalk ground, which has been disced but once, or even twice, if it has been left in a rough and cloddy condition.

It is apparent that the seed should not only be planted at a proper depth but at a uniform depth as well. This can be accomplished only by means of the drill. As in the case of other seeds, clover seed should be planted as shallow as the conditions which govern germination will permit.

201. Seed Selection and Analysis. - Before we take up a more or less detailed study of how to grow the various legumes, let us consider briefly the importance of seed selection and analysis.

Comparatively few of the many noxious weeds which infest our grain fields, meadows and pastures, are natives of America. Instead they have come into our country for the most part in agricultural seeds, as explained in Section 37.

State and national laws require certain standards of purity, that is, it is required that not more than a given percentage of certain specified weed seeds may be present in agricultural seeds sold within the state.

Just how pure a sample of seeds is in this respect may be determined in a very simple manner, the process being known as seed analysis. This work may be done at home. It avoids the necessity of sending seed away to be examined, and often detects impurities which might not otherwise be brought to the attention of farmers or of the authorities. 


\section{EXERCISE 50}

Object. - To determine the percentage of good seeds, of weed seeds, and of other impurities in a sample of clover or alfalfa seed.

Procedure. - Procure a handful of seed from the top of a sack or other large sample of clover or alfalfa seed, another from the middle of the sack, and still another

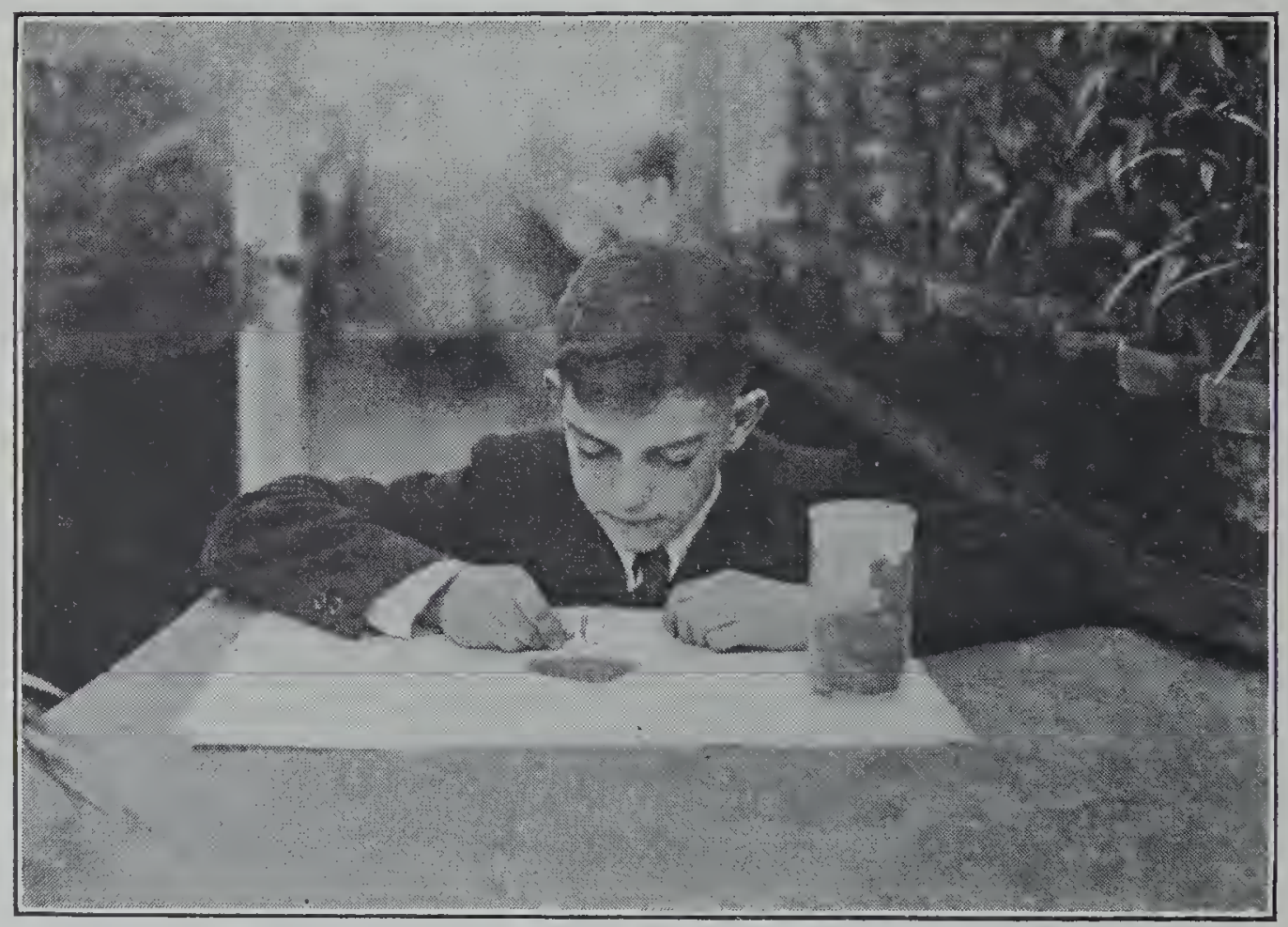

Fig. 115. - Detecting the weed seeds.

from the bottom. Mix the three handfuls thoroughly and then dip out a rounding teaspoonful. Spread this out on a sheet of white paper, and with the aid of a hand lens, separate the good seed into one pile and the impurities into another. Now separate the weed seeds, each kind being placed in a small pile, and the shriveled clover seed, the dirt and the chaff together in another pile.

Identify each kind of weed seed, referring if necessary 
to your collection made as required in Section 38; or the illustrations in Figure 116 may help you in this work.

By referring to the table which follows, you can determine the percentage of each particular weed seed in your sample. For example, suppose you find thirty seeds

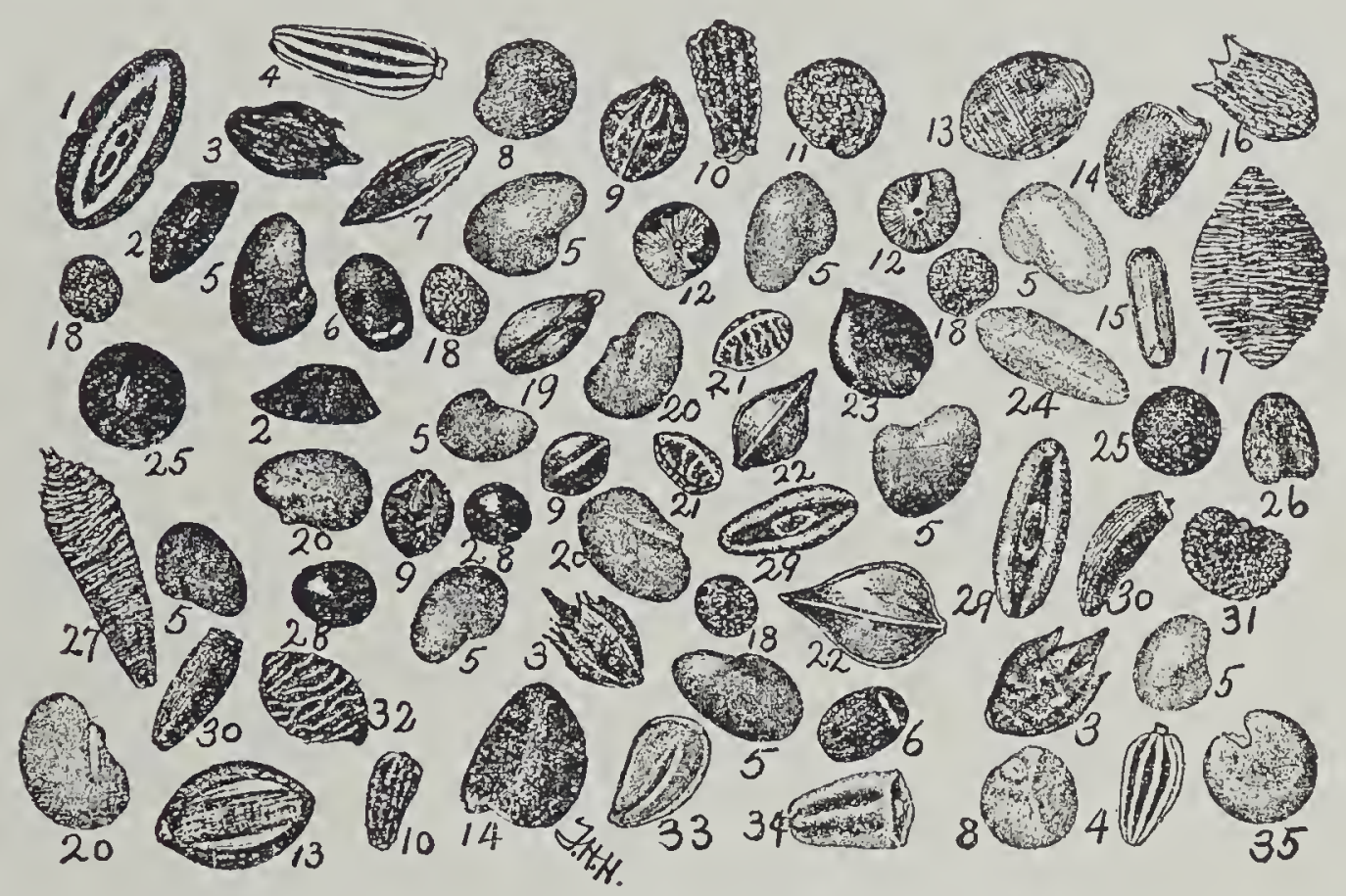

Frg. 116. - Seeds of some of the common weeds (many times enlarged).

1, Bracted plantain; 2, black seeded plantain; 3, rag weed; 4, oxeye daisy; 5 , red clover; 6 , catmint; 7 , crab grass; 8 , field dodder ; 9, sorrcl; 10, dog fennel; 11, chickwecd; 12, lamb's quarter; 13, green foxtail ; 14 , prickly sida; 15 , vervain; 16 , madder; 17 , yellow foxtail ; 18 , clover dodder ; 19, heal-all ; 20 , yellow trefoil ; 21 , spurge ; 22, curled 'dock; 23, lady's thumb; 24 and 29, buckhorn, showing two faces; 25 , mustard; 26, alsike; 27, ox-tongue; 28, pigwced; 29, buckhorn; 30, Canada thistle; 31 , campion; 32, wild geranium; 33 , peppergrass; 34 , camomile ; 35 , mallow.

of buckhorn. According to the table, fifty-seven seeds of this weed make one per cent of a teaspoonful of clover or alfalfa seed. Therefore you have thirty fifty-sevenths, or .526 of one per cent of buckhorn in your sample. If any particular weed seed found in your sample does not 
appear in the table, compare it with one as nearly the same size as possible, estimating the number that should be equal to one per cent.

Determine in this way the percentage of each kind of weed seed, and estimate the percentage of dirt and chaff.

It is necessary next to make a germination test of the sample. Procure two pie plates or dinner plates and a piece of clean, boiled muslin four or five inches wide and about eighteen inches long. Dip the muslin in water and wring it out. Then double it once, lay one end in one of the plates, scatter one hundred average seeds on it, fold over the muslin again so as to cover the seeds. Lay the other plate upside down on this one. The muslin should not protrude from between them; and they should fit as closely as possible so that little moisture will escape.

The plates should now be set away while the seeds germinate. However, the upper one should be lifted off every day or two to make sure that the muslin has not become dry. If it has done so, add water drop by drop until it is well moistened but not saturated.

At the end of a week, open the cloth and examine the seeds. You will doubtless find that most of them have germinated, but that some which look perfectly sound and good have not done so, while still others are shriveled or discolored, showing that they are incapable of germination. The second class, those which appear good but have not germinated, are known as hard seeds. It is generally considered that one half of them would probably germinate in the soil, but that the remainder would not do so. In determining, then, the percentage of germinable, or viable, seeds, we count those that have actually germinated and add to this number one half of the hard seeds, and the remaining seeds are regarded as non-germinable.

Conclusion. - Make a copy of the following form in 
your notebook and place there a record of the analysis of your sample by substituting the right names and numbers:

Record of Seed Analysis

Kind of seed

Red Clover

Secured from

John Jones

Percentage of pure seed

95.237

Percentage of weed seeds . . . . . . . . . . . . . 33133

Percentage of dirt and inert matter . . . . . . 1.630

Weed seed present:

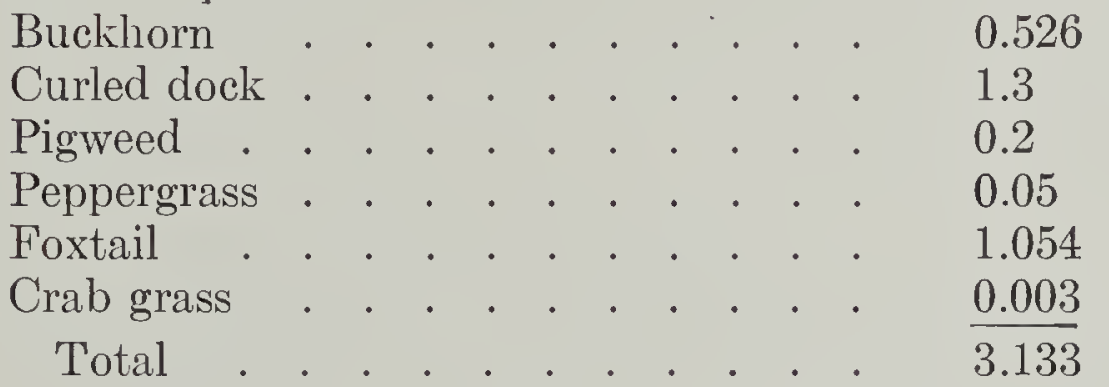

Percentage of germinable seeds . . . . . . . . . . . . . 91

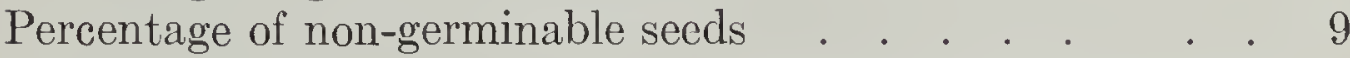

Date of Analysis

William Brown, Analyst.

202. Table of Weed Seed Weights. - In the first column of numbers below is given the number of seeds of each of the common weeds, required to make one per cent of a rounded teaspoonful of clover or alfalfa seed; in the second column are the numbers of seeds of the respective weeds required to make one per cent of a sample of the same size of timothy or millet seed:

Velvet leaf

Quack grass . . . . . . . . . . 20

Tumbleweed . . . . . . . . . . . 135

Small ragweed . . . . . . . . . . . 20

Wild mustard . . . . . . . . . . . 24

Black mustard . . . . . . . . . . . 62

Lambsquarter . . . . . . . . . . . 72

Canada thistle . . . . . . . . . . . 45

Wild carrot . . . . . . . . . . . 63

Smooth crab grass . . . . . . . . . 192 
Crab grass . . . . . . . . . . . . 185

Barnyard grass $\quad . \quad . \quad . \quad . \quad . \quad . \quad . \quad .62$

Morning glory . . . . . . . . . . . 2

Peppergrass . . . . . . . . . 125

Tickle grass . . . . . . . . . . . 125

Bracted plantain . . . . . . . . . 36

Buckhorn

Plantain . . . . . . . . . . . . . 111

Black bindweed . . . . . . . . . . 11

Pennsylvania smartweed . . . . . . 10

Sheep sorrel

Curled dock

Russian thistle . . . . . . . . . . . 65

Yellow foxtail

203. Methods of Culture of Legumes. - Red Clover. Most of the soils of the Corn Belt where red clover has been long and successfully grown contain the bacteria required by it so that inoculation is not often necessary. Aside from this, all the requirements named in Section 195 must be most carefully complied with if one would grow this legume successfully. Acidity of the soil, the supply of phosphorus, the methods of seeding and the use of a suitable nurse crop are matters requiring special attention.

Most of the red clover grown in the United States is mixed with timothy. It is advisable, however, that the clover seed be sown in the spring while the timothy is often sown in the fall. If mixed in this way, about six pounds of clover seed and ten pounds of timothy per acre are used. The growth the first season after the nurse crop is harvested is good - and it is mostly clover. The second year, however, the growth should be heavy with timothy predominating. Two cuttings of hay are usually

1 This table is taken from Dr. L. H. Pammel's excellent book, "Weeds of the Farm and Garden." It also appears in Iowa Bulletin 115. 
secured, after which, if the timothy is not greatly desired, and a regular rotation is being practiced, the ground is prepared for corn the following year.

If red clover is grown alone, about ten pounds of seed per acre are used. The second season, a cutting of hay may be taken off in early summer, and the succeeding growth of clover may be cut for hay, allowed to form seed,

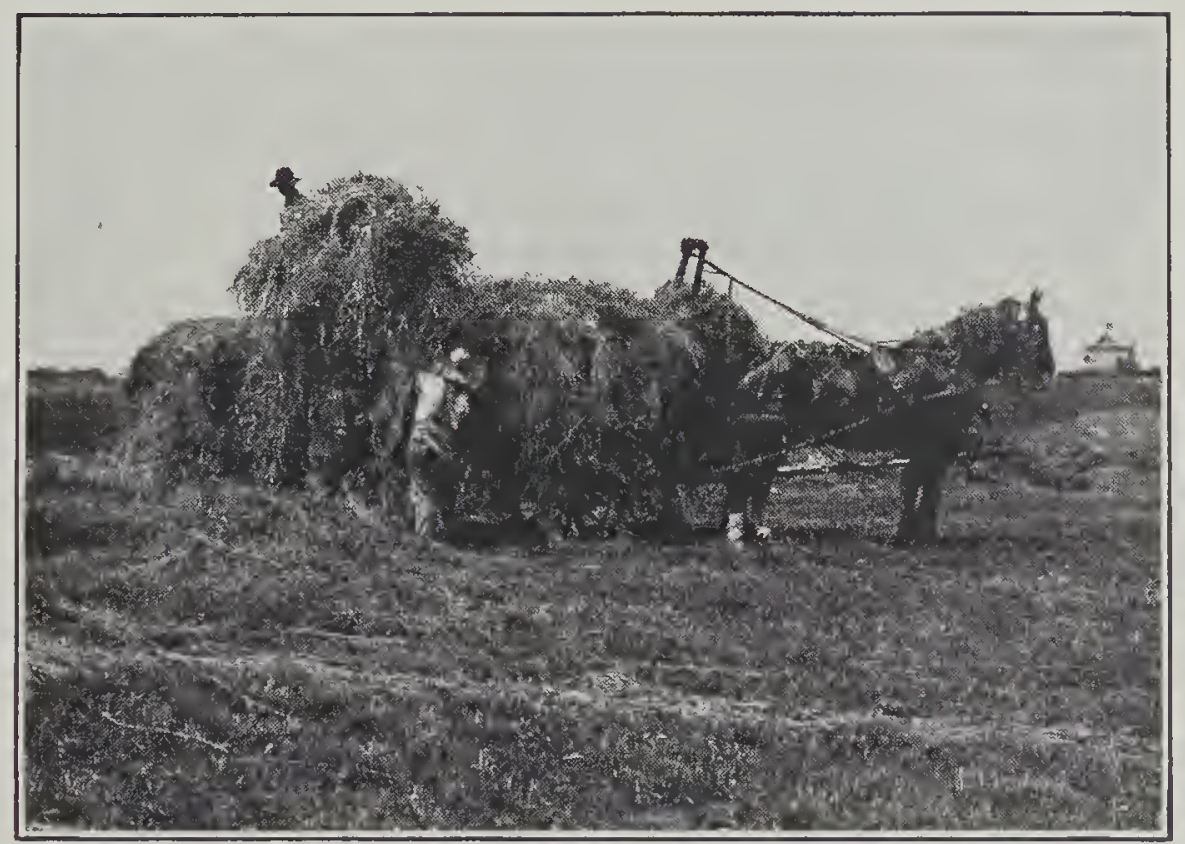

Courtesy Iowa State College.

Fig. 117. - Making alfalfa hay.

or be plowed under. Since the plant is a biennial, it dies in the fall of the second year.

Alfalfa. - There is no requirement named in Section 195 that may be safely disregarded in growing alfalfa east of the Missouri River. Furthermore it is necessary that the land be perfectly drained and that the weeds be kept in check.

West of the Missouri, it is only rarely that soil acidity is found or that the land is lacking in phosphorus. Moreover, the soil usually contains those bacteria which alfalfa requires so that inoculation is generally unnecessary. 
In the older states, inoculation is a highly important matter as a rule. Soil for this purpose may be procured either from another alfalfa field, or from a field of sweet clover, or even from a patch of this plant along the roadside, since the two kinds of plants require the same bacteria.

The majority of growers in these states prefer not to sow alfalfa with a nurse crop at all. Instead, they sow

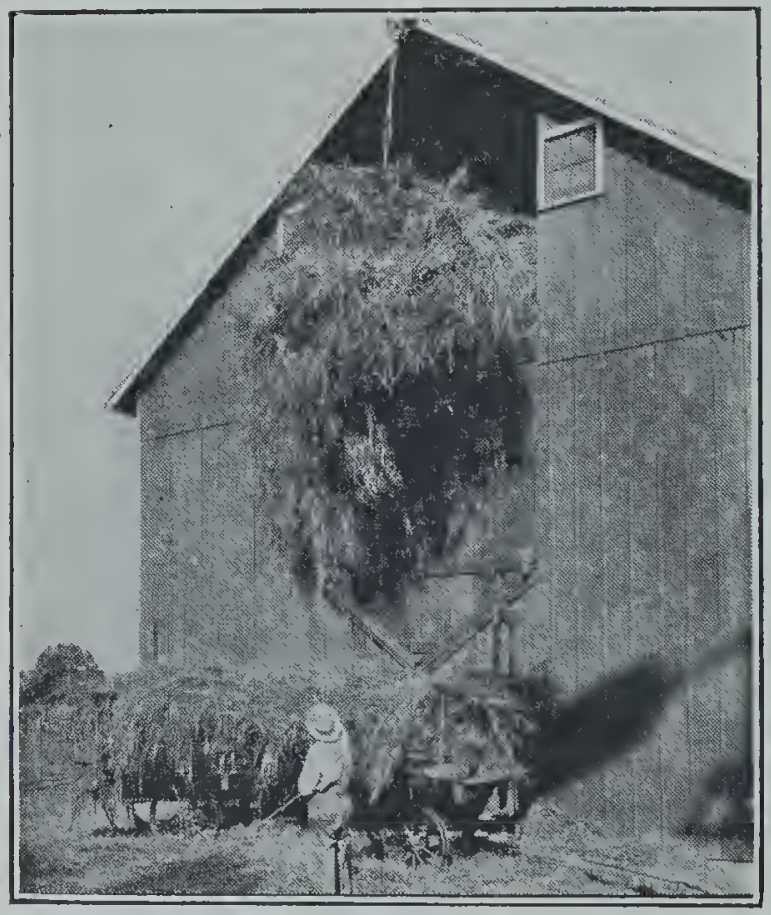

FIg. 118. - Putting alfalfa in the mow. it alone in the late summer either in land that has yielded a crop of small grain or in land that has borne no crop but has been kept idle or summer fallowed.

If stubble ground is used for alfalfa, it should be disced and plowed as soon as the small grain crop has been removed. After this, it should be disced and harrowed every few days until later summer. In this way, weed and other. seeds are induced to germinate and are subsequently killed; and at the same time moisture from midsummer showers is stored and conserved.

In late summer, then, the seed is drilled in at the rate of fifteen or twenty pounds per acre. This should be done early enough so that the young plants will have become established before winter. In many sections, alfalfa is sown in the spring with a nurse crop, just as is red clover. 
The crop is commonly cultivated at least once each season, a spring tooth harrow or a disc being used after the second cutting. In this way, the growth of weeds, including blue grass, which is a particular enemy of alfalfa, may be partly or wholly controlled.

Alfalfa should be cut for hay just after the new shoots appear at the crowns near the surface of the ground and before these shoots become so long that their tips will be clipped off by the mower.

Sweet Clover.-There are three classes of sweet clovers; viz., the white flowering biennial, the yellow flowering biennial and the yellow flowering annual. The last one has little or no value from an agricultural standpoint, while of the other two, the first is regarded as the superior plant.

Notwithstanding the fact that this plant, which commonly grows along roadsides, has long been regarded as a noxious weed, its value as a feed for live stock is nearly or quite equal to that of alfalfa when once animals have become accustomed to it, it is second only to alfalfa in its ability to restore nitrogen and humus to the soil, and it is no more difficult to eradicate from a cultivated field than is red clover.

Since it is a biennial, its cultural methods are similar to those of red clover except that about twenty pounds of hulled seed per acre are sown, as sweet clover contains an unusually high percentage of hard seeds which do not grow the first year. It will not succeed in an acid soil nor in one that does not contain the necessary bacteria. Thus limestone and inoculation are frequently necessary. Sweet clover differs from other legumes, however, in that it will thrive in a soil exceedingly low in humus, as in clay banks and in abandoned fields, provided there is a sufficient supply of lime in the ground. This gives it a value as a restorer of worn-out soils possessed by no other plant. 
Owing to the high percentage of hard seeds, a germination test, such as was made in Exercise 50, should in every case be made before the seed is either purchased or used. At least 30 to 40 per cent should prove germinable.

Sweet clover is cut for hay when about twenty to twentyfour inches in height. If allowed to grow longer, the hay becomes coarse and woody. In mowing it, a stubble from four to six inches high is usually left, as otherwise many young shoots will be cut off and later growth retarded, or the plants may even be killed outright.

Alsike. - Alsike clover may be used either for pasture or as a hay crop. It succeeds better than red clover in poorly drained soils or in those deficient in lime, and for this reason, it is often grown in fields in which it is known that red clover can not thrive.

Often it is mixed with timothy and red clover because it matures at about the same time, about four or five pounds of alsike seed per acre being used in addition to the usual amounts of the other seeds. In this case, it becomes a sort of substitute for the red clover, that is, in those spots or places, where the red clover fails, the alsike usually establishes itself.

White Clover. - The little white clover is the standard pasture plant among the clovers just as is blue grass among the grasses.

This clover is not usually seeded, but, like the blue grass, finds its way into pastures that are suited to it. The seed will lie in the ground for several years and will germinate when conditions become right. It may be sown in pasture mixtures, in which case, from two to five pounds of the seed per acre may be used.

Japan Clover. - This is an annual clover which is commonly used in the southern states for pastures though on fertile soils it sometimes grows to a height of 
twenty-four to thirty inches and may be cut for hay. Each year a new crop grows from the seed which fell to the ground from the preceding year's plants so that the land may seem to remain in the same crop permanently.

Japan clover may be mixed with Bermuda grass, making an excellent pasture, corresponding in a way to the white clover and blue grass pastures of the North. Its growth is checked by the heat of midsummer and it is killed by the frosts of winter. It follows that its chief value is for spring and fall pasture.

Cowpeas and Soy Beans. - These crops are adapted to the warmer parts of the Corn Belt, though soy beans will succeed somewhat farther north than will cowpeas. Both are grown quite extensively in the South.

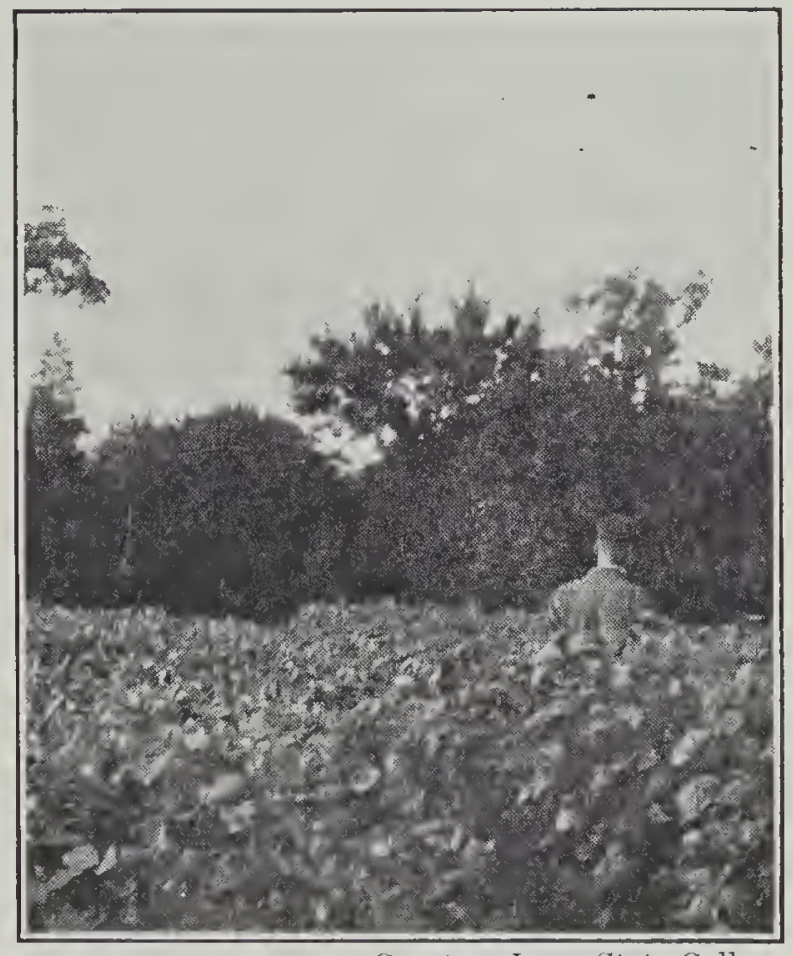

Courtesy Iowa State College.

FIG. 119. - Soy beans in field.

They may be sown broadcast in corn at the last cultivation or drilled between the rows afterwards; or they may be planted in stubble ground after the small grain is removed. They require a well-prepared seed bed, should be covered as a rule to a depth of about two inches, and can not be sown until the soil has become thoroughly warmed up in the late spring. If sown broadcast, from six to eight pecks of seed per acre are used; but if they are 
drilled in, less seed is sufficient. They should not be put into the ground until danger of frost is past. Inoculation is often necessary in soils in which these crops have not previously grown.

Field peas, or Canadian field peas, are grown in the cooler parts of the Corn Belt and northward, often with oats as a pasture for hogs or for hay. They are more hardy with respect to cold than are cowpeas or soy beans. However, the cultural methods of the three crops are similar.

The Vetches. - Two kinds of vetch, the common, and the hairy, or winter vetch, are rather extensively grown especially in sandy soils.

They may be sown broadcast in corn or cotton at the last cultivation. The winter vetch may be planted in late summer or early autumn.

Inoculation is usually necessary the first time the crop is grown. The soil in which garden peas are growing may be used for this purpose.

Vetch may be used for hay, but it is preëminently a green manure crop; that is, it is plowed under to add humus to the soil.

204. Securing the Maximum Benefits from Legumes. If the soil is to acquire all the nitrogen which any given leguminous crop takes from the air, it is, of course, necessary that the latter be plowed under. This, however, is ordinarily not done. Rather the hay is fed to animals and the manure returned to the land. A considerable loss of nitrogen results from this in most cases; but the profit derived from the feeding of the hay more than offsets this.

On the other hand, it is not advisable in any case, if we consider the effect upon the fertility of the soil, to remove 
and sell the hay, retaining only the roots in the land. If this is done, the store of nitrogen in the soil is not increased at all as a rule, while that of other essential elements is actually diminished.

\section{QUESTIONS}

1. Name six ways in which legumes benefit the farmer.

2. How do legumes add nitrogen to the soil?

3. State seven reasons why clovers frequently fail.

4. How would you test a field for acidity?

5. Rank the small grains according to their suitability as nurse crops for clovers.

6. What is the objection to sowing clover seed broadcast and harrowing it in?

7. Under what conditions may we attribute clover failures to drouth or winterkilling?

8. Name five rules to follow in order to succeed with clovers and other legumes.

9. How would you correct soil acidity?

10. How would you inoculate a field for alfalfa?

11. State in detail how you would make a seed analysis.

12. Why is a germination test particularly necessary before sowing sweet clover?

13. Why is sweet elover superior to any other plant for restoring wornout soils?

14. What is the standard pasture plant among the clovers?

15. Why should not the hay from legumes be sold from the farm? 


\section{CHAPTER XX}

\section{THE FIBER CROPS}

205. Three Crops yielding Valuable Fibers. - The plants that yield the supply of material from which certain kinds of cloth, thread, rope, twine and similar products are made, are called fiber crops. There are between thirty and forty plants in the world, which yield materials of this kind. Only three such crops, however, are grown extensively in the United States; viz., cotton, flax and hemp.

In Section 82 we learned that it is a portion of the stem of the flax and of the hemp which is used in the manufacture of linen, rope, and other important products. In the case of cotton, it is the lint which grows on the seeds that furnishes the material for cloth, thread and twine.

These vegetable fibers are not only used alone but they are often mixed with animal fibers, such as wool; or they are sometimes used as a substitute for the latter. It is not difficult to distinguish one from the other, however, as vegetable fibers leave a white ash when burned while animal fibers leave a dark coal.

206. Valuable Products Other than Fiber. - The value of these crops lies not alone in the cloth and cordage material which they yield but also in the rich oils and protein feeds for animals which come from their seeds.

Cottonseed meal and oil are staple articles of commerce. Flax seed meal, or linseed meal, as it is usually called, is extensively used in stock feeding while the oil from the 
seed is used in all paints and varnishes of good quality. Hemp seed oil is used in cooking and in the manufacture of paints, varnishes and soap.

\section{Cotton}

207. The Importance of Cotton. - Cotton has often been called the king of crops because it is our leading article of export. More farm land in the United States is planted each year, however, to corn, oats or wheat than to cotton.

The great value of cotton lies in the fact that it furnishes the greater part of the clothing of the people of the earth. The magnitude of the cotton-growing industry has increased to such an extent that the whole economic world is unsettled when war

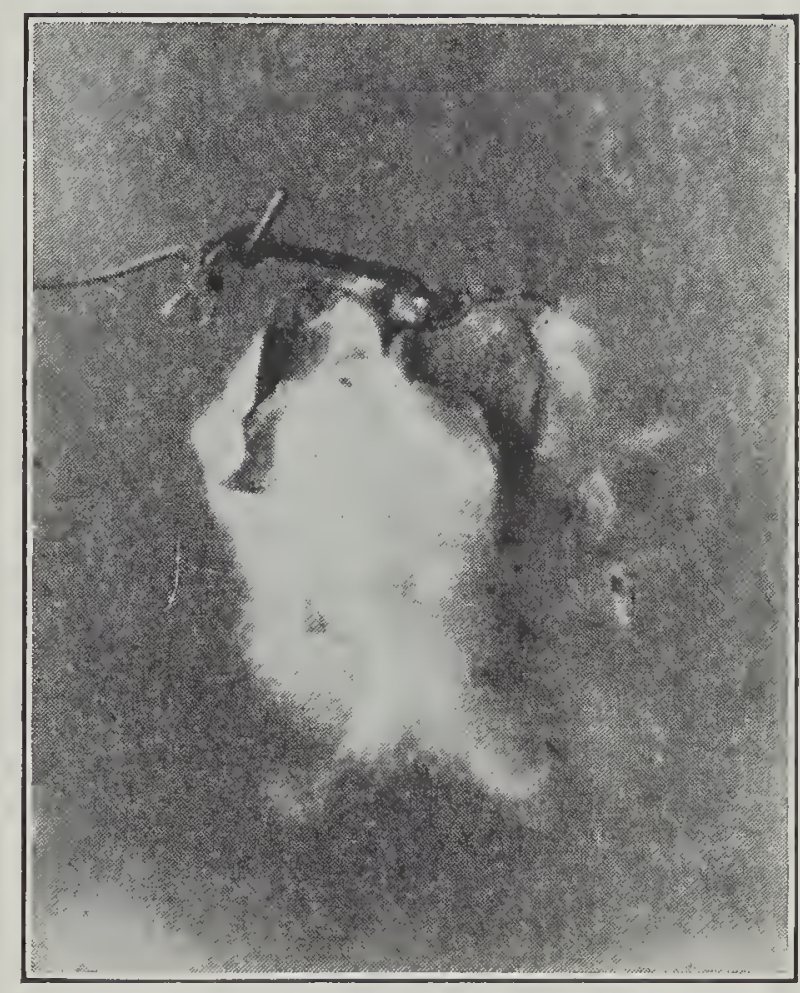

Fig. 120. - An opened cotton boll. or any other disaster interferes with its movement in the raw or manufactured state to and fro between countries. Our exports of cotton in a single year ordinarily amount to more than three hundred million dollars, from which we may readily see how serious a matter it is to our people if the ports of the world become closed against it.

208. Where Cotton is grown in the United States. The states of South Carolina, Georgia, Alabama, Missis- 
sippi, Arkansas, Louisiana and Texas constitute what is known as the Cotton Belt. There are a number of reasons why this part of the country has become the leading cottonproducing section of the world:

(1) The cotton plant thrives best in a climate where the temperature is uniformly high for four or five months after the seed is planted, followed by two or three months of cooler weather. These temperature conditions prevail in the Cotton Belt.

(2) The cotton plant thrives on clay and silt loam soils, which are the predominating types in this region.

(3) The cotton plant makes its best yield when the rainfall is comparatively heavy and well distributed during the growing season, followed by rather dry weather during the picking season. The weather records show that the Cotton Belt receives its rainfall in about this way.

(4) A cotton crop requires a great deal of hand labor. Cheap and efficient help can be secured in this region.

(5) Owing to the fact that it is so largely exported, the crop requires adequate facilities for transportation. Railroads and steamships quickly move the enormous number of bales grown in the cotton states from the various points of shipment.

209. The Cotton Plant. - For those persons who live where cotton grows, no description of the plant is necessary, while for others it may be compared with another familiar plant, a noxious weed, which belongs to the same family. The Indian mallow, butter print, or velvet leaf, as it is variously called, belongs to the mallow family, to which also the cotton belongs.

Both plants have a strong, deep tap root with finer lateral ones spreading in all directions, often to a distance of three or four feet from the main root. Both have 
stout, erect stems from one to five feet tall with wide, spreading branches, the longest ones being nearest the ground and the shortest ones at the top. The flowers of both are regular, with five petals which are creamy white or yellow in color. The butter print flower remains open but a short time while the flowers of many varieties of cotton open in the early morning, showing a creamy yellow color, turn pink or red during the day and at nightfall close never to open again. The pistil of the flower of either butter print or cotton develops into a boll. When ripe, these bolls open, exposing dark-colored seeds. Those of the butter print show a

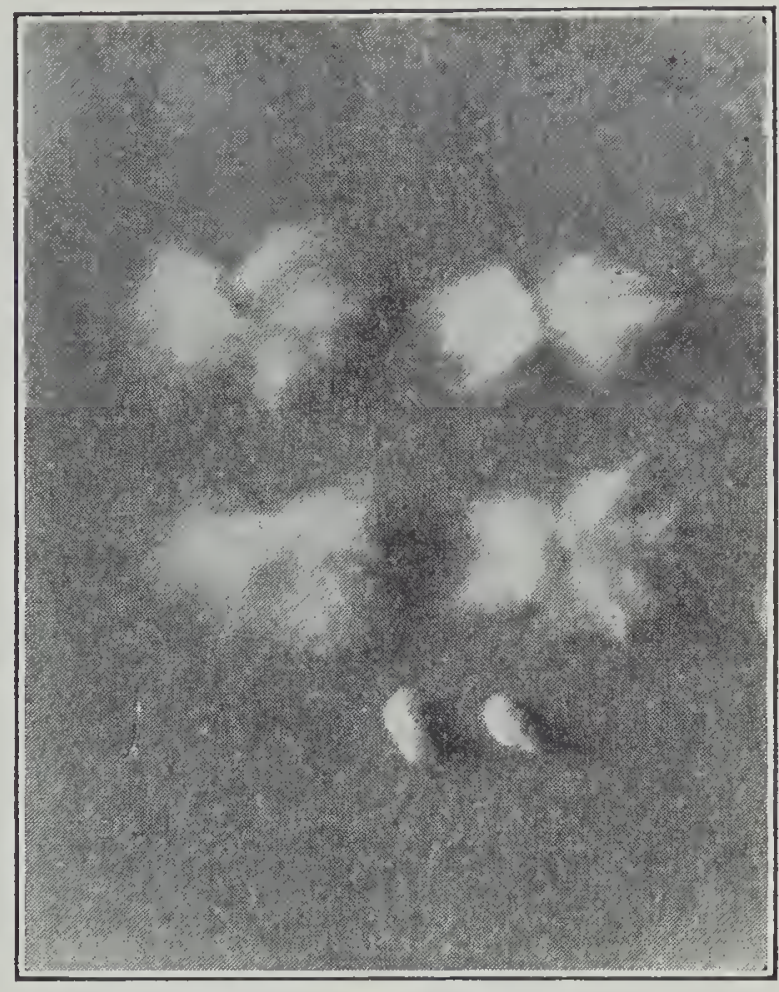

Fig. 121. - Cotton seeds with lint. trace of lint when examined under the hand lens, while the lint on the cotton seed is pearly white and from onehalf to two and one half inches long.

210. Growing the Cotton Crop. - Rotation. - The chief criticism offered to the methods practiced by cotton growers is that they raise this crop in the same fields too many years in succession, selling the fiber and seed and returning nothing to the land.

The yield of the crop is in proportion to the fertility of the soil. To maintain this fertility, a rotation of at least 
two or three years is essential, as, for example, cotton followed by crimson clover the first year ; corn, the second year; and wheat followed by cowpeas the third year.

It is unnecessary that the field occasionally "lay out," that is, be left idle to grow up to weeds for two or three years.

A rotation, moreover, tends to hold in check that dreaded enemy of the cotton grower, the boll weevil.

Fertilizers. - There is probably no general crop grown in this country upon which commercial fertilizers are so extensively and profitably used as upon cotton. The Georgia Station has found after fourteen years of experimental work that upland, worn soils should receive nitrogen, phosphorus and potassium in the ratio of three, ten and three.

On many of the prairie soils containing plenty of lime, the use of commercial fertilizers is not profitable, while even on soils where their use now brings returns, a careful rotation will greatly lessen the need of them.

Seed Bed and Seeding. - Land which is to be planted to cotton should not be left bare during the winter. Crimson clover, bur clover or winter vetch, sown in the fall and plowed under not later than February first, will make a loose, fertile seed bed.

If a fertilizer is to be used, it is often placed in a furrow, opened by a lister, or "middle buster," as it is called. The soil is then thrown back over the fertilizer with a small plow; and the seed is planted over it with a slight furrow left between the rows.

Another method used is to open the furrows with a lister, or middle buster, from three to four feet apart, and to plant the seed on the ridges with a single row planter, adding fertilizer with the seed as desired.

The practice has been to plant from one to three bushels of seed per acre, which means from 100,000 to 600,000 


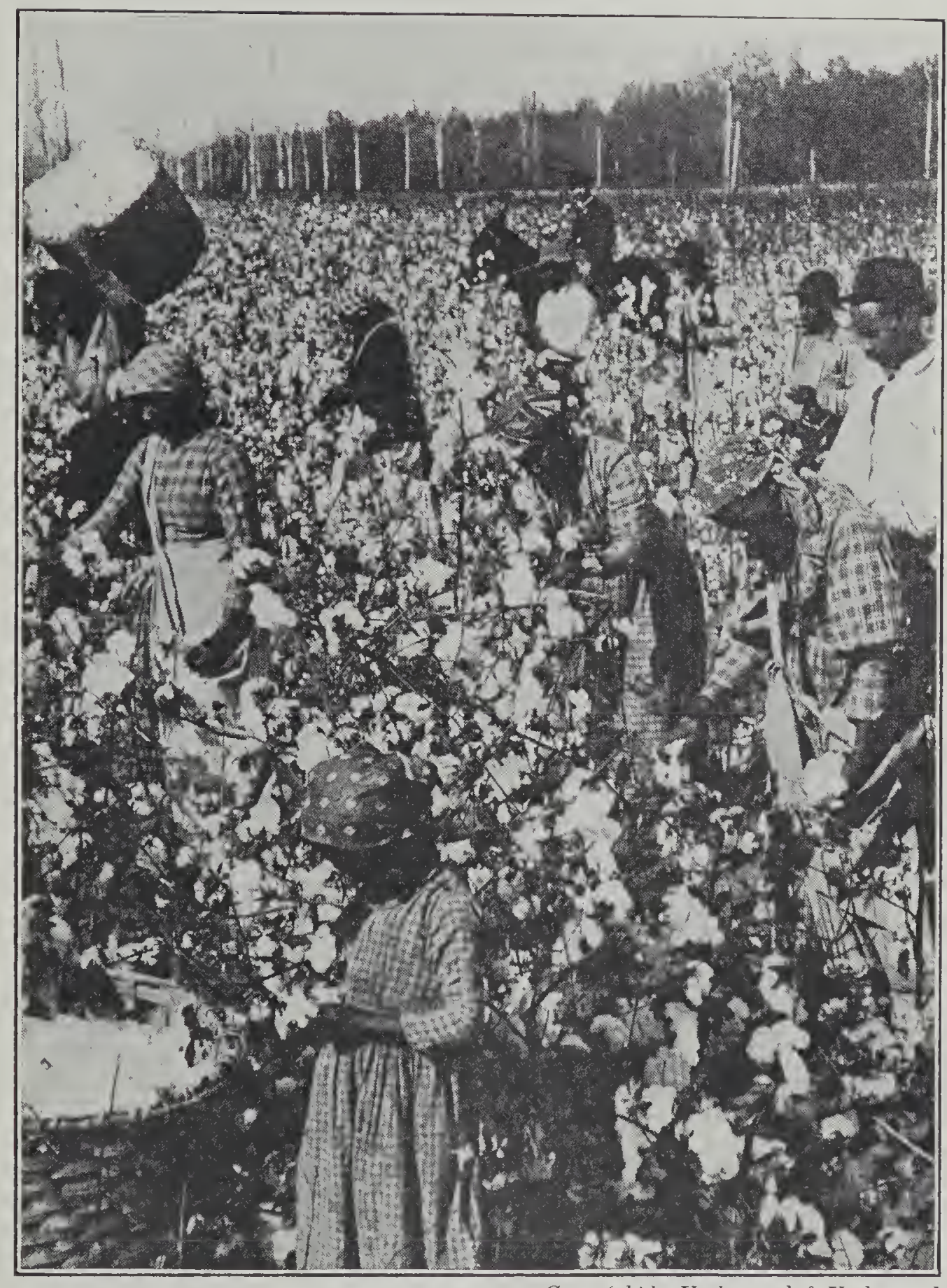

Copyright by Underwood \& Underwood.

FIG. 122. - Negroes picking cotton. 
seeds. When the plants have pushed their way up out of the ground, most of them are cut out, leaving those not destroyed about eighteen inches apart in the row.

It is an excellent practice to use only large, plump seeds, planting fewer of them per acre and applying cottonseed meal as a fertilizer for the growing crop.

Cultivation. - A sweep cultivator which stirs the ground two or three inches deep is commonly used. It leaves a loose mulch on top, conserves the moisture, helps to make plant food available, destroys weeds and brings about that continuous, rapid growth so essential to a satisfactory yield of cotton.

211. Harvesting the Crop. - One of the characteristic scenes of the South is that of cotton picking. No machine has ever been invented to gather cotton satisfactorily, for the bolls ripen successively, which means that the field must be gone over several times.

Picking usually begins in late August and continues until the first of November. Fitted over the shoulders of the pickers and trailing out to a distance of perhaps ten or twelve feet behind them, are the picking sacks, in which the seed cotton is placed. From these sacks it is transferred to deep-boxed wagons and hauled to the gin.

212. Ginning the Cotton. - From the wagons the cotton is unloaded or drawn by suction into the hoppers where revolving saws remove the lint from the seed. The lint is removed from the saws by revolving cylinders and drawn by suction into a condenser, from which it passes on to the press. The fiber comes out from these power or screw presses in bales of five hundred pounds.

As the seeds are separated from the fiber by the saws, they drop through openings and those which are not 
saved for planting are reginned to remove the clinging lint. Their hulls are then removed and the embryos, or "meats," of the seeds cooked for about fifteen minutes to drive off the water and melt the oil. Pressure is then applied to extract the oil, which goes to the refinery.

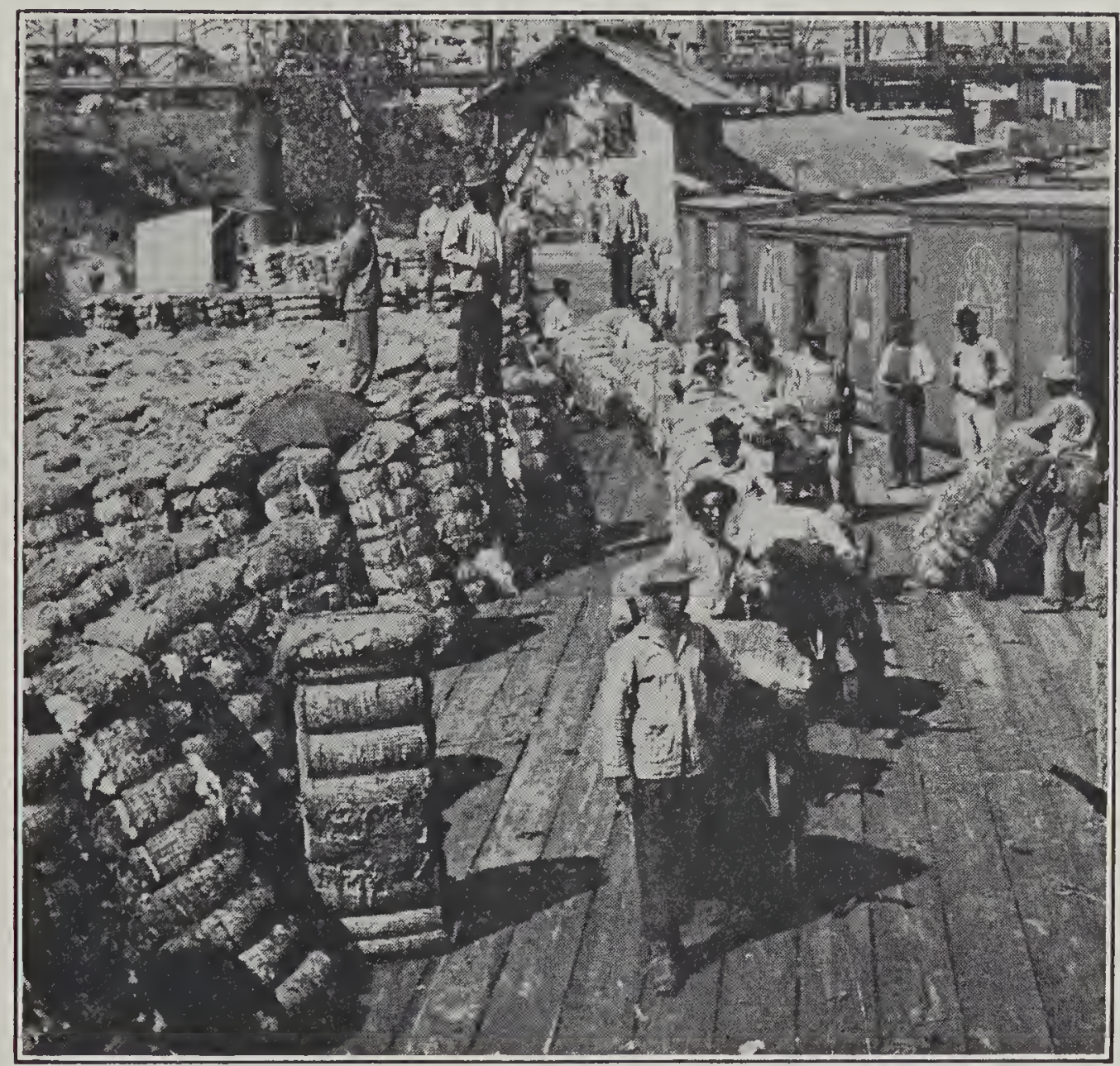

Copyright by Underwood \& Underwood.

Frg. 123. - Bales of cotton ready for shipment.

The remainder is dried, cooked once more and ground into cottonseed meal.

213. Proportion and Value of Seed and Lint. - It takes about fifteen hundred pounds of cotton as it comes from the field to make a five-hundred-pound bale. 
The value of the lint lies in its cheapness, flexibility, uniformity and wearing qualities. It is spun and woven with ease into nearly all kinds of fabrics.

The hulls of the seeds are used for fuel, as a fertilizer, as a feed for cattle, and for paper stock, while the oil is used in the manufacture of oleomargarine, as a substitute for olive oil, in lard compounds and for other culinary purposes. The cake left after the oil is extracted, or the meal made from it, is used as a feed for stock and as a fertilizer.

\section{FLAX}

214. How and where Flax is grown. - The production of flax has moved westward and northward as the newer parts of the Mississippi Valley have been settled. The pioneers have broken up the prairie sod, and while they were waiting for it to decay sufficiently for wheat to grow, they have raised a crop of flax. This new land has hitherto been abundant enough to supply the amount of flax required in this country.

Flax thrives and is raised principally in northern Europe, where a cool, moist

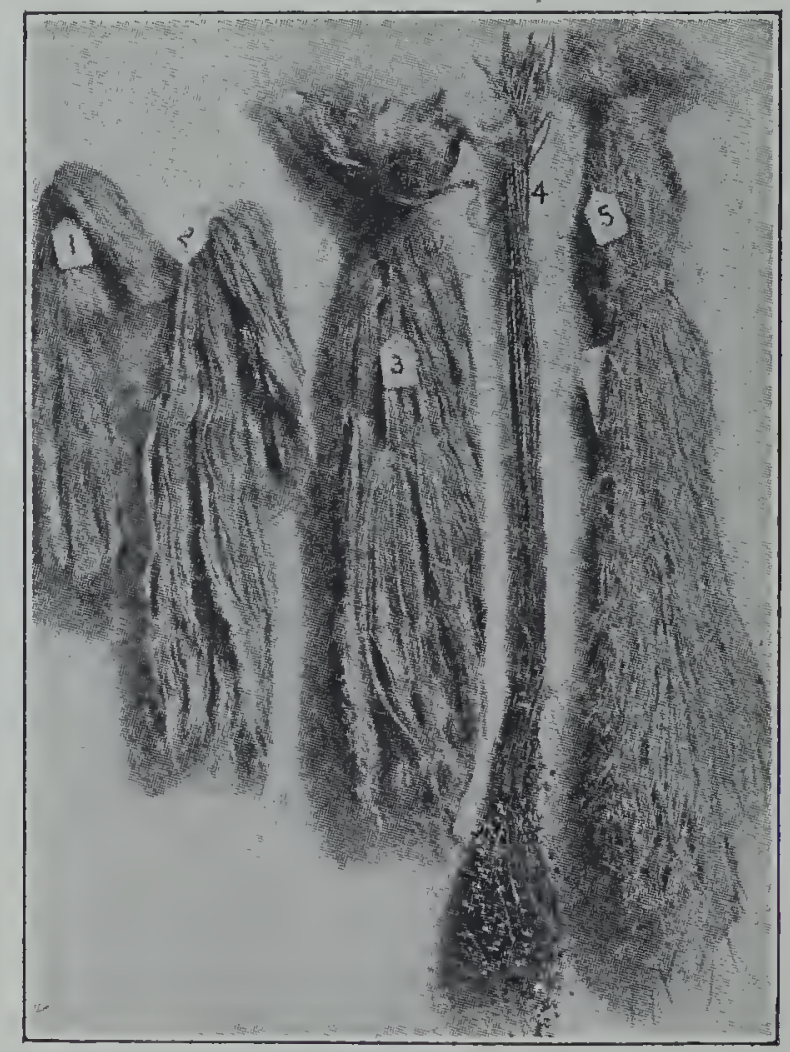

Fig. 124. - Flax plant and fiber. atmosphere exists. This explains in part why the states of Minnesota, North Dakota and South Dakota produce the greater part of the crop raised in this country. 
Flax seed is sown in the spring, the average depth at which it is planted being about one inch. Like wheat, the crop requires no cultivation after being sown. If seed is desired, the stand should be somewhat thin in order that the plants may branch well. On the other hand, if fiber is wanted, the seed is sown thickly to make the plants grow tall and straight. When sown for seed, from one to three pecks per acre are used while nearly four times this amount of seed is sown for a fiber crop.

Flax is cut with an ordinary self-binder, and is considered one of the most pleasant crops to handle. It has long been regarded as one of the most exhaustive crops grown on any soil. A disease, known as flax wilt, develops when the crop is raised a second or third year in succession in the same field; and many growers believe that it is this disease, rather than the gross feeding habit of the plant, that has given it so bad a reputation.

\section{Methods of Handling and Value of the Fiber and} Seed. - After the crop has been cut with the binder, or pulled by hand as is sometimes done, it is placed in shocks and allowed to stand for two or three weeks. If the fiber is desired, the seed is then removed by passing the heads between rapidly revolving cylinders or rollers, which crush the seed pods. The straw is bound into bundles, and later, usually in October or November, it is spread out on the ground to "ret," or rot. During this process the portions of the stems, other than the bast (Section 82), decay, or become sufficiently softened to permit an easy separation of the parts. The long, straight fibers, from one to three feet in length, are called long lint while the short and tangled ones are called tow. From the former, fine laces, linens, dress goods and thread are made, while 
bagging, upholstering material and twine are made from the tow.

Flax fiber has been called "the fiber of luxury," while cotton has been called "the fiber of the masses."

If the crop is not raised for the fiber, but only for the seed, it is threshed with an ordinary threshing machine. The seed secured is eventually crushed, after which it is heated to about 165 degrees Fahrenheit, placed between layers of coarse cloth and the oil extracted by pressure. The solidified mass remaining is known as oil cake. This cake may be ground, in which case it is called "old process linseed meal." If the oil is extracted, not by pressure but by the use of petroleum naphtha, the remaining meal is known as " new process linseed meal."

Oil cake and linseed meal are among the most valuable protein feeds for live stock known. Linseed oil is used in making paints and varnishes, printing ink, linoleum, soap and artificial India rubber.

\section{HEMP}

This plant is a coarse annual, growing from eight to twelve feet tall and yielding a rather coarse fiber which is used in making cordage and warp for carpets. The crop demands a somewhat warmer climate than does flax and in this country is raised principally in the blue grass regions of Kentucky and Tennessee. The crop does not exhaust the soil so quickly as flax; and if the waste is returned to the field, it may be grown several years in succession on the same land.

The hemp crop is cut with a heavy mower or with a selfrake reaper, or it may be cut by hand.

The fallen plants are allowed to lie on the ground until the dews and rains have "retted," or rotted, the stems. 
Then it is stacked and later the fiber is separated by machinery. The seed is not so eagerly sought by paint manufacturers as is that of flax, although considerable

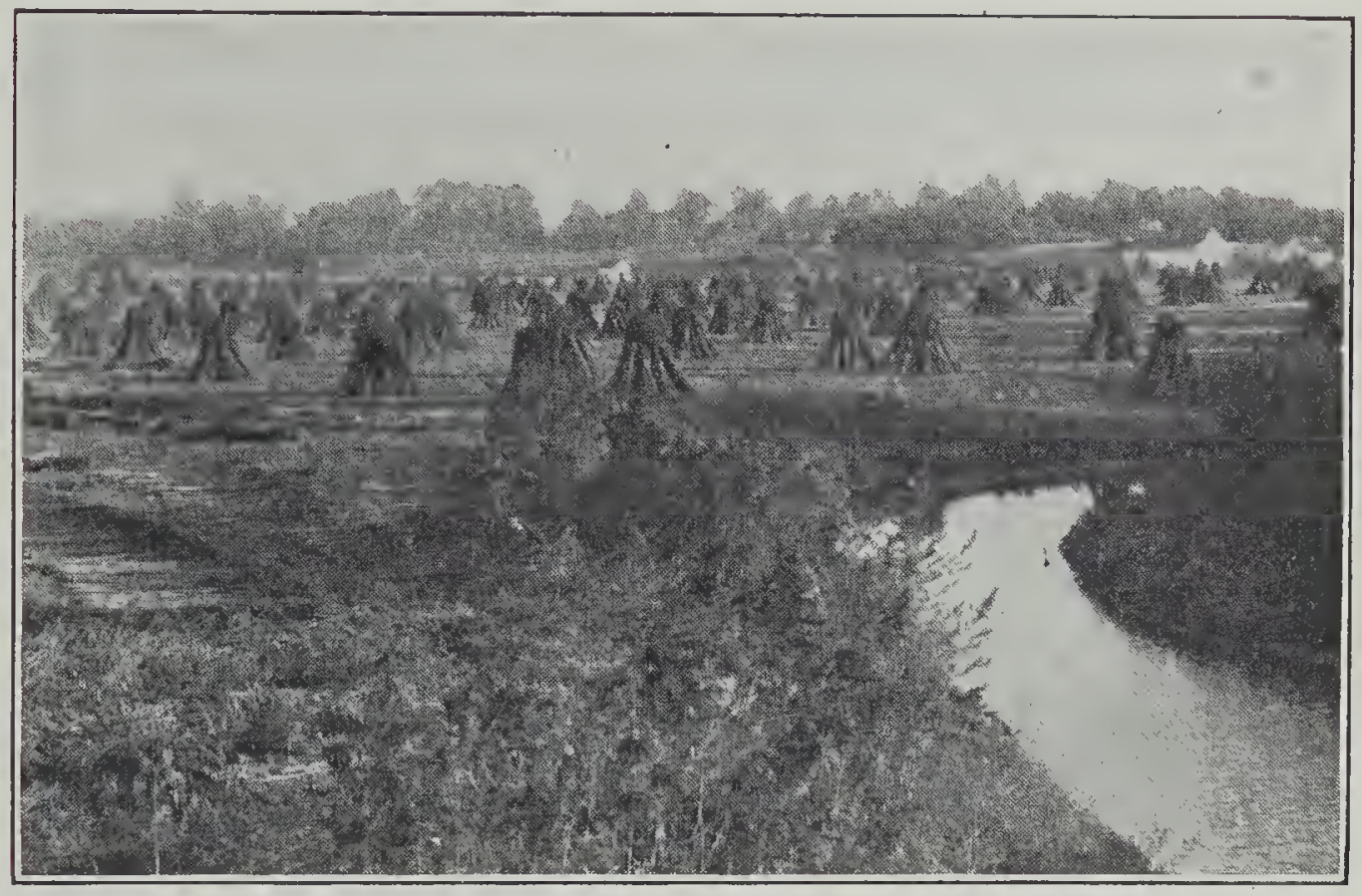

Fig. 125. - A Kentucky hemp field.

use is made of it as an ingredient of oil colors and varnishes.

\section{QUESTIONS}

1. Name the three principal fiber crops of America and tell where each is grown.

2. What two portions, or parts, of these fiber plants are used and why is each valuable?

3. Name five reasons why the southern part of the United States is adapted to the culture of cotton.

4. Give a good crop rotation for a cotton plantation and tell why such a rotation is important.

5. State briefly how to prepare and plant a field of cotton.

6. Tell briefly how cotton is picked and how the seed is separated from the lint. 
7. Why is cotton lint, or fiber, so extensively used by the "masses"?

8. In what kind of soil is flax usually grown?

9. What is the principal use of flax seed, and for what is the fiber used?

10. Describe the hemp plant and tell how it is harvested and for what the fiber is chiefly used. 


\section{CHAPTER XXI}

\section{FRUIT GROWING}

216. Horticulture and Agriculture. - In ancient times, the people lived together within walled cities for protection and cultivated "intensively" the small plots of land within the inclosures. The larger fields were outside and could not be so carefully attended as those within.

The Latin word hortus means a garden, or inclosure; ager, a field; and cultura, cultivation or culture. Thus the word horticulture has come down to us meaning the care, or culture, of those crops which were grown within the walled cities; viz., fruits, vegetables and flowers, while agriculture signifies the cultivation of grain crops, grasses and other crops grown in the large fields outside.

The older a country becomes and the denser its population, the fewer are the field crops grown, while fruit and vegetable crops tend to increase.

217. Where our Fruits originated. - If we were to travel from New York to Seattle, passing through Chicago, Omaha, Denver and Salt Lake City on our way, we should find apple orchards, large or small, in most places along our route where the land is capable of cultivation. Then if we were to journey down the Pacific coast, we should find prune, peach, orange and lemon orchards and the vineyards which yield our supply of raisins, as well as large red or white solid-fleshed grapes. In the southern part of California and in Arizona, the date flourishes; and in 
this same district and extending eastward into Texas, we should find the fig. In the Cotton Belt and extending slightly north of it, large orchards of peaches grow, and in Florida, the orange, lemon and grapefruit grow in abundance.

Did all these fruits originate on this continent? Not one. All of them came to us from Europe or Asia, having been introduced into this country by the white man. These fruits have, however, been improved and selected according to adaptation to different soils and climates of the United States. Moreover, the native fruits of other kinds which the first settlers found growing here have been improved. From the wild cranberries, plums, raspberries and grapes, have come thousands of superior varieties worthy of a name and of a place in our gardens and orchards.

Not many of those varieties of apples, oranges, peaches or other fruits which were originally introduced from foreign lands are now to be found growing in American orchards. They have been replaced by better varieties, the offspring of these foreign parents.

It is an interesting fact that almost none of these superior varieties have come from known parents. A seed may be dropped on the roadside by a bird or a thoughtless passer-by; a tree springs up, and by one chance in a thousand perhaps, or even less, its fruit proves to be better than any other similar fruit growing in that locality. Buds or twigs are taken from it and united with other plants of the same species, the variety is given a name, and it thus becomes introduced into cultivation.

218. Developing the Young Tree. - After the budding or grafting has been done as explained in Section 104, the young tree is trained in the nursery for one or more years. It is then taken up with as many roots as can be 
conveniently secured, packed in moist moss and straw and shipped to the person who wishes to plant it.

219. The Location of the Orchard. - The location of a young orchard should not be chosen hastily or without careful consideration. In the selection of an orchard site, these factors should be kept in mind :

(1) Convenience to the home and to a desirable market if fruit is to be raised to sell.

(2) Soil. - Each fruit has a particular type of soil upon which it succeeds best. This can usually be determined by studying different orchards in your own locality.

(3) Water Drainage. - There is an old saying that fruit trees do not like wet feet. The gravity water (Section 12) in any orchard site must be removed by drainage before the plants will thrive.

(4) Air Drainage. - It must be remembered that air drains like water. The cold air is the heavier and settles into the "pockets," or low places; and if trees or vines are planted there, they are very liable to be injured by the frost.

220. The Distances between the Trees. - If the location and soil preparation are satisfactory, we must next determine the distances at which the various plants make their best growth.

The following table of distances between the plants is recommended, though it may be varied slightly on different soils and with different varieties.

Apples

Pears

Peaches and nectarines

Plums Apricots
36 feet each way

20 to 25 feet each way

20 feet each way

20 feet each way

20 feet each way 
Cherries . . . . . . . 20 feet each way

Cherries (sweet) . . . . . 30 feet each way

Figs . . . . . . . . . 20 to 25 feet each way

Oranges and lemons . . . . 25 to 30 feet each way

Grapes . . . . . . . $6 \times 8$ feet to $8 \times 10$ feet

Currants . . . . . . $4 \times 6$ feet to $6 \times 8$ feet

Blackberries . . . . . $4 \times 7$ feet to $6 \times 9$ feet

Raspberries . . . . . $3 \times 6$ feet to $5 \times 8$ feet

Strawberries . . . . . $1 \times 3$ feet to $1 \times 4$ feet

221. Cutting back and Planting the Young Trees or Vines. - Suppose that the trees or vines have been re-
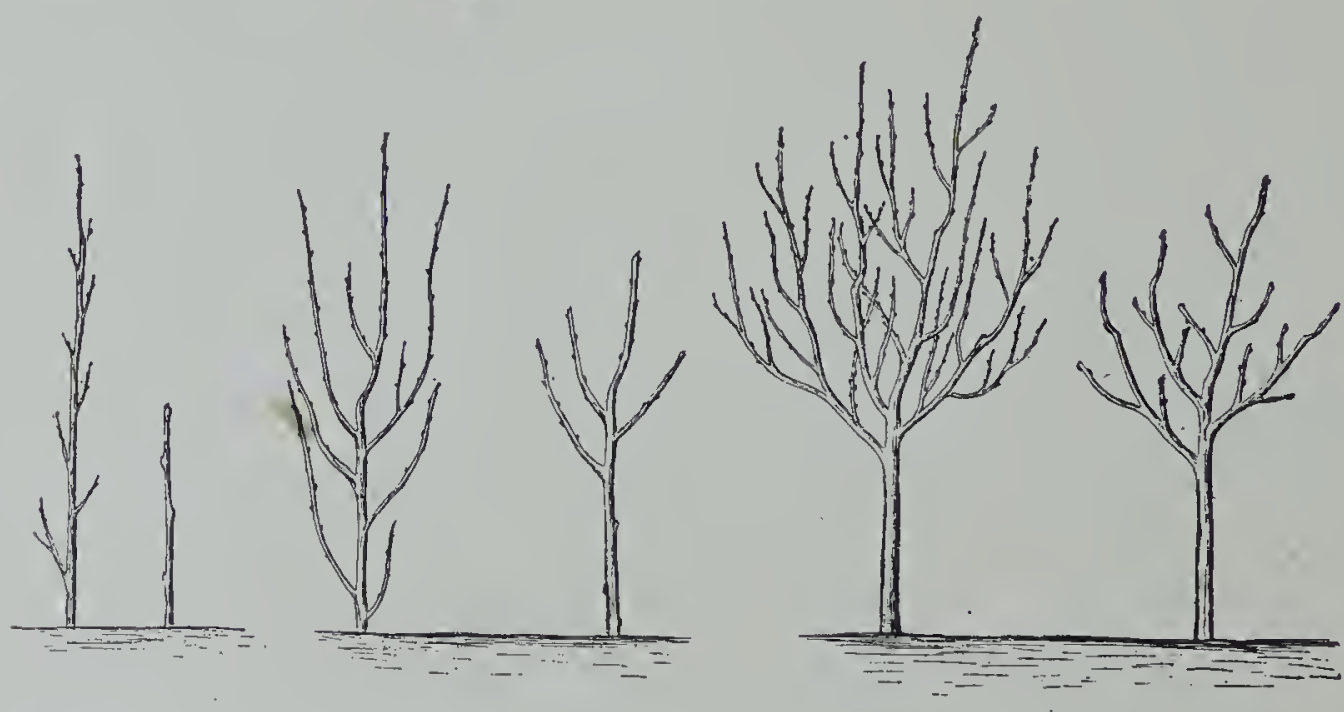

FIG. 126. - Trees cut back for planting.

ceived from the nursery. They must be protected from the sun and wind until they are planted; and moreover, only as many should be taken to the orchard at a time as can be protected while the work is going on.

It is impossible to remove a tree from the nursery row or from the ground elsewhere without cutting away a part of the roots. The top must be cut back then, to offset this loss of roots. It may be given almost as a fixed rule that young trees should be cut back at least one half of the last season's growth and vines and shrubs should be cut back 
to the ground, leaving only two or three buds on the short stems.

A tree should be planted slightly deeper than it was in the nursery row, the roots well spread out, and the soil packed firmly about them.

222. Cultivation of the Young Plants. - We are already familiar with the reasons for tilling the soil, but we cannot apply these principles in fruit growing without knowledge of the needs of the roots of our trees and vines. The root systems of fruit-bearing plants have been thoroughly studied; and, as will be seen, the cultivation of each one must be governed largely by the character of the underground part of the plant.

(1) The Strawberry. - This plant has a shallow root system which does not extend far beyond the area covered by the leaves. Strawberries must receive frequent and shallow cultivation or be mulched with straw between the rows to produce the best fruit.

(2) The Raspberry. - This plant, too, has a shallow root system and can not endure deep cultivation as the heavy main roots will be torn out or cut off. Moisture should be retained with a dust or straw mulch.

(3) The Grape. - The grape has a deep root system and should therefore receive thorough cultivation, while the plant itself delights in a deep, porous, even gravelly soil where its feeding roots may range deep and wide.

(4) The Tree Fruits. - Most tree fruits, as the apple, pear and cherry, have deep feeding roots; and in those soils in which the roots are able to penetrate deep and wide, cultivation is used principally to put the soil in a condition to receive and hold moisture. In fact, as the trees become older, the orchard may be planted to some annual or biennial clover. Grasses, however, which are 
likely to rob the trees of their moisture, and those which allow the water to run off instead of soaking into the ground, should not be allowed to take possession of the soil.

223. The Training of the Young Plants. - The training of the young plants must begin the same season they are set out, as usually the first few seasons determine the form of the tree or vine. Three facts should be kept in mind in pruning, or training any young trees, limbs or vines :

(1) Each plant should be so placed and trained that all its leaves may receive plenty of sunlight in order that they may manufacture an abundance of food for the plant.

(2) Except in a very few localities in the United States, the main limbs of a tree should be quite close to the ground. A low-headed, vase-formed tree is less liable to injury from wind and sun, the branches receive plenty of light, and the fruit is much easier to gather.

(3) Heavy pruning, one year in many, upsets the habits of the plant and results in too much wood growth. On the other hand, those pruned lightly each year maintain a normal, healthy growth.

224. When and how Fruit Buds form. - When by proper cultivation and pruning we have developed a tree or vine of the type which we desire, we must turn our attention to making it bear fruit.

Fruit develops from blossoms. Blossoms develop from blossom buds, or fruit buds, as they are called. And these blossom buds develop from slight enlargements, or protuberances, within the protecting leaf buds.

If we were to take two or three eggs each day from an incubator, break them open and examine them, we could 
trace the development of a chick until it is fully formed. Similarly, by cutting open buds every week from the first of July until the first of the following April, and examining them under a powerful microscope, we can trace the development of a blossom.

At some time about the middle of the growing season, often as early as July first with apples, plums, peaches and cherries in the central parts of the United States - a slight protuberance may be found within the protecting scales at the base of a leaf bud. It is the beginning of a fruit bud; and as the season advances, the parts of the flower are slowly formed within the bud, - first, the sepals, next, the petals, then the stamens and lastly the pistil.

When the warm days of spring come on, the protecting scales open and the full flower expands.

\section{Conditions which favor the Formation of Fruit} Buds. - While it is not possible for a fruit grower to control all the conditions which surround his plants, it is surprising how many things he can do that favor the formation of fruit buds; and we must remember that an abundance of fruit buds usually means a crop of fruit the following year.

Two principles must be kept in mind; and with these to guide him, the fruit grower is able to control in a measure the yield of fruit from his orchard from year to year :

(1) Fruit buds form when the plants are in a healthy condition and full of reserve food. (Section 70.)

(2) Fruit buds form when there is a check in the growth of the plants.

We can readily see how a grower may keep his plants in healthy condition and full of reserve food by cultivation, by pruning, and by the addition of organic matter to the soil if need be; and how he may favor their 
growth by protecting them against disease (Section 99) and insects.

But how is he to check their growth?

The fruit grower in the irrigated country will tell you that it can be done by withholding nearly all water from the trees during the latter part of the growing season.

The man who cultivates his orchard will tell you that you can check the growth by stopping the cultivation early in July and sowing oats, rape, buckwheat, vetch or some other crop which will take the moisture and plant food from the soil.

The man who once had a very healthy orchard in the central part of the United States, but all growing perhaps to heavy wood and bearing no fruit, will tell you that he pruned his trees in June and that the next year he had a full crop.

Your grandfather would probably have told you to drive into the body of the tree rusty nails or small bolts.

The man who prunes and cultivates, who checks his irrigation stream, or who sows a crop in his orchard at midsummer is thinking about securing a crop of fruit, and at the same time about keeping his trees in healthy condition. Grandfather's method produced fruit, but in many cases it shortened the life of the tree. A tree that is injured by rabbits or mice, by storms or by careless treatment is very likely to bear fruit the next year, - and the next year it is apt to die.

By careful soil management, by proper pruning, by intelligent irrigation, by timely spraying, and by thinning the fruit, we can aid the fruit buds to form and at the same time maintain healthy, long-lived trees.

\section{Age of Wood upon which Fruit Buds appear. -} One of the most interesting ways to fix in mind the dif- 
ference between a leaf bud and a fruit bud is to examine them at any time in the winter. You will find then:

(1) That the fruit buds of the cherry and plum are in

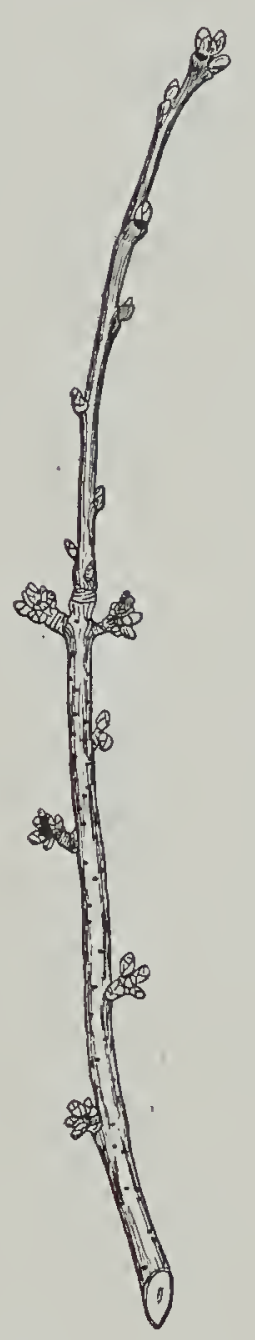

Frg. 127. - A cherry twig as it looks in winter.

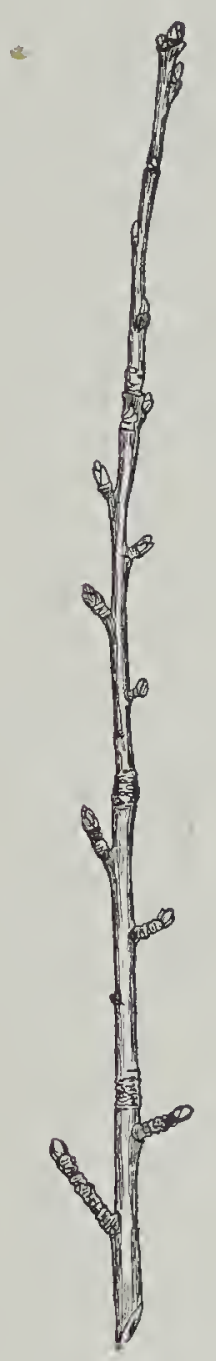

Fig. 128. - An apple twig in winter.

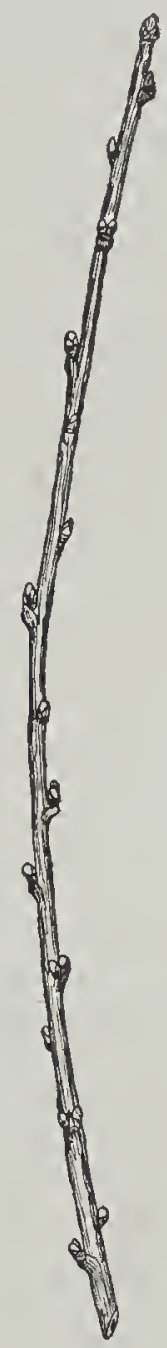

FIG. 129. - A peach twig as it looks in winter.

clusters on short spurs while the leaf buds lie close against the twig.

(2) That the fruit buds of the apple are likewise borne on spurs, but that there is usually only one on each spur while the leaf buds lie against the twig. 
(3) That the buds of the peach are in clusters of three, not on spurs, but lying close against the twig, the middle one of each cluster being a leaf bud while the other two are fruit buds.

By studying Figures 127-129, or better still the twigs themselves, you will see that not all varieties of fruit buds are borne on wood of the same age. There is always a set of rough rings, or wrinkles, separating each year's growth on a twig from that of the year before; and by beginning at the tip and counting the sections, or divisions, between these rings, you can easily determine the age of any portion of the twig or branch.

\section{EXERCISE 51}

Object. - To learn the form and position of fruit buds and the age of the wood upon which they appear.

Procedure. - Secure a branch or twig three feet or more in length of a cherry, peach, plum, apple, or other fruit tree, and lay it on the desk or table before you.

Examine it carefully for the rough rings, which separate the wood of different years' growth. Then point out the fruit buds and note that they are usually plumper, as well as grayer or darker in color than the leaf buds, .while the leaf buds, which lie along the twig, are usually rather pointed in comparison with the fruit buds.

Conclusion. - Describe carefully in your notebook the color, form and position of both the fruit buds and the leaf buds, and state the age of the wood upon which the fruit buds appear.

Make a drawing of the twig to show this.

Put your twig in a vase or glass of water so that the buds may open.

The fruit of the grape is borne on wood, or canes, of the same season's growth as the fruit itself, - not on the wood 
of the year before, or the second, third, or fourth year before as is the case with most of the tree fruits. Remember to examine your grape vines next year to see that this is true.

We readily see then how closely the questions of fruit buds and pruning are related.

The clusters of fruit that you will pick from your grape vines next fall will be borne only on the young, new wood formed during the spring and summer; and because of this fact, the old wood should have been pruned away last fall, save only a very few canes from which the new ones might grow. This would cause the plant to devote its entire strength and vigor to the development of the new fruit-bearing wood as well as to that of the fruit itself.

The fruit of the blackberry and raspberry, like that of the grape, is borne only on the new twigs, or wood, of the same season's growth as the berries themselves; and these new twigs branch only from those canes which have grown up from the ground the year before. This means that the twigs from which you will gather berries next summer will be found branching out from canes that came up from the ground last summer, - and these twigs will not begin to grow until spring has come. Therefore you should have cut away all old wood that had borne fruit as soon as the crop was gathered last summer so that the new canes could have possession of the ground.

Peaches are always borne on twigs of the previous season's growth. It follows that pruning should have been done last summer to induce the growth of new twigs from which the next season's crop must come.

Plums and cherries usually, but not always, are borne on wood that is two years old, and fortunately these trees get along well with very little pruning. 
Apples are usually borne on wood older than two years, and frequent use of the pruning saw and knife must be made to induce the fruit spurs on these trees to develop where we want them.

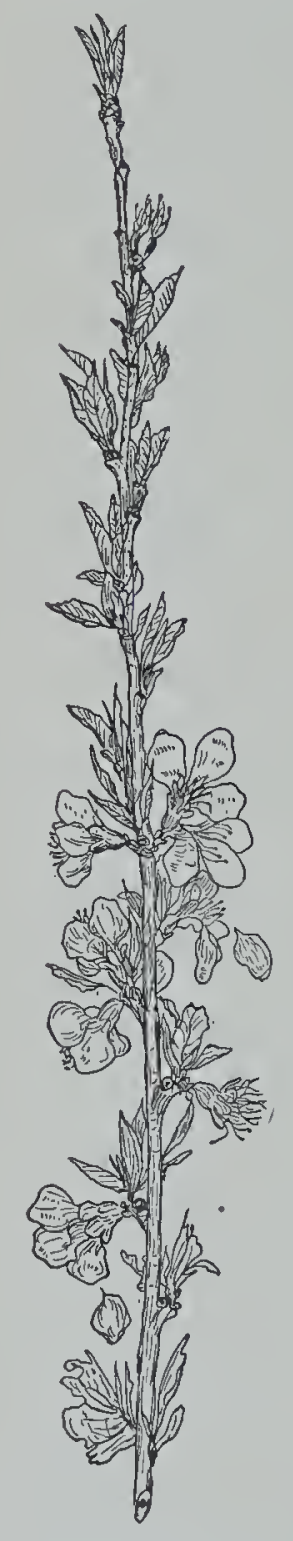

FIG. 130.-

A peach twig as it looks in spring.

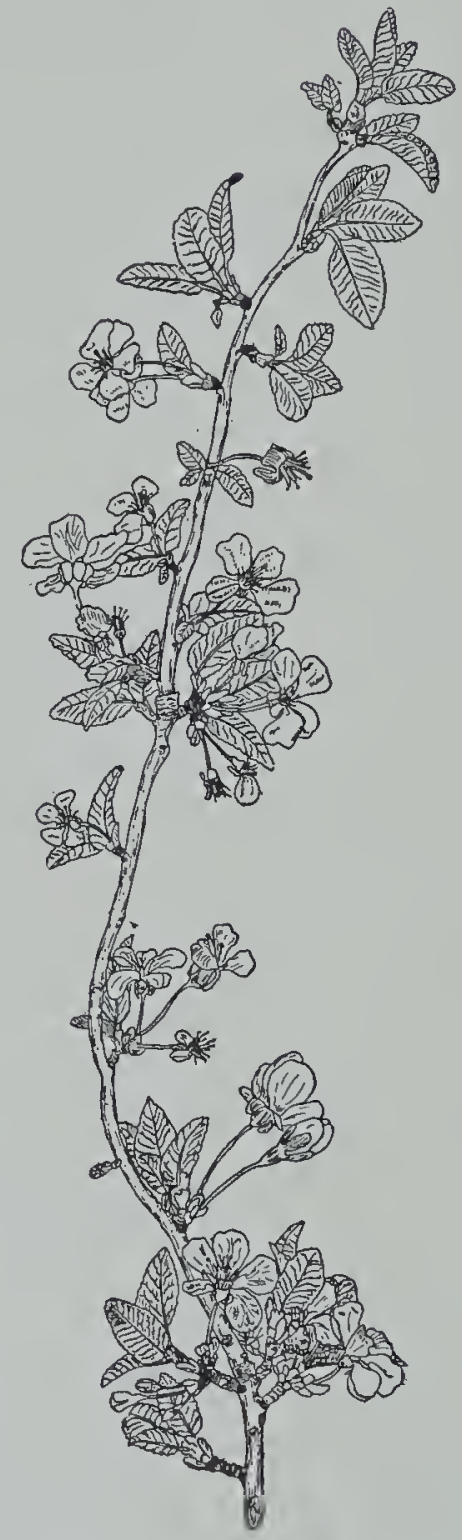

FIg. 131. - A cherry twig as it looks in spring.

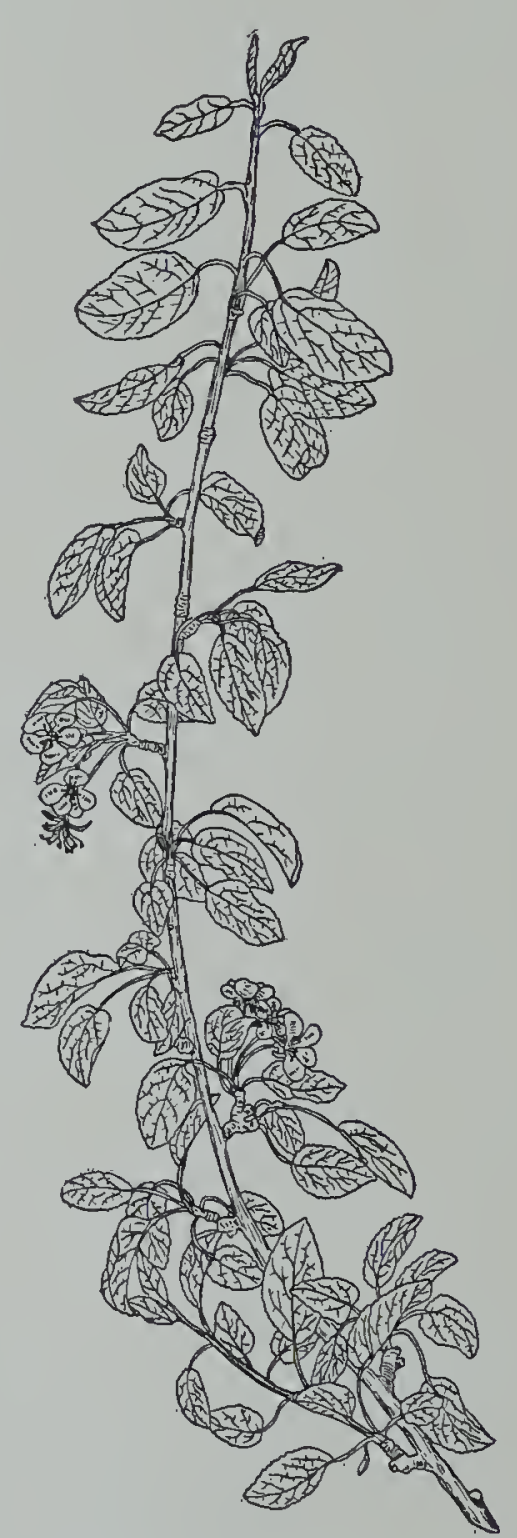

Fig. 132. - An apple twig as it looks in spring.

227. The Reasons for Pruning. - We have studied about pruning in connection with the training of the 
young trees or vines and also as a means of inducing the formation of fruit buds. Let us bring together the reasons for this important operation. They are:

(1) To regulate the size and shape of the tree or vine.

(2) To remove unnecessary and rubbing twigs or small limbs which prevent the sunlight from reaching the fruitbearing wood in the inner parts of the tree top.

(3) 'To remove any dead or diseased portions of the plant. Many of the diseases of both the limbs and the fruit may be controlled by cutting out and burning the limbs as soon as the blights or cankers appear.

(4) To increase the vigor and health, and thereby the wood growth of the tree or vine. Plants which have a feeble root system are greatly benefited by pruning, while the rate of growth of healthy trees is increased in the same way if the work is done in the dormant season.

(5) To increase fruitfulness. As has been shown, checking the growth of trees and vines tends to stimulate the formation of fruit buds. Pruning in the early summer, unlike that done in the winter, checks the growth of wood and favors that of fruit buds.

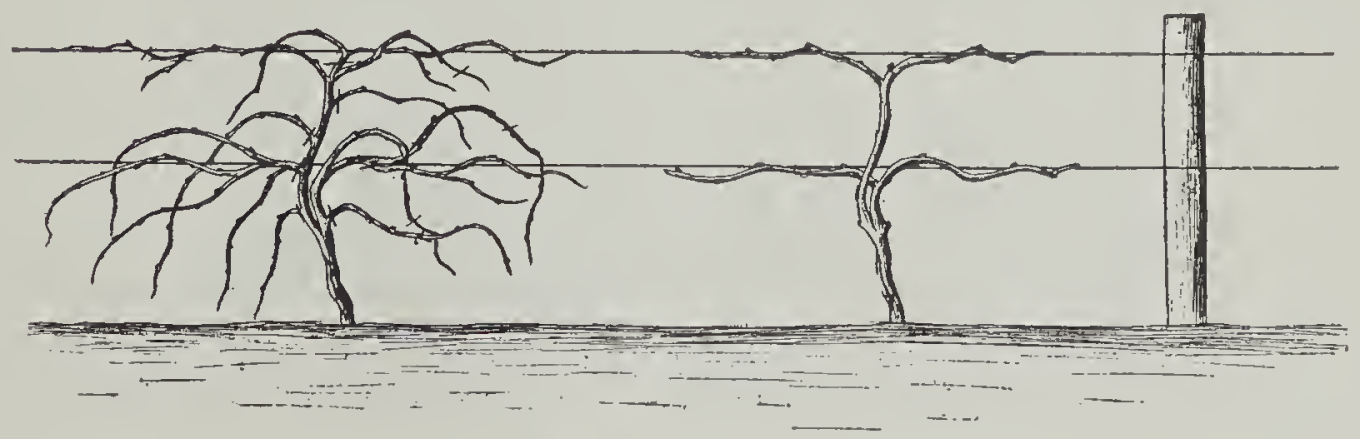

FIG. 133. - Grape vine pruned to a double T.

228. Methods of Pruning. - With the reasons for pruning clearly in mind, we are ready to take up the methods of performing this important work. These will 
vary somewhat with the age, variety and vigor of the plant, and with the locality in which it is grown.

The Grape. - Many methods are used in pruning the grape vine, but only one will be given here:

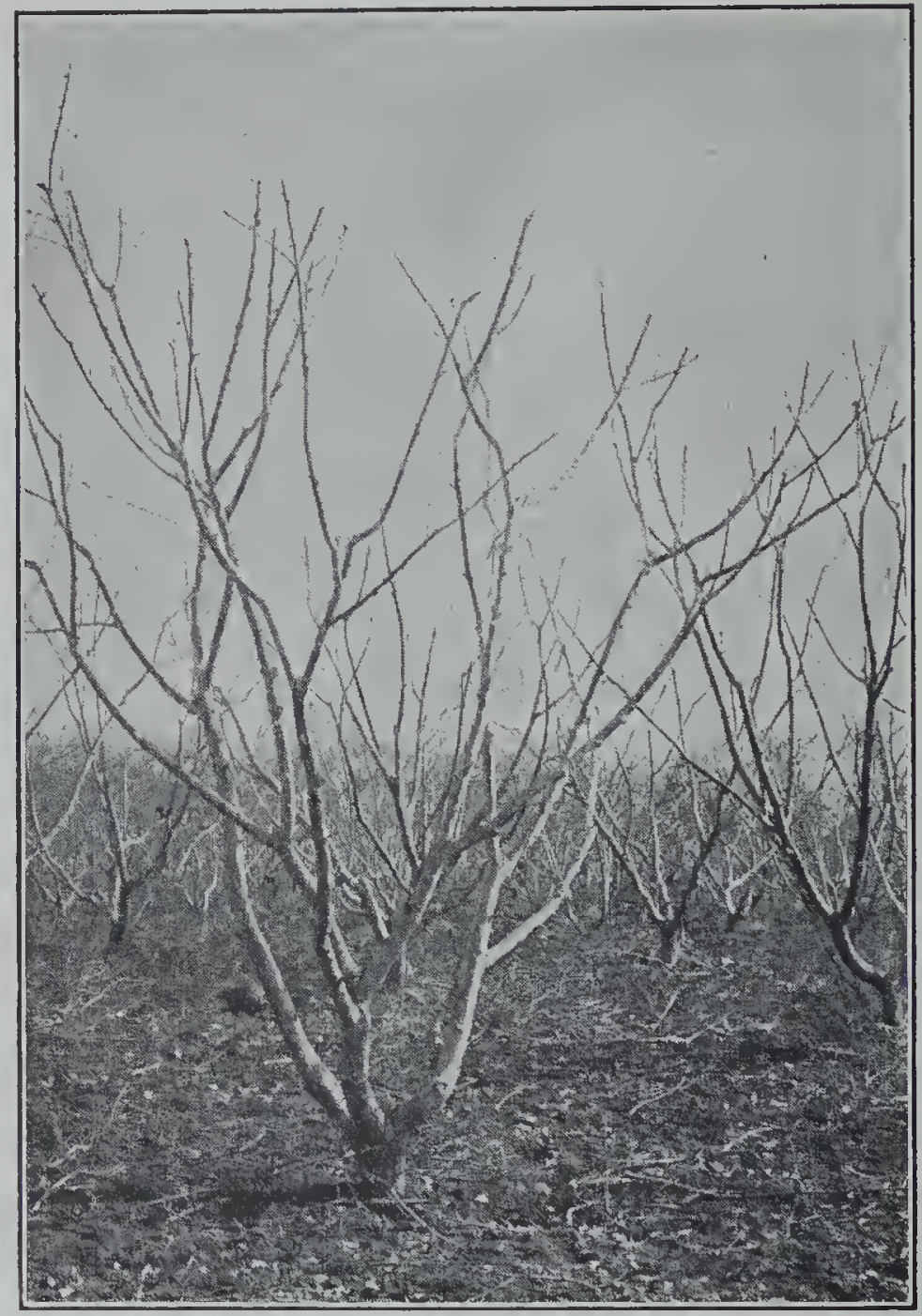

FIG. 134. - Peach trees headed back.

The young vine is trained up a two-wire trellis and there encouraged to form a letter ' $\mathrm{T}$ with a second letter $\mathrm{T}$ immediately above it. The erect stems of the two letters, then, are of wood, usually as old as the vine itself, while the spreading "arms " are of wood of the previous season's 
growth. From the buds, which may be readily found on these arms, are to come the branches that will bear the fruit.

The grape should be pruned in the late winter, when all the wood should be cut away save the old stems and four new branches, less than one year old, which will form the arms of the two T's.

Raspberries and Blackberries. - Soon after these berries have been picked, the canes which bore them die, and beside them, growing up from the same root, are found new canes.

The old canes should be removed as soon as the fruit has been gathered, and early the following spring the new canes should have their very tips pruned off as this

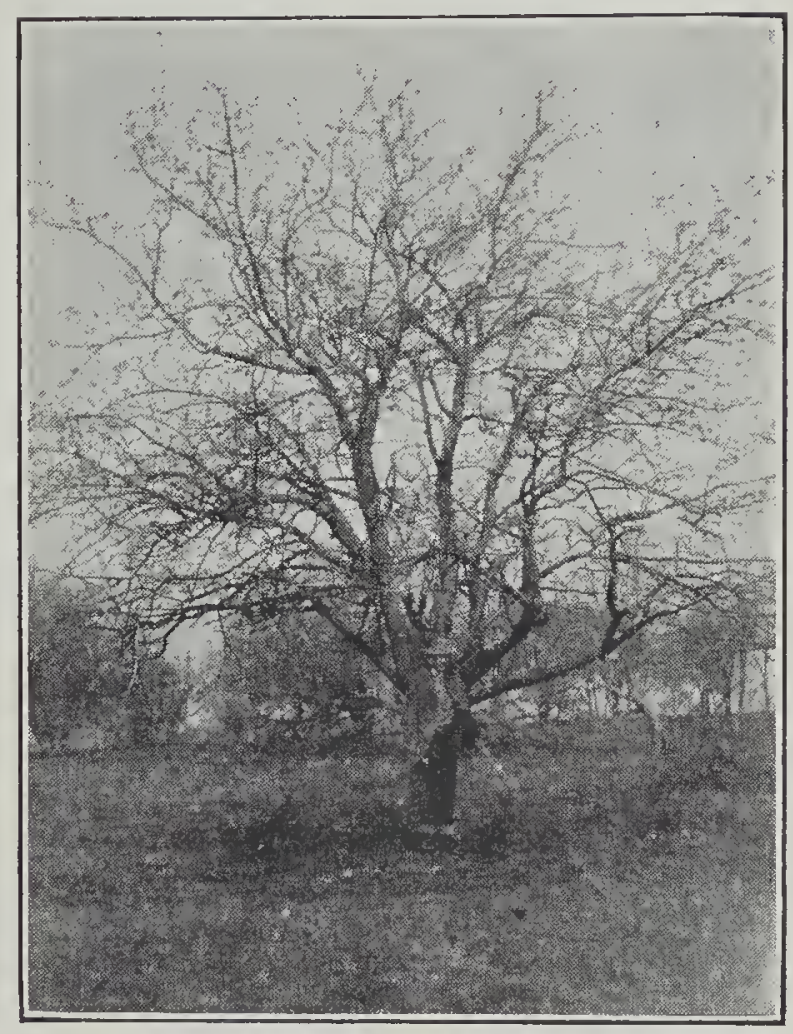

Courtesy Iowa State College.

Fig. 135. - Apple tree before pruning. favors the development of the lateral twigs, or branches, which are to bear the fruit.

Cherries and Plums. - Cherry and plum trees need little pruning, save to remove the dead, diseased or broken limbs, or those which densely shade the inner parts of the tree top.

Peaches. - Peach trees tend to grow tall. Their buds are sometimes killed in the winter by the severe cold. We can tell when this has happened by cutting through the 
buds in the late winter with a sharp knife. If the middles are black instead of a healthy green, we need expect no peaches. This, then, will be the year to "head in " our peach trees; that is, the main branches are cut back a part of their length. New twigs will grow vigorously from them to form buds for the next season's crop.

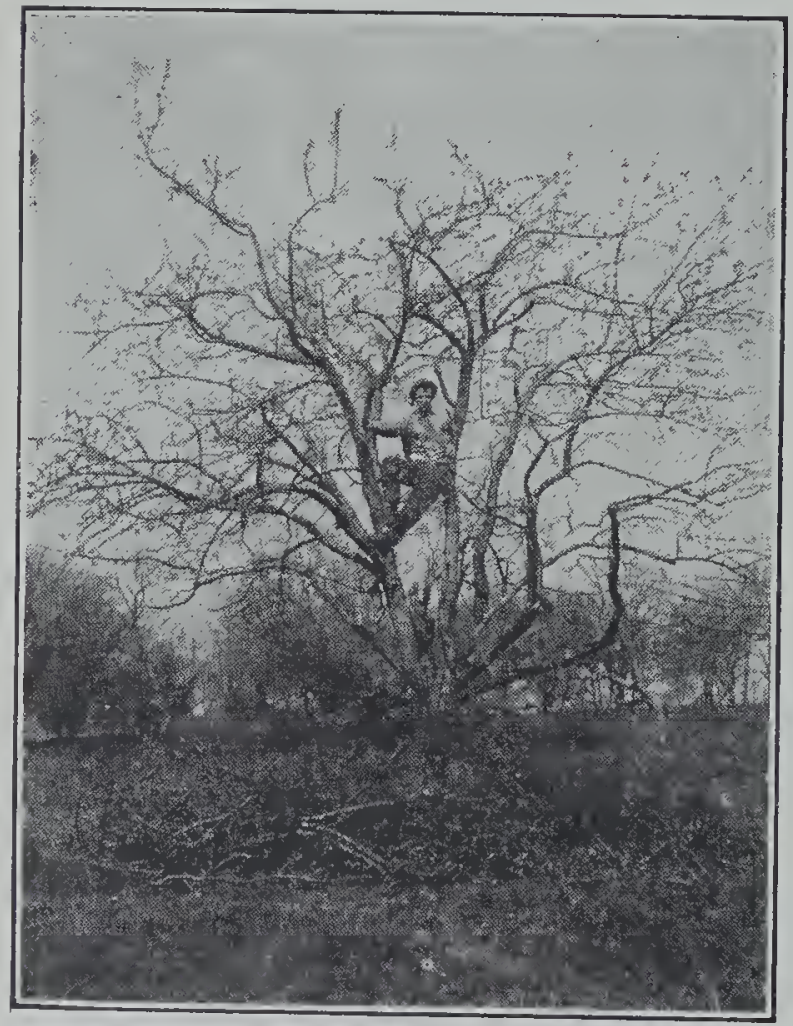

Courtesy Iowa State College.

Apples. - The best form of an apple tree is one which has a low, vase-shaped, open head, or top. In developing a young tree, it is not difficult to produce this vase-like form. Two branches will be found growing from the same limb, one tending to grow upright and the other to spread. The upright one should be removed, and thus the spreading vaselike forms will be developed.

FIG. 136. - Apple tree after pruning.

Even after the tree has reached its full size, the pruning must be continued in about the manner explained below :

First. - Remove all water sprouts, - those long, slender, switchlike branches, which bear no fruit. If, however, a part of the tree top is found vacant, one or more of these water sprouts should be encouraged to grow in that direction. By cutting them back later, we can induce them to bear fruit. 
Second. - Remove all dead limbs, all limbs which rub or injure others, and those which make the inner parts of the tree dark and damp.

In pruning apple trees, it is better to begin at the top of the tree and work downward, opening the outer branches so as to let the sunlight in and give the tree the desirable vase-like form, than to begin at the bottom and simply remove some of the large limbs.

Strawberries. - We do not ordinarily regard pruning as necessary or desirable for strawberries; yet there are few plants which really need it more, at least while they are very young.

When a strawberry plant is set out in the spring, all its vigor and strength should go to the development of a strong root system. The runners which it sends out

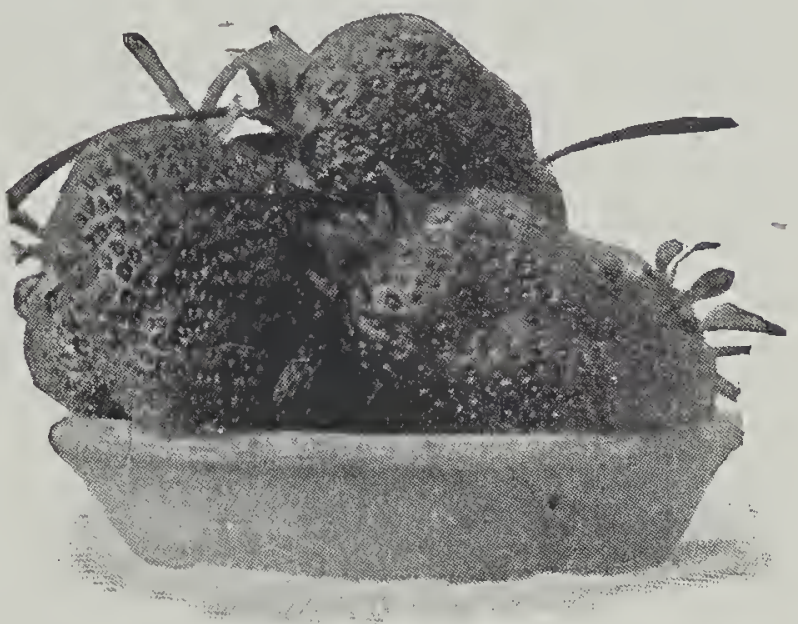

FIG. 137. - Strawberries. and the blossoms which it puts forth should be cut away.

About the middle of the growing season, however, the runners may be distributed along the row as they appear and allowed to take root. After this, the space between the rows should be kept cultivated or mulched, and the runners should be kept out of them.

If after two or three years the rows become matted, the runners may be allowed to take possession of the space between them, and the old rows may be plowed or hoed out. In this way, we can virtually secure a new bed with little effort. 
229. Precautions to be taken in Pruning. - Care must be exercised not to remove the fruit spurs, which we should be able by this time to recognize, nor to remove so much wood in a single season that the roots and top of the tree will be thrown out of " balance."

We should bear in mind that pruning for vigor; i.e.,

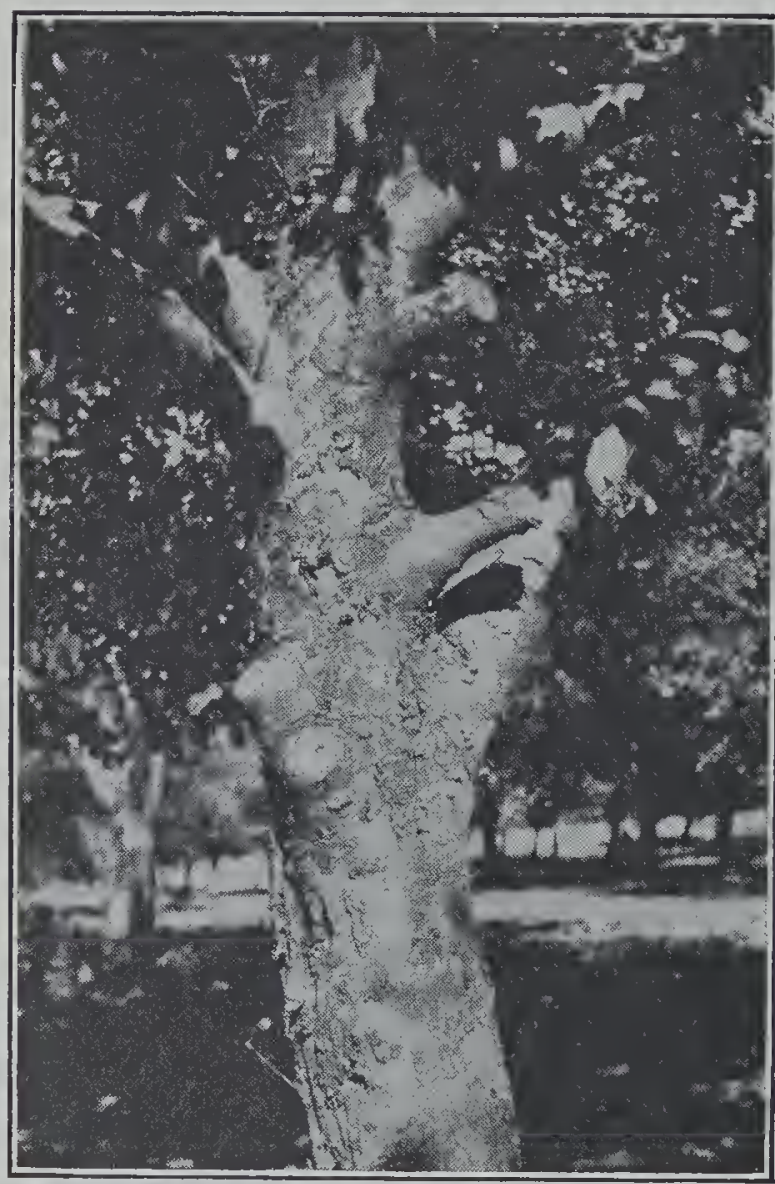

Courtesy Iowa State College.

FIG. 138. - Improper pruning. for wood growth, is usually done while the plants are dormant, usually in the late winter; but pruning as a means of checking the growth of the tree is done during the growing season. Pruning for wood growth is usually a severer operation than that which is intended to check the growth and induce the formation of fruit buds. Indeed, the latter may consist only of pinching the terminal buds from the branches. This summer pruning of trees and vines must be done with caution, for a plant which is already somewhat weakened may be injured by pruning at this time. The most important end to be gained in pruning is the filling of the tree with reserve food, and this is accomplished by pruning for wood growth.

In pruning off either large limbs or small ones, the cuts 
should be made close to the limbs or trunks which support them, for a long stub like those shown in Figure 138 eventually decays, leaving a hole in the tree into which enter in regular order first moisture, then spores of decay, and finally the decayed wood itself, which may extend far into the trunk or limb. On the other hand, a cut made close to the tree heals over in a very few years. As a measure of safety, however, the stubs of large limbs, even when cut off close to the tree, should be painted with white lead and unboiled linseed oil to exclude the moisture and spores of decay which might otherwise enter.

\section{Protecting Fruit-Bearing Plants from their Ene- mies.}

Mice and Rabbits. -D During the winter months, damage is often done, particularly to young trees, by mice and rabbits. They gnaw away the bark and cambium layer from about the trunk, thus stopping the downward current of food and causing the roots to starve, as explained in Section 79.

If the trees, bushes or vines are covered with lime-sulfur spray mixture, which may be purchased at any drug store, the mice and rabbits will be repelled. It may be necessary to paint the solution on the trunks of the trees with a brush, especially if the rabbits are numerous and the ground covered with snow so that they have trouble in finding other food.

Frost. - The first way - and a very important one of securing protection against frost is to choose a proper location for the orchard. A body of water, a belt of timber, a windbreak, and always good air drainage will help in preventing injury by frost. However, in even the best of locations, frosts will sometimes occur.

Low growing plants like the strawberry may sometimes be covered with straw or hay. 
A blanket of smoke from burning litter will prevent the escape of heat from the soil and in this way will often prevent frost. Among the interesting sights to be seen at times in some commercial orchards are the long lines of pots of burning oil or coal, which make a dense smoke and

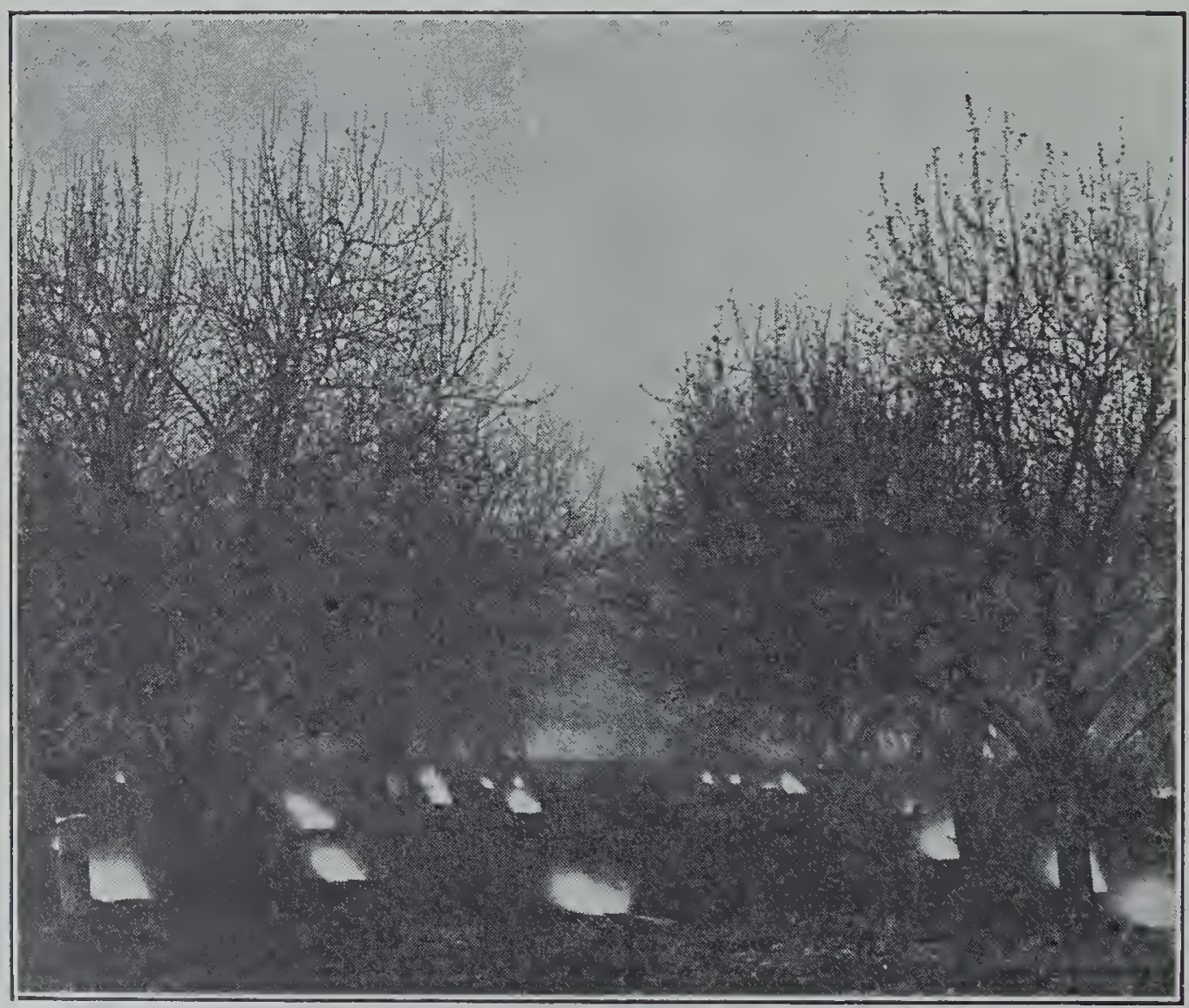

Courtesy Iowa State College.

FIG. 139. - Keeping Jack Frost away.

at the same time generate heat enough to keep the temperature of the orchard above the danger point.

Sunscald. - Undue exposure of the trunks of young trees to heat and cold may destroy a part of the bark, producing what is known as sunscald. Binding a layer of cornstalks, wood veneer or burlap about the trunks will protect them in the winter and early spring. These 
should, however, be removed during the growing season. As the tree becomes older, the low, vase-shaped top will protect the trunk.

Insects. - Injurious insects are divided into two classes; viz., those that chew, or eat the tissues of the plant, and those that suck the juices from it.

In the first class, we find such insects as the apple worm, or codling moth, the canker worm, the strawberry leaf eater and the potato bug. These insects devour the leaves or fruit, leaving nothing but the mere skeleton of the leaf or perhaps a fruit filled with long tunnels to show where they have eaten their way through.

In asmuch as these insects devour the parts of

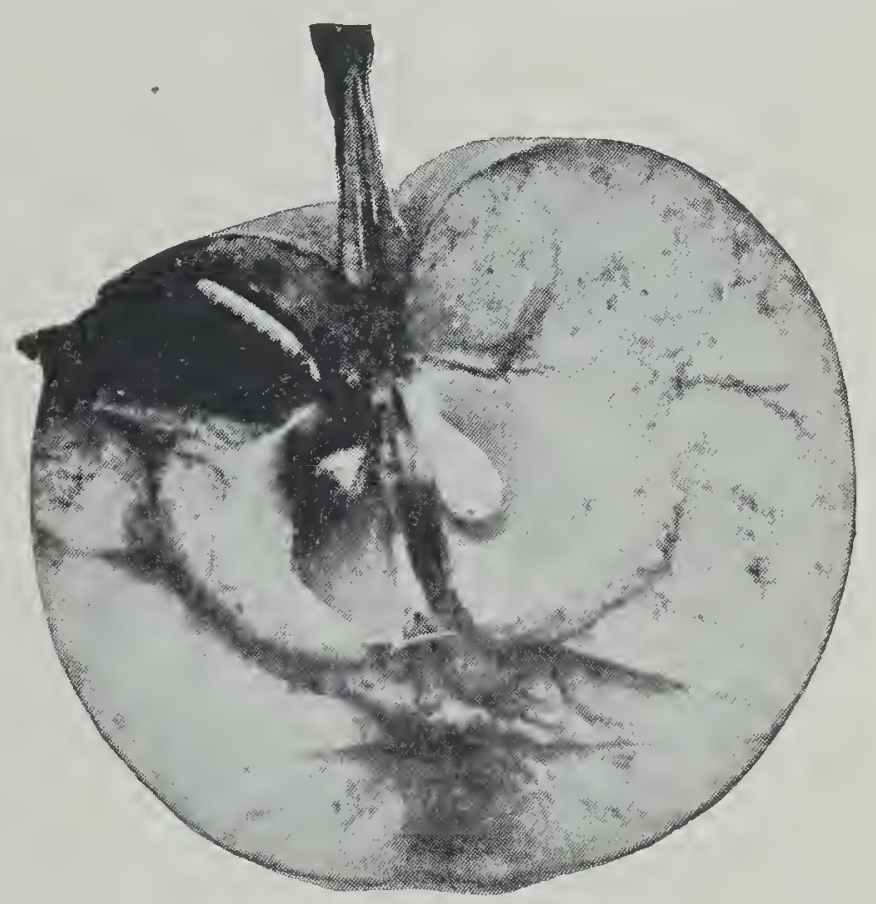

FIG. 140. - Codling moth and its work. the plant, they may be destroyed by applying a mist, or spray, containing some deadly poison, such as Paris green or lead arsenate. The latter is usually the more satisfactory because it stays on the leaves better and never burns them as the Paris green sometimes does. If two pounds of lead arsenate are dissolved in fifty gallons of water, the solution will destroy almost any chewing insects. It is used as a spray as they appear.

In combating strawberry worms or cabbage worms, it is often unsafe to use either of the poisons named above. 
In these cases, hellebore or pyrethrum (insect powder), may be substituted.

Those insects which suck, as the plant lice, or aphids, and the melon bugs, push their "beaks" down into the tissue of the leaf or fruit and take out the juices, destroying the plant or a part of it in this way. No poison, applied to the surface of the leaf, will affect them. A spray of

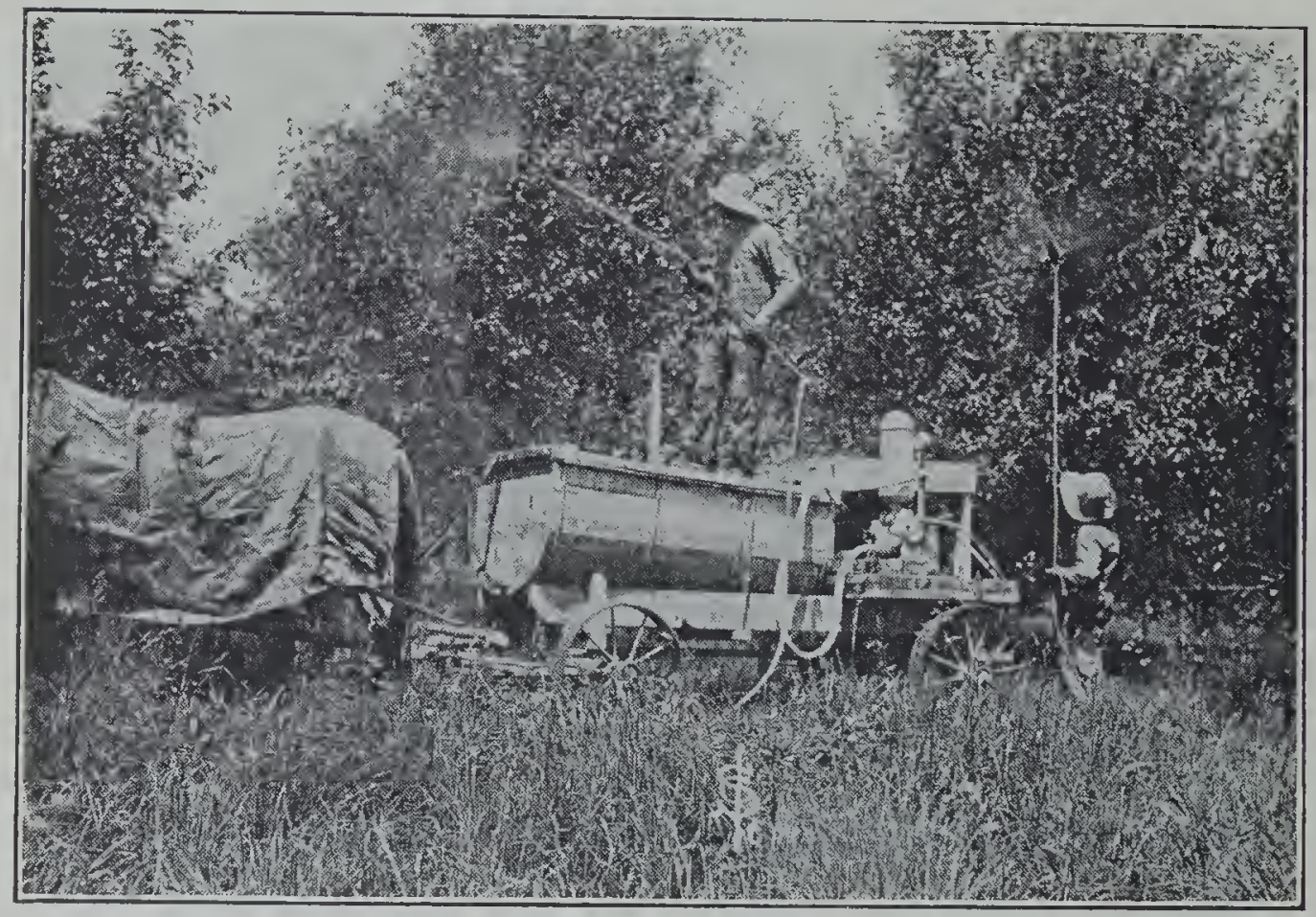

Courtesy Iowa State College.

FIG. 141. - Spraying an orchard.

tobacco decoction, lime-sulfur, or kerosene and soap, applied to the plants, comes in contact with the bodies of the insects and destroys them. The tobacco decoction, which is called nicotine sulfate, or Black Leaf 40 , and the lime-sulfur preparation may be purchased at most drug stores. Directions for dilution and application accompany the mixtures. The kerosene and soap mixture, called kerosene emulsion, is made as follows: 
Dissolve a half pound of laundry soap in one gallon of boiling rain water. Remove from the fire and add two gallons of kerosene. Churn, or mix violently, until you have a light, creamy mixture. Dilute this mixture with from twenty to twenty-five times as much water for plants in full leaf.

Fungous Diseases. - We have already studied at some length in Section 98 how the spores of disease are spread and how they may be controlled. With nearly all fruits, it is best to apply a spray of Bordeaux mixture or limesulfur just before the leaves expand. Another application, with lead arsenate added, should be made just after the petals have fallen from the blossoms. One or more applications of this spray may be necessary during the growing season if insects or diseases are feared.

One ought not to try to remember all of the sprays and when to apply them, but to keep in the bookcase instead, one of the government or state bulletins, which gives the whole spraying schedule. These bulletins can be had for the asking.

231. Gathering and Storing the Fruit. -- Now that we have assisted in the formation of fruit buds, have kept away the rabbits and mice during the winter, have protected the developing blossoms and fruit from the danger of spring frosts, and have brought them unharmed past the strongholds of their enemies, insects and diseases, we have a right to expect as our reward luscious, mellow, fragrant fruit; and whether we expect to eat it soon after gathering,' or to store it away to eat in the long winter evenings as we are gathered about the fire, we must exercise care in harvesting it.

Three rules, which need no explanation, should be observed at picking time: 
(1) Pick in the cool of the morning.

(2) Handle the fruit as few times as possible.

(3) Avoid bruising it as much as possible.

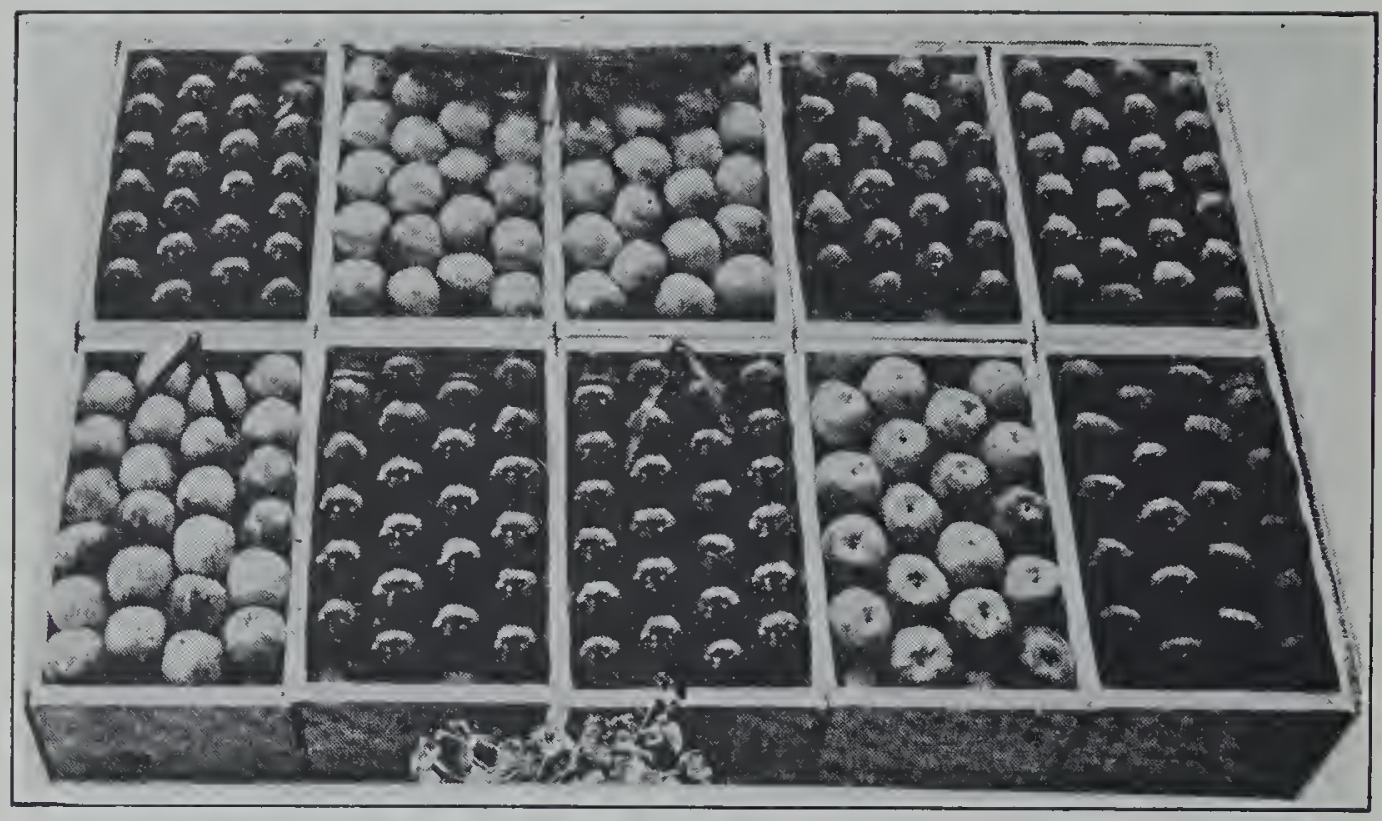

FIG. 142. - Boxes of apples.

Fruits which are to be stored away, such as apples and pears, should be picked while they are firm, wrapped in papers, and packed away in boxes in a cool cellar where the dry, hot air from a furnace room can not reach them.

\section{QUESTIONS}

1. What is meant by the term horticulture.

2. Name three important fruits which originated in America and three which originated in foreign countries.

3. Name four points to be considered in locating an orchard.

4. Why do we cut back young trees and vines at the time of transplanting?

5. Under what two conditions do fruit buds form?

6. Upon wood of what age is the fruit of the grape, the peach and the apple borne?

7. Give five reasons for pruning.

8. Name three rules to follow in picking fruit.

9. Name two classes of insects, telling means of control. 


\section{CHAPTER XXII}

\section{VEGETABLE GROWING}

Those plants, known as vegetables, which are grown for their roots, stems, leaves, or fruits, may be roughly divided into cool season crops and warm season crops. There are some plants, which must be started in the cool season, but which continue to grow throughout the summer. Plants of this kind will be considered here among the cool season crops.

232. Cool Season Crops. - Almost all of the vegetables which are grown for their roots, stems or leaves, fall into this class.

The seed of those which are grown for their roots, such as the radish, carrot, parsnip and beet, will germinate while the soil is yet quite cool and make their best growth before the heat of summer comes on. In order to succeed well, all of the root crops require a deep, rich, loose, mellow, cool soil, plenty of surface cultivation and enough moisture and cool weather to keep them growing rapidly.

The potato, which may also be regarded as a root crop, though the tuber is really an underground stem, likewise delights in a cool climate and a rich, deep, cool soil, which contains enough humus to give it a large moisture-holding capacity.

Onions, together with a number of less common vegetables, such as the shallot, leek, garlic and chive, are known as bulb crops, for they all grow from, and produce a bud in the middle of a cluster of, shortened, thickened leaves, 
known as a bulb. These plants thrive in a cool, moist, well tilled soil, rich in available plant food.

Those vegetables, which are grown for their edible leaves, such as the cabbage, lettuce, spinach and others, are all cool season crops.

233. Warm Season Crops. - Almost all of the vegetables which are raised for their seed or fruits grow best in the warm part of the season.

This rule has an important exception in the case of the pea. The smooth pea is among the first vegetables to be sown in the open ground. Wrinkled peas demand a slightly warmer soil, though they may still be regarded as cool season plants.

Beans, on the other hand, are very sensitive to cold and can not be safely planted until the soil is warm and "the oaks are in leaf."

Sweet corn, like field corn, must not be planted until the ground is warm and the danger of frost is past.

The tomato, egg plant and peppers, all related by the way, are warm, or even hot, season plants, and are easily cut down by the frosts of either spring or fall.

The vine crops, such as the muskmelon, cucumber, pumpkin, squash and water-melon, are all sensitive to frost and require therefore a warm season and sunny weather.

The sweet potato, which is a true root, succeeds best in a loose, warm, sandy soil and in a warm, sunny climate.

234. Getting ahead of the Season. - Since many of the garden crops can not be planted in the open ground until late spring, - often not until nearly June in the northern part of the United States - it is highly desirable to start the plants in some favorable and protected place, from which they may be transplanted later to the 
open ground. The place where plants are usually started in this way is called a hotbed.

Cabbage and lettuce may be started in these beds while the ground is yet frozen. Radishes and lettuce may be grown to maturity in them. Tomatoes may grow in these beds to be several inches tall before the ground outside is warm enough even to receive the seed. Muskmelons and water melons may be started in inverted pieces of sod in the hotbed and then transplanted when favorable

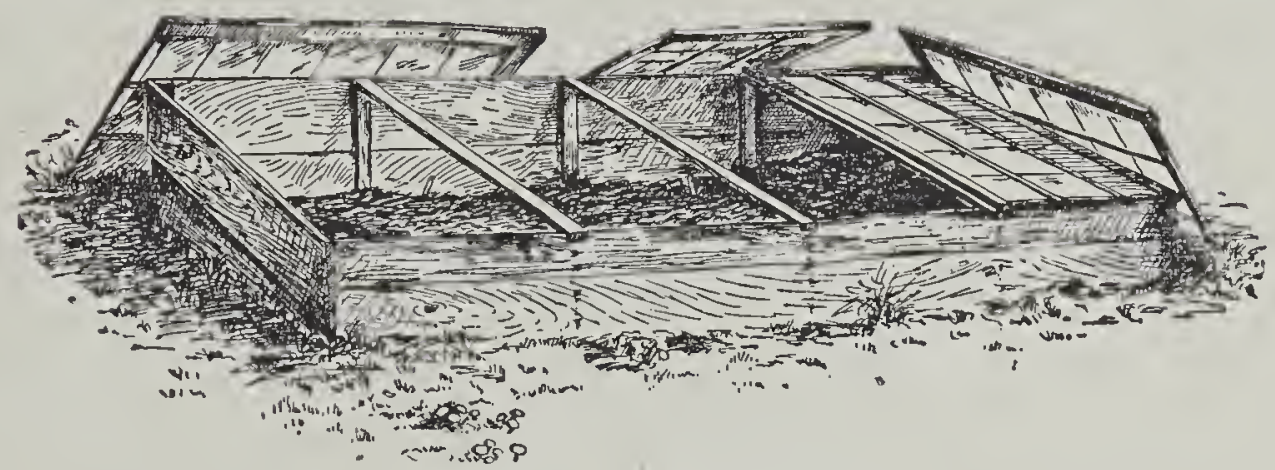

Fig. 143. - A hotbed.

weather comes on. In this way we can secure melons several weeks earlier than we could otherwise.

\section{EXERCISE 52}

Object. - To learn how to make and manage a hotbed.

Procedure. - Select some place on or near the school ground where the soil is well drained. A south slope is preferable, and a gravelly or sandy soil drains better than one of heavy clay.

Dig a pit two feet deep and as long and as wide as the window frame which you can secure to cover the hotbed. Build a frame out of lumber to hold your window sash, allowing it to slope as shown in Figure 143.

Secure a load of fresh, horse barn litter, of which about one half is bedding. Place this in a long, narrow pile three or four feet wide and about the same height. This manure 
should be moist, but not wet. It should be forked over ${ }^{1}$ every few days and kept moist by the addition of water as necessary, as this treatment will cause it to begin heating. When the pile has begun to steam uniformly, which usually takes place after about two weeks, it may be placed in the pit which you have dug. This should be done by putting in a shallow layer, tramping or packing it down well, then adding another layer, and so on until you have from twelve to eighteen inches of well packed manure in the bottom of the pit. This material will probably heat up quickly, cool down in a few days, and then begin gradually to heat again. When it begins to warm up the second time, it should be thoroughly tramped and then covered with about six inches of rich, mellow, sandy soil.

A thermometer should be placed in the soil; and when the temperature has again fallen below ninety degrees Fahrenheit, the seeds may be safely planted. We should keep in mind at this time that the cool season plants require a lower temperature than the warm season crops.

Plant some radishes, lettuce, cabbage and tomatoes in rows, and some melons in little squares of inverted sod. The rows should be far enough apart to prevent crowding.

After the little plants come up, it is necessary to watch the hotbed to see that they receive ventilation. The sash should be raised, or taken off entirely, on warm days, and closed down, or even covered over with old blankets during cold nights and days. Then, too, the watering must be done carefully. Apply enough with a watering pot to keep the soil moist, but not wet. Perhaps the best time to do this is about four o'clock in the afternoon. One good watering every other day, or even less frequently, is better than watering lightly, more often.

${ }^{1}$ For small hotbeds the manure may be taken from the barn and placed directly in the hotbed. 
The soil should be kept stirred to keep down the weeds and to prevent baking. If the little plants are crowded, some of them should be removed.

A cold frame is made in exactly the same way as a hotbed, only that the pit, containing the heated manure, is omitted.

From the hotbed, the plants may be taken to the cold frame to be "hardened" before they are finally transplanted into the garden.

Conclusion. - Write a brief account in your notebook of the method of making a hotbed, the time required by the various seeds to germinate and reach the surface, and the management of it until the young plants are transplanted or otherwise disposed of.

235. In the Garden Proper. - Now that we have attended to those vegetables which may be grown, or at least started in the hotbed, let us turn our attention to the garden itself.

The ground should have been fall plowed, or spaded, and during the winter it should have had an application of well rotted barnyard manure to provide plant food and to make the soil more mellow when worked into the ground.

Our next task is to make a plan of the garden in order that we may know just where each vegetable is to be planted. In making this plan, we must bear in mind that good gardeners no longer use the old-fashioned beds, for they are hard to weed and moreover cultivation must be done largely by hand. Long, straight rows give a garden a very neat appearance and permit the use of that great labor saver, the wheel hoe.

Prepare in your notebook a plat of your home garden. Make the scale such that one inch on the paper represents twenty feet in the garden. The size should depend upon 
the number of people that are to be supplied by it with fresh and winter vegetables. A well managed garden one hundred by one hundred fifty feet should supply five persons.

The following diagram will assist you in making your plan :

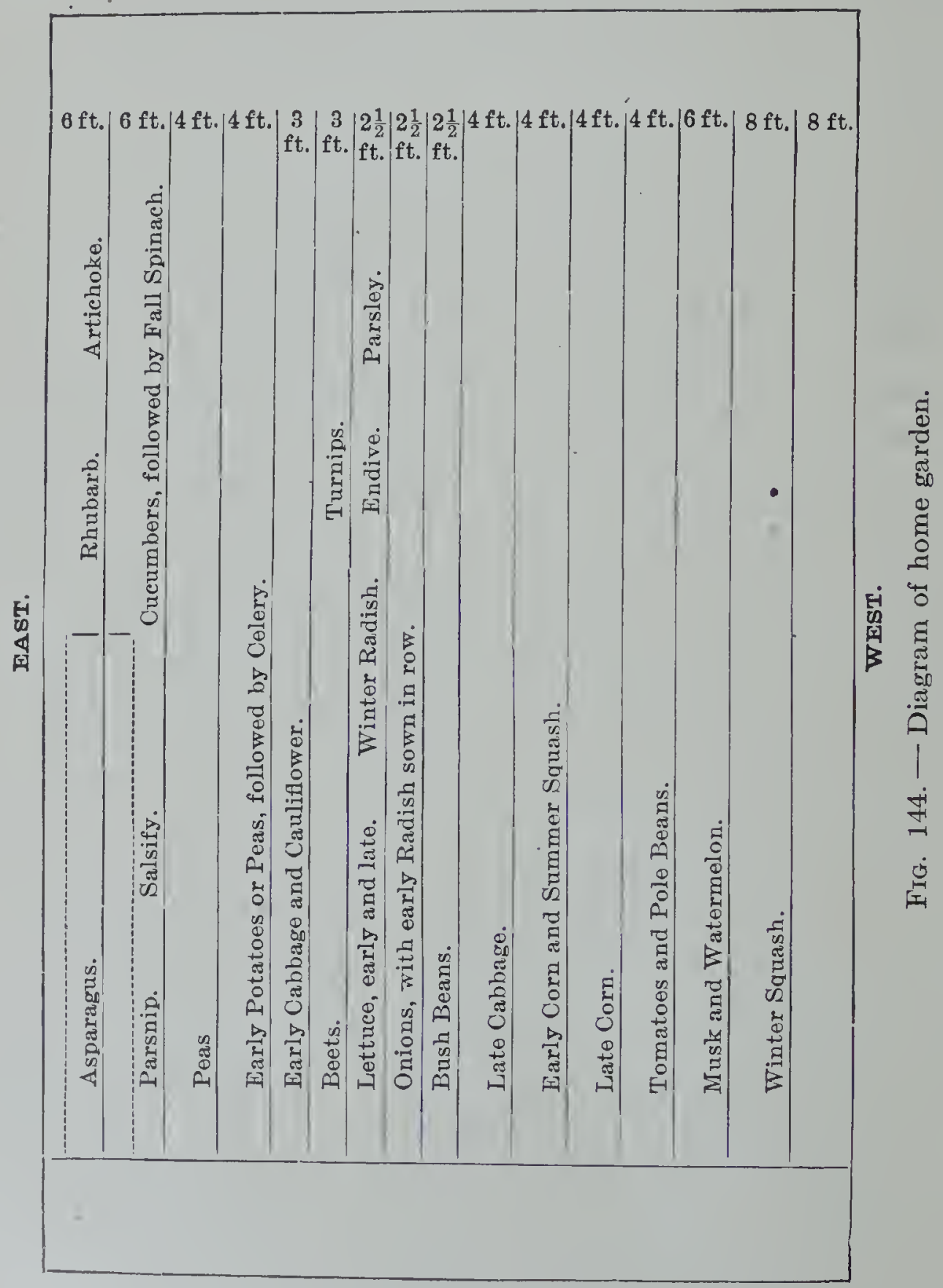


236. The First Planting. - There are several of the cool season crops that we shall want to plant at once. Among them are :

Beets. - Hardly any other vegetables are more easily raised than beets. If you plant the rows eighteen inches apart in a loose, cool soil, and cultivate with the wheel or hand hoe frequently to conselve the moisture and to keep down the weeds, you will soon have a row of vigorously growing young beet plants. You should pull out enough of them to allow the remainder to stand six or eight inches apart. The tops of the young beets which you remove will make excellent greens.

Later sowings may be made every two weeks into the early summer. In the South, they are frequently used even as a fall crop.

Cabbage. - If we have succeeded in raising stocky, thrifty young cabbage plants in the hotbed, and have transplantëd them into a cold frame or perhaps a frame covered with cloth so as to expose them to weather conditions down nearly to freezing to make them hardy, we are almost certain of very early, crisp cabbages.

At this time, the plants may be set in the open ground, for they will endure considerable frost without injury. The transplanting, however, should be done with care. Near the close of the day, begin by opening the rich, mellow soil with the hands or with a small garden shovel. Place a plant in each hole, draw only enough dirt loosely about it to hold it in place, and then pour in about half a pint of water. The following morning, hoe the dirt carefully about them, making the surface of the soil level. This same method of transplanting should be followed with tomatoes or any other plants which we may set out.

Cabbages should be set about two feet apart each way. They should be cultivated very frequently to conserve the 
moisture and should be dusted if necessary with hellebore to destroy the cabbage worms.

Late cabbage may be sown in open beds and transplanted to the fields as late as the middle of June. The early cabbages should be used as soon as ripe or the heads will tend to burst open.

Carrots. - These may be sown as soon as the soil is in suitable condition in the spring. The earth must be finely pulverized as the seeds germinate slowly. Inasmuch as the young plants are somewhat delicate, they are easily overcome by weeds.

Perhaps we should mark the carrot rows, which are to be eighteen inches apart, by sowing a few radish seeds in them. These will germinate quickly, breaking the crust over the carrot seeds. Our task after this is simply to thin out the young carrot plants until they stand from three to five inches apart and to cultivate them with the wheel hoe to keep out the weeds and to keep a mulch on the surface of the ground.

Lettuce. - Few vegetables are appreciated any more in the spring and early summer than fresh, crisp lettuce, and, moreover, it is easily grown.

The plants may be started in the hotbed and transplanted into the garden if we wish "to get ahead of the season "; or the seeds may be sown directly into mellow, rich soil. Frequent cultivation should be given to hasten the growth of the crop.

Lettuce belongs to that group of plants called " salad crops," and a good salad depends upon the crispness of the material used. It may be sown at intervals of two or three weeks in any space available in the garden until the heat of summer comes on. It may be sown again as a fall crop.

Onions. - Both the seeds and the sets of these vegetables may be planted. The latter produce the young, 
green table onions so desirable in the early part of the season, while the seed is used to grow the main crop for fall and winter use. Onions from sets are easily and quickly grown, but the crop grown from the seeds requires special attention.

They are sown thickly in the row; and as soon as the little plants have pushed above the soil far enough to be seen, they should be thinned out. As beginners, it will perhaps be well for us to confine our efforts to raising onions from sets. Only by strict attention to the soil, which must be loose, rich and cool, by much tedious labor in thinning, and by close and frequent cultivation, may we expect to raise a crop of onions from the seed.

Parsnips. - These vegetables also revel in a cool, loose, deep soil, in which their long, tapering roots may develop without branching. The seed may be sown as soon as the soil is warm in the spring and will occupy the ground throughout the entire summer. In fact, most parsnips are allowed to remain in the ground all winter as freezing does not injure them. However, if one wants parsnips for winter use, they must be dug in the fall and stored, preferably in moist sand in a cool cellar. In planting parsnips, as in the case of carrots, it is advisable to mark the row by planting a few radish seeds in it. The distances between the rows and between the plants in the row are the same as those between carrots.

Potatoes. - You will notice by the home garden plan shown in Figure 144, that only early potatoes were included, and these were to be removed as soon as they were large enough to be eaten, after which the space was to be devoted to celery. If enough potatoes are to be raised to supply the entire family throughout the year, they should usually be planted in a space outside the garden where they may be cultivated by horse power. 
Early potatoes may be started in the hotbed or in a box of sandy soil in a window. If this is done, the best results are obtained by planting whole potatoes of medium size and removing all of the sprouts as they appear except the strongest one. In three or four weeks, the plant will have made thrifty growth. It may then be transplanted

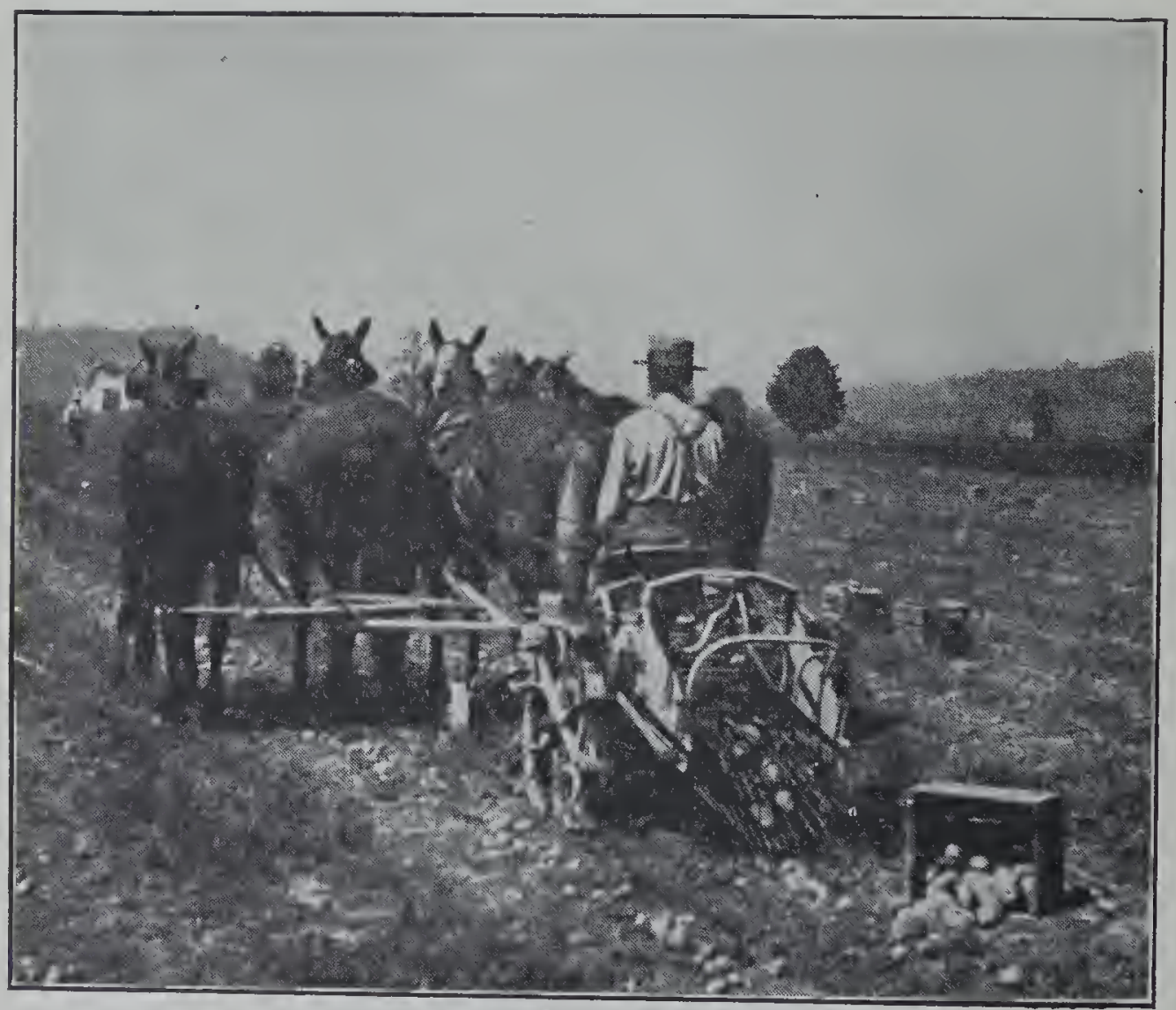

Frg. 145. - Harvesting potatoes.

to the garden and new potatoes gathered from it several days or even weeks before those which were planted as dormant tubers on the same date in the open ground.

New potatoes begin to appear in the markets of the northern cities in February and March. These are grown in Florida. During the months from February to July, northern markets are supplied by gardens in succession 
from Florida northward. In July, these markets are supplied by home gardeners.

No matter where the grower lives, he knows that the potato delights in a cool, rich, moist sandy loam. The Florida man found his soil cool in January, the Wisconsin man, in June. Each planted his tubers perhaps a little more than three inches deep, gave the plants frequent, shallow tillage, sprayed them with Bordeaux mixture (Exercise 37) to keep the spores of disease from germinating, and with lead arsenate (Section 230) to kill the insects.

The movement of the potato harvest from south to north shows that the plant thrives best in a cool soil and accounts for the fact that most of our potatoes for winter use are grown in Maine, New York,

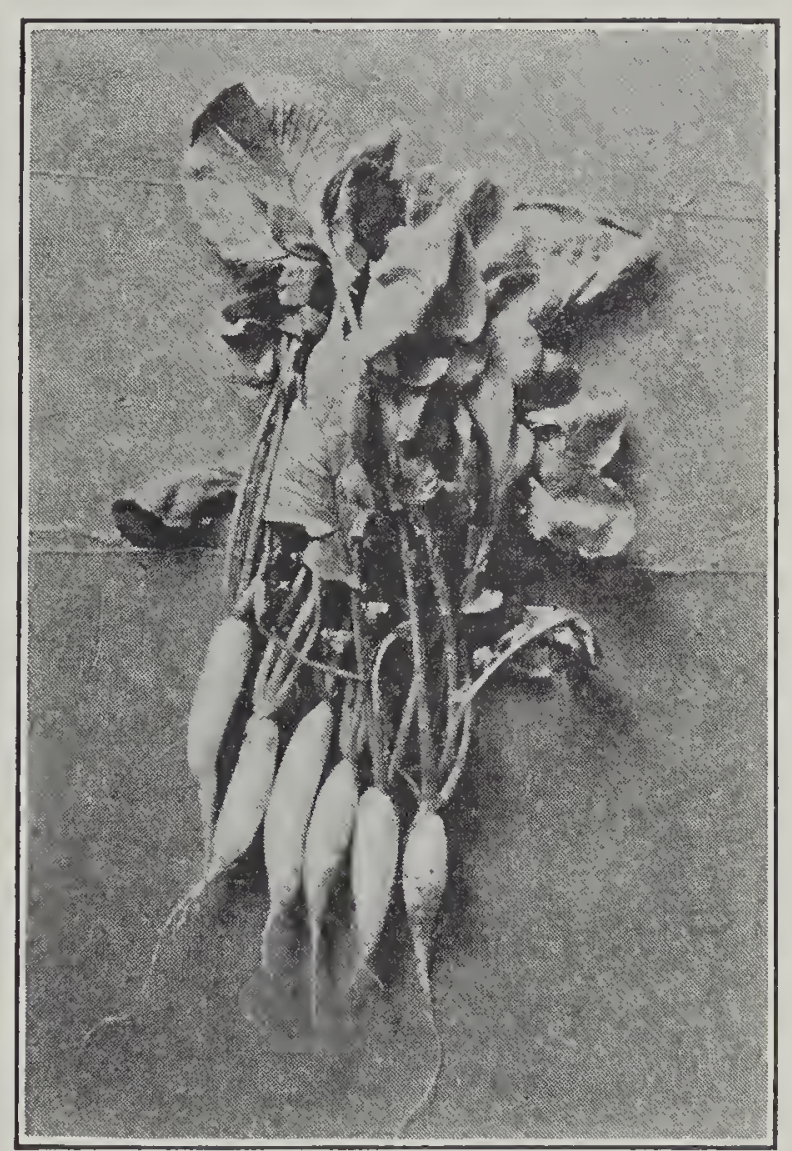

FIG. 146. - Bunch of radishes.

Michigan, Wisconsin, Minnesota and North Dakota.

Radishes. - Radish seeds have already been used to mark the rows of carrots and parsnips, and these will probably furnish enough radishes for early table use. If not, more seed may be sown in nearly any place in the garden. It will germinate quickly and the crop will thrive.

Tender, crisp radishes can be produced only when the 
growth of the plants is rapid and continuous, and for this reason, mellow, rich land is best. Successive plantings of radish seed should be made at intervals of about ten days until the hot weather comes on. A continuous supply of these vegetables can easily be secured if the season is at all favorable.

Spinach. - One of the most popular plants for greens is spinach. We may sow the seed very early in the spring, and in the cool, moist weather, the plants grow rapidly, producing an abundant supply of fresh, green leaves.

Turnips. - The turnip is as easy to grow as the radish, and the soil, season and cultural methods of the two plants are the same.

Early turnips are sown as soon as the soil is warm enough to receive them. The young vegetables are eaten fresh. A fall crop, the main crop, is sown in the latter part of July, or even later farther south, matures during the cool weather of fall and is harvested before the temperature falls to freezing.

A turnip or radish which grows and matures quickly is crisp and sweet; one which grows slowly is woody and bitter.

Peas. - Two types of peas should be recognized: those with smooth seed coats and those whose seed coats are wrinkled.

The smooth-seeded varieties, such as the "Alaska" or "First and Best," may be planted with the earliest of the cool season crops, while the wrinkled varieties, such as "Nott's Excelsior," should not be planted until two weeks later, or even more, as the seed will rot if cold, wet weather comes on.

The early varieties are usually rather low growing and require no support for their pods, while the late varieties tend to form vines and produce the best pods when sup- 
ported by brush or wire netting. These tall varieties are sown in rows three or four feet apart, while the "dwarf" varieties may be planted as near together as eighteen inches. The seeds of both kinds are planted about two inches apart in the row and covered about two and one half inches deep.

237. When the Danger of Frost is past. - In making our plans for the warm season crops, we may study first, those plants which were started in the hotbed, and second, those whose seeds are planted directly in the warm, open soil.

Tomatoes. - These plants need a long, warm growing season and therefore thrive best in the South. By starting the plants under glass, however, and transplanting them to cold frames later,

- stocky, vigorous plants may be produced, which are well on their way by the time warm weather arrives. In this way, tomatoes are grown even north of the Canadian line.

In any locality, the best tomatoes are grown on a rich, moist soil. In addition to this, some means must be pro-

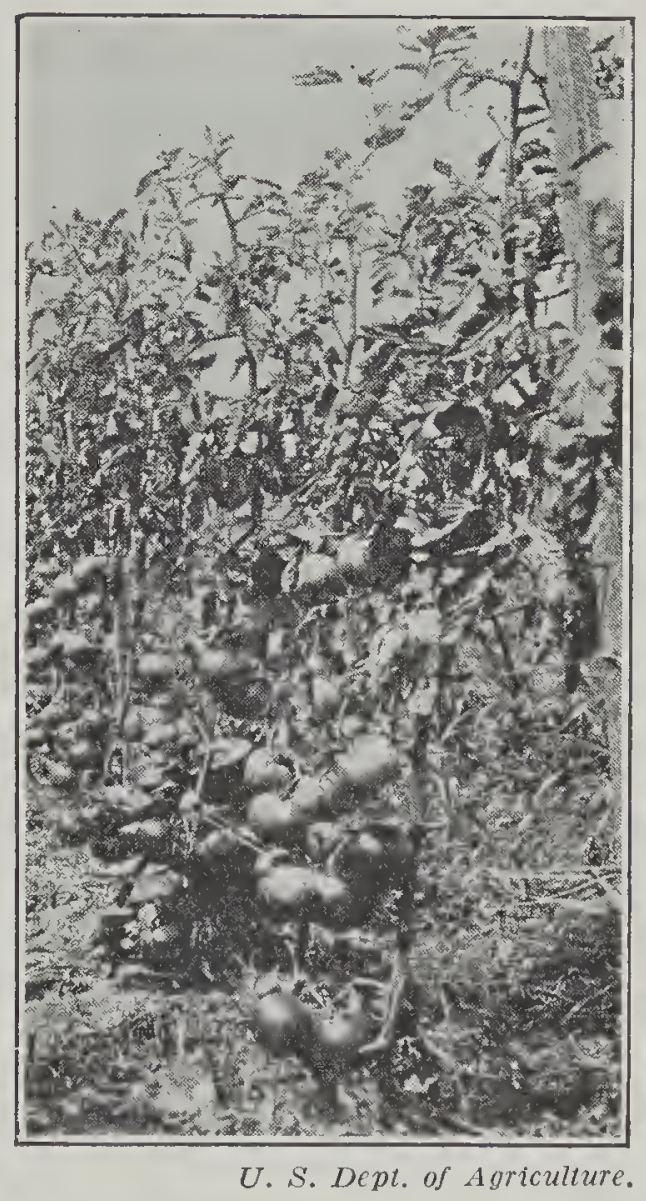

Fig. 147. - Pruned tomato vines. vided of keeping the vines up out of the dirt. A wooden or wire frame may be placed under the vines to hold them up, or they may be pruned to a single stem and tied up to a stake, or lath. In fact, some 
of the finest tomatoes are raised by the latter method. The pruning checks the growth, which induces earlier fruiting and permits the growth of more vines in a row of given length. If the vines are not pruned and they are found making plant growth at the expense of fruit growth, the terminal buds should be pinched out.

Sweet Potatoes. - In the South,

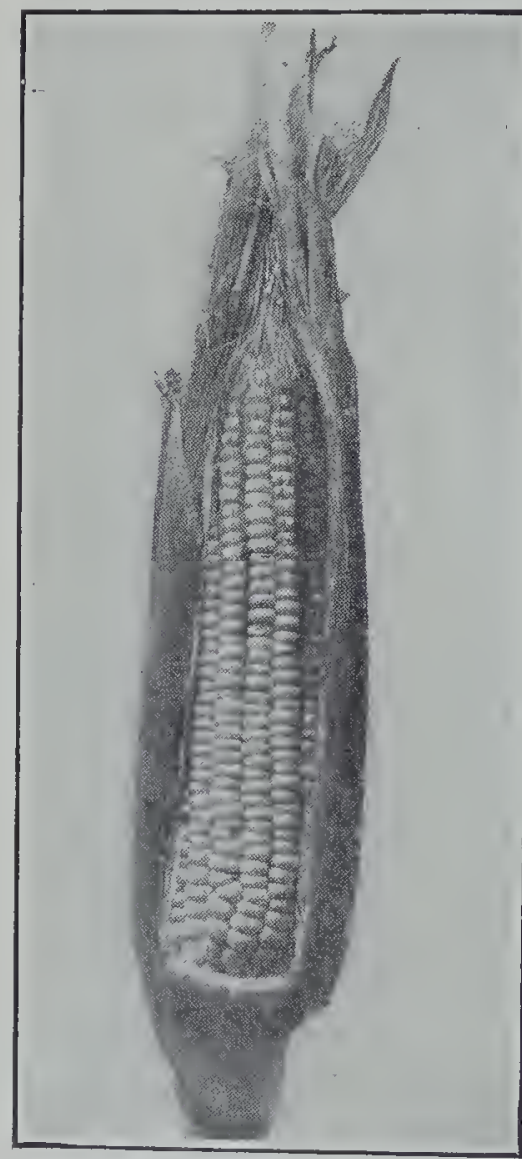

FIG. 148, - A roasting ear. sweet potatoes are called potatoes, while other potatoes are called Irish potatoes. This goes to show that the sweet potato is really most at home in the warm, sandy soil south of the Ohio and Missouri rivers.

Young plants may be secured by planting the sweet potatoes, either whole or split once lengthwise, in the hotbed and covering: them with four or five inches of sand. When the plants have attained some size, and the soil is warm, they may be transplanted to ridges in the open ground. These ridges are usually made three feet apart, and the plants on the ridges are set from one to two feet apart. Special cultivators, or the hand hoe, are used to keep the soil free from weeds.

Celery. - One of the most unsatisfactory crops to attempt to grow is celery.

The seeds start very slowly in the hotbed, - the plants are delicate, can not endure hot, dry winds, and they demand a cool, very rich, and very moist soil. Moreover, 
after careful tillage, the plants must still be blanched by banking earth or leaning boards against the stems.

If by careful preparation of the soil, by transplanting the small plants to level ground or to the bottom of a furrow, by painstaking cultivation and banking, you succeed in raising celery, you will often find the homegrown product superior to that purchased at the market.

Celery is grown in immense fields of reclaimed muck or swamp land in Michigan and California.

Sweet Corn.- Like other corn, this is a warm season crop, demanding a great deal of sunlight, moisture and available plant food.

Sweet corn, or sugar corn, in common with other vegetables grown for their seeds, is never transplant ed. We should remember, however, that some varieties mature more quickly than others and endure a little more cold weather. Our first planting, which should not be made until

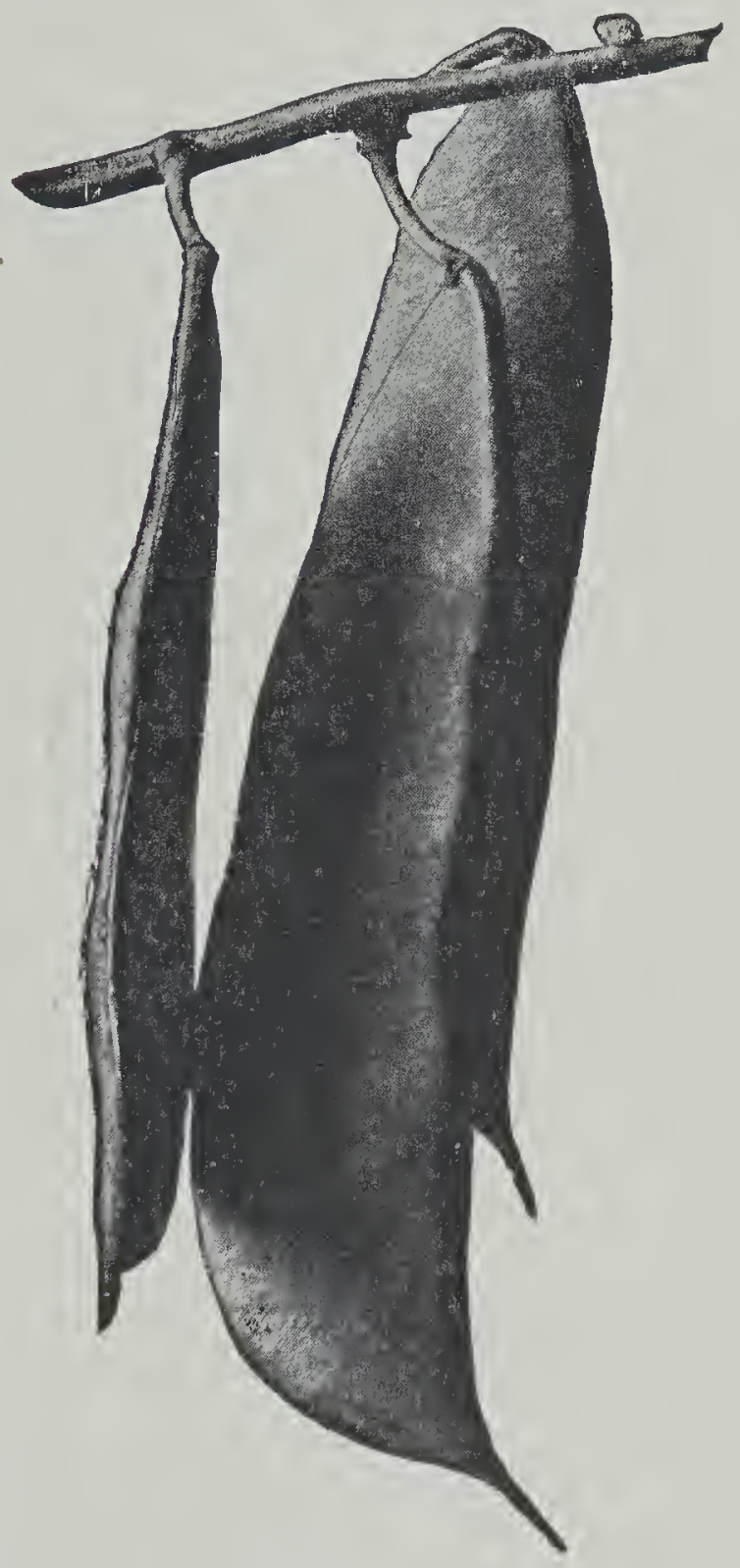

Fig. 149. - Lima beans. the soil is fairly warm, should be of the small-stalked varieties, such as the "Early Minnesota," the "Golden 
Bantam," or the "Peep-o'-Day." A week or two after the first planting, some such variety as the "Country Gentleman" may be planted. Late plantings should be of the large-stalked, large-yielding, sweeter varieties of the type of "Stowell's Evergreen." The cultivation of sweet corn is similar to that of field corn.

Beans. - These are divided into two classes, string beans and Lima beans. While both are warm season

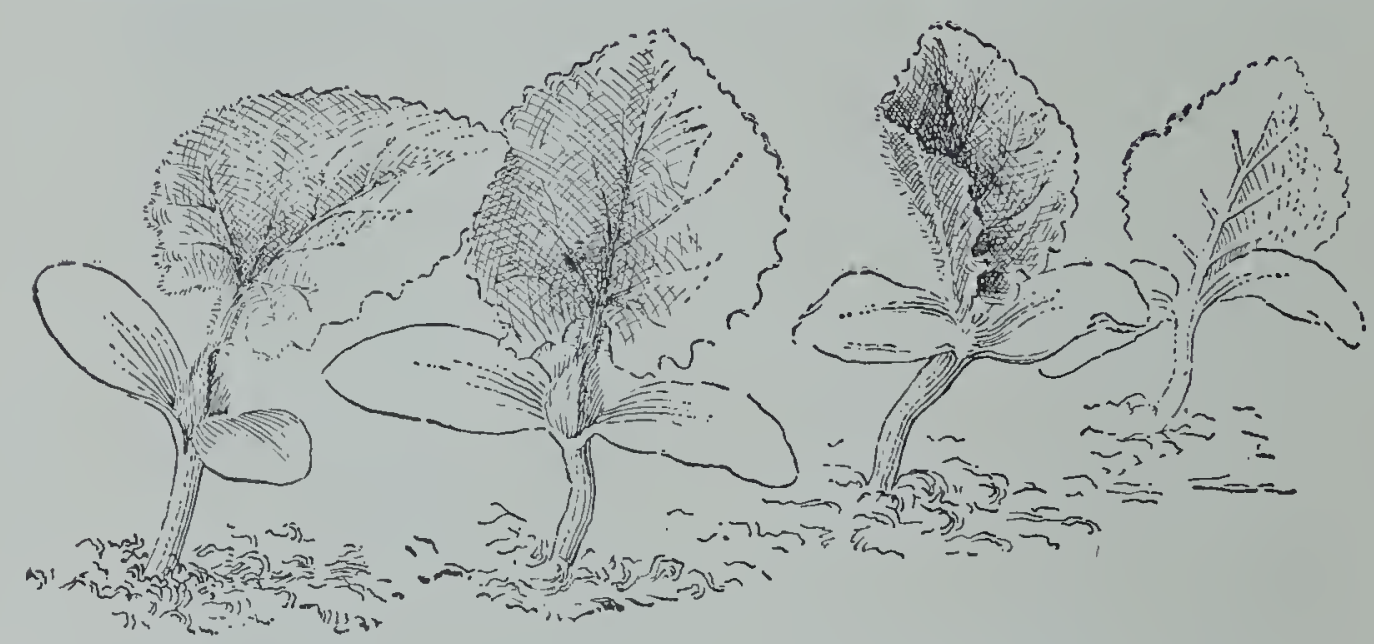

FIG. 150. - Young melon plants are this much ahead of the season if started in overturned sods or boxes.

crops, and can not be planted until the danger of frost is past, the Lima beans require even a higher temperature than the others. In fact, it is best to delay the planting of the Limas until fully two weeks after it is deemed safe to plant the string beans.

Of the string beans, there are two classes, the green and the wax beans. Both are easily grown, requiring only good tillage, and if the "vining" varieties are raised, a support, such as is provided for tall peas.

Dwarf Lima beans are now grown, although less than thirty years ago only the pole Limas were known. The dwarf, small-seeded varieties are rather to be preferred for a home garden, though an Indian "wigwam" built 
of slender poles, or even a single pole, driven into the ground, will support the large Limas which grow from eight to ten feet tall and produce heavy crops of seed.

Vine Crops. - Cucumbers, watermelons, muskmelons, pumpkins and squashes, which are known as vine crops, may all be considered together, for in their manner of growth, as well as in their soil and moisture requirements, they are very much alike.

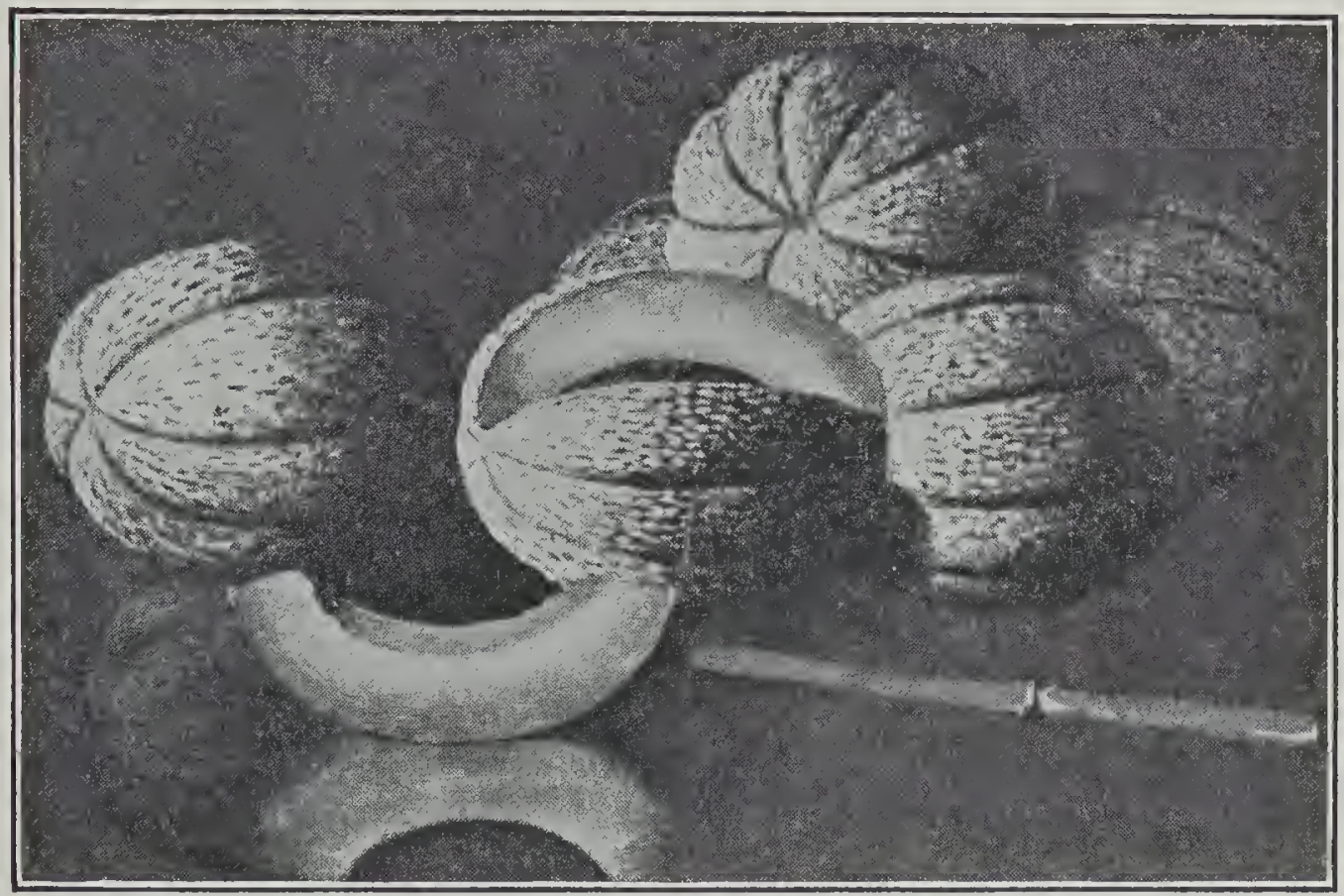

Copyright The Gerlach-Barklow Co.

FIG. 151. - Ready for the table.

Pumpkins and squashes are usually planted in the open ground after the danger of frost is past. We are not usually concerned as to when they will ripen, for we think of them in connection with the autumn frosts.

On the other hand, we are anxious to have watermelons and muskmelons mature as early in the season as possible. In starting either melons or cucumbers, our hotbed again comes into use. By making paper boxes of heavy cardboard, by using wooden strawberry boxes and filling them with rich 
earth, or even by making use of small squares of sod, turned upside down, a seed bed is secured. Here the plants may grow for several weeks; and when the ground has become warm enough, they may be taken to the field and transplanted, care being taken to avoid disturbing the roots.

The precautions to be taken in growing vine crops are:

(1) Provide well drained, rich soil ; and for watermelons, choose a sandy one if possible.

(2) Plant the seed in hills far enough apart to allow the vines to spread. The distances should vary from four by four feet for cucumbers to eight by eight feet or more for watermelons.

(3) Thin out the plants in each hill, leaving only three or four of the strongest ones.

(4) Remove the first plants that show melon bugs or lice. If this does not check them, spray with Black Leaf 40. (Section 230.)

(5) If the striped beetles appear, cover the vines with small frames of mosquito netting, spray with dilute Bordeaux mixture and lead arsenate, or dust lightly once or twice a day with sifted ashes, gypsum or other fine powder.

(6) Cultivate between the rows frequently until the vines become too long. Then use the hoe.

\section{QUESTIONS}

1. Divide vegetable crops into two groups according to the season in which the seed is planted. Name five vegetables of each group.

2. Tell fully how to make and manage a hotbed.

3. What is a cold frame and how is it made?

4. Tell briefly how to plant cabbages in the hotbed, harden them in the cold frame and transplant them into the garden.

5. Divide peas into two classes and tell when each should be sown.

6. Are onion seeds rather to be chosen than sets for the home garden? Why? 
7. How may you secure "extra early" potatoes? Where is most of our winter supply of potatoes grown? Why?

8. What two classes of beans do we have and when should each be sown?

9. Tell briefly how to grow tomatoes in the hotbed, how to transplant them, and how to prune them to a single vine.

10. Name five rules to follow in growing vine crops. 


\section{CHAPTER XXIII}

\section{PERMANENT AGRICULTURE}

THE land in the United States of America has been called the "floor space of the nation." The work for three hundred years has been to occupy this floor space. Forests have been cut down, swamps have been drained, and streams have been spread out to furnish moisture for fields in places where little came from the clouds.

So long as there was new land to occupy, - rich fields awaiting the plow, - there was food in plenty and to spare. Now, however, there is little new land to occupy, and the number of mouths that must be fed continues to increase.

Land can no longer be abused and then thrown back upon a generous Nature to repair the waste of man.

The soil has been compared to money in the savings bank, upon which the interest only may be drawn each year. If more than this is wanted, we begin to draw upon the principal. That is to say, a certain amount of plant food - nitrogen, phosphorus, potassium, etc. - is unlocked each year by the rain, the frost and the unseen organisms of the soil.

Certain plants take out more of a given element than do others. While clover, for example, is taking out a great deal of potash, the store of nitrogen in the soil is increasing; and when corn later begins to draw upon the nitrogen, the drain upon the potassium is lessened.

It is definitely known just how much of each element is taken out of the soil by each crop. It therefore 
becomes a matter of good farming to restore to the land in some way that which is removed from it by the crops grown in it.

We may, it is true, increase our crop yields by the selection of better seed, by the selection of superior varieties, by improved methods of cultivation, or otherwise; but a permanent agriculture, upon which the future prosperity of the nation depends, rests finally upon the maintenance of fertility of the soil.

238. The Result of selling Crops from the Land. - The fertility of the soil is very largely, though not altogether, a matter of the presence in it of those elements which plants must have in order to make healthy growth, - particularly nitrogen, phosphorus and potassium. (Section 7.)

Let us suppose that an acre of ground produces a crop of fifty bushels of ear corn. This amount of corn contains approximately fifty pounds of nitrogen, nine pounds of phosphorus and fifteen pounds of potassium; and if the crop is sold, these three elements will be lost from the farm in the amounts named.

The small grains do not remove so much fertility from the soil as does corn, since the amount of food material which they produce is actually much less. Thus a crop of twenty bushels of wheat per acre takes twenty-four pounds of nitrogen and about five pounds each of phosphorus and potassium from the land, while a fifty-bushel crop of oats removes from the soil approximately thirtytwo pounds of nitrogen, six pounds of phosphorus and eight pounds of potassium.

Timothy may remove even more of the elements of fertility from the soil than do the small grains. A crop yielding one and one half tons of hay per acre, takes about thirty-seven pounds of nitrogen, seven pounds of 
phosphorus and twenty-five pounds of potassium from the land.

In a very true sense, then, the farmer who sells his crop to others is really selling the fertility of his soil; or we may say that, little by little, he is selling the land itself. To continue such a practice year after year must inevitably result in the gradual exhaustion of the soil. It is chiefly due to this fact that much of the land of the older sections of the country has become, as we say, "worn out," by which we mean that it has reached the stage at which it will not produce crops that will yield a profit above the actual cost of care and cultivation.

\section{How the Three Important Elements of Fertility} may be restored to the Soil. -

Nitrogen. - The store of nitrogen in the soil may be increased in three ways :

(1) By growing legumes.

(2) By the application of barnyard manure.

(3) By the application of commercial fertilizers.

How the bacteria which live on the roots of legumes take nitrogen from the air and convert it into a form that plants can use was explained in Section 180. The actual amount of nitrogen that is received from the air in this way by the legumes varies with the different plants. A crop of red clover, sweet clover or crimson clover, yielding one and one half tons of hay per acre, receives from the air as a rule between sixty and seventy pounds of nitrogen; a cutting of alfalfa or cowpeas, yielding the same amount of hay per acre, contains usually from seventy to eighty pounds of nitrogen which has been taken from the air; and it follows that if a crop of any one of these plants which would yield a ton and a half of hay per acre were plowed under, nitrogen would be added to each acre of the soil 
in the amount named. To cut the hay and sell it from the farm, however, would give a far different result. In this case, little or no nitrogen would be added to the soil by the iegume since the amount contained in the roots and stubble is usually about the same as that which these plants have actually drawn from the soil itself; but on the other hand the land would lose heavily in phosphorus and potassium, owing to the fact that legumes take large amounts of these elements from the soil.

By the application of barnyard manure, not only nitrogen, but also phosphorus and potassium may be added to the soil. A ton of ordinary barnyard manure contains about ten pounds of nitrogen, two pounds of phosphorus and eight pounds of potassium. If we compare these figures with the amounts of the same elements removed from an acre of ground by a fifty-bushel crop of corn, we see that it would require the application of about five tons of manure per acre to replace the nitrogen removed by a single corn crop.

The use of commercial fertilizers to restore nitrogen to the soil is much more general in the older sections of our country than in the newer parts where the virgin fertility has not been altogether exhausted and where the clovers may be more easily grown. The fertilizers which are commonly used to add nitrogen to the soil are as follows:

Sodium nitrate, called also Chile saltpeter. Each hundred pounds of this product contains from fifteen to sixteen pounds of nitrogen. It should be applied to the land after plants have begun to grow, as it dissolves readily and is soon leached or washed out of the soil. It should be mixed with three or four times its weight of soil, as otherwise it may injure the growing plants. The amount used varies from one hundred to two hundred pounds 
per acre; and to secure the best results, this is not all applied at one time but two or three applications in smaller amounts are made during the growing season.

Ammonium sulfate, which contains about twenty-one per cent of nitrogen, is often used. It is quite effective; but a rather serious objection to it is found in the fact that it apparently tends to leave the soil acid.

Calcium nitrate, which is manufactured chiefly in Norway, and which contains about twelve per cent of nitrogen, is a highly satisfactory fertilizer save for the fact that the nitrogen in it is rather more expensive than that in the products named above.

Fish fertilizers, consisting usually of the dried, ground bodies of the menhaden, are often used with excellent results. They contain from eight to eleven per cent of nitrogen as a rule and also from one to two per cent of phosphorus.

Phosphorus. - Unlike nitrogen, this element can not be restored to the soil by growing legumes or any other special crops. Rather it can be added only in the form of barnyard manure, as already stated, or in the form of commercial fertilizers.

The commercial fertilizers commonly used for this purpose are:

Ground phosphate rock, or floats. This rock is quarried in Florida, the Carolinas, Tennessee and some of the western states. It is also called rock phosphate or insoluble phosphate of lime. It contains from eleven to thirteen per cent of phosphorus. It is insoluble in water and for this reason could not be used as a fertilizer at all but for the fact that it is very gradually dissolved by the acids which are formed by the decay of the humus in the soil. It is usually applied with barnyard manure. Its effects are not quickly seen as a rule but extend over a 
period of several years, increasing during the first three or four years.

Calcium acid phosphate, called also simply acid phosphate, soluble phosphate of lime, one lime phosphate, superphosphate, etc. It is soluble in water and hence gives quick results though the effects are not seen so long as in the case of floats. An average sample contains about seven per cent of phosphorus.

Ground or steamed bone, which is chemically nearly the same as floats, and which contains from ten to eleven per cent of phosphorus in addition to about two and a half per cent of nitrogen.

Basic slag, a by-product of the manufacture of steel, is considerably used as a source of phosphorus. It contains from six to nine per cent of this element. It dissolves very slowly and hence should be finely ground.

Potassium. - Most new soils contain enough potassium to supply the needs of plants for a very long time. However, sandy soils, or newly drained swamp land, may be deficient in this element as well as those soils which have been long under cultivation. It may be restored only in the form of barnyard manure or commercial fertilizers.

The chief commercial fertilizers containing 'potassium are :

Potassium chloride, called also muriate of potash. It gives satisfactory results for ordinary crops; but potatoes, tobacco, sugar beets and other plants which use much potassium appear to be injured by the chlorine present.

Potassium sulfate, which is of special value for those crops which are injured by the chloride.

Kainite, which contains from ten to twelve per cent of potassium in the form of both chloride and sulfate. 
240. The Care and Importance of Barnyard Manure. About eighty per cent of the essential elements contained in the grain and hay fed to live stock is returned in the excrement. If the manure, both solid and liquid, is carefully preserved and returned to the soil without loss, only about twenty per cent of the fertility contained in the crops fed is lost from the land. Usually, however, the manure is not properly handled; and as a result, about one third of the fertility which it contains is lost. In this case, but little more than half of the fertility taken from the soil in the crops gets back to it again.

It follows that no farm can maintain its fertility indefinitely simply by feeding the crops which it produces to live stock and returning the manure to the land. If the fertility is to be maintained by means of barnyard manure, it is necessary either to secure some from an outside source to be added to that which the farm produces or to purchase supplementary feeds or grain from others and feed them on the farm.

The chief losses of fertilizing elements from manure occur in three ways:

(1) The manure is not protected from rains, and much of the fertility which it contains is leached, or washed out of it. This may be prevented by protecting it by a suitable roof or by applying it at once to the fields.

(2) The liquid manure is allowed to escape. Pound for pound, it is more valuable than the solid manure, owing to the large amount of nitrogen and potassium which it contains. Sufficient bedding should be used to absorb all of it, or it should be drained into a cistern to be applied later to the land.

(3) Much loss results from fermentation, by which nitrogen escapes in the form of ammonia. This fermentation may be detected by the heating and steaming of the 
manure heap or even by the odor of ammonia about the barnyard. It is due to basteria which can exist only in the presence of air ; and if the manure heap is kept compact and moist, it may be easily prevented.

Notwithstanding the necessity of supplementing barnyard manure with legumes or with other fertilizers, it is still true that it is by far the most valuable fertilizing agent known. The farm, on which all crops produced are fed to live stock and the manure carefully preserved and returned to the land, will continue profitable production from three times to five times as long as will one from which all crops are sold. It is for this reason that "stock" farms are almost invariably found to be more productive than adjoining "grain" farms. It follows of course that there should be enough live stock on every farm to consume all, or practically all, the grain and forage which it produces.

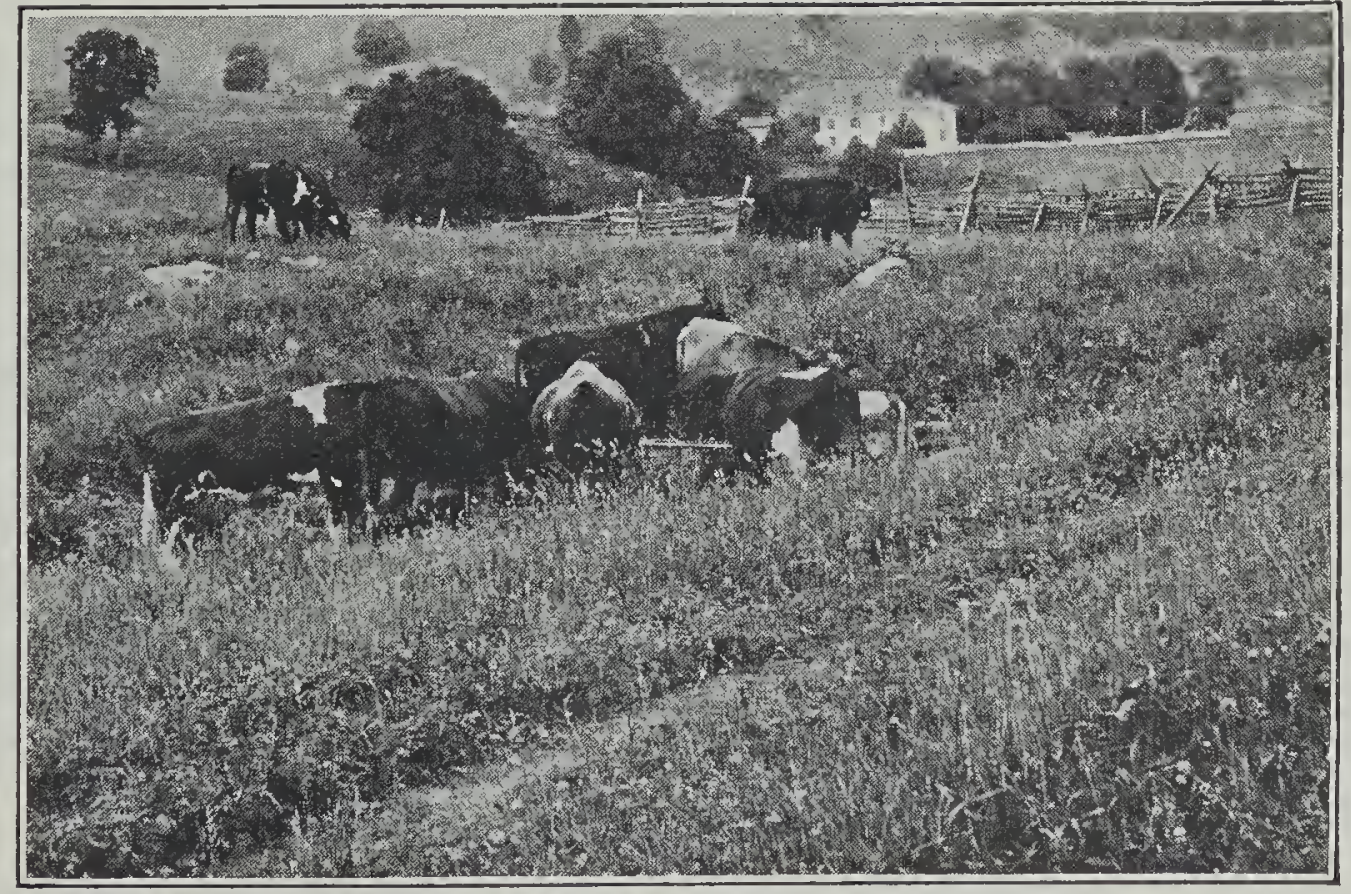




\section{EQUIPMENT}

A list of apparatus, which will assist the student in performing the exercises outlined in the foregoing lessons, is given below : ${ }^{1}$

20 12-oz. Gas Bottles, or Wide-mouthed Preserve Jars.

6 Small Steel or Iron Frying Pans.

1 Trip Seale with Rider.

1 Set Avoirdupois Weights, 1 lb. to $\frac{1}{2}$ oz.

1 Set Metric Weights, $1 \mathrm{Kg}$. to $5 \mathrm{~g}$.

20 Tin Cans, No. 3, with lids and bottoms removable.

20 circular pieces Screen Wire, slightly larger than lids of cans above.

2 Thermometers, Soil or Dairy preferred.

20 Test Tubes, $6 \times \frac{5}{8}{ }^{\prime \prime}$, with corks to fit.

1 Glass Graduate, 100 c.c.

20 One-hole Rubber Stoppers to fit test tubes above.

20 Glass Tubes, $2^{\prime \prime}$ in diameter and $15^{\prime \prime}$ long ; or ordinary lamp chimneys may be used.

5 Racks to hold tubes above.

10 Wire Baskets, factory- or home-made of screen wire, $6^{\prime \prime}$ in diameter and $6^{\prime \prime}$ deep.

6 Books Blue Litmus Paper.

6 Books Red Litmus Paper.

4 Medium Size Alcohol Stoves.

1 Galvanized Iron Pail with Vertical Sides, capacity 3 gals.

6 Granite or Agate Pans, capacity 2 qts.

12 Hand Lenses.

1 gal. Denatured Aleohol.

8 oz. Saturated Iodine Solution.

4 lbs. Paraffin. four.

1 This list includes enough apparatus for twenty students, working in groups of 
$1 \mathrm{lb} .40 \%$ Formalin.

5 lbs. Blue Vitriol, or Copper Sulfate.

5 lbs. Fresh Unslaked Lime, to be kept in fruit jars, or otherwise protected from the air.

1 lb. Beeswax.

$\frac{1}{2}$ lb. Raw Linseed Oil.

6 Small Muslin Sacks for holding soil samples.

Seeds of Rough Rice, Teparie Beans, Wax Beans, Corn, Wheat, and Oats.

$\frac{1}{4} \mathrm{lb}$. Absorbent Cotton.

24 pieces No. 14 Wire, $8^{\prime \prime}$ long.

6 Safety Razor Blades. 


\section{PUBLICATIONS}

No list of bulletins is here suggested, inasmuch as the ones now available may be out of print at any time; and moreover, new ones are being continually added to the list.

The list of available publications from any station may be secured at any time; and it is suggested that if bulletins are needed, such a list be secured from the station or stations as desired.

\section{U. S. DEPARTMENT OF AGRICULTURE}

\section{Bureau of Publications}

Alabama. - College Station: Auburn.

Canebrake Station: Uniontown.

Tuskegee Station: Tuskegee Institute:

Alaska. - Sitka.

Arizona. - Tueson.

ArKansas. - Fayetteville.

Califfornia. - Berkeley.

Colorado. - Fort Collins.

Connecticut. - State Station: New Haven.

Delaware. - Newark.

Storrs Station : Storrs.

Florida. - Gainesville.

Georgia. - Experiment.

Guam. - Island of Guam.

HawaII. - Federal Station: Honolulu. Sugar Planters' Station: Honolulu.

IDaHo. - Moscow.

Ilinois. - Urbana.

Indiana. - La Fayette.

Iowa. - Ames.

KANSAS. - Manhattan.

KenTUCKY. - Lexington.

Louisiana. - State Station: Baton Rouge. 
Louisiana. - Sugar Station: Audubon Park, New Orleans. North Louisiana Station: Calhoun.

Maine. - Orono.

Maryland. - College Park.

Massachusetts. - Amherst.

Michigan. - East Lansing.

Minnesota. - University Farm: St. Paul.

Mississippi. - Agricultural College.

Missouri. - College Station: Columbia. Fruit Station: Mountain Grove.

Montana. - Bozeman.

Nebraska. - Lineoln.

Nevada. - Reno.

New Hampshire. - Durham.

New Jersey. - New Brunswick.

New Mexico. - State College.

New York. -- State Station: Geneva.

Cornell Station: Ithaca.

North Carolina. - College Station: West Raleigh. State Station: Raleigh.

North Dakota. - Agricultural College.

OHio. - Wooster.

OKlahoma. - Stillwater.

Oregon. - Corvallis.

Pennsyluania. - State College.

State College: Institute of Animal Nutrition.

Porto Rico. - Federal Station: Mayaguez. Insular Station: Rio Piedras.

Rhode Island. - Kingston.

South Carolina. - Clemson College.

South Daкota. - Brookings.

Tennessee. - Knoxville.

Texas. - College Station.

UтAн. - Logan.

VERMONT. - Burlington.

Virginia. - Blackburg.

Norfolk: Truck Station.

Washington. - Pullman.

West Virginia. - Morgantown。

-Wisconsin. - Madison.

Wyoming. - Laramie. 



\section{INDEX}

Acid soil, 252.

effect on clovers, 252 .

litmus test for, 254.

how corrected, 258.

Agriculture defined, 287.

Air, amount in soil, 25.

in soil, effect upon temperature, 31.

space in soil, how increased, 25. why necessary in soil, 25.

Alfalfa, 246.

methods of culture, 267.

range of, 246.

Alsike, 249.

methods of culture, 270 . range of, 249.

Anthers defined, 108.

Apple, age of bearing wood, 298, 295.

how pruned, 302.

Bacteria, how added to the soil, 260. necessary to clovers, 255.

Barley, climatic range, 221. preparation of seed bed for, 221 . uses of, 221.

Bamyard manurc, care of, 336 . composition of, 333. how fertility is lost from, 336 . value of, 333,337 .

Bast fibers, 105.

Beans, how grown, 326.

Beets, how grown, 317.

Bermuda grass, 234.

advantages of, 234 .

disadvantages of, 234.

how propagated, 234.

range and character of, 234.

Blackberry, age of bearing wood, 297.

how pruned, 297, 301.
Blue grass, 230.

advantages of, 232.

character and valuc, 230.

disadvantages of, 232 .

seeding of, 231.

Bordeaux mixture, how made, 131. how used, 131, 309.

strength for stone fruits, 132 .

Bread mold, 126.

Brome grass, 233.

advantages of, 233.

disadvantages of, 233 .

value of, 233 .

Cabbage, how grown, 317.

Calyx defined, 108.

Cambium layer defined, 104.

Carbon, 10.

Carbon dioxide, 69.

given off by germinating sceds, 69.

test for, 69.

Carrots, how grown, 318.

Celery, how grown, 324.

Cereals defined, 203.

leading in various countries, 203.

Chaffiness defined, 156.

Cherry, pruming of, 301. age of bearing wood, 295.

Cloddy fields, cause of, 39 .

Clover, crimson, 245.

range of, 245 .

Japan, methods of culture, 270. Japan, range of, 242.

red, methods of culture, 266 .

red, range of, 248 .

sweet, methods of culturc, 269.

swcet, range of, 248 .

white, methods of culture, 270 .

Clovers, causes of failure, 250.

effect of acid soils, 252.

cffect of careless seeding, 256. 


\section{Clovers (continued).}

effect of drouths, 257.

effeet of friendly baeteria, 255 .

effeet of lack of humus, 255 .

effeet of lack of phosphorus, 254.

effeet of nurse erop, 256.

hard seeds of, 264.

methods of seeding, 261 .

how to suceeed with, 258.

why sown with grasses, 236.

Cold frame, how made, 315 .

Color of soil, effect on temperature, 34.

Corm defined, 229.

Corn, aereage in United States, 149. Belt, how pushed northward, 54. climatic requirements of, 152 .

cultivation of, 191.

depth of cultivation, 193.

desirable characters of ear, 157.

desirable eharacters of kernel, 162.

desirable eharacters of stalk, 53 .

desirable butt described, 160 .

desirable shape of ear, 159.

desirable size of ear, 158.

desirable size of kernels, 163.

desirable shape of kernels, 163 .

desirable tip described, 161 .

detasseling of, 116 .

distribution of, 150 .

effect of climate on type, 151.

seed, how dried, 172.

seed, how graded, 179 .

seed, how stored, 173.

seed, how tested, 174.

seed, selection in field, 169 .

frequency of cultivation, 195.

harvesting of, 196.

ideal seed bed for, 181.

immaturity in, how recognized, 155.

listed, cultivation of, 200 .

moisture requirements, 152 .

planting, depth of, 188 .

planting, distance between rows, 189.

planting, methods of, 185 .

planting, number kernels in hill, 189.

planting, time of, 187.

seed bed in eornstalk ground, 184. seed bed in sod ground, 182 . seed bed in stubble ground, 185 . replanting, 190 .

sensitiveness to elimatie ehanges, 152.

soil requirements of, 154 .

substitute crops for, 198.

sweet, how grown, 324 .

unsoundness in, how reeognized,

155.

uses of, 149.

why barren stalks are avoided, 55 . why stalks with suckers are avoided, 55.

Corolla defined, 108.

Cotton, how ginned, 280.

how harvested, 280.

importance of, 275.

methods of culture, 277.

plant described, 276.

range of, 275.

Cottonseed meal, 282.

Cotyledon defined, 62.

effeet of removing, 74 .

Cowpeas, methods of eulture, 271. range of, 245 .

Cross-fertilization by hand, 113.

Cross-fertilization defined, 113.

Cucumbers, how grown, 327.

Cultivation of corn, depth of, 193 .

Cultivation of corn, frequeney of, 195.

Cultivation of listed eorn, 200.

Cuttings, 138.

Deeay, eause of, 126 .

Dieotyledon defined, 62.

Dicotyledons, flowers of, 108.

roots of, 84 .

seeds of, 63 .

Diseases, eause of, 126.

how prevented, 128 .

Drouths, effects on clovers, 257.

Drying seed corn, 172.

Dura, 198.

Earthworms, work done by, 9 .

Elements, essential, 10.

Embryo, 62.

enemies of, 46 .

how proteeted, 46 . 
Endosperm, 63.

effect of removing, 73 .

Fertilization, cross-, 113.

defined, 113.

self-, 113.

Feterita, 198.

Fiber crops, leading, 274.

Fibro-vascular bundles, 101.

Filament, 108.

Flax, methods of culture, 282. methods of handling, 283. range of, 282. value of products, 284.

Flowers of dicotyledons, 108. of legumes, 238. of monocotyledons, 109. pistillate, 110. staminate, 110. fertilized by insects, 111. fertilized by wind, 111.

Food, stored in leaves, 96. stored in roots, 87. stored in seed, 92. stored in stems, 137, 229. made from starch, 92 . source of all, 92.

travels how from leaves to roots, 103.

Formalin, use of, for oat smut, 128. use of, for potato scab, 130.

Frost, prevention of injury by, 305.

Fruit buds, age of wood bearing, 295.

Fruit buds, conditions favoring formation of, 293.

how and when formed, 292.

Fruit, gathering and storing, 309.

Fruits, places of origin, 287.

Fruit trees, cultivation of, 291. distances between, 289 .

how developed when young, 288. training of, 292.

how planted, 290.

Garden, plan of, 316 .

Germ defined, 46, 62 .

Germination, conditions of, 64 . optimum temperatures for, 67 .

Girdling trees, effect of, 103.

Glacier defined, 1.
Glumes, 109.

Grading of seed coln, 179.

Grafting wax, 139.

Graft, cleft, 142.

whip, 140.

Grape, age of bearing wood, 296. cultivation of, 291.

method of planting, 291.

method of pruning, 300 .

Grasses, charactcristics of, 224.

leading cultivatcd, 227.

habit of growth, 226.

range of each, 236.

Heat from germinating seeds, 71 .

Hemp, how handled, 284.

range of, 284.

Hessian fly, 210.

Horticulture defined, 287.

Hotbed, 313.

Humus defined, 5.

effect on air space in soil, 29 .

effect on soil structure, 37 .

cffect on watcr-holding capacity, 15.

how added to soil, 259.

necessary to clovers, 255.

Hydrogen, 11.

Hypocotyl, 62.

Inoculation, defined, 260.

method of, 260.

Insects on vine crops, how combated, 328 .

prevention of injury by், 307 .

Kafir corn, 198.

cultivation of, 200.

planting of, 200.

Leaf likencd to a mill, 90.

Leaves, functions and uses, 89. storage of food in, 96.

Legumcs, as nitrogen gatherers, 240. benefits of, 239 .

characteristics of, 238.

flowers of, 238.

range of, 242.

securing maximum benefits from, 272.

Lettuce, how grown, 318. 
Limestone, how applied to soil, 259. uses of, 258.

Linseed meal, 284.

Linseed oil, 284.

Loam soil defined, 4.

Manure, effect on air space, 29.

Mice, prevention of injury by, 305 .

Milo maize, 198.

Moisture, film or capillary, 19.

hygroscopic, 19.

in soil, effect on temperature, 33. necessary for germination, 65 .

requirements of corn, 152.

why injurious to stored sceds,

$133,173$.

Monocotyledon, defined, 62.

seeds of, 63 .

flowers of, 109.

leaves of, 225 .

roots of, 83 .

stems of, 101.

Mulch, dust, 42 .

use of, 23.

Muskmelons, how grown, 327.

Nitrogen, 11.

amount in barnyard manure, 333.

amount in corn, 331.

amount in oats, 331.

amount in timothy, 331.

amount in wheat, 331.

commercial fertilizers containing, 332 .

how added to soil by legunes, 240.

how restored to soil, 332 .

how lost in process of burning, 92 .

Nodules on roots, 240.

Nurse crop, defined, 256.

influence on clovers, 256.

crops suitable for clovers, 260.

Oatmeal, 219.

Oats, character of crop, 213.

advantages of stacking, 219.

how planted, 215.

how shocked, 218.

loose smut of, 127.

Oats, seed, desirable characters of, 216. sced bed for, 215 .

seed, selection of, 216 .

spring, 214.

used for hay, when cut, 218.

uses of, 219.

varieties of, 214 .

when harvested, 218.

winter, 214.

Onions, how grown, 318.

Orchard, location of, 289.

Osmose, defined, 78.

law of, 78 .

Ovule defined, 113.

Oxygen, 11.

nccessary for germination, 65 .

Palea defined, 109.

Parsnips, how grown, 319.

Peach, age of bearing wood, 296. development of young tree, 144. how pruncd, 301.

Peas, how grown, 322.

Petals defincd, 108.

Phosphorus, 11.

amount in barnyard manure, 333 . amount in corn, 331 .

amount in oats, 331 .

amount in timothy, 331.

amount in wheat, 331 .

commercial fertilizers containing, 334.

necessary to clovers, 254.

Photosynthesis defined, 89.

Pistil defined, 108.

Planting corn, methods of, 185. time of, 187.

depth of, 188.

Plants, classes according to useful parts, 144.

how propagated, 124.

life cycle of, 44 .

two great classes of, 62 .

Plowing under stubble and clods, 21.

Plum, age of bearing wood, 295.

pruning of, 301.

Plumule defined, 62.

Pollen, defined, 108.

how carried from plant to plant,

111.

Pollination defined, 111.

Potassium, 12. 
Potassium (continued).

amount in barnyard manure, 333 . amount in corn, 331 .

amount in oats, 331 .

amount in timothy, 331 .

amount in wheat, 331 .

commercial fertilizers containing, 335 .

how restored to soil, 335.

Potatoes, how grown, 319.

swcet, how grown, 324 .

Propagation, by budding, 142 .

by bulbs, 136 .

by grafting, 139 .

by layers, 135 .

by runners, 134 .

by seeds, 133.

by spores, 124 .

by suckers, 135 .

by tip layers, 135 .

Protein, in lcgumes, 242.

effect of feeding, 120 .

Pruning, methods of, 299.

why necessary, 298.

precautions necessary, 304.

Pumpkins, how grown, 327.

Rabbits, prevention of iujury by, 305.

Radicle defincd, 62.

Radishes, how grown, 321.

Raspberry, age of bearing wood, 297. how pruned, 301. methods of cultivation, 291.

Redtop, advantages of, 233.

disadvantages of, 233.

range and character of, 232 .

Ricc, how cared for, 223.

how harvested, 223.

how planted, 223.

how prepared for use, 223.

production of, in U. S., 222.

secd bed for, 222 .

soil requircments of, 222 .

uses of, 224 .

Root hairs, origin of, 81 .

Roots, absorbing, 80 .

anchorage, 80 .

anchorage, origin of, 81.

benefits of, 88 .

functions of, 77 . food stored by, 87 .

how minerals are dissolved by, 79 .

how tips are protected, 82.

of dicotylcdons, 84 .

of monocotyledons, 83 .

rapidity of growth in early

stages, 76 .

region of growth, 82 .

why moisture enters, 77 .

Rotation, bencfits of, 29,85 .

defined, 206.

that is often recommended, 206.

Rye, soil requirements of, 221.

uses of, 221.

Sands, shifting of, 85.

Sappiness defined, 156.

Seed analysis, 261.

Seed bed for barley, 221.

for corn, 181.

for corn, how prepared, 182.

for oats, 215.

for ricc, 222.

for wheat, 207.

for wheat, how prepared, 206.

Seed collection, how made, 50 .

defincd, 62 .

functions of, 46 .

Seedling, dcfined, 75 .

vigor of, how determined, 74, 76 .

Seeds, effect of moisture upon, 59.

enemics of, 46.

explosive or creeping, 48.

first factors determining vitality of, 60 .

how scattcred by man, 49 .

how scattered by naturc, 46 .

how scattered by animals, 48 .

how scattcred by water, 47 .

how scattered by wind, 47 .

sclection of, by man, 52 .

sclection of, by naturc, 52 .

size of, effect on scedlings, 73 .

storagc of, by man, 58 .

Self-fertilization defined, 113.

Scpals defined, 108.

Shocking oats, methods of, 218.

Sicve tubes, 103.

Silt, 4.

Soil acidity, effect on clovers, 252 .

test for, 254. 
Soil binders, 85 .

Soil, how water is lost from, 13. how made, 1.

how mixed and laid down, 2.

Soil making, rôle of animals in, 8 . rôle of plants in, 7 .

Soil material, two sources of, 5 .

Soil names, 4.

Soil requircments, of corn, 154 . structure defined, 36 . texture defined, 36 .

Soil, what it is, 1 .

Sorghums, characteristics of, 199.

Soy beans, 249 .

methods of culture, 271.

Spinach, how grown, 322.

Spores causing disease or decay, 126.

how entrance is favored, 133.

how spread, 127.

how prevented from spreading, 128.

summer, 130 .

winter, 130.

Spring defined, 17.

Squashes, how grown, 327.

Stacking grain, when advisable, 219.

Stamens defined, 108.

Starch, manufacture of, 89.

Starchiness defined, 156.

Stems, climbing, 99.

erect, 99 .

forms of, 98 .

functions of, 98 . prostrate, 98 .

Stigma defined, 108.

Stomata defined, 93.

Strawberries, how grown, 291. pruning of, 303.

Structure of soil, crumb, 37 . how affected by freezing, 37 .

how affected by humus, 38 . of soil, puddlcd, 37 .

puddled, how caused, 37.

Style defined, 109.

Sulfur, 11.

Sunscald, injury by, 306.

Temperature of soil, how governed, 30. optimum for germination, 30,68 .
Tile drains, effect on air space, 29. how water enters, 18.

why uscd, 18.

Tillage, effect on air space, 28.

why nccessary, 36 .

when soil is wet, 39 .

Timothy, advantages of, 228.

time of cutting, 229.

use of, 227.

where grown, 227.

Tomatoes, how grown, 323.

Trampling soils when wet, 39 .

Transpiration defined, 89.

Tree, how to tell age of, 102 .

Tuber defined, 137.

Turnips, how grown, 322.

Vegetablcs, cool season, 311. warm season, 312 .

Vctches, methods of culture, 272. range of, 249.

Vitality of sceds, how determined, 60 .

Water, amount given off by leaves, 94.

film, or capillary, 19.

free, or gravity, 19.

Water-holding capacity, how affected by humus, 15.

Water-holding capacity of different soils, 16.

Water, how lost from soil, 13.

hygroscopic, 19.

travels how from root to leaf, 101.

Watermelons, how grown, 327.

Weed seeds, weights of, 265.

Weeds, when most casily destroyed, 42.

Wheat, climatic conditions requircd, 205.

harvesting of, 211.

planting of, 210 .

seed bed for, 207.

seed bed for, how prepared, 206.

seed, desirable characters of, 208.

sclection of seed, 207.

spring, 205.

timc of planting, 210 .

uses of, 212.

why extensivcly grown, 203.

winter, or fall, 205.

Printed in the United States of America. 


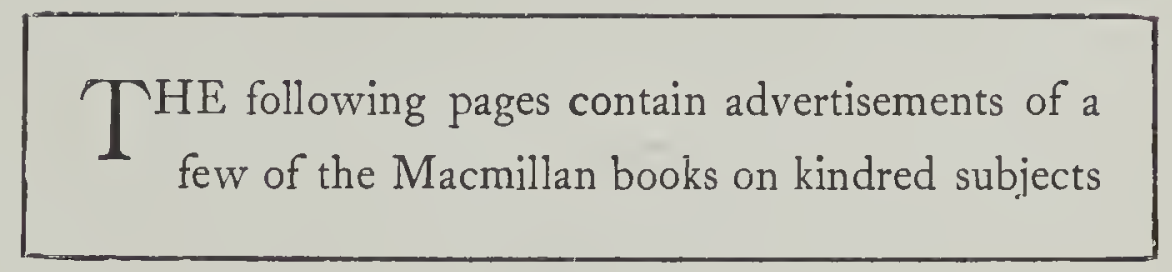





\title{
Teaching of Agriculture in the High School
}

\author{
BY GARLAND A. BRICKER
}

Department of Agricultural Extension, College of Agriculture, Ohio State University

With an Introduction by Dr. W. C. Bagley

202 pages, $\$ 1.00$

A skilful exposition of the place of agriculture in the high school course of study which first defines the nature of secondary agriculture, and then proceeds to discuss the rise and development of secondary agriculture in the United States; the social results of teaching secondary agriculture; the psychological and the seasonal determination of sequence; the organization of the course; the aim and methods of presentation; and finally the educational aims, values, and ideals in teaching agriculture in high schools.

\section{Materials and Methods in High School Agriculture}

By WILLIAM G. HUMMEL, M.S.

Assistant Professor of Agricultural Education, University of California, and

BERTHA R. HUMMEL, B.L.S.

385 pages, $\$ 1.25$

This book has been prepared for the use of persons interested in the introduction or in the teaching of agriculture in high schools of towns, cities, or rural communities where large numbers of students are drawn from the farming population, or where the prosperity of the high school community is largely dependent upon agriculture.

The first chapters give a general treatment of the reasons for placing agriculture in the high school course and the authors then proceed to discuss the method, the equipment, and the subject matter of the course.

\section{THE MACMILLAN COMPANY Publishers




\section{Harper : Animal Husbandry for Schools}

Written for the high school course, this book treats of horses, cattle, sheep, swine, and poultry, each discussed with reference to breeds, judging the animal, feeding, care, and management. Practical questions and laboratory exercises supplement the text and compel the student to think through each subject as he proceeds.

\section{Livingston : Field Crop Production}

This book is intended to meet the needs of agricultural high schools and of brief courses in the colleges. It is based on the results of actual studies at the experiment stations and it indicates the better way of performing every operation in the raising of crops, from selecting the field to harvesting and marketing the product. It treats in detail some eighteen individual crops and explains fully the principles of crop rotation.

\section{Warren: Elements of Agriculture}

A book by a farmer, an agricultural expert, a professor of Farm Management in the New York State College of Agriculture. The text covers such topics as: the improvement of plants and animals; the propagation of plants; plant food; the soil; maintaining the fertility of the land; some important farm crops; enemies of farm crops; system of cropping; farms and feeding; the various animal types, in five chapters; farm management; and the farm home. There is a valuable appendix and the text is excellently illustrated.

\section{THE MACMILLAN COMPANY}

Publishers

64-66 Fifth Avenue

New York 


\section{Chemistry and its Relations to Daily Life}

By LOUIS KAHLENBERG AND EDWIN B. HART

Professors of Chemistry in the University of Wisconsin

Cloth, I2mo, illustrated, 393 pages. List price, $\$ 1.25$

If the contributions of chemical science to modern civilization were suddenly swept away, what a blank there would be! If, on the other hand, every person were acquainted with the elements of chemistry and its bearing upon our daily life, what an uplift human efficiency would receive! It is to further this latter end that this book has been prepared. Designed particularly for use by students of agriculture and home economics in secondary schools, its use will do much to increase the efficiency of the farm and the home. In the language of modern educational philosophy, it "functions in the life of the pupil."

Useful facts rather than mere theory have been emphasized, although the theory has not been neglected. The practical character of the work is indicated by the following selected chapter headings :

II. The Composition and Uses of Water.

IV. The Air, Nitrogen, Nitric Acid, and Ammonia.

IX. Carbon and Its Compounds.

XII. Paints, Oils, and Varnishes.

XIII. Leather, Silk, Wool, Cotton, and Rubber.

$\mathrm{XV}$. Commercial Fertilizers.

XVI. Farm Manure.

XX. Milk and Its Products.

XXI. Poisons for Farm and Orchard Pests.

THE MACMILLAN COMPANY 64-66 FIFTH AVENUE 


\section{BOOKS ON AGRICULTURE}

\section{ON TILLAGE}

Bailey's Principles of Agriculture . . . . . . . \$1.25

Hilgard's Soils . . . . . . 4.00

King's The Soil . . . . . . . . 1.50

King's Irrigation and Drainage . . . . . . . . . I.50

Livingston's Field Crop Production . . . . . . . . . I.40

Lyon and Fippin's The Principles of Soil Management . . . . 1.75

Roberts's The Fertility of the Land .. . . . . . . . I.50

Snyder's Soils and Fertilizers . • • . . . . . . 1.25

Voorhees's Fertilizers . • • • • t.25

Wheeler's Manures and Fertilizers . . . . . . . . . . .

Widstoe's Dry Farming . . . . . . . . . . . I.50

\section{ON· GARDEN-MAKING}

Bailey's Garden-Making . . . . . . . . . . . r.50

Bailey's Vegetable Gardening . . . . . . . . . 1.50

French's How to Grow Vegetables : $\quad$. . . . . . . . .75

ON FRUIT GROWING, etc.

Bailey's Fruit Growing . • • • • • I.75

Bailey's The Pruning Book . . . . . . . . . . I.50

Card's Bush Fruits. . . . . . . . . . . . I.50

\section{ON THE CARE OF LIVE STOCK}

Harper's Animal Husbandry . • . . • . • • . . I.40

Jordan's The Feeding of Animals . . . . . . . I.50

Lyon's How to Keep Bees for Profit . . . . . . . . I.50

Mayo's Diseases of Animals . . . . . . . . . . 1.50

Phillips's Beekeeping . . . . . . . . . I.50

Valentine's How to Keep Hens for Profit ! . . . . . 1.50

Watson's Farm Poultry . . . . . . . . . . . r.50

\section{ON DAIRY WORK}

Ėckles's Dairy Cattle and Milk Production . . . . . . . r.6o

Sheldon's The Farm and the Dairy . . . . . . . . 1.00

Snyder's Dairy Chemistry . . . . . . . . . . 1.00

Wing's Milk and its Products . . . . . . . . . 1.50

ON PLANT DISEASES

Massee's Diseases of Cultivated Plants and Trees . • • . . 2.25

O'Kane's Injurious Insects . . . . . . . . . . 2.00

Slingerland and Crosby's Fruit Insects . . . . . . . . 2.00

Stevens's Fungi of Plant Disease . . . . . . . . . 400

\section{ON ECONOMICS AND ORGANIZATION}

Fairchild's Rural Wealth and Welfare . . . . . . . . r.25 $^{2}$

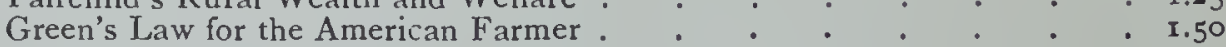

Ogden's Rural Hygiene . • . . . . . . . . . r.50

Roberts's The Farmer's Business Handbook : . : : . : 1.25

\section{THE MACMILLAN COMPANY}

\section{4-66 Fifth Avenue, New York}

BOSTON CHICAGO ATLANTA DALLAS SAN FRANCISCO






A45588 